Portland State University

PDXScholar

Winter 11-25-2014

\title{
Evaluation of Energy Policy Instruments for the Adoption of Renewable Energy: Case of Wind Energy in the Pacific Northwest U.S.
}

Remal Abotah

Portland State University

Follow this and additional works at: https://pdxscholar.library.pdx.edu/open_access_etds Let us know how access to this document benefits you.

\section{Recommended Citation}

Abotah, Remal, "Evaluation of Energy Policy Instruments for the Adoption of Renewable Energy: Case of Wind Energy in the Pacific Northwest U.S." (2014). Dissertations and Theses. Paper 2128.

https://doi.org/10.15760/etd.2126

This Dissertation is brought to you for free and open access. It has been accepted for inclusion in Dissertations and Theses by an authorized administrator of PDXScholar. Please contact us if we can make this document more accessible: pdxscholar@pdx.edu. 
Evaluation of Energy Policy Instruments for the Adoption of Renewable Energy:

Case of Wind Energy in the Pacific Northwest U.S

by

Remal Abotah

A dissertation submitted in partial fulfillment of the requirements for the degree of

\author{
Doctor of Philosophy \\ in \\ Technology Management
}

Dissertation Committee:

Tugrul U. Daim, Chair

Bruce Gilley

Jisun Kim

Dundar F. Kocaoglu

Portland State University

2015 


\begin{abstract}
The wide use of renewable energy technologies for generating electricity can be seen as one way of meeting environmental and climate change challenges along with a progression to a low-carbon economy. A large number of policy instruments have been formed and employed to support the adoption of renewable energy technologies in the power generation sector. However, the success of these policies in achieving their goals relies on how effective they are in satisfying their targets and thus increasing renewable energy adoption. One measurement for effectiveness of policy instruments can be their contribution to the input of the process of renewable energy adoption and their effect on satisfying regional goal.
\end{abstract}

The objective of this research is evaluate the effectiveness of energy policy instruments on increasing the adoption of renewable energy by developing a comprehensive evaluation model. Criteria used in this assessment depend on five perspectives that are perceived by decision makers as important for adoption process. The decision model linked the perspectives to policy targets and various energy policy instruments. These perspectives are: economic, social, political, environmental and technical. The research implemented the hierarchical decision model (HDM) to construct a generalized policy assessment framework. Data for wind energy adoption in the Pacific Northwest region were collected as a case study and application for the model. Experts' qualitative judgments were collected and quantified using the pair-wise comparison 
method and the final rankings and effectiveness of policy alternatives with respect to the mission were identified. Results of this research identified economic feasibility improvement of renewable energy projects as the most influential perspective and that renewable portfolio standards and tax credits are the two most effective criteria to accomplish that. The research also applied sensitivity analysis and scenario analysis to identify the effect of regional perspectives future priority changes on determining the most effective policy for this perspective. Results showed that renewable portfolio standards and tax credits were found to be the two most effective policies among the alternatives assessed. The research model and outcome can serve as policy check tool in policy making for renewable energy development in any region. Based on the overall research findings, policymakers can apply specific policy instruments to support adoption efforts for any given scenario and regional emphasis. 


\section{DEDICATION}

To my beloved parents, Hussein and Maha Abu Taha, who showed me the value of education and sacrifice

To my wonderful husband, Hussein, who stood by my side for bad and for good and supported me

To my precious kids, Amirah, Rashed, Rama, and Abdullah, who were the perfect kids that anyone could wish for

To all my dear siblings, Jumana, Rawdi, Deema, Mohammad, Ibrahim and Hala, who believed in me and encouraged me

Without you all, I would never be here 


\section{ACKNOWLEDGMENTS}

I sincerely acknowledge the many individuals who have provided motivation, encouragement and guidance throughout this research effort.

I would like to give my gratitude for, Dr. Tugrul Daim, my mentor and chairman of my committee for having confidence in me and helping me overcome all the challenges throughout my study. His encouragement and patience highlighted the way toward my success especially during the difficult times in the PhD research.

I would like to express my sincere appreciation to our father Dr. Dundar Kocaoglu, for his understanding and kind support. It was an honor to work with him as he demonstrated how to be an inspirational leader. His continuous feedback to the research was of remarkable importance for improvements.

I am grateful to Dr. Bruce Gilley for his guidance and feedback with respect to my dissertation analysis and research findings.

I would like to thank Dr. Jisun Kim for his support and encouragement, and providing valuable help during the research and report writing process.

I would like to thank all faculty members, staff and friends in the ETM department who had been like my second family during the years I spent here. 
I would like to thank all of the research participants and experts for their time and effort spent on the questionnaires and feedbacks. 


\section{TABLE OF CONTENTS}

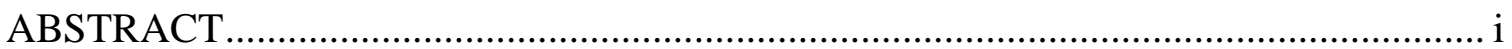

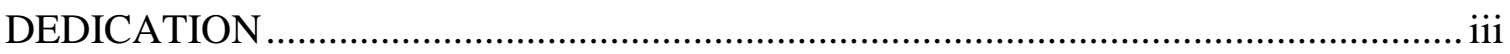

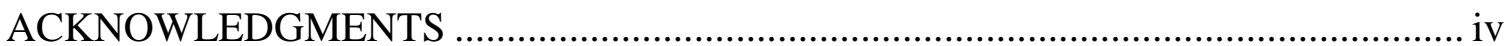

LIST OF TABLES .................................................................................................. xii

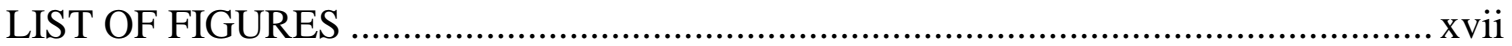

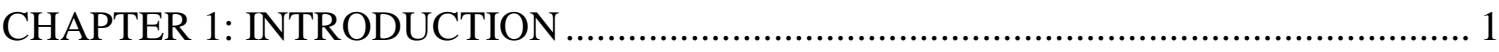

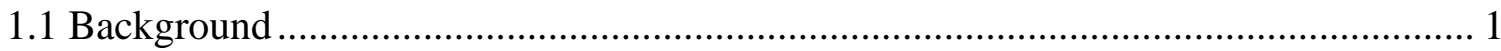

1.2 Research scope

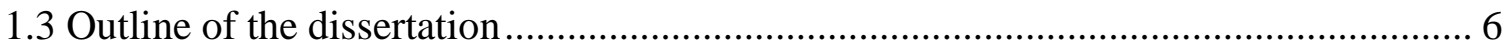

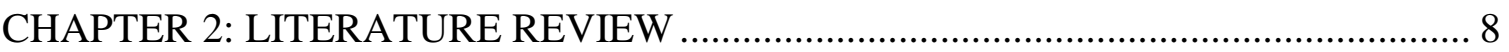

2.1 Renewable Energy Adoption ................................................................................. 9

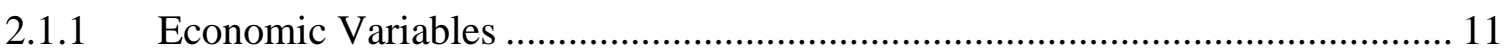

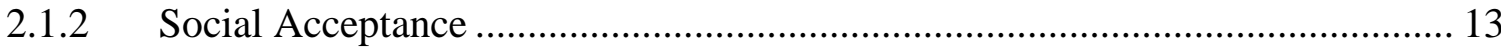

2.1.3 Institutional and Government Support ...................................................... 14

2.1.4 Environmental Concerns ........................................................................ 16

2.1.5 Integrating Renewable Energy Sources into the Grid ..................................... 17

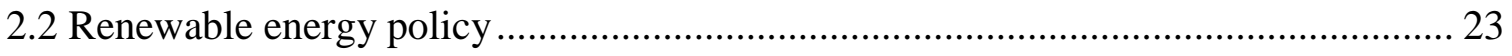

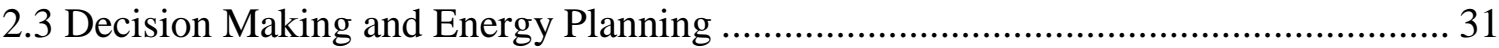

2.3.1 Technology Forecasting: .............................................................................. 32

2.3.2 Multi-criteria Decision Making Methods (MCDM) …….................................. 34 
2.3.3 Decision Analysis in the Renewable Energy Sector ......................................... 39

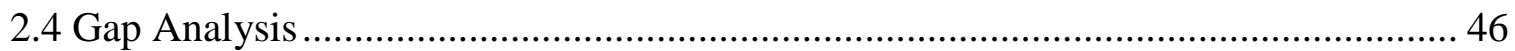

CHAPTER 3: RESEARCH METHODOLOGY ………….......................................... 50

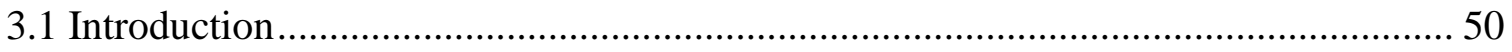

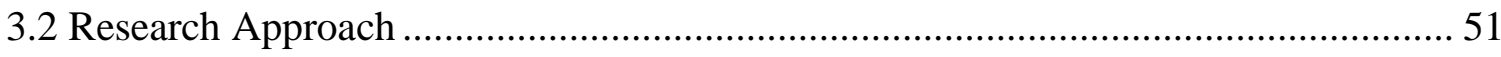

3.3 Hierarchical Decision Model …………………….............................................. 52

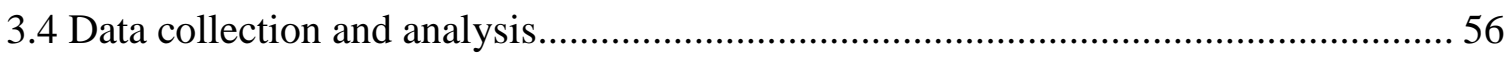

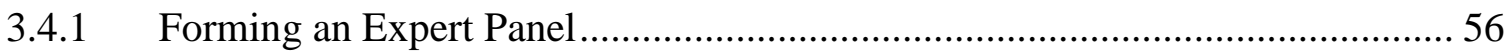

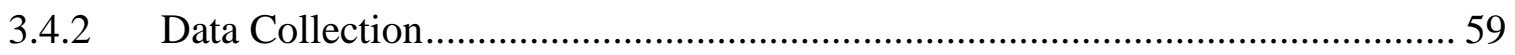

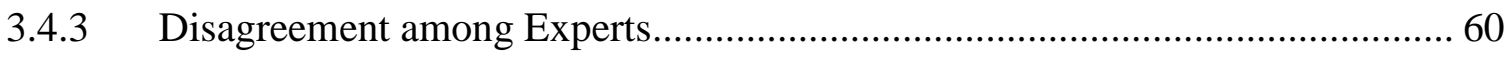

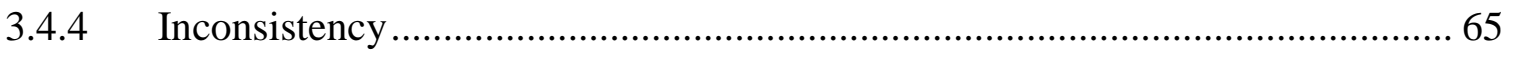

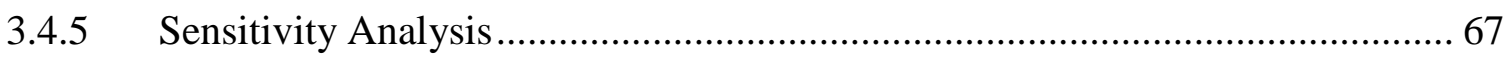

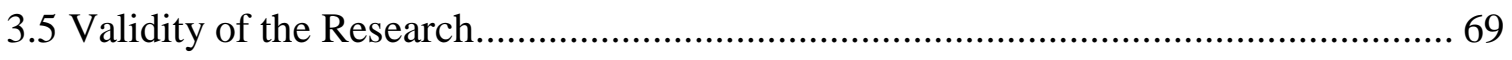

CHAPTER 4: CASE STUDY BACKGROUND …………………........................... 72

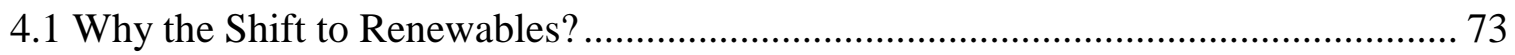

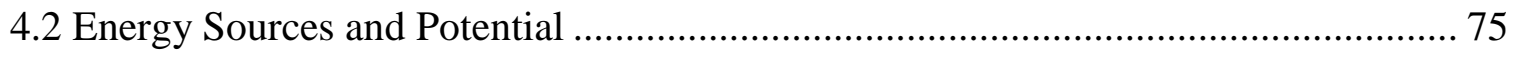

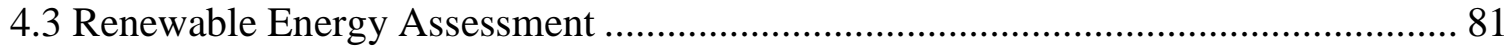

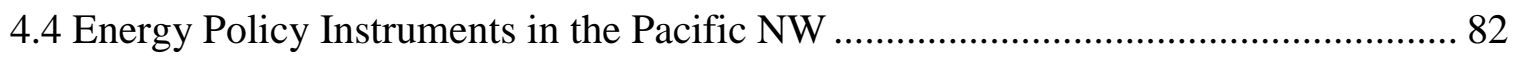

4.4.1 Voluntary Green Power Option (Green Pricing)................................................. 83

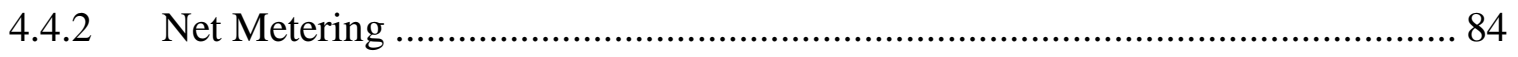

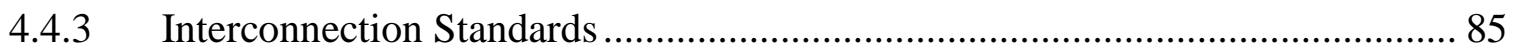




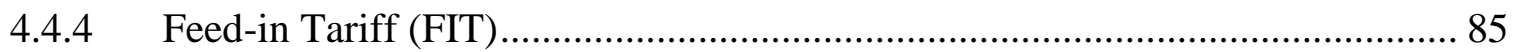

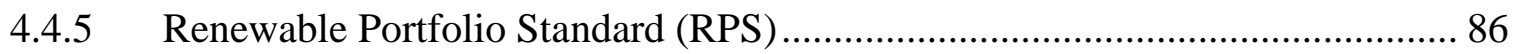

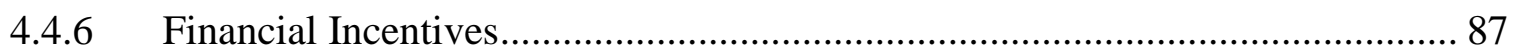

CHAPTER 5: CASE STUDY MODEL DEVELOPMENT ............................................. 90

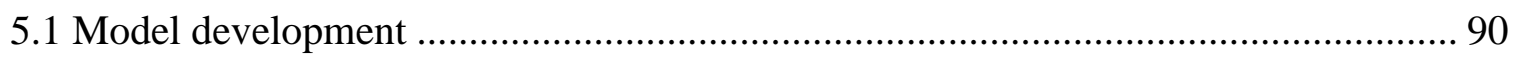

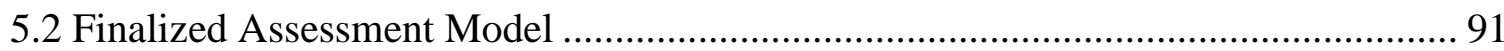

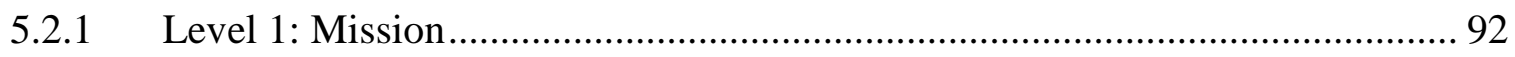

5.2.2 Level 2: Assessment Perspectives................................................................. 92

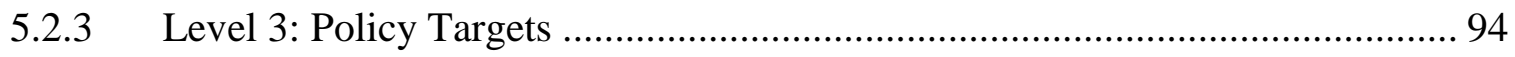

5.2.4 Level 4: Energy Policy Instruments ……………....................................... 99

5.3 Data collection and expert panels design ............................................................... 102

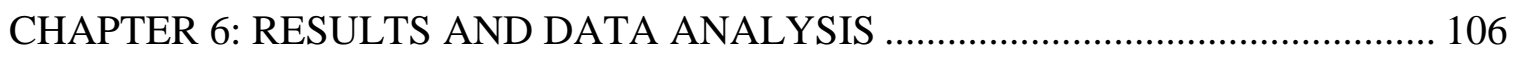

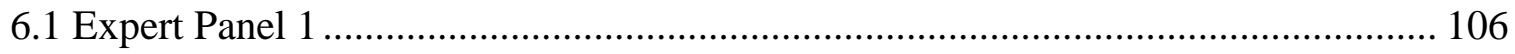

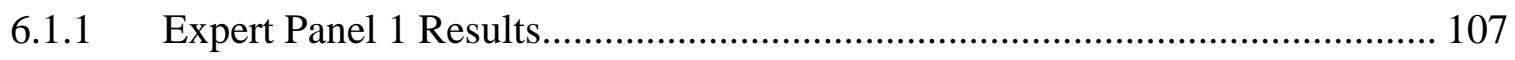

6.1.2 Analysis of Expert Panel 1 Results .............................................................. 108

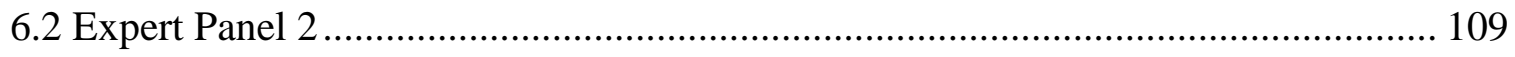

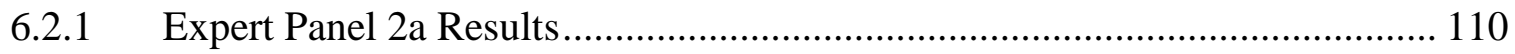

6.2.2 Analysis of Expert Panel 2a Results .......................................................... 110

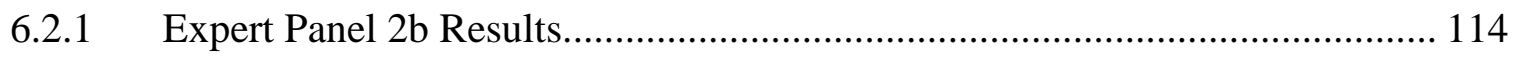

6.2.2 Analysis of Expert Panel 2b Results ........................................................... 117

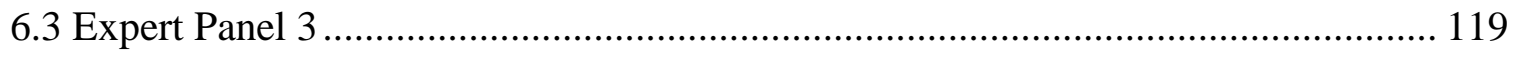


6.3.1 Expert Panel 3a Results..................................................................... 120

6.3.2 Analysis of Expert Panel 3a Results ....................................................... 120

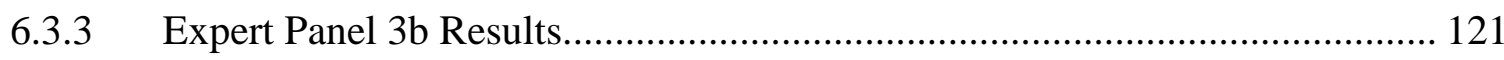

6.3.4 Analysis of Expert Panel 3b Results .......................................................... 123

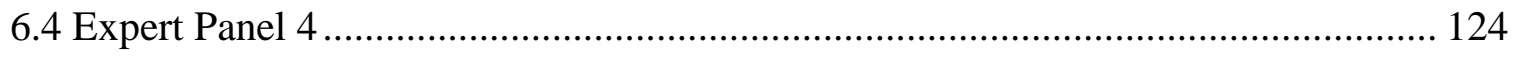

6.4.1 Expert Panel 4a Results.......................................................................... 125

6.4.2 Analysis of Expert Panel 4a Results ........................................................... 126

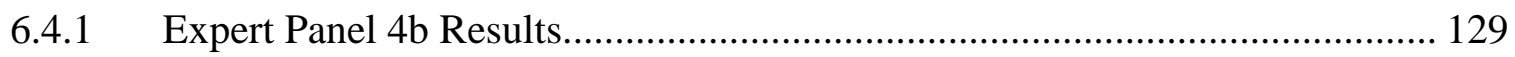

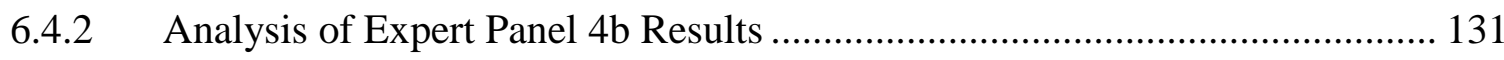

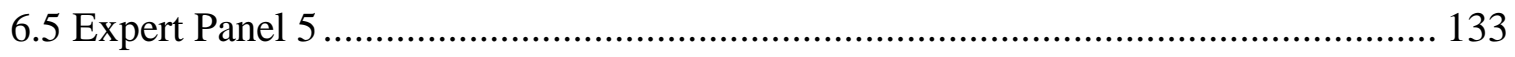

6.5.1 Expert Panel 5a Results........................................................................... 134

6.5.2 Analysis of Expert Panel 5a Results ........................................................ 135

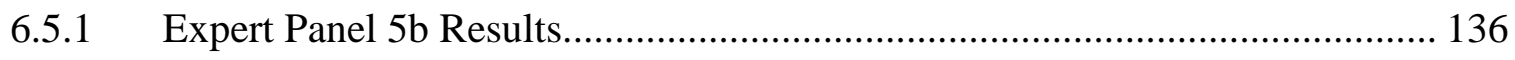

6.5.2 Analysis of Expert Panel 5b Results ......................................................... 138

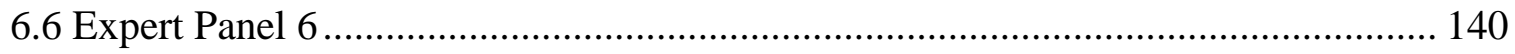

6.6.1 Expert Panel 6a Results........................................................................... 141

6.6.2 Analysis of Expert Panel 6a Results ......................................................... 142

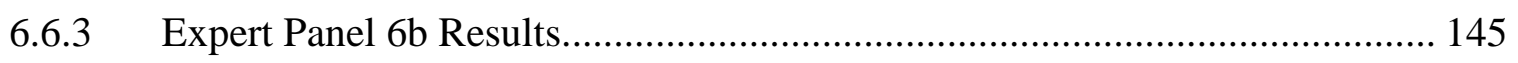

6.6.4 Analysis of Expert Panel 6b Results .......................................................... 148

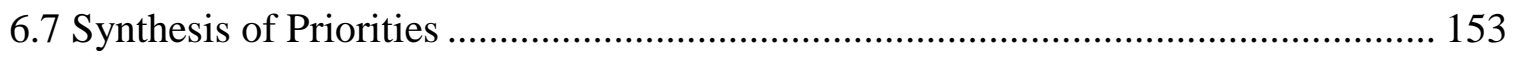

6.7.1 Relative Importance of Policy targets with Respect to the Mission ................. 154 
6.7.2 Relative Importance of Policy Alternatives with Respect to Perspectives ...... 157

6.7.3 Overall Importance of Policy Alternatives with Respect to the Mission......... 161

6.8 Analysis of Expert Panel Disagreements and Priorities ...................................... 163

6.8.1 Priorities Analysis with Respect to Expert Panel 2a Disagreement................. 163

6.8.2 Priorities Analysis with Respect to Expert Panel 4a Disagreement................. 164

6.8.3 Priorities Analysis with Respect to Expert Panel 6a Disagreement................. 166

6.8.4 Priorities Analysis with Respect to Expert Panel 6b - Integration Capabilities

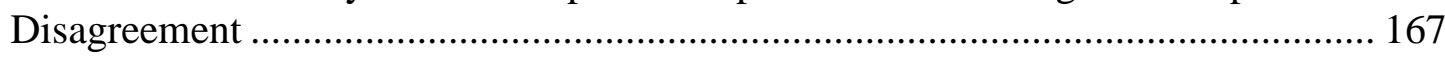

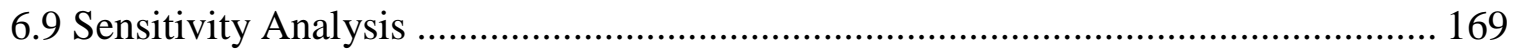

6.9.1 HDM SA at the Policy Design Considerations Level to Preserve the Ranking of the Best Alternative..... 170

6.9.2 HDM SA at the Policy Design Considerations Level to Preserve the Ranking of all Alternatives 171

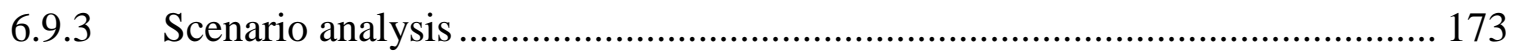

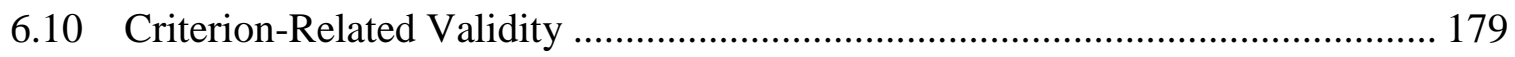

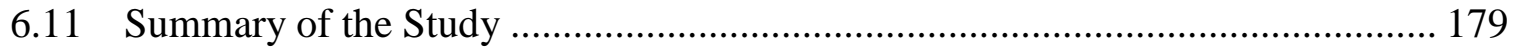

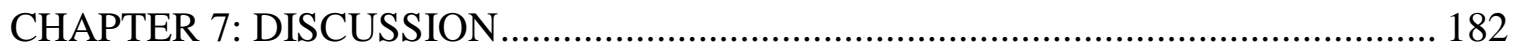

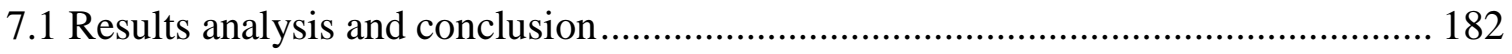

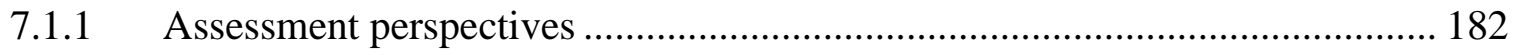

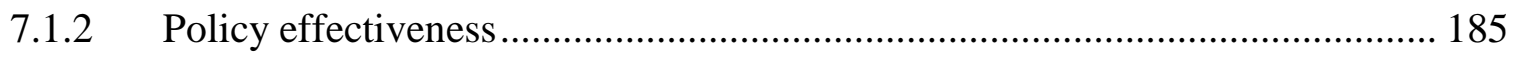

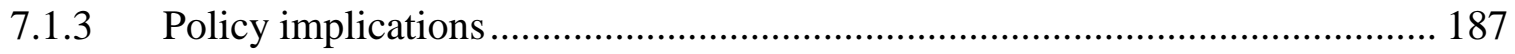

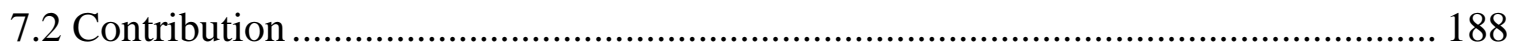

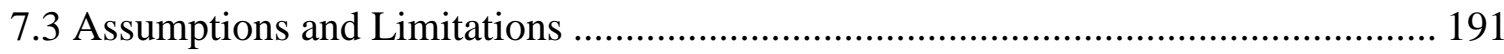




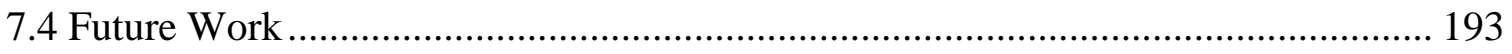

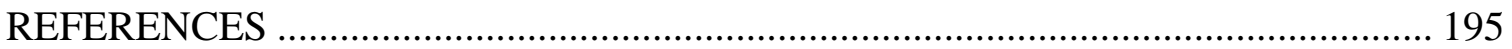

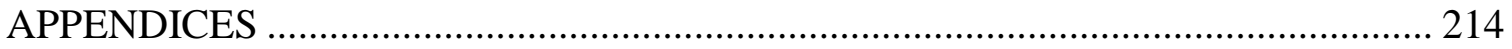

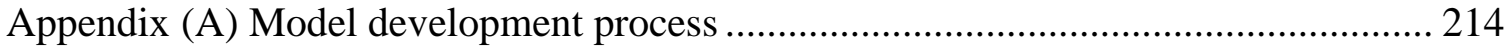

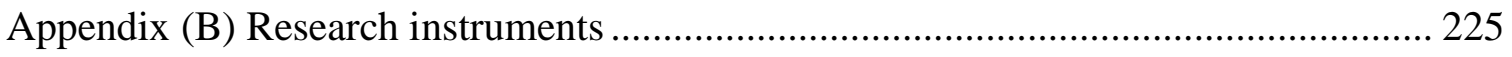

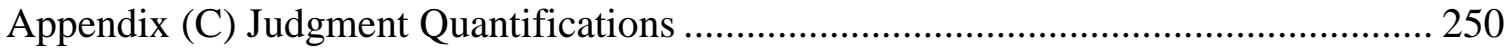

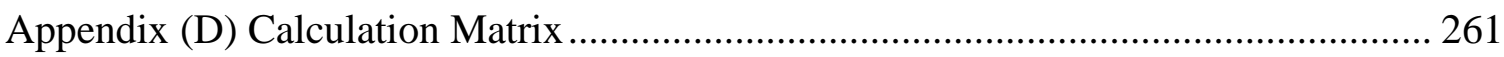




\section{LIST OF TABLES}

Table 1: Summary of Technologies Studied and Methodologies Used for Evaluating

Their Adoption 17

Table 2: Summary of Energy Policy and Corresponding Literature to Assess Adoption 28

Table 3: Literature for RE Policy Assessment........................................................... 30

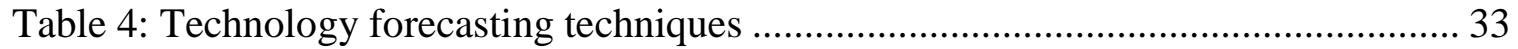

Table 5: Criteria for choosing forecasting technique................................................. 34

Table 6 Literature review on MCDM methods and applications ................................ 46

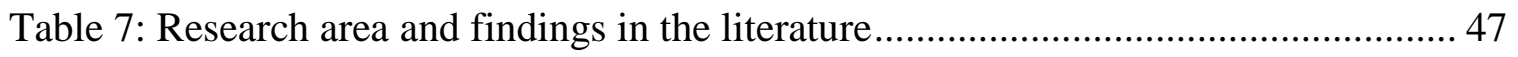

Table 8: Connecting the gaps to research questions .................................................. 49

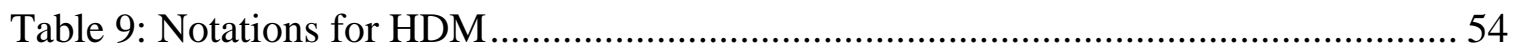

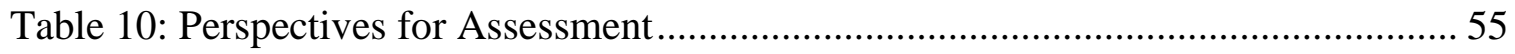

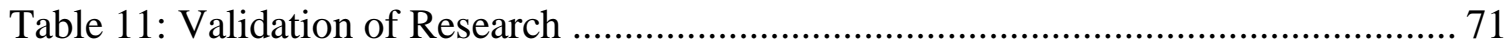

Table 12: Detailed Financial Incentives Policy in the PNW ..................................... 88

Table 13: Criteria and Policy targets in the HDM Model........................................... 91

Table 14: List of Alternatives in the HDM Model ..................................................... 100

Table 15: Role of Each Expert Panel and Required Expertise. ................................... 103

Table 16: Quantification Judgment Experts' Profiles ............................................... 103

Table 17: Distribution of Experts over Judgment Quantification Panels ...................... 105

Table 18: Expert Panel 1 Experts' Profiles ............................................................... 106

Table 19: analysis of expert panel 1 results, assessment perspectives with respect to the

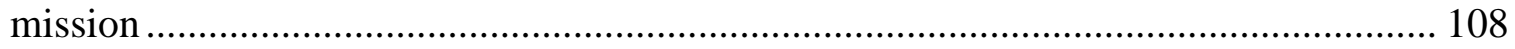


Table 20: expert panel 2 experts' profiles 109

Table 21: analysis of expert panel 2a results, economic policy targets with respect to perspective

Table 22: analysis of subgroup A results in expert panel 2a

Table 23: analysis of subgroup B results in expert panel 2a.

Table 24: analysis of subgroup $\mathrm{C}$ results in expert panel $2 \mathrm{a}$.

Table 25: analysis of expert panel $2 \mathrm{~b}$ results, decision alternatives with respect to reducing investment cost.

Table 26: analysis of expert panel $2 \mathrm{~b}$ results decision alternatives with respect to offering future cost reductions

Table 27: analysis of expert panel $2 \mathrm{~b}$ results decision alternatives with respect to encouraging private sector investment.

Table 28: analysis of expert panel $2 \mathrm{~b}$ results decision alternatives with respect to reducing

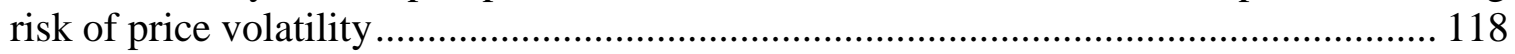

Table 29: Expert Panel 3 Experts' Profiles .................................................................... 119

Table 30: Analysis of Expert Panel 3a Results, Social Policy targets with Respect to Perspective.

Table 31: analysis of expert panel $3 \mathrm{~b}$ results, decision alternatives with respect to increasing social acceptance

Table 32: analysis of expert panel $3 \mathrm{~b}$ results, decision alternatives with respect to increasing public knowledge and awareness

Table 33: expert panel 4 experts' profiles

Table 34: analysis of expert panel 4a results, regulatory policy targets with respect to perspective

Table 35: analysis of subgroup A results in expert panel 4a ................................... 128

Table 36: Analysis of subgroup B results in expert panel 4a .................................. 128 
Table 37: analysis of subgroup $\mathrm{C}$ results in expert panel $4 \mathrm{a}$.

Table 38: analysis of expert panel $4 \mathrm{~b}$ results, decision alternatives with respect to compatibility with other policies

Table 39: analysis of expert panel $4 \mathrm{~b}$ results, decision alternatives with respect to policy ease of application.

Table 40: analysis of expert panel $4 \mathrm{~b}$ results, decision alternatives with respect to ratepayer equity.

Table 41: expert panel 5 experts' profiles

Table 42: analysis of expert panel 5a results, environmental policy targets with respect to perspective 135

Table 43: analysis of expert panel $5 \mathrm{~b}$ results, decision alternatives with respect to mandating emission reduction

Table 44: analysis of expert panel $5 \mathrm{~b}$ results, decision alternatives with respect to regulating land use

Table 45: analysis of expert panel $5 \mathrm{~b}$ results, decision alternatives with respect to preserving natural habitats

Table 46: analysis of expert panel $5 \mathrm{~b}$ results, decision alternatives with respect to protecting species and migration corridors....

Table 47: expert panel 6 experts' profiles

Table 48: analysis of expert panel 6a results, technical policy targets with respect to perspective

Table 49: analysis of subgroup A results in expert panel $6 \mathrm{a}$ 143

Table 50: analysis of subgroup B results in expert panel 6a. 144

Table 51: analysis of subgroup $\mathrm{C}$ results in expert panel $6 \mathrm{a}$. 144

Table 52: analysis of subgroup D results in expert panel 6a 145 
Table 53: analysis of expert panel $6 \mathrm{~b}$ results, decision alternatives with respect to facilitating grid access.

Table 54: analysis of expert panel $6 \mathrm{~b}$ results, decision alternatives with respect to enhancing transmission capabilities.

Table 55: analysis of expert panel $6 \mathrm{~b}$ results, decision alternatives with respect to improving integration capabilities

Table 56: analysis of subgroup A results in expert panel 6b - improving integration capabilities

Table 57: analysis of subgroup B results in expert panel 6b/ improving integration capabilities.

Table 58: analysis of subgroup $\mathrm{C}$ results in expert panel $6 \mathrm{~b}$ - improving integration capabilities

Table 59: analysis of subgroup D results in expert panel $6 \mathrm{~b}$ - improving integration capabilities

Table 60: analysis of expert panel $6 \mathrm{~b}$ results, decision alternatives with respect to leading to technological development

Table 61: comparisons of judgments quantification of expert panel 2a before and after grouping 163

Table 62: alternatives global ranking with expert panel 2a disagreements 164

Table 63: expert panel 4a disagreement results 165

Table 64: alternatives global ranking with expert panel 4a disagreements 165

Table 65: expert panel 6a disagreement results 166

Table 66: alternatives global ranking with expert panel 6a disagreements 167

Table 67: expert panel $6 \mathrm{~b}$ disagreement results 168

Table 68: alternatives global ranking with expert panel $6 \mathrm{~b}$ disagreements 168 
Table 69: global weights and rankings of policy alternatives with respect to the mission 170

Table 70: HDM SA at the policy assessment perspectives level to preserve the rank of the best alternative 170

Table 71: HDM SA at the assessment perspectives level to preserve the ranking of all alternatives

Table 72: Perspectives weights in case of extreme variations scenarios...... 173

Table 73: Scenarios and regional emphasis 174

Table 74: Alternatives rankings in case of extreme variations scenarios 178 


\section{LIST OF FIGURES}

Figure 1 U.S. Renewable Energy Consumption: Historic and Projected Values (Quads) . 3

Figure 2: Multi-criteria decision making ………………........................................ 36

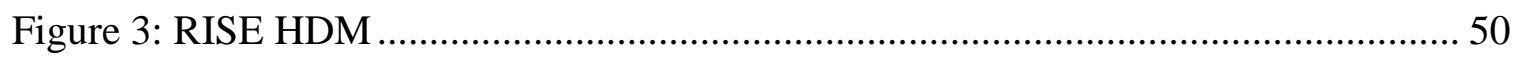

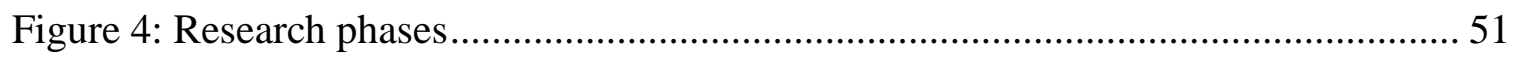

Figure 5: Generic form of HDM with four decision levels ............................................. 53

Figure 6: Oregon's power source portfolio …………………................................... 75

Figure 7: Washington's power source portfolio ............................................................ 75

Figure 8: Oregon's Renewable Energy Consumption (trillion Btu) 1960-2008 ............... 76

Figure 9: Washington's Renewable Energy Consumption (trillion Btu) 1960-2008........ 76

Figure 10: Wind Energy Development in the Pacific Northwest [186]........................... 78

Figure 11: Solar/PV Energy Development in the Pacific Northwest [186] ...................... 79

Figure 12: Finalized Hierarchical Decision Model....................................................... 101

Figure 13: relative importance of energy policy design criteria .................................... 107

Figure 14: relative importance of economic policy targets to economic feasibility

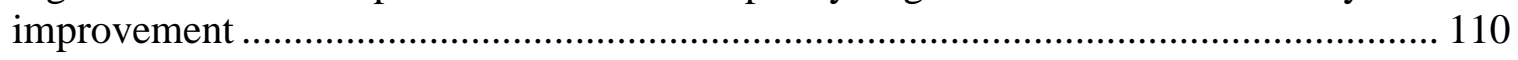

Figure 15: subgroups in expert panel 2a using dendrogram ...................................... 111

Figure 16: relative importance of decision alternatives with respect to reducing

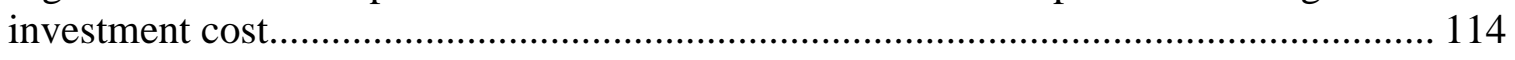

Figure 17: relative importance of decision alternatives with respect to offering future cost

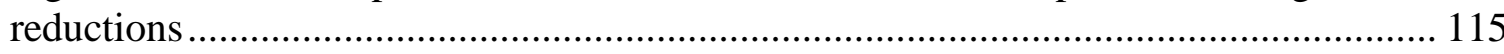

Figure 18: relative importance of decision alternatives with respect to encouraging

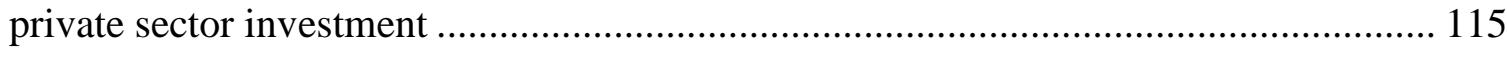


Figure 19: relative importance of decision alternatives with respect to reducing risk of price volatility 116

Figure 20: relative importance of social policy targets to community support encouragement

Figure 21: relative importance of decision alternatives with respect to increasing social acceptance

Figure 22: relative importance of decision alternatives with respect to increasing public knowledge and awareness.

Figure 23: relative importance of regulatory policy targets to regulatory implementation considerations 126

Figure 24: subgroups in expert panel 4a using dendrogram 127

Figure 25: relative importance of decision alternatives with respect to compatibility with other policies 130

Figure 26: relative importance of decision alternatives with respect to policy ease of application.....

Figure 27: relative importance of decision alternatives with respect to ratepayer equity

Figure 28: relative importance of policy targets with respect to environmental protection promotion.

Figure 29: relative importance of decision alternatives with respect to mandating emission reduction

Figure 30: relative importance of decision alternatives with respect to regulating land use

Figure 31: relative importance of decision alternatives with respect to preserving natural habitats.....

Figure 32: relative importance of decision alternatives with respect to protecting species and migration corridors 
Figure 33: Relative Importance of Regulatory Policy targets to Technical System

Development

Figure 34: subgroups in expert panel 6a using dendrogram

Figure 35: relative importance of decision alternatives with respect to facilitating grid access

Figure 36: relative importance of decision alternatives with respect to enhancing transmission capabilities

Figure 37: relative importance of decision alternatives with respect to improving integration capabilities

Figure 38: relative importance of decision alternatives with respect to leading to technological development

Figure 39: subgroups in expert panel $6 \mathrm{~b}$ - improving integration capabilities using dendrogram 150

Figure 40: relative importance of policy targets with respect to the mission 155

Figure 41: relative importance of policy alternatives with respect to economic feasibility improvement 157

Figure 42: relative importance of policy alternatives with respect to community support encouragement 158

Figure 43: relative importance of policy alternatives with respect to regulatory implementation considerations

Figure 44: Relative Importance of Policy Alternatives with Respect to Environmental Protection Promotion 160

Figure 45: relative importance of policy alternatives with respect to technical system development 161

Figure 46: overall importance of policy alternatives with respect to the mission 162

Figure 47: Global contributions of alternatives to the mission/ Scenario 1 174

Figure 48: Global contributions of alternatives to the mission/ Scenario 2. 175 
Figure 49: Global contributions of alternatives to the mission/ Scenario 3.................. 176

Figure 50: Global contributions of alternatives to the mission/ Scenario 4.................. 177

Figure 51: Global contributions of alternatives to the mission/ Scenario 5.................. 178 


\section{CHAPTER 1: INTRODUCTION}

\subsection{Background}

The demand for alternative energy resources has increased in the last two decades as a response to major concerns of projected scarcity in fossil fuel supply as well as climate change issues. After the oil crisis of the 1970's, renewable energy (RE) resources emerged as sustainable, clean, and abundant alternatives to fossil fuels [1-6]. Beside environmental concerns, energy availability concerns and political pressure have prompted governments to look for alternative energy resources that can minimize the undesirable effects of current energy systems. Shifting away from conventional fuel resources and increasing the percentage of electricity generated from renewable resources is an opportunity to guarantee lower carbon dioxide $\left(\mathrm{CO}_{2}\right)$ emissions and to create better economic opportunities for the United States.

Renewable energy sources offer a reliable alternative for the current fossil fuel system because of their minimal impact on the environment and unlimited availability. Utilizing more abundant and environmentally safe energy sources to replace current fuels has undisputable benefits for cutting carbon emissions and reaching energy security. However, renewable resources still represent a relatively small percentage of the overall energy supply. In spite of all the efforts to reduce greenhouse gas (GHG) emissions and develop a more sustainable energy system, fossil fuels still generate the most U.S. power. In 2011 , coal provided $42 \%$ of the energy supply and was the most prominently used fuel 
for generating electricity. Natural gas, nuclear power, and petroleum followed with usage percentages of $25 \%, 19 \%$, and $<1 \%$ respectively; while renewable energy sources comprised the remainder, only $13 \%$ of the total portfolio. Hydropower is the main source of renewable energy; followed by biomass, wind power, geothermal, and solar power, ranked accordingly.

Even though a diversity of renewable energy sources is available in the US and the development of the technologies themselves is mature, the use of such resources is still very limited in the USA, compared to Europe. As the fossil fuel system is deteriorating, however, with price increase and supply scarcity, the transition to a new era of renewable energy is inevitable [7]. Policy can play an important role in promoting the penetration of renewable energies into the power generations marketplace/portfolio [8].

Over the past decade, federal and state governments have adopted policies and initiated programs to accelerate the development and adoption of renewable energy technologies as energy sources. Nationwide, 30 states have mandatory plans to integrate renewable technologies in their energy mix by the year 2025 [9]. Federal and state governments are working to prepare and employ policies that can meet current energy demand from renewable sources, and in doing so, make a step toward a sustainable future. The emphasis is now on developing programs that foster research, encourage government-industry partnership, and promote tax credits and other incentives which can 
increase the rate of adoption of renewable energy technologies and expedite replacing traditional fuels [10].

When designing and selecting a comprehensive and coordinated group of policies that focus on energy adoption goals, a variety of variables should be taken into consideration and considered as policy targets. These variables could be either to overcome the barriers facing such adoption or increase the positive outcomes of renewable energy adoption. Figure 1 shows the projected levels of renewable energy consumption in the U.S. until 2030 in different sectors. (Historic and Projected Values (Quads) [9]) Policy makers have to lay out policies that would guarantee reaching those desired levels and a smooth transition of the energy system.

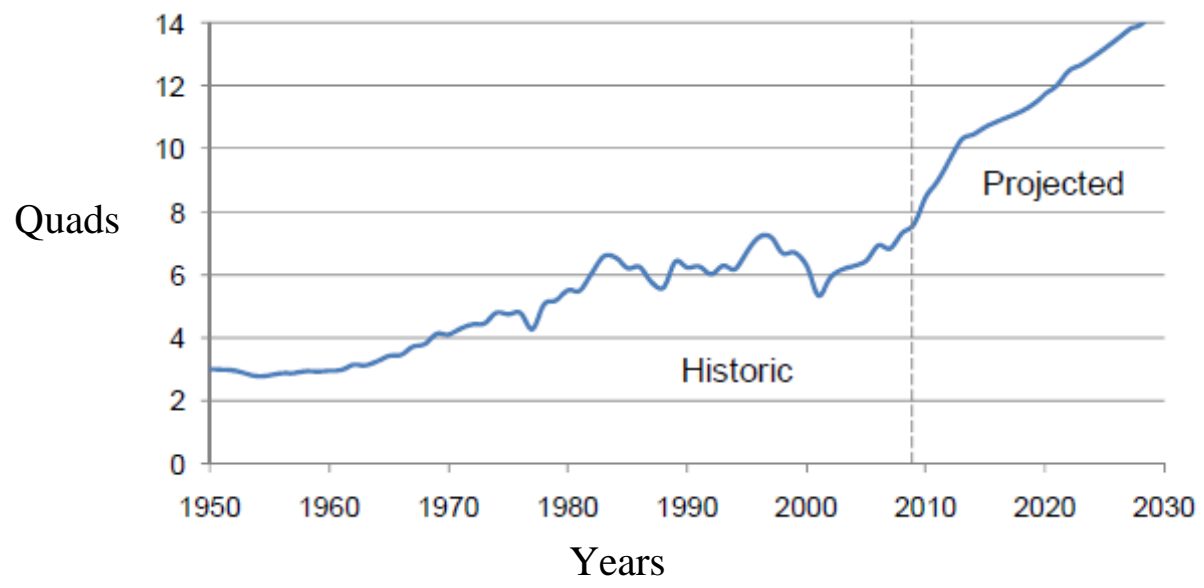

Figure 1 U.S. Renewable Energy Consumption: Historic and Projected Values (Quads)

Renewable energy technologies are becoming an increasingly important component of the electricity supply mix; however they still face some challenges involving large scale deployment and commercialization. It is important to understand that RE 
technologies have different adoption systems than conventional energies that would facilitate their wide spread use. Analyzing the effectiveness of policies can be helpful in the current policy portfolio design and as a feedback for what is needed to be accomplished. Recent literature has started to investigate the effectiveness of energy policy on increasing the usage of renewable energy in the power generation. With different energy policies implemented and still debated, literature emphasized on the need to evaluate these policy instrument to verify their ability of achieving their targets [11-13]. This evaluation can serve as feedback and give information to decision makers about policy effectiveness which might lead to redesign the policy or its implementation process.

\subsection{Research scope}

The objective of this research is to evaluate the effectiveness of energy policy instruments on increasing the adoption of renewable energy by developing a comprehensive assessment decision model. Adopting relatively new renewable energy sources is a multidimensional decision process that involves a number of different variables and several perspectives: economic, technical, social, political and environmental $[14,15]$. Understanding these characteristics of renewable energy sources is needed to improve current production and increase the deployment of RE in the power generation sector. From this point of view, multi-criteria analysis appears to be a suitable tool to merge and analyze all perspectives concerned with the decision-making process, 
by establishing a relationship among all alternatives and factors that influence decisions. It can provide a technical-scientific decision-making support tool that is able to justify preferred options clearly and consistently in the renewable energy sector [16]. It is important to realize that since there will be conflicting viewpoints and different hypothetical solutions, the "best" choice resulting from applying multi-criteria decision analysis (MCDM) methods would be the best negotiated solution and not necessarily the explicitly optimum one. Currently there are no models to assess the effectiveness of different policy instruments that can combine multiple perspectives of renewable energy adoption with different policies. This study develops a research framework that can assist decision makers in the energy sector to develop a comprehensive energy policy while taking into consideration different perspectives that involve various goals in order to find the optimum policy pathways. The research goals that support the achievement of the research objective are:

- Provide a systematic approach for comprehensive evaluation of policy effectiveness on RE technology adoption and implementation.

- Develop a multi-criteria model to evaluate and prioritize current RE policies and measure their relative contribution to this adoption.

- Explain long term uncertainties resulting from overall environmental changes and change in energy planning priorities. 
This research has answered the following research questions (RQ) that have been formulated to handle the current problems and support the research objective:

- What are the current policies employed to increase the adoption of renewables?

- What are the criteria for assessing the effectiveness of these policies?

- Which policy instrument has the highest effect on accelerating the adoption?

- How does the change in energy planning priorities affect the decision in policy analysis?

\subsection{Outline of the dissertation}

This dissertation is outlined as follows:

- Chapter 1: Introduction, presents an introduction and an overview of the dissertation. The research background, objectives, and approaches are summarized.

- Chapter 2: Literature review, presents a comprehensive literature review in three areas: renewable energy adoption motivations and barriers, renewable energy policy and planning, and methodologies in energy decision making. This chapter summarizes key literature and identifies research gaps, goals, and questions.

- Chapter 3: Research methodology, describes the research methodology applied and research steps. The research steps are described by providing details of the 
Hierarchical decision model (HDM) methodology, expert panel selection, methods for collecting and validating data, and sensitivity analysis.

- Chapter 4: Case study background, presents the background of the case study. This chapter explains in detail the case of renewable energy sources in the Pacific Northwest and energy policies employed in the region.

- Chapter 5: Case study model development: definition of the variables of the generalized assessment model used in the research is presented in this chapter. Model development and data collection phases are explained in details.

- Chapter 6: Results and data analysis, presents the case study results. Data collected from expert panels are discussed and analyzed. Ranking of policy alternatives and overall importance of model variables are calculated for each level and tested for inconsistencies and disagreement among experts. Sensitivity analysis and scenario analysis are performed. Finally, validation of the research is discussed and a summary of the research is presented.

- Chapter 7: Discussion, includes conclusion and discussion the of results and energy policy effectiveness. Research contribution, assumptions, limitations as well as future research opportunities to expand this research are presented in this chapter. 


\section{CHAPTER 2: LITERATURE REVIEW}

Fossil fuels still account for over 80 per cent of the total primary energy supply worldwide. Even with the oil crises, the depletion problem and the awareness of the environmental consequences of the use of fossil fuels, the share of renewable energy in the total primary energy supply is still small. During the last 20 years, there has been an increasing amount of literature on renewable energy technologies. The diffusion of renewable energy technologies is beginning to take place and a new energy era has begun. This diffusion has so far been driven by environmental and socio-economic factors and political regimes [17]. However, we are still at a very early stage of the diffusion of these technologies. There are still many questions to answer through the research regarding this transformation from the conventional sources of energy to the renewable energy technologies and obstacles to overcome towards the adoption of these new energy technologies. Future research issues that should be addressed is how to develop an innovation system that is based on the capability of the new technologies while this system guarantees the involvement of all actors and institutions which support this new transformation. Furthermore, design an adoption model or frame work that can emphasize on distributing the knowledge and awareness in the network through effective communication channels to achieve effective diffusion of the new technologies. Policies and government support are major drivers for the diffusion. Governments can drive the changes required, by setting mandates and policies at the federal or state level, and by 
establishing the institutions needed at the local and provincial level to help drive these developments.

\subsection{Renewable Energy Adoption}

Diffusion of innovation refers to the rate of new ideas and technologies to spread among people and end users. Rogers has explained the diffusion process from different viewpoints and explained that consumers go through a number of stages before accepting and adopting a new product. When a new technology or idea is introduced, it is originally adopted by a small group of people, but later, the new technology spreads to a wider group of people. The estimated number of users and adopters of an innovation defines its market potential, which further depends on a number of other factors such as: perceived value, awareness of the technology, etc. There are different diffusion theories that could be used for understanding the adoption of new technologies, but the bulk of literature is based on the diffusion of innovation theory. Diffusion of innovation theory is a key methodology for this research. Rogers [18] defines diffusion as, "the process by which an innovation is communicated through channels over time among members of a social system. It is a special type of communication, in that the messages are concerned with new ideas." According to this definition, in order for diffusion to occur there should be a new idea or technology, people involved, and different communication channels within the social system that spread this innovation. 
There is a large amount of literature which discusses the factors that affect the adoption and diffusion of RE technologies. Several frameworks and models have been developed over the years to analyze different aspects and drivers of technology adoption and diffusion in order to calculate the rate of adoption and forecast or roadmap the future of new technologies. Jacobson and Johnson demonstrated that a process of diffusion of a set of renewable energy technologies is now beginning to take place and identified the essentials of an analytical framework for studying the transformation process of the energy sector. They emphasized the need to use an innovation system perspective when analyzing the processes of innovation and diffusion [19]. The Bass Model provides a good framework for analysis of energy technologies and description of interventions that may interact with the diffusion. Energy installed capacity can be used to obtain the diffusion parameters for the model which can reflect the rate of adoption of that certain technology [20,21]. Sales growth models have been proposed to measure the effectiveness or success of a new idea among end users [22, 23] and the Bass Model is one of the most applied models in this area $[21,24]$. Due to its simplicity and flexibility in dealing with historical data, the Bass Model received a great amount of attention from marketing and consumer behavior scientists in analyzing diffusion patterns. A limitation for this type of analysis is that it does not take into account any other drivers of diffusion that would influence the decision process, such as price or market dimensions, and assumes that the technology does not change or develop over time. Growth and experience curves can be used to analyze the possibilities and limitation of diffusion of a 
certain technology but the methodology so far was not able to compare between renewable technologies in terms of diffusion status.

A large number of researchers studied the factors that affect the rate of diffusion of RE technologies. Cantono and Silverberg developed a network model of new technology diffusion to analyze the relationship among the diffusion of a new technology, learning economies and financial support, and to further investigate the path of diffusion of a new energy technology when some consumers are willing to pay more for goods that are perceived as "green" [25]. Kobos et al. argued that without institutional support, emerging energy technologies are limited from adoption and reaching consumer markets by their costs [26]. Their analysis explored the relationship among research and development (R\&D) investments, energy cost reduction, and market penetration. The methodology used in their study combines two theoretical frameworks: the estimate of energy cost as a function of cumulative installed capacity (a learning by doing factor) and cumulative R\&D expenditures (a learning by searching factor). The study concludes that institutional policy instruments play an important role for renewable energy technologies in reaching sufficient cost reductions and furthering market adoption.

\subsubsection{Economic Variables}

Renewable energy sources are like any other new technologies where economic factors heavily influence the rate and extent of diffusion. Consumers are willing to adopt renewable energy and other alternatives if they are financially competitive to current 
sources. Diaz-Rainey \& Tzavara linked the willingness to pay (WTP) literature with the current innovation literature by developing a diffusion model of an induced environmental customer market [27]. The cost of developing new technologies is one of the main concerns for both the supplier and consumer. Diffusion and adoption of renewable energy technologies depends on development of more mature technologies and cost cutting strategies which can be achieved through innovation and experience. Kapur et al developed a two dimensional technology innovation model which combines the adoption time of technological diffusion and price of technology. The analysis confirmed that studying the key elements that influence the adoption of a technology is crucial to assess the competitiveness of new technologies [22]. Neij used experience curves to analyze the prospects for diffusion and adoption of renewable energy technologies [28]. The analysis discussed in his article explained how it is possible to accomplish cost reductions in the future for renewable energies that would make them competitive with conventional sources.

There are different policies and legislative actions that help to set up the targets and directions to transfer the energy system to renewable energy utilization, but meeting the desired targets depends on the advancements of technologies and the change of consumption preference from customers. Feed-in-tariff, for example, is a price for electricity that is paid by national authorities for individuals or businesses when they produce and sell energy generated by RE sources, and it's usually higher than regular prices. This mechanism has been introduced in many European countries and in the 
United States (US) and is proven to be effective in stimulating the adoption of RE sources [29]. Several articles discussed renewable energy adoption in the US and European Union (EU) from the public policy and government legislation point of view. The European commission has established a project for the assessment of external energy cost (ExternE Project). This project produces a series of reports describing analysis of nuclear, fossil, and renewable fuel cycles for assessment of the externalities associated with electricity generation [30]. The methodology used in this project is called ImpactPathway-Approach. Impact pathway assessment is a bottom-up-approach, meaning that by following the pathway from source emissions, physical impacts, environmental benefits and costs can be estimated for the energy and hence expressed in monetary benefits and costs [30].

\subsubsection{Social Acceptance}

For many new technologies, customer interaction and satisfaction can enhance the image of the product and increase the acceptance of it, but the main motivation for acceptance remains the competitive price [22]. The option of purchasing electricity from renewable sources is increasingly available to customers across the United States but appropriate electricity pricing affects the use and choice of energy sources [31]. When energy prices are high, it's likely associated with drop of demand for that certain energy [27]. Kotchen and Moore analyzed household decisions about participating in greenelectricity programs and investigated the factors that influence this participation [32]. Increasing awareness of the environmental consequences from conventional fuel usage 
and shifting values into using more environmentally friendly technologies can change individual and organizational attitudes toward the adoption of new technologies, such as the purchase of electricity from providers that generate it using renewable sources.

Public satisfaction and market behavior can have a major influence on the rate of diffusion of any innovation. A marketing strategy focuses on select market niches and being able to integrate the innovation aspect into a policy toward marketing alternative renewable technologies $[33,34]$. A study by Harmon and Cowan examined the market for renewable (green) energy using the TOP framework (technical, organizational, personal) and discussed the market adoption barriers for green energy [35]. In addition to marketing strategies, the adoption of new products depends on its perceived value by the individual purchaser as well as other potential adopters in the same social network. Beck et al. studied the effect of customer networks and word of mouth on diffusion of new technology based on the similarities of previous ones. They developed a formal adoption and diffusion model to consider the roles of direct and indirect network effect to analyze investors' and consumers' adoption dynamics [36].

\subsubsection{Institutional and Government Support}

One of the driving forces to achieve technology diffusion is the channel of diffusion, which is the driving force between both the diffusing party and the recipient. Institutional support and research and development (R\&D) investments are important factors that can push diffusion of emerging energy technologies [26]. Previous studies 
have shown that government support and energy strategies have a great impact on the diffusion of energy technologies [26, 37]. Shi Yan et al. analysis of technology diffusion channels in China demonstrated that in addition to diffusion driving forces, diffusion channels are equally important to consider [38]. Patents are a direct channel for technology diffusion; a higher frequency of patent citation reveals a faster diffusion and greater adoption of the technology [38]. Patents are used to analyze technology trends, including growth and diffusion, as well as competitive parameters between emerging technologies $[39,40]$. Previous studies have found that the quantity of patents and amount of knowledge spillover are highly correlated with R\&D expenditures [41-44].

On the other hand, bibliometrics can also be used to understand patterns of technology development and adoption and potentially forecast the future [45-47]. Norton defined bibliometrics as the measurement of text and information. Researchers have used bibliometric analysis to track academic journal citation and identify the competitive position of a technology and its level of maturity [48, 49]. Both bibliometric and patent analysis can be used as a measures of technology maturity and hence adoption rate. These studies emphasized different policies in various energy fields and their effect on stimulating RE diffusion, but they have ignored market-based schemes. Danica analyzed government support systems for promoting and marketing diffusion of RE technologies from an investor perspective [50]. Attempts have been made to study the influence of market availability and marketing plans on familiarizing customers with the advantages of renewable energies and facilitating their adoption. 


\subsubsection{Environmental Concerns}

Different studies also explored how policymakers could influence processes of technology adoption in different sectors [51, 52]. Morrow et al. examined different policies related to the transportation fuel sector in the US market and the feasibility of these policies to meet the governmental goal of reducing GHG emissions. The analysis confirmed the importance and the role of different policies in all sectors, especially the transportation sector, to reduce GHGs [53].

The use of food resources such as the land, for energy production, is a rising issue for research and debate. In their article, Dritschilo et al. reviewed some of the major issues in the food vs. fuel dilemma [54]. By applying a quantitative measure approach, they presented estimates of resource usage by a selected set of technologies and attempted to quantify, through the use of an energy-food resource ratio, the amount of competition for resources between food production and energy production. They concluded that wind farms are the most favorable whereas ethanol is at the other extreme - its production is most land-intensive. Sherrington et al. reviewed the policy intended to stimulate the use of biomass in the UK, and discussed whether this policy is based on any consideration of the farmers' supply response [55]. They discussed a number of barriers to adoption: concerns over the security of contracts, the current high wheat price that increases the opportunity cost of committing land to perennial energy crops, the impact of willow roots on field drains, and the cost of returning the land to other uses. Their review 
concluded by detailing a number of important issues relevant to policy makers and suggested future research needs.

Table 1: Summary of Technologies Studied and Methodologies Used for Evaluating Their Adoption

\begin{tabular}{|c|c|c|}
\hline Technology & Methodology & Literature \\
\hline \multirow{3}{*}{ Energy efficiency technologies } & Patent analysis & {$[56]$} \\
\hline & Case studies & {$[57]$} \\
\hline & AHP/DEA & {$[58]$} \\
\hline \multirow{7}{*}{ Wind (offshore, wind farms) } & MCDM & {$[59]$} \\
\hline & Empirical study & {$[60]$} \\
\hline & System dynamic & {$[61]$} \\
\hline & Case study & {$[62]$} \\
\hline & Linear regression & {$[63]$} \\
\hline & Bass diffusion model installed capacity & {$[20]$} \\
\hline & Case study & {$[64]$} \\
\hline \multirow{4}{*}{ Solar (PV, CTP) } & Experience curves & {$[65]$} \\
\hline & MCDM & {$[16,66,67]$} \\
\hline & Case study, levelized cost method. & {$[68][17]$} \\
\hline & Bass diffusion model & {$[21]$} \\
\hline $\begin{array}{c}\text { Other renewables (biomass, } \\
\text { geothermal) }\end{array}$ & Case study & {$[17,55]$} \\
\hline
\end{tabular}

\subsubsection{Integrating Renewable Energy Sources into the Grid}

Worldwide, the demand for power generation systems fueled by renewable energy (RE) sources has shown an unparalleled increase over the past 10 years. As we work to replace centralized fossil-fuel power generation facilities with more sustainable and environmentally friendly energy sources, we should be aware of the weatherdependent and distributed characteristic of renewable energy. The electric system as described by U.S Department of Energy is a cohesive value chain which consists of 
generation, transmission, distribution, storage, and end-use entities. The focus here is on the power delivery system or "the grid," which is the part of the electric infrastructure that extends between the power plant and the end user. The increase in domestic energy demand and consumption combined with the aging infrastructure and transmission lines has put pressure on researchers and experts to closely examine the status and health of the nation's electrical grid. It is expected that the deployment of some major RE sources will be accelerated due to recent technological advancements [69]. Policy makers expect the power grid to sustain the new power sources and continue to remain resilient even with the high level of renewable power penetration mandated by state renewable portfolio requirements [70].

There are concerns that the U.S. transmission grid is in need of urgent modernization. The current grid is becoming congested because while electricity demand has continued to grow, generation facilities have not matched the demand by building new transmission lines [71]. The increasing number of installed or planned RE facilities calls for new strategies and technology development of the electricity grid in order to improve the power supply quality and reliability. The Office of Technology Assessment (OTA) report "Renewing our Energy Future," reviewed the status of renewable energy development in the US and summarized the characteristics of renewable energy sources that affect their development and in turn shape policy that should be targeted for their deployment [72]. Differences between conventional power sources and new renewable ones affect the way the transmission grid is used and create challenges in transition to RE 
generation, since the grid was originally designed for conventional power. These characteristic differences relate to: site specificity, intermittency, resource intensity, and technological maturity. The assessment of a new RE power generation system begins with evaluating its technological appropriateness and economic feasibility. Carrasco et al. presented new trends in technologies in Europe that facilitate the integration of renewable energy sources into the grid [73]. Their results agreed with George and Banerjee's discussion [74] that wind is now the most advanced RE technology due to recent improvements of the power electronics and control systems which have minimized some disadvantages of wind energy, such as harmonic distortions.

A transmission system denotes any system that was designed according to certain parameters and capabilities that limit its performance. The U.S. electric grid is a big network of independently owned and operated power plants and transmission lines. This variation makes the RE integration requirements and characteristics unique for each utility. The nature of renewable energy sources is different from conventional fuels that are predominantly used in power generation. Wind and solar, for example, are highly intermittent sources, their availability and harvest potential depends on the site location and season. This intermittency causes some technical issues when connected to the current grid. Intermittency of the source creates challenges like the necessity to have a dispatchable source to compensate for supply when RE's are not working. Site specificity for RE plays an important role in RE integration to the grid. RE's are site 
specific, meaning that the grid should follow the source where it can be generated at a feasible rate.

- Transmission Capacity

Renewable energy sources are mainly site-specific, meaning their energy can only be harvested in specific locations. Geothermal sources are only available in regions where there are good underground temperature sources, hydropower is available where there are sufficient river flows, solar energy can be distributed anywhere, but is best in sunny and dry desert areas, and wind sources are best harvested along coastal regions, mountain passes, and open plains. To transmit power generated from these distributed resources, new transmission lines should be built and the current grid expanded. The lack of transmission capacity is one obstacle for more RE deployment. Building more transmission lines is costly, and since the same lines are shared by many power producers, this creates a dilemma where no individual company is willing to pay. This requires scheduling and allocation of new plants so current plants are able to share the cost of new transmission lines being built and connected to the current main grid [75]. Non-hydropower renewable, particularly solar and wind had shown growth rates of about $20 \%$ worldwide in the last few years [74]. Because a significant portion of new renewable electricity generation would come from irregular or distant sources, grid improvements, such as increases in transmission capacity are critical for successful connection of these renewables into the grid. The U.S. Department of Energy has 
identified the current congested grid as a limitation for productivity and is forcing a higher cost of electricity to customers due to its inefficiency [76].

- Reliability

A power generation system is considered reliable when it can produce constant output at the necessary time. The use of intermittent renewable power sources creates a challenge in keeping and increasing a grid's reliability with the growing number of new technologies being added to the grid (generation, storage, distribution). As solar and wind are never constant, keeping the output power of these systems constant is not viable. One suggested approach is to utilize hybrid models for power generation that consist of renewable resource as well as a certain amount of other dispatchable sources to ensure security of supply and to be able to ramp up or down electricity produced according to demand [77]. Adding storage technologies to the grid can also help in separating electricity generation capacity from demand. Energy from renewable intermittent technologies can be generated during times when it's most available or in times of low demand and then stored before being transmitted in times of high demand or shortage in energy supply.

- Power Quality and Stability of Source

Power quality of a power source is measured by how much voltage and frequency variation it undergoes. These factors must be taken into consideration when integrating 
intermittent renewable sources into the grid. High quality power has constant voltage. The greater the variance in voltage, the lesser the quality of power the source produces. Voltage variances can cause damage or disruption to electronics. There are limits to the power quality that must not be exceeded, therefore, grid impedance must be considered when renewable energy converters are connected to the grid [78]. Developing new transmission technologies can increase the integrating capabilities of the transmission system to the point that renewable portfolio standard levels are met from renewables. These new technologies increase the grid's carrying capacity to handle the additional electric power flow [79].

- Distributed generation facilities

Since RE power generation plants need a large area of land to produce on a utility scale, most of these facilities are located in remote areas, which in turn require an extension of available transmission lines. Renewable energy distributed generation (DG) systems can offer a solution for the extension of transmission lines from large scale utility plants. DS systems are based mainly on renewable energy sources and are accessible to remote locations. DG systems have the benefits of saving power losses in transmission, increasing reliability and power quality, and reducing land use [80]. Recognizing those advantages, DG power generation systems' share in the world market has increased noticeably. The need for DG systems determine whether a system will be a grid Fconnected system or a standalone one that provides power locally [81]. 
- Policy Options

Several policies can be created to target renewable resource deployment in the power generation sector. To enhance transmission capabilities specifically, policy options should focus on resource assessment, research and development, private-public sector relationships, and infrastructural support. Resource assessment allows for the evaluation of sites where specific sources are available within a geographic region, enabling more accurate planning for the grouping of transmission lines for new plants. R\&D would allow the technological development needed for RE integration and offer solutions for intermittency and reliability. Enhancing public-private investor relationships would facilitate the commercialization of technologies and in turn, lower cost. Modernization of the current grid and infrastructure can lead to utilizing distributed sources efficiently and decreasing congestions and bottlenecks.

\subsection{Renewable energy policy}

Large efforts have been put into developing policies dedicated to fostering alternative energy adoption. Loiter and Norberg-Bohm have presented historical information about technological and political developments pertaining to wind energy technology. The study stated that supply push and demand pull policies are effective in supporting emerging technologies at the initial stages, however, they have limited capacities if efforts do not lead into creating a big, consistent market that can provide cash flow and give investors the confidence to take risks in developing wind energy 
technologies [82]. Information campaigns around wind resource availability and political support can help in building a renewable energy market. Moreover, a close relationship between R\&D projects and market response should be established so that market feedback can be reflected in new development projects.

Similarly, Norberg-Bohm proposed a policy-making approach that considers demand push and pull principles by analyzing the historical, technological, and commercial development of four electric power technologies: photovoltaic, fluidized bed combustion, wind, and gas turbines. It has been asserted that during the periods of precommercialization, first commercial use, and lead adoption, governments should provide ongoing support for new emerging energy technologies. Size, strength and structure of industry sectors, risk of private market niche, and financial and technological capability of the firms, have been identified as significant factors that can be used in policy decisions[83]. Renewable technologies in the US, Europe, and Japan have been supported for over 20 years with R\&D investments, and some technologies like wind and solar, with tax credits or other subsidies.

Birgisson and Petersen explained that the US has still not completed federal policy for adopting and benefiting from the renewable energy sources available, but there is a mix of policies and programs on both the federal and state levels to promote RE development [84]. Their article discussed the incentives, requirements, and marketing methods that are currently being used to support renewable energy along with their 
strengths and weaknesses, and then it evaluated their ability to achieve long-term growth of renewable energy. It concluded that the growth of the renewable energy sector should be ensured through determined, long-term, and widespread obligatory plans. Bird et al. discussed in their article the key policy and market factors that affect the amount of wind energy capacity being developed or planned in the US [85]. They noted that an increasing number of states are investing more in wind energy projects; currently about half of all states have at least one wind power project.

Birgisson and Petersen also summarized the weaknesses of some mechanisms for promoting renewable energy development, such as voluntary and mandated retail purchases, as well as wholesale procurements. Study results have implied that existing mechanisms are not providing long term success due to weaknesses in design or unpredictable variables. Wide spread adoption of renewable energy technologies can best be achieved through mandatory objectives rather than voluntary actions[84]. Tsoutsos and Stamboulis have worked on developing a policy-making tool specifically for renewable technologies which are different from conventional energy systems in regards to technological system dynamics [33]. Thus, in order to sustain diffusion of renewable energy technologies, a system-wide holistic policy approach should be in place. In order to address the gap, authors propose an approach that enables bridging supply and demand sides of the renewable energy production systems by integrating innovation dimension into policy making. Large scale deployment of renewable technologies will require a technological regime shift due to their unique dynamics which are not experienced within 
conventional energy systems. The geographically disperse nature and technologically unique characteristics of renewable energy sources and their relation to generation, distribution, and regulation, should be taken into consideration in new energy policies. Identification of specific niche markets for renewable energy can provide new learning opportunities for development of renewable energy technologies.

Diffusion of alternative energy technologies has been addressed by studying the factors that inhibit or favor users' adoption decisions. Further research studies could work on exploring ways to create the best portfolio of strategies to be used in policy designs. One part of this implementation gap has been addressed by Kydes, who has analyzed the effects of renewable portfolio standards (RPS) on adoption of non-hydro renewable energy alternatives, energy prices, fossil fuel consumption, and emissions [51]. RPS in the US requires $20 \%$ of the energy sold by 2020 to be extracted from non-hydro renewable energy technologies. Renewable portfolio standards will positively affect the adoption of renewable alternatives, but will also cause an increase in energy generation costs from around thirty five to sixty billion dollars, a 3\% increase, by the year 2020 . This analysis provided insights into future cost projections of proposed policies; however it does not provide quantification of the benefits or challenges that might result. Another study was conducted by Huang which aimed to determine the significant factors affecting adoption decision of RPS among US states by employing explanatory variables from political, environmental, economic, and social perspectives. Results indicated that gross state product and growth rate of population are the two important variables that have a 
positive effect on adoption of RPS. Therefore, the federal government should put more emphasis on these two variables in order to ease adoption of RPS. Also, education level of the population and political party dominance are found to have an effect on the adoption of RPS. Natural resource expenditure showed a negative correlation with the expectations, thus a more comprehensive set of explanatory variables can be employed to clarify this point. Further research is needed to focus on explaining how explanatory variables affect different levels of RPS adoption decisions. A more continuous approach could give better insight into RPS policy adoptions.

Similar studies have also been carried out with respect to European policy making tools. Accordingly, Fouquet and Johansson compared Feed in Tariff and Green Certificate Systems in terms of their effect on adoption of renewable energy technologies by members of the EU [86]. It has been found that Feed in Tariff provides a less risky environment for investors to move into renewable energy technologies, thus countries that have adopted this system have experienced rapid development. However, countries that have adopted Green Certificates are facing slow adoption rates. It is also emphasized that small and medium-sized companies are vulnerable to price changes when using Green Certificates, due to unstable market conditions, a reality that might negatively impact job creation opportunities.

Public awareness of the benefits of RE is an important step that would help their adoption. It is simple, if the population (end users) accepts it and uses it; it will reach the 
desired adoption level. Zoellner and his colleagues investigated the public acceptance of renewable energies and the social factors that influence this attitude [87]. Public acceptance was measured by qualitative interviews and standardized questionnaires focused on public perception of renewable energies (photovoltaic, biomass, and wind) for four different areas in Germany. Results show that there is general public acceptance for renewable energies under investigation with two major influencing parameters; economics as perceived by individuals (cost-benefit ratio) and level of involvement in the planning and decision-making process. More in-depth research that includes technological and environmental parameters and the psychological behavior of society toward those parameters, can give a valuable contribution to a more comprehensive understanding [87].

Table 2: Summary of Energy Policy and Corresponding Literature to Assess Adoption

\begin{tabular}{|c|c|c|}
\hline Policy & Methodology & Literature \\
\hline \multirow{4}{*}{$\mathrm{R} \& \mathrm{D}$ funding } & $\begin{array}{l}\text { Technology S-curves to analyze RE performance and } \\
\text { R\&D investments. }\end{array}$ & {$[88]$} \\
\hline & $\begin{array}{c}\text { Experience curves for energy cost as a function of } \\
\text { cumulative capacity and R\&D investments. }\end{array}$ & {$[26]$} \\
\hline & $\begin{array}{c}\text { Comparison between R\&D funding between different } \\
\text { countries and its effect on wind adoption. }\end{array}$ & {$[60]$} \\
\hline & $\begin{array}{l}\text { Patent analysis to investigate the effect of new knowledge } \\
\text { on energy investment decisions. }\end{array}$ & {$[89]$} \\
\hline \multirow{3}{*}{$\begin{array}{l}\text { Tax credits, grants, } \\
\text { and incentives. }\end{array}$} & Empirical study & [90] \\
\hline & Case study & {$[85]$} \\
\hline & Quantitative cash flow analysis & [90] \\
\hline \multirow{2}{*}{ Cap-and-trade } & Case study & {$[91]$} \\
\hline & Scenario analysis & [92] \\
\hline \multirow{3}{*}{$\begin{array}{l}\text { Renewable portfolio } \\
\text { standard (RPS) }\end{array}$} & Case study & {$[52,85]$} \\
\hline & $\begin{array}{c}\text { Empirical research with incentives as indicator of } \\
\text { magnitude and capacity. }\end{array}$ & {$[93]$} \\
\hline & $\begin{array}{l}\text { Fixed-effect model to evaluate the effectiveness of RPS } \\
\text { and percentage of RE generation. }\end{array}$ & {$[94]$} \\
\hline
\end{tabular}




\begin{tabular}{|c|c|c|}
\hline \multirow{2}{*}{} & Case study & {$[95]$} \\
\cline { 2 - 3 } & Scenario analysis, numerical simulation. & {$[96]$} \\
\cline { 2 - 3 } $\begin{array}{c}\text { Renewable energy } \\
\text { credits (REC) }\end{array}$ & $\begin{array}{c}\text { Linear regression } \\
{[63]}\end{array}$ \\
\cline { 2 - 3 } Feed-in-tariff & Comparative study for different energy policies adopted \\
and the effect of integrating REC. & {$[97]$} \\
\cline { 2 - 3 } & in European countries. & {$[95]$} \\
\cline { 2 - 3 } & Case study & {$[98]$} \\
\hline \multirow{2}{*}{$\begin{array}{c}\text { Mandatory green } \\
\text { power option }\end{array}$} & Fixed-effect model & {$[99]$} \\
\cline { 2 - 3 } & Linear regression & {$[68]$} \\
\hline
\end{tabular}

As the adoption of renewable energy sources in the power generation sector gains more attention worldwide, an emphasis on designing a policy system that facilitates this adoption and overcomes many of the obstacles is crucial. In the US, there have been many policy instruments deployed on the state or federal level. A survey of policies intended to increase the adoption of renewable energies (RE) in the power generation sector revealed three main policy types:

- Mandated regulations: sets targets and standards for price and quantity fixing, grid access regulations, and power generation fuel resources.

- Financial based policy: comes in the form of rebates, credits, and grant funding and is aimed at reducing cost, encouraging investment, and encouraging distributed generators. 
- Market-based policy: creates markets for mandated increased levels of RE as

well as increasing consumer awareness.

Different methodologies were discussed in the literature attempting to assess the effect of energy policies on renewable energy adoption. The bulk of literature focused on case studies and empirical research that measured the effect of certain policy instruments on RE adoption (see Table). The most studied resources were wind and solar, followed by transportation fuels.

Table 3: Literature for RE Policy Assessment

\begin{tabular}{|c|c|c|c|}
\hline Methodology & Strength & Weakness & Literature \\
\hline $\begin{array}{l}\text { Technology S- } \\
\text { curves and } \\
\text { experience } \\
\text { curves to } \\
\text { analyze RE } \\
\text { performance } \\
\text { and R\&D } \\
\text { investments. }\end{array}$ & $\begin{array}{l}\text { Give a notion about the relation } \\
\text { between investment in a } \\
\text { technology and resulting } \\
\text { technology performance as well } \\
\text { as allow comparison between } \\
\text { technologies. Describe the } \\
\text { relationship between cost and } \\
\text { cumulative production or } \\
\text { adoption of technology. }\end{array}$ & $\begin{array}{l}\text { If the cumulative investment is } \\
\text { not constant over time, the } \\
\text { resulting S-curve may not give } \\
\text { an obvious relationship. There } \\
\text { are many other perspectives } \\
\text { creating multiple dimensional } \\
\text { relationships which these curves } \\
\text { cannot capture }\end{array}$ & [88] [26] \\
\hline $\begin{array}{l}\text { Patent analysis } \\
\text { to investigate } \\
\text { the effect of } \\
\text { new knowledge } \\
\text { on energy } \\
\text { investment } \\
\text { decisions. }\end{array}$ & $\begin{array}{l}\text { Can be linked to the role of } \\
\text { technological advancement } \\
\text { embedded in number of patents } \\
\text { filed on increasing investment in } \\
\text { renewable energy capacity } \\
\text { installed. Direct measure of } \\
\text { R\&D efforts and policy role. }\end{array}$ & $\begin{array}{l}\text { Number of patents is not a } \\
\text { perfect measure of technology } \\
\text { innovation since many patents } \\
\text { don't have a commercial value } \\
\text { and the patent system is different } \\
\text { between countries which may } \\
\text { give ambiguous information. } \\
\text { Time and effort consuming to } \\
\text { track and count patents. Limited } \\
\text { to finding trends in innovation } \\
\text { and policy. }\end{array}$ & [89] \\
\hline Case study & $\begin{array}{l}\text { Covers real events in real time } \\
\text { and focus on a specific topic. } \\
\text { Emphasizes details related to a } \\
\text { number of events or situations } \\
\text { and their relationships and } \\
\text { identifies factors driving } \\
\text { development. }\end{array}$ & $\begin{array}{l}\text { Useful only as exploratory tool. } \\
\text { The findings can be biased to the } \\
\text { case studied and sometimes lack } \\
\text { reliability or generality to other } \\
\text { situations. Limited in scope for } \\
\text { specific cases. }\end{array}$ & $\begin{array}{c}{[60][85]} \\
{[91][52,85]} \\
{[95][97]} \\
{[95][98]}\end{array}$ \\
\hline
\end{tabular}




\begin{tabular}{|c|c|c|c|}
\hline $\begin{array}{l}\text { Quantitative } \\
\text { cash flow } \\
\text { analysis, } \\
\text { economic } \\
\text { models. } \\
\end{array}$ & $\begin{array}{l}\text { Easy to calculate and compare } \\
\text { different financial benefits to } \\
\text { certain policies. }\end{array}$ & $\begin{array}{l}\text { Neglects the effect of other } \\
\text { qualitative factors. }\end{array}$ & [90] \\
\hline $\begin{array}{l}\text { Statistical } \\
\text { models, linear } \\
\text { regression, } \\
\text { empirical } \\
\text { research, fixed } \\
\text { effect models } \\
\end{array}$ & $\begin{array}{l}\text { Thorough statistical analysis that } \\
\text { considers key factors. Identifies } \\
\text { casual effect of policy on } \\
\text { percentage of renewable energy } \\
\text { adoption. }\end{array}$ & $\begin{array}{l}\text { Definition of variables affects the } \\
\text { results, bigger sample size } \\
\text { needed for accuracy. Results } \\
\text { cannot be generalized and } \\
\text { analysis should be updated as } \\
\text { policies change and mature. }\end{array}$ & $\begin{array}{l}{[90][93]} \\
{[94][63]} \\
{[100][63]}\end{array}$ \\
\hline $\begin{array}{l}\text { Scenario } \\
\text { analysis }\end{array}$ & $\begin{array}{l}\text { Appropriate for integrating } \\
\text { different factors and predicting } \\
\text { different paths for long time } \\
\text { frame and measure uncertainties. }\end{array}$ & $\begin{array}{l}\text { Lack data inputs and are } \\
\text { judgment intensive methodology. }\end{array}$ & [92] [96] \\
\hline $\begin{array}{l}\text { AHP/DEA, } \\
\text { MCDM }\end{array}$ & $\begin{array}{l}\text { Structure the problem into a } \\
\text { simple hierarchy to evaluate } \\
\text { quantitative and qualitative } \\
\text { factors in a systematic manner } \\
\text { and prioritize relative efficiency } \\
\text { or productivity. }\end{array}$ & $\begin{array}{l}\text { Definition of criteria is } \\
\text { significant and changes the } \\
\text { outcome of the model. }\end{array}$ & $\begin{array}{c}{[12,31,101-} \\
106]\end{array}$ \\
\hline
\end{tabular}

\subsection{Decision Making and Energy Planning}

Energy is a necessity for human beings, but current energy resources are forecast to be limited in the coming years and their usage is accompanied by destructive consequences to the environment. Renewable energy is emerging as a solution for a sustainable, environmentally friendly, and overall cost-effective source of energy for the future. Renewable energy alternatives are capable of replacing conventional sources of energy in most of their applications, at competitive prices in the long-term [107, 108]. Selecting the appropriate source of energy in which to invest is a process that involves multiple factors and policies. Technology road mapping and forecasting research aims to predict and develop models that can be effective tools for decision making. 
Understanding the factors that can increase or prevent the adoption of each suggested technology, however, would give even more insight into the direction that future policies and efforts should be steered. To fully understand emerging technology adoption both by individuals and industry, and the effect any applied strategies could have on this adoption, new models should combine the behavioral analysis model along with strategic problem solving methods.

\subsubsection{Technology Forecasting:}

Technology forecasting is a systematic way to analyze and describe the technical, economic, and performance attributes of a technological innovation [109]. The role of forecasting is to analyze the situation to assist in the decision making plan. Technology forecasting can reduce the degree of uncertainty which can refine the decision making process. Many studies have attempted to classify forecasting techniques to help the analyst choose the right forecasting technique. Porte et al. classified forecasting techniques into three types: direct, correlative, and structural [110]. Technology forecasting methodologies are widely studied. One of the most common techniques is the use of growth curves such as S-curves and Pearl and Gompertz models [111, 112]. Daim et al. suggested that when sufficient historical data are not available, bibliometrics and patent analysis in technology forecasting is an appropriate methodology [45]. Kim et al. also utilized dual AHP to select the best electrical device technology in Korea[113]. Table 4 summarizes forecasting methodologies and techniques used in each methodology. 
Choosing the right techniques depends on several factors: data availability, data validity, technology similarity, method adaptability and ease of operation. Table 5 shows guidelines for selecting the appropriate methodology depending on the time frame of the problem as well as the use of the forecast. In the case of the absence or lack of data, judgment quantification is an appropriate methodology using the Delphi and Analytical approach.

Table 4: Technology forecasting techniques

\begin{tabular}{|c|c|c|}
\hline Forecasting methods & Approach & Forecasting technique \\
\hline \multirow{4}{*}{ Extrapolation } & \multirow{4}{*}{ Rely on expert opinion } & Delphi \\
\hline & & HDM \\
\hline & & Analogy models \\
\hline & & Scenario planning \\
\hline \multirow{6}{*}{ Qualitative judgment } & \multirow{6}{*}{$\begin{array}{c}\text { Extrapolate current patterns and } \\
\text { trends }\end{array}$} & Graphical summaries \\
\hline & & Numerical summaries \\
\hline & & Simple and multiple regression \\
\hline & & Intervals \\
\hline & & Exponential smoothing \\
\hline & & Time series decomposition \\
\hline \multirow{4}{*}{ Modeling and simulation } & \multirow{4}{*}{$\begin{array}{l}\text { Construct model to forecast } \\
\text { behavior }\end{array}$} & Explanatory casual models \\
\hline & & Lotka-Volterra \\
\hline & & System dynamics \\
\hline & & Agent models \\
\hline \multirow{2}{*}{ Leading indicator } & \multirow{2}{*}{ Past/future time series } & Growth curves \\
\hline & & Bass models \\
\hline \multirow{2}{*}{ Probabilistic } & \multirow{2}{*}{$\begin{array}{l}\text { Based on probability } \\
\text { distribution }\end{array}$} & Queuing theory \\
\hline & & Manufacturing lines, traffic flow. \\
\hline
\end{tabular}


Table 5: Criteria for choosing forecasting technique.

\begin{tabular}{|c|c|c|c|}
\hline Type & Horizon & Use & Method \\
\hline Very long range & $5-15$ years & $\begin{array}{c}\text { Long term strategy, planning for } \\
\text { new technologies }\end{array}$ & $\begin{array}{c}\text { Qualitative judgments, } \\
\text { Delphi }\end{array}$ \\
\hline Long Range & $2-5$ years & $\begin{array}{c}\text { Fixed capacity planning, plant } \\
\text { and equipment development }\end{array}$ & $\begin{array}{c}\text { Regression, trend, } \\
\text { annual forecast }\end{array}$ \\
\hline Medium range & $6-18$ months & $\begin{array}{c}\text { Adjustable capacity planning, } \\
\text { labor and inventory levels }\end{array}$ & $\begin{array}{c}\text { Regression with } \\
\text { seasonal forecast }\end{array}$ \\
\hline Short range & $\begin{array}{c}\text { 1 or more } \\
\text { weeks }\end{array}$ & $\begin{array}{c}\text { Item by item production } \\
\text { planning }\end{array}$ & $\begin{array}{c}\text { Moving average, } \\
\text { exponential smoothing }\end{array}$ \\
\hline
\end{tabular}

\subsubsection{Multi-criteria Decision Making Methods (MCDM)}

Renewable energy decision making can be viewed as a multiple criteria decisionmaking problem with correlating criteria and alternatives. This task should take into consideration several conflicting aspects related to the increasing complexity of social, technological, environmental, and economic factors [101]. Traditional single criteria decision-making approaches can no longer handle the complexity of current systems when dealing with this problem. Multi-criteria decision making methods (MCDM) provide a flexible tool that is able to synthesize and appraise a wide range of variables in different ways and offer useful insight to the decision maker in mapping out the problem. MCDM can provide a technical-scientific decision-making support tool that is able to justify its choices clearly and consistently, especially in the renewable energy sector.

In general, evaluating energy systems requires complex analysis that can be defined as a multi-dimensional space of different indicators and objectives. The use of 
multi-criteria decision analysis (MCDA) techniques provides a reliable methodology to rank alternative renewable energy sources, technologies, and projects in the presence of different objectives and limitations. Even with the large number of available MCDA methods, none of them is considered the best for all kinds of decision-making situations. Different methods often produce different results, even when applied to the same problem using same data. There is no better or worse method but only a technique that fits better in a certain situation.

MCDM is a branch of operation research models and a well-known field of decision making. These methods can handle both quantitative as well as qualitative criteria and analyze conflict in criteria and decision making. Several classifications and categorizations exist, but in general, MCDM methods can be divided into two categories, multi-objective decision making (MODM) and multi-attribute decision making (MADM) [114]. In MODM, the decision making (DM) problem is characterized by the existence of multiple and competitive objectives that should be optimized against a set of feasible and available constraints, whereas in MADM, a set of alternatives are evaluated against a set of criteria. MADM is one of the most popular MCDM methods adopted to solve complex problems. MCDM contain several different methods, the most important of which are the analytic hierarchy process (AHP), preference ranking organization method for enrichment evaluation (PROMETHEE), elimination et choix traduisant la realité or elimination and choice translating reality (ELECTRE) method, and multi-attribute utility theory (MAUT). 
In general, MCDM methods have four basic steps that support the making of more efficient, rational decisions: 1) Structure the decision process, alternative selection, and criteria formulation. 2) Display tradeoffs among criteria and determine criteria weights. 3) Apply value judgments concerning acceptable tradeoffs and evaluation. 4) Evaluate results and make a decision (see Figure 2) [115]. There are many discussions in the literature about which MCDM methodology is best to use; there is controversy about which is the "right" method to apply to a real-life problem. Multi-criteria analysis is used to select the "best fitting" solution from distinct multi-attribute options.

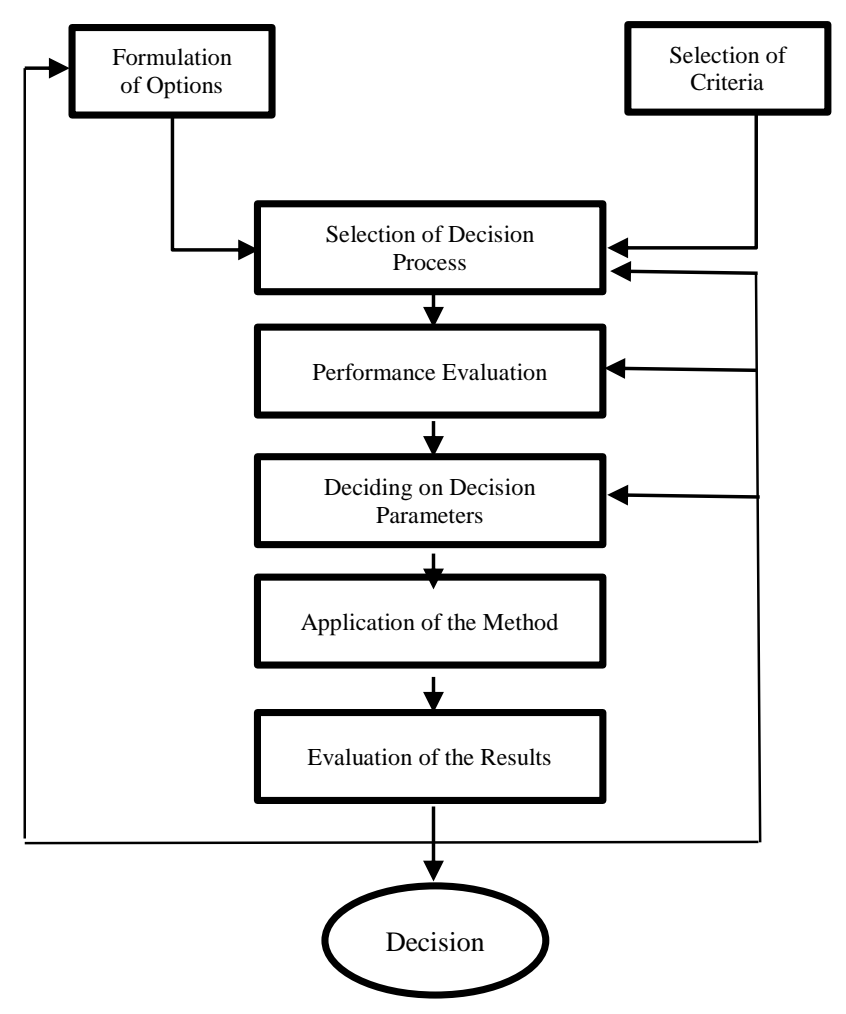

Figure 2: Multi-criteria decision making 
The comparison of MCDM methods in relation to renewable energy planning is discussed in the literature [103, 115-119]. In a previous analysis by Pohekar et al., MAUT was the most common MCDM method used in the energy planning literature, followed by AHP, PROMETHEE, ELECTRE, MAUT, fuzzy methods and decision support systems (DSS) [115]. The main objective of MADM is to select the alternative that has the highest score according to the set of evaluation criteria. A summary of the most well-known MCDM methods is presented below:

- Analytic Hierarchy Process (AHP): This MADM method was first introduced by Saaty [120]. In AHP, the problem is constructed as a hierarchy, breaking down the decision from the top to the bottom. The goal is at the first level, criteria and policy targets are in the middle levels, and the alternatives are at the bottom level of the hierarchy. Input of experts and decision makers is considered as a pair-wise comparison, and the best alternative can be selected according to the highest rank among alternatives.

- Analytic Network Process (ANP): The ANP methodology is a general form of the AHP; and was also introduced by Saaty [121, 122]. Although AHP is easy to use and apply, its unidirectional relationship characteristic cannot handle the complexity of many problems. ANP deals with a problem as a network of complex relationships between alternatives and criteria, in which all the elements can be connected. Cheng and $\mathrm{H}$. Li provide an empirical example to illustrate the use of ANP [123]. 
- Preference ranking organization method for enrichment evaluation (PROMETHEE): This method is characterized by ease of use and decreased complexity. It uses the outranking principle to rank the alternatives and performs a pair-wise comparison of alternatives in order to rank them with respect to a number of criteria. Up until now, the family of PROMETHE has included PROMETHEE I \& II [124].

- The elimination and choice translating reality (ELECTRE) method: This method is capable of handling discrete criteria that are both quantitative and qualitative in nature and provides a complete ordering of the alternatives. The analysis is focused on the dominance relationship between alternatives. It is based on the outranking relations and exploitation notions of concordance. The outranking method uses pair-wise comparison between alternatives. The family of ELECTRE includes ELECTRE I, II, III, IV.

- The technique for order preference by similarity to ideal solutions (TOPSIS): The basic concept of this method is that the selected alternative is the one that has the best value for all criteria, i.e. the one that has the shortest distance from the negative ideal solution [125].

- Multi-attribute utility theory (MAUT): This is one of the most popular MCDM methods in decision making. The theory takes into consideration the decision maker's preferences in the form of the utility function, which is defined over a set 
of attributes where the utility of each attribute or criterion doesn't have to be linear [126].

\subsubsection{Decision Analysis in the Renewable Energy Sector}

A review of the literature revealed that renewable energy research had gained momentum in the past 20 years. The use of MCDM analysis was found to be of importance since it analyzes the problem from a multi perspective point of view. Pohekar and Ramachandran presented a review and analysis of several published papers on MCDM and highlighted their applications in the renewable energy arena [115]. Burton and Hubacek investigated a local case study of different scales of renewable energy provision for a local government in the UK and compared the perceived social, economic, and environmental cost of small-scale energy technologies to larger-scale alternatives [127].

The application area of MCDM in RE research can be divided into four categories: renewable energy planning and policy, renewable energy evaluation and assessment, technology and project selection and allocation, and environmental impact (see Table 6). Renewable energy planning and policy refers to the assessment of a feasible energy plan and/or the diffusion of different renewable energy options. The key factors are RE adoption to reach a certain national target, decision factors, national planning, and the system's indicators. Renewable energy evaluation and assessment refers to the assessment of different alternative energies or energy technologies. Choosing 
between alternatives could be for assessing the "best" energy to be utilized in electrical or thermal energy or any other systems. Project selection and allocation refers to site selection, technology selection, and decision support in renewable energy harnessing projects. Environmental impact is concerned with alternative technologies and their impact on the environment and climate change specifically.

In the past, selecting between alternative energies was usually focused exclusively on cost minimization. It is widely recognized now that energy planning involves a much more complicated decision making process with many actors and variables involved. Renewable energy is foreseen as a sustainable, economical alternative to conventional energy sources and can be utilized in different ways. Wang et al. conducted a literature review on MCDM methods used for the selection of energy sources and their applications to energy issues. The review shows that there are four main categories for the evaluation of energy source and site selection problems: technical, economic, environmental, and social [118]. Köne and T. Büke, in keeping with the sustainability perspective, presented a multi-criteria analysis, analytic network process (ANP), to determine the best alternative technology to generate electricity in Turkey [128]. Zhao et al. utilized an AHP model to evaluate alternative power supply technologies and determine the best option according to the criteria of sustainable development, including environmental costs and energy security. The study will help the government of Guangdong Province to plan for the best power generation technology when expanding the local installed capacity [129]. San Cristóbal applied the multi-criteria optimization and compromise 
solution (VIKOR) method to the assessment of several renewable energy alternatives in order to select the most fit project for the Spanish government to reach its target of $12 \%$ total RE in 2010 [105].

Topcu and Ulengin dealt with the problem of selecting the most suitable electricity generation alternative for Turkey. They focused on a multi-attribute decisionmaking evaluation of energy sources and provided an integrated decision aid framework for the selection of the most suitable multi-attribute method for ranking of alternatives [130]. Cavallaro applied an outranking methodology of MCDA to evaluate different PV technologies according to given criteria to be selected in the process of thin film production [66]. Kocaoglu and Sheikh also used MCDA combined with the (STEEP) approach to multiple perspectives and decision modeling for PV technology assessment [15]. Cavallaro extended a classic TOPSIS MCDA methodology to the framework of fuzzy-set theory and used it to compare different heat transfer fluids used in CSP in order to examine the feasibility of using a new molten salt alternative [67].

Keeney et al. presented another application of MCDM methods for national energy policy. The authors followed a systematic approach of value trees to come up with a set of criteria that would be used in the assessment of alternative energy systems in Germany [104]. Lee et al. analyzed the competitiveness of Korea among 30 other nations in hydrogen energy technology development using AHP and two potential scenarios to determine criteria [131]. Lee et al. also used AHP and DEA to prioritize 
energy efficiency technologies in the sector of long-term national energy planning [132]. Hobbs and Horn used different MCDM methods to develop a set of recommendations in energy planning and policy through an interview process and several group discussions between stakeholders. The authors discussed the difference between using MCDM for evaluation of criteria and alternatives instead of monetizing all criteria, and concluded that the best approach is a combination of the two methods [103]. Hamalainen and Karjalainen utilized AHP and value trees to determine the relative weights of the evaluation criteria of Finland's energy policies [133]. Kablan used an AHP framework to support management in the prioritization process of energy conservation policy instruments in Jordan [134]. For Istanbul as a case study, Kaya used multi-criteria decision-making analysis to determine the most appropriate RE in Istanbul and the most suitable area to establish it in [135].

Chatzimouratidis and Pilavachi assessed different power plant types and made comparisons between traditional and new RE power generating technologies according to the technological, economic, and sustainability characteristics. They presented sensitivity analysis by comparing the original criteria weights with four alternative scenarios, changing each criteria weight at each scenario [136, 137]. Haralambopoulos and $\mathrm{H}$. Polatidis presented a new group decision-making framework of multi-criteria analysis for renewable energy project ranking. The suggested framework utilized the PROMETHEE II outranking method to achieve group consensus in evaluating renewable energy projects. The proposed framework was applied to data from different scenarios in a case 
study of exploitation of geothermal energy sources in the island of Chios, Greece [138]. They also presented a new participatory, multi-criteria approach where stakeholders can be engaged in the planning and decision making process. The methodology was applied to a number of case studies in Greece in order to evaluate renewable energy options for future investments [139].

Considering the different possible scenarios for adopting renewable energies provides better insight about the feasibility of such adoption and the conflicts in policies or alternatives. Beccali et al. utilized ELECTRE-III to assess an action plan for the selection and diffusion of renewable energy technologies under different scenarios on a regional scale on the island of Sardinia [140].Many researchers applied two or more MCDM methodologies to assess the feasibility of technologies by comparing the results and investigating the shortcomings of each alternative. Cavallaro and Ciraolo applied a multi-criteria method in order to support the selection and evaluation of one or more of the solutions and make a preliminary assessment of the feasibility of installing wind energy turbines in a site on the island of Salina in Italy [59]. Kahraman et al. utilized two different multi-criteria decision-making approaches to select the most appropriate renewable energy in Turkey. The fuzzy axiomatic design (AD) and fuzzy analytic hierarchy process were applied to the same set of criteria and alternatives, and the results from both methodologies are compared [141]. Daim et al. utilized MCDA to evaluate the feasibility of two clean power generation technologies: wind and clean-burning coal in the Pacific Northwest [142]. 
One of the main issues currently is the adoption of renewable energy to ensure a sufficient electricity supply. Expansion of current projects or planning new ones to meet energy demands is a task that involves finding a set of sources and ranking them in an optimal manner. The MCDM process can provide a systematic approach to rank alternatives and select the most "suitable" technology. Aragonés-Beltrán et al. applied two multi-criteria decision analysis methods, a hierarchy AHP model and a networkbased ANP model, and compared the resulting data to select between different proposed photovoltaic solar technologies to be invested in a power plant [143]. Cherni et al. investigated the outcome of applying a new multi-criteria decision support system methodology (SUREDSS) to the case of a rural area in Colombia in calculating the most appropriate energy option for providing power and fulfilling local demand [144].

Project selection and allocation is a complex decision-making process that involves different aspects and several stakeholders. Aras et al. used AHP to determine the most convenient location to build a wind observation station [107]. Goumas et al.'s prioritization extended a multi-criteria method of ranking alternative projects, PROMETHEE, to deal with fuzzy input data. The proposed method was applied for the evaluation and ranking of geothermal energy exploitation projects [129, 136]. Lee introduced wind farms and developed the criteria for successful implementation in China taking into account experts' opinions and stakeholders' input. He proposed a new multicriteria decision-making (MCDM) model based on AHP, associated with benefits, opportunities, costs and risks (BOCR) to select a suitable wind farm project [145]. 
Different multi-criteria methods have been applied to assess renewable energies from an environmental perspective $[129,136]$. MCDM has been increasingly adopted in the area of environmental planning due to the growing awareness of these issues. Zhou et al. provided a survey and literature review and an update of the survey on decision analysis (DA) in energy and environmental modeling by Huang [146]. The update showed that the usage of multiple criteria decision-making methods and energy-related environmental studies has almost tripled since 1995 [119, 147]. Greening and Bernow referred to the potential of MCDM in energy and environmental policy planning [148]. Lahdelma et al. discussed these methods for environmental planning and management [149]. Patlitzianas et al. presented an integrated multi-criteria decision-making approach for assessing the environment of renewable energy producers in the fourteen different member states of the European Union accession [150]. Mirasgedis and Diakoulaki compared the external costs of power plants that used different energy sources by a multicriteria analysis where environmental impacts were expressed in a qualitative scale. They identified similarities and disparities in the obtained rankings and clarified them on the basis of the fundamental principles of the two approaches, external cost estimates and multi-criteria analysis [151]. A summary literature review on the MCDM methods used for energy planning can found in Table 6 . 
Table 6 Literature review on MCDM methods and applications

\begin{tabular}{|c|c|c|}
\hline Category & Application Area & Literature \\
\hline $\begin{array}{c}\text { Renewable energy } \\
\text { planning and policy }\end{array}$ & $\begin{array}{c}\text { Assessment of a feasible energy plan and/or the } \\
\text { diffusion of different renewable energy options. }\end{array}$ & $\begin{array}{c}{[12,31,101-} \\
106] \\
{[132]}\end{array}$ \\
\hline $\begin{array}{c}\text { Renewable energy } \\
\text { resource evaluation }\end{array}$ & $\begin{array}{c}\text { Assessment of different alternative energies or } \\
\text { energy technologies according to specified criteria. }\end{array}$ & $\begin{array}{c}{[59,127,139,} \\
152-155]\end{array}$ \\
\hline Project selection & $\begin{array}{c}\text { Site selection, technology selection and decision } \\
\text { support in renewable energy harnessing projects. }\end{array}$ & {$[144,156-159]$} \\
\hline Environmental impact & $\begin{array}{c}\text { Assessment of alternative technologies and their } \\
\text { impact on the environment and climate change. }\end{array}$ & $\begin{array}{c}{[119,146,148-} \\
151,160]\end{array}$ \\
\hline
\end{tabular}

\subsection{Gap Analysis}

A numerous number of academic journals, conference articles, government reports, web articles and books related to energy policy assessment were reviewed as a part of the literature review for this research. Table 7 presents a summary of the findings on energy policy and renewable energy adoption from the literature review. The literature review covered the following areas:

- Variables and perspectives for renewable energy adoption and deployment in the power generation sector.

- National energy policy planning and the effect of different policies on the deployment of RE.

- Decision making methodologies in energy planning and assessment. 
Table 7: Research area and findings in the literature

\begin{tabular}{|c|c|c|}
\hline Research area & Findings & Literature \\
\hline $\begin{array}{l}\text { Variables and } \\
\text { perspectives for } \\
\text { renewable energy } \\
\text { adoption and } \\
\text { deployment in the } \\
\text { power generation } \\
\text { sector. }\end{array}$ & $\begin{array}{l}\text { Renewable energy adoption is effected by several } \\
\text { barriers and drivers that decision makers should } \\
\text { take into consideration for energy policy planning. } \\
\text { Policy effectiveness current assessment models use } \\
\text { mainly monetary values of cost or capacity } \\
\text { installed as an indicator of adoption }\end{array}$ & $\begin{array}{c}{[28,29,56,57,60,71} \\
\quad 73,75,77-83,161]\end{array}$ \\
\hline $\begin{array}{l}\text { National energy } \\
\text { policy planning and } \\
\text { effect of different } \\
\text { policies on the } \\
\text { deployment of RE. }\end{array}$ & $\begin{array}{l}\text { The significance of different policy instruments and } \\
\text { policy acts on successfully influencing and } \\
\text { facilitating the incorporation of renewable energy } \\
\text { sources into the power mix. Current policy } \\
\text { assessment models have been used mainly in policy } \\
\text { evaluation for the current situation but not as policy } \\
\text { instrument choice for different situations. }\end{array}$ & {$[12,31,52,101-106,132]$} \\
\hline $\begin{array}{l}\text { Decision making } \\
\text { methodologies in } \\
\text { energy planning and } \\
\text { assessment. }\end{array}$ & $\begin{array}{l}\text { Energy policy planning is a multi-criteria situation } \\
\text { with different variables, inputs and constraints. } \\
\text { Most literature consisted of case studies or a single } \\
\text { criteria methodology emphasis on the current } \\
\text { situation, lacking the sensitivity analysis for macro } \\
\text { and micro changes. }\end{array}$ & $\begin{array}{c}{[12,26,60,85,88-96} \\
101,102,105,116,162 \\
163]\end{array}$ \\
\hline
\end{tabular}

Table 7 summarizes key research areas and the findings and gaps in energy policy assessment area which were also confirmed by the research of several other scholars and earlier studies. Those gaps are:

- Current assessment models take into consideration monetary value, various studies and assessment models focused on drivers of adoption from a limited point of view.

- There isn't a comprehensive multi criteria decision making model that measures the effect of energy policy on the input of the renewable energy adoption process 
in a qualitative, quantitative and systematic way. No MCDM model that can be used for policy choice and explains ineffectiveness.

- Most literature consisted of case studies or single criterion methodology emphasis on current situation lacking the sensitivity analysis for macro and micro changes. The effects of changing priorities in future policy planning areas and the analysis of different scenarios have not been fully explored.

Several research questions have been developed with the purpose of addressing these gaps. This research will address the following research questions:

- What are the criteria for assessing the effectiveness of energy policy on increasing the adoption of renewable energies?

- What are the current policies employed to increase the adoption of renewables?

- Which policy instrument has the highest effect on accelerating the adoption?

- How does the change in energy planning priorities affect the decision in policy analysis?

See Table 8 below for description and connection of research gaps, goal and questions related to this study. 
Table 8: Connecting the gaps to research questions

\begin{tabular}{|c|c|c|}
\hline Research gaps & Research goal & Research questions \\
\hline $\begin{array}{l}\text { Current assessment models take } \\
\text { into consideration monetary } \\
\text { value, Various studies and } \\
\text { assessment models focused on } \\
\text { drivers of adoption from a } \\
\text { limited point of view. }\end{array}$ & \multirow{4}{*}{$\begin{array}{l}\text { Evaluate the effectiveness of } \\
\text { energy policy instruments on } \\
\text { increasing the adoption of } \\
\text { renewable energy adoption by } \\
\text { developing a comprehensive } \\
\text { decision model. }\end{array}$} & $\begin{array}{l}\text { What are the criteria for } \\
\text { assessing the effectiveness of } \\
\text { energy policy on increasing the } \\
\text { adoption of renewable energies? }\end{array}$ \\
\hline $\begin{array}{l}\text { The lack of a comprehensive } \\
\text { multi criteria decision making } \\
\text { model that measures the effect of } \\
\text { energy policy on the input of the } \\
\text { renewable energy adoption } \\
\text { process in a qualitative, } \\
\text { quantitative and systematic way. } \\
\text { No MCDM model that can be } \\
\text { used for policy choice and } \\
\text { explains ineffectiveness. }\end{array}$ & & $\begin{array}{l}\text { What are the current policies } \\
\text { employed to increase the } \\
\text { adoption of renewables? }\end{array}$ \\
\hline \multirow{2}{*}{$\begin{array}{l}\text { Most literature consisted of case } \\
\text { studies or single criterion } \\
\text { methodology emphasis on } \\
\text { current situation lacking the } \\
\text { sensitivity analysis for macro } \\
\text { and micro changes. }\end{array}$} & & $\begin{array}{l}\text { Which policy instrument has the } \\
\text { highest effect on accelerating } \\
\text { the adoption? }\end{array}$ \\
\hline & & $\begin{array}{l}\text { How does the change in energy } \\
\text { planning priorities affect the } \\
\text { decision in policy analysis? }\end{array}$ \\
\hline
\end{tabular}




\section{CHAPTER 3: RESEARCH METHODOLOGY}

\subsection{Introduction}

The Research Institute for Sustainable Energy (RISE) in the Department of Engineering and Technology Management at Portland State University initiated a project to develop a comprehensive framework that evaluates energy technologies, renewable and conventional, from five perspectives: technical, economic, environmental, social, and political, with all corresponding criteria (Figure 3 Kocaoglu \&Daim). This research draws on the RISE model in that it evaluates current policy instruments according to the same five perspectives which provide an extensive frame of reference when setting policy goals. Using the same methodology, a hierarchical decision making model (HDM) was developed in this research that could be used as a policy assessment tool for policy decision makers to analyze policy instruments and create the ideal energy policy portfolio, according to multiple situations and scenarios.

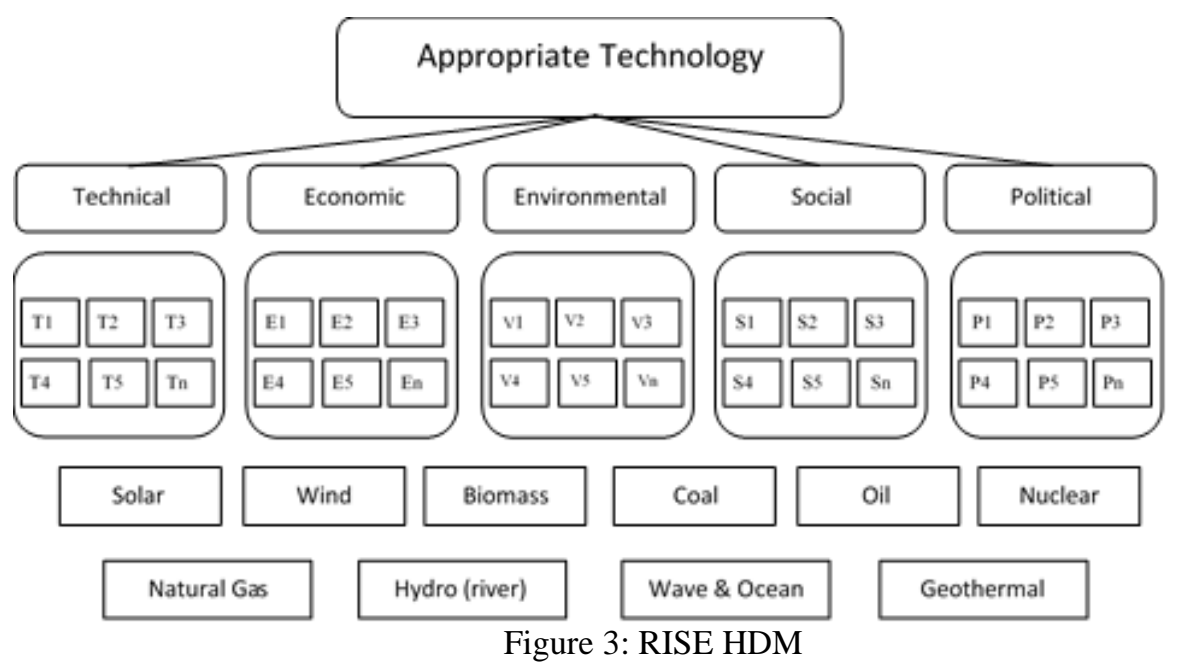




\subsection{Research Approach}

The objective of this research is to evaluate the effectiveness of energy policy instruments on increasing the adoption of renewable energy adoption by developing a comprehensive decision model and applying it to a specific case study. It is believed that taking a systematic approach to analyze policy goals from a multi-perspective point of view that complements the existing assessment models will provide a comprehensive analysis of policy instruments and a ultimately a more appropriate tool for decision making. The proposed methodology involves four phases:

- Phase 1: Literature review to identify gaps and research opportunities.

- Phase 2: Model development and identifying mission, perspectives, goals, and alternatives.

- Phase 3: Data collection by identifying the expert panels and collecting their judgmental quantification for the model via pair-wise comparison instruments as well as model and data validation.

- Phase 4: Policy evaluation and ranking, and sensitivity analysis.

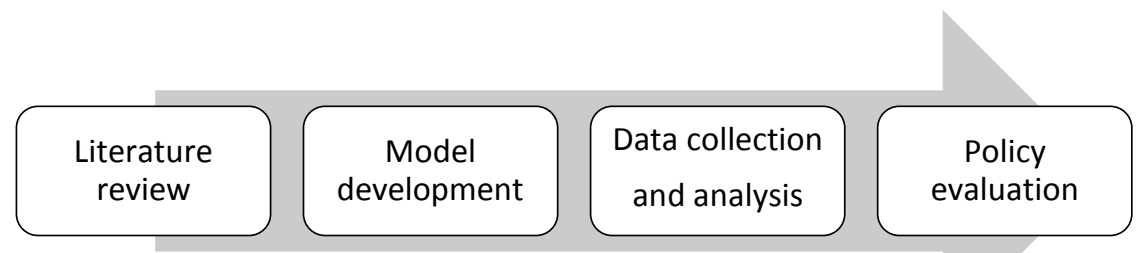

Figure 4: Research phases 
Figure 4 illustrates the research process flow chart; Phase 1 was discussed in Chapters 1 and 2 where gaps were identified and research questions formulated. Chapters 3, 4 and 5 describes phase 2 of the research which is the model development process and case study application. In chapter 6 phase three is conducted with the data collection process and judgment quantification analysis. Phase 4, policy evaluation and recommendations, are presented in chapter 7.

\subsection{Hierarchical Decision Model}

The human brain is designed to analyze complexities by compartmentalizing them and splitting the parts in turn into smaller parts to deal with individually, since it cannot deal with too many factors at the same time. This hierarchical vertical structure is our natural way of thinking. A cross-sectional way of analyzing relations is beneficial when you have a certain objective and want to understand the effect of other factors or the relationship between entities. HDM allows the decision maker to divide the problem into its smaller entities for analysis and therefore reveal any hidden relationship between elements. This methodology has been used for policy planning for a variety of objectives and was proven practical $[131,133,164-166]$.

The other advantage of the HDM is the ability to screen and select a large number of alternatives. Also, a large number of criteria and sub criteria can be used, which allows the analyst to cover the topic under investigation from many different angles. The results of the HDM are not just solid numbers or ranking, this model allows the analyst to dig 
deep into the results and identify other trends or priorities within the same criteria. This will be of great value for the proposed model since policy analysis is not a binary problem, but needs deep analysis of the integrated relationship among objectives, barriers, and benefits.

This approach will be useful to gain insight into current policies and criteria that are constantly changing with the fast pace of technology development, which is not always accounted for in the literature. This research has utilized the HDM methodology which allows for breaking down the problem into a hierarchical structure in order to analyze the relationship between a mission, objectives, and alternatives (see Figure 5). HDM is used to quantify expert qualitative judgments and convert them to numerical values using a pair-wise comparison method.

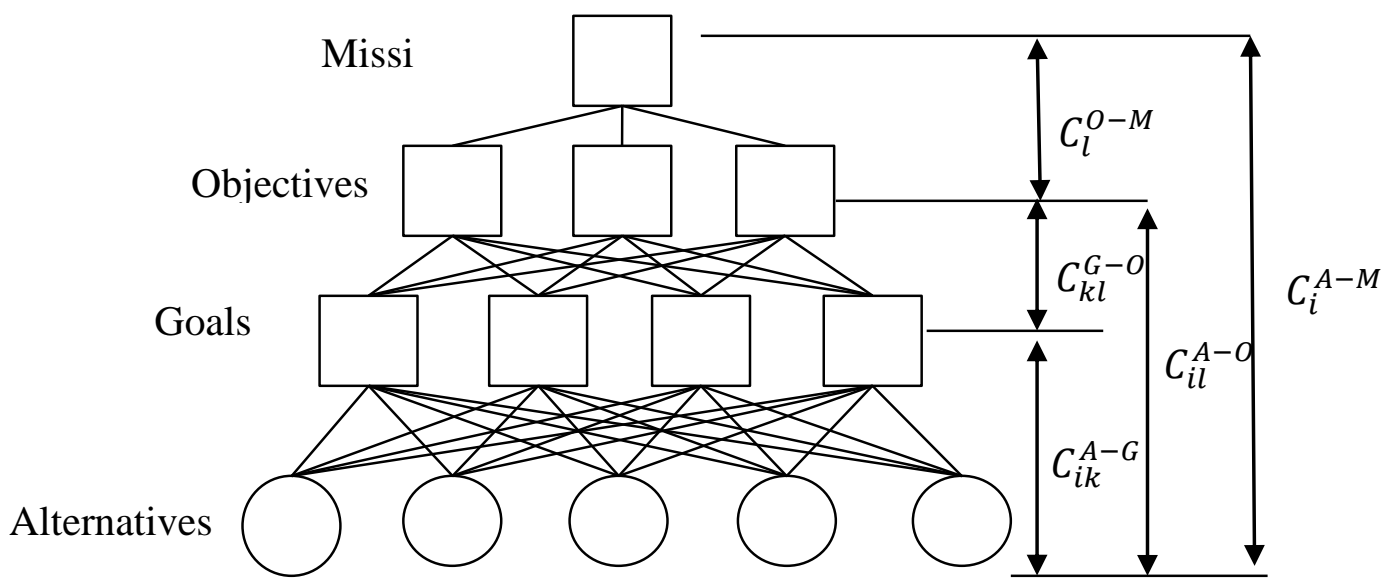

Figure 5: Generic form of HDM with four decision levels 
Table 9: Notations for HDM

\begin{tabular}{|c|c|c|}
\hline Where: & & \\
\hline $\begin{array}{c}O_{l}: \text { Objectives, } \mathrm{l}= \\
1,2, \ldots l\end{array}$ & $\begin{array}{c}C_{l}^{O-M}: \begin{array}{l}\text { relative contribution of the } \mathrm{L}^{\text {th }} \\
\text { objective to the mission }\end{array}\end{array}$ & \\
\hline$G_{k}:$ Goals, $\mathrm{k}=1,2, \ldots, \mathrm{k}$ & $\begin{aligned} C_{k l}^{G-O}: & \text { relative contribution of the } \mathrm{k}^{\text {th }} \\
& \text { goal to the } \mathrm{L}^{\text {th }} \text { objective }\end{aligned}$ & \\
\hline $\begin{array}{c}A_{i}: \text { Alternatives, } \\
\quad \mathrm{i}=1,2, \ldots \mathrm{i}\end{array}$ & $\begin{array}{c}C_{i}^{A-M}: \begin{array}{l}\text { Overall contribution of the } \mathrm{i}^{\text {th }} \\
\text { alternative to the mission }\end{array}\end{array}$ & $\begin{array}{l}C_{i k}^{A-G} \text { : relative contribution of the } \\
\mathrm{i}^{\text {th }} \text { alternatives to the } \mathrm{k}^{\text {th }} \text { goal }\end{array}$ \\
\hline & & $\begin{array}{l}C_{i l}^{A-O}: \text { relative contribution of the } \\
i^{\text {th }} \text { alternative to the } \mathrm{k}^{\text {th }} \text { objective }\end{array}$ \\
\hline
\end{tabular}

By using Constant-Sum Method, a total of one hundred points was assigned by experts, divided between any two elements at the same level. For the level of mission (M), quantifying expert judgment relative to the contribution of the objective level to the mission is given as $C_{l}^{O-M}$ (see Table 9 for all model notations). The overall relative contribution of the energy policy alternative (A) to the mission (M) is calculated by adding the sum products of all local contribution matrices between $\mathrm{M}$ and $\mathrm{A}$ and is given by [167]:

$$
C_{i}^{A-M}=\sum_{l=1}^{L} \sum_{k=1}^{K} C_{l}^{O-M} \cdot C_{k l}^{G-O} \cdot C_{i k}^{A-G} \quad \text { Equation } 1
$$

For each level, the judgments were collected and converted to weights. The alternative with the maximum weight sum would be the best "fit" to the mission. There is not one perfect solution and the model is expected to expand more in the future to include more policies and criteria.

Several gaps were identified from the literature review; one is the absence of a comprehensive model that evaluates energy policy from different perspectives. This 
research has filled this gap by developing a multi-criteria assessment which considers

five perspectives for policy goals: economic, social, political, environmental, and

technical. These perspectives are described in Table 10. The objective of the proposed

research is to evaluate and analyze the effectiveness of current energy policy instruments

on the adoption of renewable energy sources by developing a hierarchical decision

model based on the previously mentioned perspectives.

Table 10: Perspectives for Assessment

\begin{tabular}{|c|c|c|}
\hline Perspective & Objective & Description \\
\hline Economic & $\begin{array}{l}\text { Improve economic } \\
\text { feasibility of renewable } \\
\text { energy sources projects }\end{array}$ & $\begin{array}{l}\text { The financial aspect of renewable energy is a major obstacle } \\
\text { for adoption since RE is capital exhausting and currently not } \\
\text { competitive with other conventional sources. Although there } \\
\text { are great efforts to adopt more renewable energies in the } \\
\text { energy portfolio, these technologies are still not } \\
\text { economically comparative to conventional fossil fuels. } \\
\text { Increasing the economic feasibility of renewable energy is a } \\
\text { challenge that policy design considers. This variable } \\
\text { measures the importance of economic factors for the } \\
\text { adoption of renewable energy. }\end{array}$ \\
\hline Social & $\begin{array}{l}\text { Encourage community } \\
\text { support for renewable } \\
\text { energy sources projects }\end{array}$ & $\begin{array}{l}\text { It is apparent that the adoption of new renewable sources will } \\
\text { lead to a more sustainable and energy-secured future. } \\
\text { Customer interaction and satisfaction can enhance the image } \\
\text { of the product and increase its adoption. This variable } \\
\text { measures the importance of community support in } \\
\text { facilitating the adoption of renewables. }\end{array}$ \\
\hline Political & $\begin{array}{c}\text { Energy policy regulatory } \\
\text { implementation } \\
\text { considerations }\end{array}$ & $\begin{array}{l}\text { It is not "political" in the usual meaning of the word; rather it } \\
\text { means other political aspects and regulatory issues regarding } \\
\text { energy policy planning. The objective is to form a policy that } \\
\text { doesn't conflict with other policies, is easy to employ, and } \\
\text { insures fair rate distribution. This variable measures the } \\
\text { importance of considering general performance of energy } \\
\text { policy to increase renewable energy adoption. }\end{array}$ \\
\hline Environmental & $\begin{array}{l}\text { Promote environmental } \\
\text { protection }\end{array}$ & $\begin{array}{l}\text { Environmental considerations are always important for RE } \\
\text { policy planning. The widespread use of renewable energy } \\
\text { technologies for generating electricity can be seen as one } \\
\text { way of meeting environmental and climate change } \\
\text { challenges along with a progression to a low-carbon } \\
\text { economy. Promoting environmental protection can be seen } \\
\text { as one way of increasing renewable energy. This variable }\end{array}$ \\
\hline
\end{tabular}




\begin{tabular}{|c|c|l|}
\hline & & $\begin{array}{l}\text { measures the importance of mandating environmental } \\
\text { regulations in order for renewable energy to be adopted. }\end{array}$ \\
\hline Technical & $\begin{array}{l}\text { Understanding the energy system changes and the need for } \\
\text { technical development is important for improving current } \\
\text { policy and for future policy planning. Different goals are } \\
\text { stated under this major objective that clarifies the technical } \\
\text { issues needed to be enhanced for wind energy adoption to } \\
\text { occur efficiently. This variable measures the importance of } \\
\text { developing the technical system for renewable energy } \\
\text { adoption. }\end{array}$ \\
\hline
\end{tabular}

\subsection{Data collection and analysis}

This research employs HDM methodology, which is a subjective approach, to evaluate the effectiveness of energy policy. This approach is used to quantify the subjective judgments of experts by assigning criteria weights according to their perspective and experience. The benefit of using this approach is that experts can assign values to decision elements for which objective measures are not typically quantified. A downside of this approach is that the results depend on the experts' point of view. This can be mitigated by forming an unbiased expert panel with a high level of expertise and knowledge. The experts' judgments will be collected via a pairwise comparison tool.

\subsubsection{Forming an Expert Panel}

Decision analysis is a discipline that focuses on making better decisions by using models that are built on stated assumptions combined with people providing logical input for the models [168]. One of the main challenges in decision analysis is choosing the right experts and ensuring reliability in assessing probabilities from these experts, taking into account the thoughts and viewpoints that experts use in forming judgments. Expert 
panels have been used for providing opinions, feedback, judgments, and relationships between alternative choices in different areas of research like education $[169,170]$, energy and technology assessment [171, 172], software engineering [173], and technology assessment [174]. Medical research experts in the field are consulted to provide insight about the problem and give recommendations for decisions [175-179]. Consultation with experts before building a decision model can provide validation and background information as valuable as a literature review. Who exactly will comprise the expert panel and how many total participants there will be can vary according to the objective of the study and methodology followed in the analysis.

An expert is defined as a person who has the relevant knowledge and experience and whose opinions are esteemed by peers in his or her field [180, 181]. Using expert judgment in decision analytic models is one area where design issues could have an impact on the results of the study. Two key issues emphasized in the literature that should be considered when forming an expert panel are: having a panel balanced with experts having varied areas of knowledge or expertise, and forming a panel that is unbiased toward the issue being analyzed so as to not affect the decision. It is critical for the validity of the study to consider who the experts are and how many experts there will be. In designing an expert panel, the researcher should consider the limitations and benefits of the group selected, who the panel members are, and how they are related to the subject. In general, experts should be selected according to the following criteria: 
- Experience and contribution to the field of study. The access level to the information needed and experience is also considered. The panel should contain various levels, since no single expert has all the information and knowledge needed.

- Absence of bias. The panel should be free of direct conflicts among panelists and experts should be chosen from multidiscipline to get an unbiased feedback. Experts should be able to provide balanced representation of ideas and an unbiased viewpoint with no personal interest in the subject.

- Willingness to participate. Participating as an expert is totally voluntary and experts should feel free to answer or withdraw any time. When experts are chosen, no dominant individual should force participation of an expert or express certain viewpoint. All judgments should be subjective and free of external influence.

Experts are expected to perform more than one task throughout the research; the role of experts is summarized below:

- Validate the model and help identify other assessment criteria.

- Recommend other experts.

- Provide quantified judgments and relative contributions for all levels of the model.

- Validate the results and outputs of the analysis. 
For forming expert panels for this research, the following steps were followed:

- Identify required expertise: according to the evaluation model, required expertise was in the field of policy planning, policy evaluation, renewable energy projects, power generation, environmentalists, socio-economic studies and academic scholars in the field.

- Populate potential experts' names and field of expertise: this step was done through an extensive research in literature review, social network analysis, government reports, websites of organizations in the field of energy policy and renewable energy projects.

- Send invitations and ask to nominate additional experts: After preparing an initial list of potential experts, emails were sent to invite them to be on the expert panel and nominate any other expert that is interested in participating (snowball method)

- Group experts into required panels: upon receiving responses from experts who approved to participate, they were grouped into panels according to their expertise and field of work.

\subsubsection{Data Collection}

As mentioned before, this research has utilized the judgment quantification method to harness the experts' judgments. An instrument was developed and sent to the experts so that they could give their judgments via the pairwise comparison method. 
Experts' invitations and data collection instruments can be seen in0. Each level of the hierarchy was assessed by different experts according to their field of expertise which will increase the validity of the model, and the clarity and reliability of the research results. Details of expert panels' formulation are explained in chapter 4.

\subsubsection{Disagreement among Experts}

Since there will be more the one expert, it is expected that they will have different opinions or judgments of the model and therefore, possible disagreement among themselves. The disagreement of experts can be understood as the deviation of their judgments from each other. Two typical measures can be used to test the experts' disagreement such as the interclass correlation coefficient and the F-test. Statistical Package for the Social Sciences (SPSS) statistics software accounts for both of these measures in the reliability analysis values and graph. The interclass correlation coefficient (ICC) is a statistical measure that determines the degree of how much the experts agree with each other on the relative contribution of $\mathrm{n}$ elements in the comparison. Typically the Pearson correlation measure is used to determine the correlation between groups, but since there is no known order for the experts in the HDM model and they all have equally important judgment, the interclass correlations factor is used. This coefficient describes the average correlation across all possible orderings of the judgments matrices. Shrout and Fleiss discussed some guidelines for choosing between six different interclass correlation factors in which $\mathrm{n}$ subjects are rated by $\mathrm{k}$ 
judges ( $\mathrm{k}>2)$, depending on the model used and its application [182]. The ICC is estimated by the following equation [182] :

$$
I C C=\frac{M S B S-M S R}{M S B S+(k-1) M S R+\frac{k(M S B J-M S R)}{n}} \quad \text { Equation } 2
$$

Where;

$$
\begin{gathered}
M S B J=\frac{S S B J}{d f_{B J}} \\
S S B J=\sum_{j=1}^{k}\left[\frac{\left(\sum X_{j}\right)^{2}}{n}\right]-\frac{\left(\sum X_{T}\right)^{2}}{n k} \\
d f_{B J}=k-1 \\
M S B S=\frac{S S B S}{d f_{B S}} \\
S S B S=\sum_{i=1}^{n}\left[\frac{\left(\sum S_{i}\right)^{2}}{k}\right]-\frac{\left(\sum X_{T}\right)^{2}}{n k} \\
d f_{B S}=n-1 \\
M S R=\frac{S S R}{d f_{\text {res }}}
\end{gathered}
$$




$$
\begin{gathered}
S S R=S S T-S S B J-S S B S \\
d f_{\text {res }}=(n-1)(k-1) \\
S S T=\sum X_{T}^{2}-\frac{\left(\sum X_{T}\right)^{2}}{n k}
\end{gathered}
$$

ICC: Interclass correlation coefficient

MSBJ: Mean square between judges

SSBJ: Sum of square between judges

$d f_{B J}$ : Degree of freedom between judges

MSBS: Mean square between judges

SSBS: Sum of square between judges

$\mathrm{df}_{\mathrm{BS}}$ : Degree of freedom between judges

MSR: Mean square residual

SSR: Sum of square residual

$\mathrm{df}_{\text {res: }}$ Degree of freedom residual

SST: Total of sum of square between judges 
$\mathrm{S}_{\mathrm{i}}$ : Relative values of expert $\mathrm{i}$

$\mathrm{X}_{\mathrm{j}}$ : Relative values for subject $\mathrm{j}$

$\mathrm{X}_{\mathrm{T}}$ : Grand total of relative values for subject $\mathrm{j}$

k: Number of judges

n: Number of subjects

The value of ICC can be $-1<\mathrm{ICC}<1$, and it can be read in the following way: ICC $=1$ is an absolute agreement between judges, ICC $=-1$ is an absolute disagreement but is treated in the same ways as $\mathrm{ICC}=0, \mathrm{ICC}=0$ is a substantial difference between judgments on value of subjects. Any value of ICC between 0 and 1 indicates a degree of agreement between judges and the higher the value, the greater the level of agreement. This gap from -1 to 1 makes ICC open for different interpretation of the results and not a very reliable coefficient for judgment.

An improved measure of the ICC is calculating it by the F-test. The F-test is a statistical test that is mostly used to decide if a statistical model is a best fit for a set of data using the least squares. The F-test tests a null hypothesis with a predetermined confidence level. We can determine that $\mathrm{H} 0$ : ICC $=0$, hence absolute disagreement between experts and no correlation. The significance level ( $p$-value) is the probability that the null hypothesis is true. The F value in an F-test can be calculated as the ratio of 
two sums of squares. With the HDM model we can use the estimator $F=\frac{M S B S}{M S R}[182]$. The desired confidence level $\alpha$ of $(0.01,0.05,0.025$ or more $)$ determines the critical value of the test from the tables which the calculated $\mathrm{F}$ value should exceed to reject the null hypothesis, and conclude that there is a correlation between tested groups. To test the disagreement among our experts in each level, the following null hypothesis is tested: H0: $\mathrm{ICC}=0$ disagreements between experts and no correlation, $\mathrm{H} 1: \mathrm{ICC}>0$ some level of agreement. F-test was noticed to be not very reliable since it doesn't explain identical or close judgments with no variance and the distribution is assumed to be normal for all data while it might not be.

Since both F-test and ICC disagreement measures show weakness in some area, PCM group disagreement index is used in this research to examine any experts' disagreements, and the Agglomerative Hierarchical Clustering analysis (AHC) is used to identify experts that are in conflict with the rest of the group and identify clusters and new regrouping of experts. The threshold value of 0.10 for the disagreement index is used to decide on any disagreement. If a group disagreement index exceeds the value of 0.10 , then it is concluded that there is disagreement among experts.

The formula below is used to calculate the disagreement index for $\mathrm{j}$ experts for $\mathrm{n}$ decision variables in each panel: 


$$
d=\sqrt{\frac{1}{m} \sum_{j=1}^{m} \frac{1}{n} \sum_{i=1}^{n}\left(R_{i}-r_{i j}\right)^{2}}
$$

Where:

$\mathrm{R}_{\mathrm{i}}$ Group relative value of the $\mathrm{i}^{\text {th }}$ element

m: The number of experts

$\mathrm{n}$ : The number of decision variables

$r_{i j}$ : Mean relative value of the $\mathrm{i}^{\text {th }}$ element for $\mathrm{j}^{\text {th }}$ expert

Due to the different expertise and fields of knowledge among different experts, it is expected to find disagreement between their judgments. This issue can be treated in this research by categorizing the experts into homogeneous groups according to common characteristics. This method of identifying the experts and arranging groups will provide insight in the analysis of the results.

\subsubsection{Inconsistency}

Inconsistency is a measure that explains how reliable and homogeneous in his or her answers each expert was through the whole questionnaire. Because this is a human judgment and there is no way that judgments can be perfect and consistent at all time, 
some inconsistency can be measured and tolerated, but it must not be so big that it leads to chaotic answers. An acceptable level of inconsistency is known to be $\leq 0.1$ when calculated for each respondent. In the case that any expert had an inconsistency indicator more than 0.1 , he or she can be asked to revise his or her answers and judgments until they reach the desired levels.

Calculating inconsistency can be explained as follows: for $\mathrm{n}$ decision variables there will be $n$ ! orientations with vectors $r_{1}, r_{2} \ldots, r_{n}$. For four decision variables $(n=4)$ there will be 24 orientations such as; ABCD ABDC ACBD ACDB,.., DBCA. If an expert was consistent with all his or her judgments, all the orientations would have the same relative values. But because of the variability of the human thought process, each orientation is expected to have slightly different relative values assigned to each decision variable. Inconsistency in the HDM methodology is calculated by the variance of the relative values of the elements in each orientation [183]. Inconsistency index can be determined according to the following formulas:

$$
\overline{r_{i}}=\left(\frac{1}{n !}\right) \sum_{j=1}^{n !} r_{i j}
$$

Where:

$r_{i j}$ is the relative value of the $\mathrm{i}^{\text {th }}$ element in the $\mathrm{j}^{\text {th }}$ orientation of an expert

$\overline{r_{i}}$ is mean relative value of the $\mathrm{i}^{\text {th }}$ element for the same expert 
Inconsistency of the $\mathrm{i}^{\text {th }}$ element is $\quad \frac{1}{n !} \sum_{j=1}^{n !}\left(\bar{r}_{i}-r_{i j}\right)^{2}$

for $i=1,2, \ldots, \mathrm{n}$ where $\mathrm{n}$ is the number of elements compared.

The variance of the expert in providing relative values for $n$ elements is the inconsistency index:

$$
\text { Inconsistency }=\frac{1}{n} \sum_{i=1}^{n} \sqrt{\frac{1}{n !} \sum_{j=1}^{n !}\left(\bar{r}_{\mathbf{i}}-\mathbf{r}_{\mathbf{i j}}\right)^{2}} \quad \text { Equation } 3
$$

\subsubsection{Sensitivity Analysis}

When the inconsistency and disagreement check has been passed, the next step is to combine the local contributions of all elements using an additive relationship to come up with the global and then the overall contribution values for the alternatives, where the latter can be ranked according to degree of contribution to the mission. Sensitivity analysis (SA) is then conducted to determine the allowable change or perturbations, on different levels of a decision hierarchy or on introducing a new alternative. This analysis can be utilized to study the effect of changes in priorities of the objectives or goals on the ultimate decision, which can provide several possible scenarios for the problem under consideration. The sensitivity analysis algorithm discussed here was developed by Chen and Kocaoglu to study any changes in the HDM under different situations [167]. Several sensitivity analyses can be conducted depending on the focus of the research. For instance, SA can be used to determine how much the decision variables can change 
before adjusting the ranking order of the alternatives. The following formula can be used to calculate the overall contributions of each alternative (Ai) to the mission (M) in a four level HDM:

$$
C_{i}^{A-M}=\sum_{l=1}^{L} \sum_{k=1}^{K} C_{l}^{O-M} \cdot C_{k l}^{G-O} \cdot C_{i k}^{A-G}
$$

Where:

$C_{l}^{O-M} \quad:$ Local contribution of the $\mathrm{L}^{\text {th }}$ objective to the mission

$C_{k l}^{G-O}:$ Local contribution of the $\mathrm{k}^{\text {th }}$ goal to the $\mathrm{L}^{\text {th }}$ objective

$C_{i}^{A-M} \quad:$ Overall contribution of $\mathrm{i}^{\text {th }}$ alternative to the mission

$C_{i k}^{A-G}:$ Local contribution of $\mathrm{i}^{\text {th }}$ alternative to the $\mathrm{K}^{\text {th }}$ goal

$C_{i l}^{A-O}:$ Global contribution of $\mathrm{i}^{\text {th }}$ alternative to the $\mathrm{L}^{\text {th }}$ objective

As mentioned above, the SA in the HDM calculates parameters that would explain the effect of any changes to any level of the hierarchy of the alternatives. Among these parameters is the tolerance. Tolerance is defined as "the allowable range in which a contribution value can vary without changing the rank order of decision alternatives" [167]. In the analysis of perturbations introduced at the objective level, let $P_{l *}^{o}$ represent 
the perturbations imposed on one of the objectives $\left(C_{l}^{O}\right)$ where $\left(-C_{l^{*}}^{O} \leq P_{l^{*}}^{O} \leq 1-C_{l^{*}}^{O}\right)$, the original ranking of $\mathrm{A}_{\mathrm{r}}$ and $\mathrm{A}_{\mathrm{r}+\mathrm{n}}$ will not change if

$$
\begin{gathered}
\lambda \geq P_{l}^{o} * \lambda^{o}, \quad \text { where } \lambda=C_{r}^{A}-C_{r+n}^{A} \\
-C_{l *}^{o} \leq P_{l *}^{o} \leq 1-C_{l *}^{o} \text { (Feasibility condition) } \\
\lambda^{o}=C_{r+n, l *}^{A-O}-C_{r l *}^{A-O}-\sum_{l=1, l \neq l *}^{L} C_{r+n, l}^{A-O} \times \frac{C_{l}^{o}}{\sum_{l=1, l \neq l *}^{L} C_{l}^{o}}+\sum_{l=1, l \neq l *}^{L} \frac{C_{r l}^{A-O}}{\sum_{l=1, l \neq l *}^{L} C_{l}^{o}}
\end{gathered}
$$

The ranking of all alternatives will stay the same if the above equations are satisfied for all $n=1$, and $r=1,2 \ldots$ I- 1 . If only the first alternative is important to remain unchanged, the condition will be that $r=1$ and $n=1,2, \ldots, \mathrm{I}-1$.

The sensitivity coefficient refers to the strength of the current decision and how flexible the objectives values can be without changing the ranking. From Chen and Kocaoglu [167]: Allowable range of perturbations on $C_{l}^{o}$ to keep the current ranking is $\left[\delta_{l-}^{o}, \delta_{l+}^{o}\right]$, Sensitivity coefficient is calculated by $1 /\left|\delta_{l+}^{o}-\delta_{l-}^{o}\right|$

\subsection{Validity of the Research}

This research has implemented three validation measures during the different phases of the study: construct validity, content validity, and criteria-related validity (Table 11) [184]. 
Construct validity indicates the degree to which the proposed model is correct and has the capacity to achieve the target of the research in serving as an assessment tool. Construct validity was first initiated during the first phase of the research when a literature review was conducted to specify the variables in the model. The second step was to validate the model and get feedback from faculty members and ETM PhD students with experience in the energy policy field as well as HDM modeling. The aim of construct validity is to ensure that decision variables are independent of each other and that there is a hierarchical relationship among the different levels.

Content validity was conducted during various stages to verify that the variables of the model can measure what they are intended to measure and that the data collection instruments are appropriate and ready for data collection. Experts were asked to verify that the variables in the model are appropriate for measuring policy effect on RE adoption. Content validations had eliminated variables that were not of importance and added new variables in the preliminary proposed model. A preliminary model was tested by a small group of experts, comprised of ETM PhD students and experts in the field, to test the clarity of the model and data collection instruments. Further validation was conducted with an expert panel throughout the model development phase.

Criterion-related validity reflects the degree to which the proposed model is effective in performing in real-life circumstances; meaning that the results and recommendations achieved from the model are applicable, accurate, and valid. This was 
done by presenting the results to experts who didn't provide judgments of the model during the data collection phase. The experts had provided feedback regarding the acceptability of the results and generalizability of the model.

Table 11: Validation of Research

\begin{tabular}{|c|c|c|}
\hline Research validation & Definition & Phase \\
\hline Content validity & $\begin{array}{c}\text { Verify that the variables of the } \\
\text { model can measure what they are } \\
\text { intended to measure and that the } \\
\text { data collection instruments are } \\
\text { appropriate and ready for data } \\
\text { collection. }\end{array}$ & $\begin{array}{c}\text { Phase 1,2 \&3: Literature review } \\
\text { model development and expert } \\
\text { evaluation }\end{array}$ \\
\hline Construct validity & $\begin{array}{c}\text { Measures the degree to which the } \\
\text { proposed model is correct and } \\
\text { has the capacity to achieve the } \\
\text { target of the research in serving } \\
\text { as an assessment tool. }\end{array}$ & $\begin{array}{c}\text { Phase 2, \& 3: Model } \\
\text { development and data collection } \\
\text { from expert evaluation. }\end{array}$ \\
\hline Criterion-related validity & $\begin{array}{c}\text { Reflects the degree to which the } \\
\text { proposed model is effective in } \\
\text { performing in real-life } \\
\text { circumstances, meaning that the } \\
\text { results and recommendations } \\
\text { achieved from the model are } \\
\text { applicable, accurate, and valid }\end{array}$ & Phase 4: Policy evaluation and \\
sensitivity analysis.
\end{tabular}




\section{CHAPTER 4: CASE STUDY BACKGROUND}

The Northwest region of the United States roughly comprises the area covered by the states of Alaska, Washington, Oregon, northern California, Idaho, Montana, and Wyoming. In the heart of the Northwest are two states, Oregon and Washington, which border the Pacific Ocean and are geographically and culturally similar, those two states are referred to as the Pacific Northwest. The state of Oregon has been strategically weighing energy demand, supply, and resources to give Oregonians a more sustainable and dependable energy future. Renewable energy is perceived by many Oregonians as a source of energy independence, rural community development, and cleaner air. After the oil crises in 1973, Governor Tom McCall launched an emergency energy conservation program and in 1975 the Oregon Department of Energy (ODOE) was established to support energy conservation and renewable energy policy planning. Many of these policies and plans are still active until today, although they have been slightly modified over the years.

The US Pacific Northwest is known for its abundant existing hydropower as a complementary for wind energy but it is limited by several environmental factors and the size of reservoirs. The crisis that hit the Pacific Northwest in the years 2000-2001 was the low rain levels which lead to lower hydropower yield and increased electricity demand with few power plants being built. Many organizations in the region now such as the Bonneville Power Administration, Energy Trust of Oregon and Renewable Northwest 
Project have been working toward a more sustainable future energy solutions such as energy efficiency and renewable energy power.

In 2013 the governors of California, Oregon, and British Columbia signed a (Pacific Coast Action Plan on Climate and Energy) that stated their plans to "lead on national and international policy on climate change" by accounting for the costs of carbon pollution, supporting renewable energy projects and transform the market for energy efficiency. In 2007 and 2009 the Oregon Legislature passed two bills that capped greenhouse gas emission and set the reduction target for the state to be 10 percent less than 1990 levels by the year 2020 and 15 percent below 2005 levels by 2020 consequently. Washington state renewable standards requires the energy mix to have $15 \%$ renewables by 2020 while Oregon requires large utilities to have $25 \%$ renewables in their energy mix by 2025 .

\subsection{Why the Shift to Renewables?}

A variety of factors have encouraged renewable energy development and deployment in the Pacific Northwest, including: market conditions, policy enhancement, skilled labor, and the cultural and environmental concerns of consumers. A famous publication about the Northwest energy paradigm is a book entitled Transition, A Book on Future Energy: Nuclear or Solar? [185] . In this book the author described the energy dilemma that the region was facing during the energy crisis, “... as energy prices rose, it became apparent that the energy systems so many had taken for granted were almost 
entirely outside of our control. In fact, about 95 percent of the energy we use in Oregon is imported." This clearly outlined the problem and the first warning that a considerable amount of the region's budget was going toward imported foreign or out-of-state energy.

Oregon's first commercial-scale wind power project was a 25-megawatt (MW) farm built in 1998. The project was planned after PGE agreed to develop and generate renewable energy to replace nuclear energy. There was a few years delay in further wind energy development until the year 2001 when wind energy development picked up to satisfy a regional supply shortage caused by the lack of rain and decreased supply from California [186]. At that time, the Bonneville Power Administration (BPA) selected seven projects out of 25 proposals to begin operating in Oregon and Washington [187].

If the population of the Pacific Northwest continues to increase as projected, the demand for energy also will continue to grow. That growing demand requires a continued search for new energy sources. In general, the people of the Pacific Northwest are environmentally-oriented and are concerned about their health and protecting natural habitats. Since renewable energy sources offer many health and environmental benefits, they have been very welcomed in the region. Utilities in Oregon and Washington offer green pricing options for consumers which has helped to encourage consumer demand for renewable power. Federal and state policies that are intended to stimulate investing in renewable energy sources have contributed enormously in the development and deployment of renewables from both a consumer and developer point of view [188, 189]. 


\subsection{Energy Sources and Potential}

Eight states: Washington, California, Oregon, New York, Idaho, Alabama, Montana, and Texas provided almost $70 \%$ of the U.S. renewable energy generated in 2006 [190]. The Pacific Northwest region is rich with many forms of renewable energy sources including various types of biofuel, geothermal, hydropower, wind, solar, and marine energy sources. All renewable energy sources can be used for power generation. In addition, solar, geothermal, and biomass can also be used to for heat generation. Alternative transportation fuels are extracted from biomass. Currently, Washington State leads the US in hydropower supply followed by Oregon State ( ); Figure 6 and [191]. Between the year 2000 and 2010, the share of non-hydro renewable energy in the power generation sector increased from $1.8 \%$ to $11.9 \%$ in Oregon and from $0.9 \%$ to $5.2 \%$ in Washington.

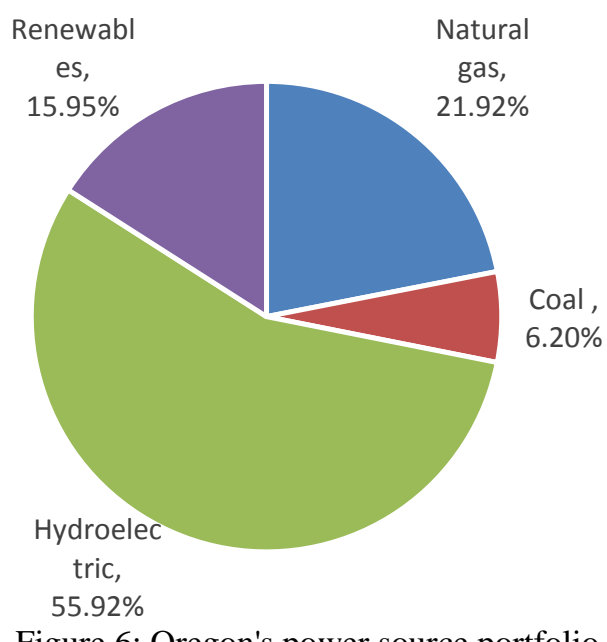

Figure 6: Oregon's power source portfolio

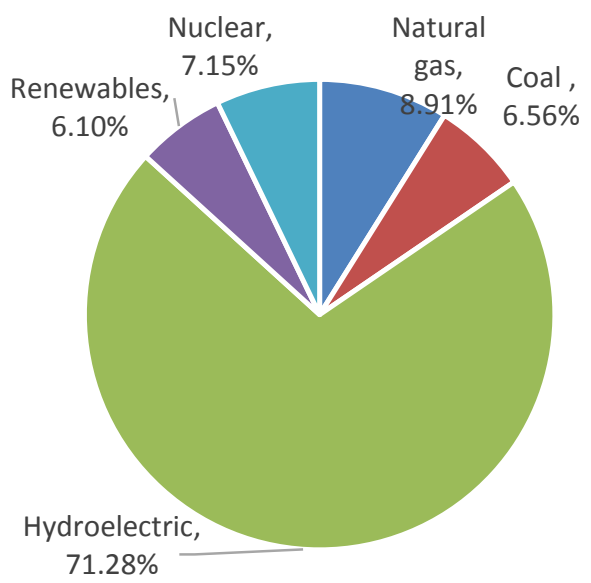

Figure 7: Washington's power source portfolio 


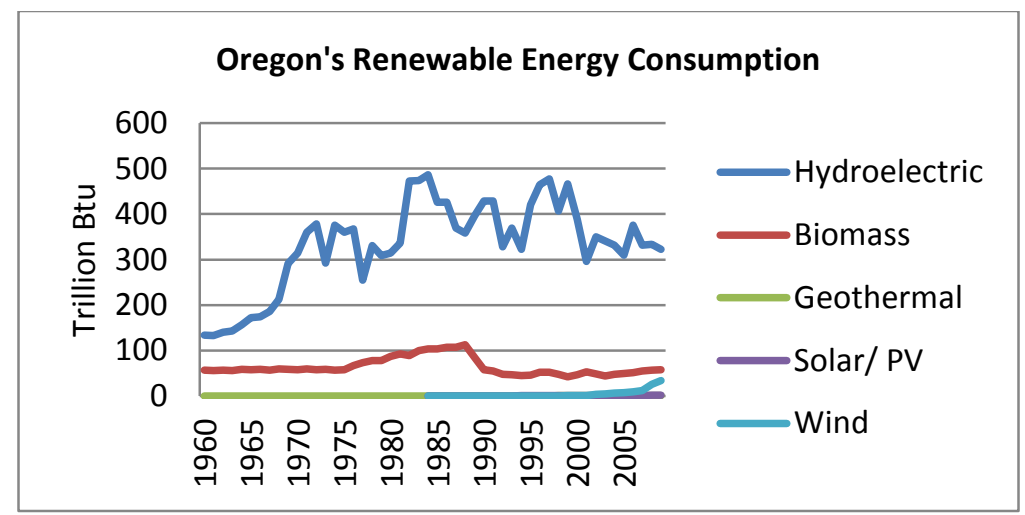

Figure 8: Oregon's Renewable Energy Consumption (trillion Btu) 1960-2008

Data source: U.S. Energy Information Administration [191]

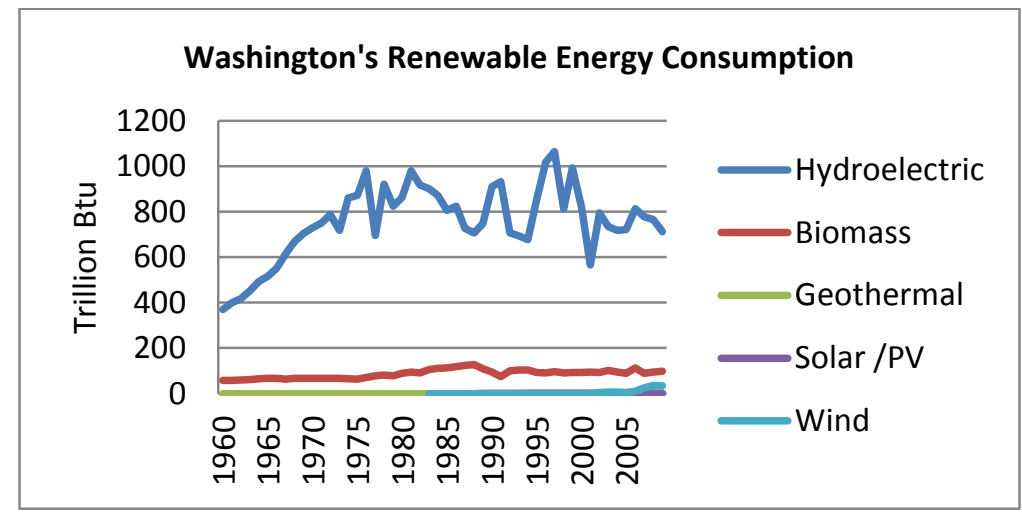

Figure 9: Washington's Renewable Energy Consumption (trillion Btu) 1960-2008

Data source: U.S. Energy Information Administration [191]

- Hydroelectric Power

Hydropower is the main source of power in Oregon's and Washington's electricity portfolio. The Bonneville Power Administration manages and markets power from 31 hydropower facilities in the Northwest, 14 of which are located in Oregon which 
benefits the consumer-owned utilities by supplying cheaper power rates from the BPA system. New growth in the hydropower sector is most likely to occur in three areas: widespread irrigation systems, improved pumped storage, and the addition of power facilities on existing dams, especially federal dams. In addition to providing a reliable, cheap source of energy in the Northwest, hydropower is useful in balancing the variation of wind energy production and the load-supply challenges.

\section{- Wind Power}

Wind power is the second most deployed renewable energy, after hydropower, in the Pacific Northwest. Percentage of Oregon's electricity provided by wind in 2013 was $12.4 \%$ of total electricity supply and percentage of Washington's electricity provided by wind in 2013 was $6.2 \%$. The two states ranked $9^{\text {th }}$ and $14^{\text {th }}$ in percent of wind generation nationwide (consequently). The first wind farm in Oregon was installed in 1998 and began operating at a capacity of $25 \mathrm{MW}$. Oregon currently ranks seventh in the nation for installed wind power, with 2,305 MW currently working and with wind projects with total capacity of 9,361 MW waiting for permits or transmission lines. Washington State is an early leader in the wind industry and currently ranks sixth in the nation with 2,357 MW currently installed and5,831 MW waiting in queue [192]. It is worthy of mention that Oregon is home to the European wind farm operator Iberdrola Renewables and is the North American headquarters of the wind turbine manufacturer Vestas, both of which are important players in wind energy development in the region [193]. California already 
purchases more than half the wind power generated in the Northwest. When the Shepherds Flat Wind Farm is completed in Oregon, all of its subsidized output is contracted to go to the Southern California Edison utility company.

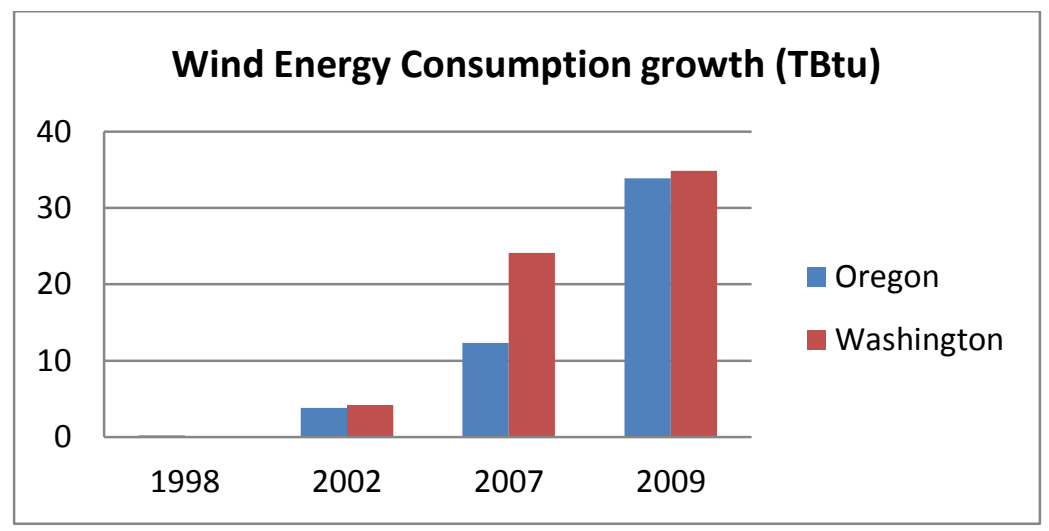

Figure 10: Wind Energy Development in the Pacific Northwest [186]

- Biomass

Biofuel is a term that includes liquid, solid, and gaseous fuels that are produced from biomass. These biofuels can be used for transportation, thermal energy, and power generation. Biomass in the state of Oregon includes agricultural residues, forest slash, and mill residuals. It is used to provide thermal heat for the forest industry as well as heat and electricity for homes, schools, and hospitals. The development of biomass has resulted from collaboration between the public and private sectors, such as the State of Oregon Forest Biomass Working Group and the Forest Cluster Economic Development Team. In Oregon, legislation passed in 2009 authorized a new low-carbon fuel standard designed to reduce the carbon intensity of 
transportation fuels by $10 \%$ by the year 2020 . Suppliers can meet this target by utilizing different alternative fuels such as ethanol and biodiesel.

- Solar Energy

Solar energy is a renewable energy source that is relatively mature and has been used for a long time in different applications. Parts of eastern and northern Oregon actually receive as much solar energy annually as Europe or Florida do. Solar energy can be utilized passively as direct light into buildings, providing light and heat, or by heating water through roof-mounted collectors, and actively by converting sunlight to electricity with photovoltaic (PV) panels or concentrated solar power (CSP). There are still no large-scale utility solar plants in Oregon like there are in California, but the residential PV market in Oregon has experienced a significant growth in the year 2010. This increase can be correlated to the state and federal financial incentives which helped reduce the cost of PV systems and increase maturity of the technology.

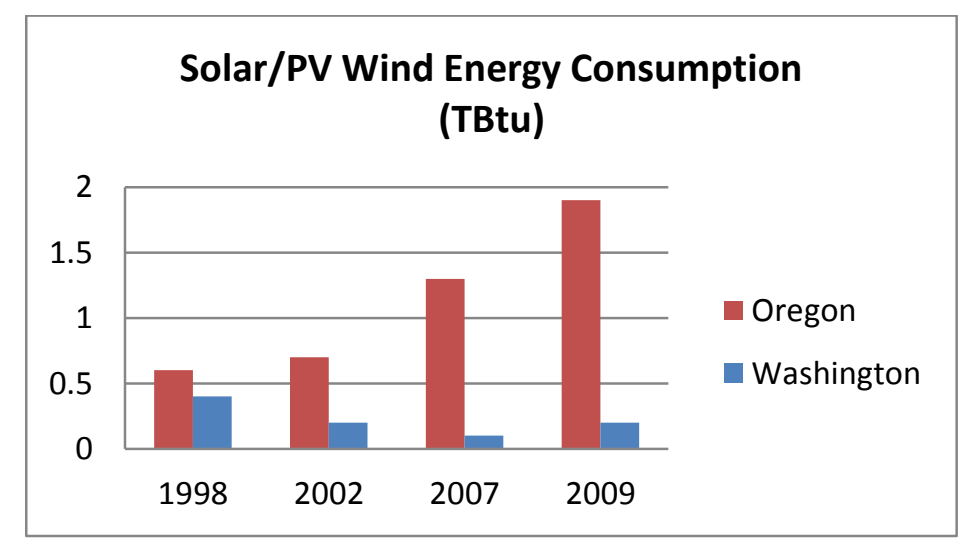

Figure 11: Solar/PV Energy Development in the Pacific Northwest [186] 
- Geothermal Power:

Geothermal energy is the energy extracted from the natural heat of the earth which provides constant base load energy. Geothermal energy in Oregon is not yet used for power generation; rather it is used for agricultural purposes as a heat source, for space heating, and to heat swimming pools at a number of spas and resorts.

- Wave Energy:

Ocean wave energy can be converted into clean, reliable and cost-effective electricity that has minimal impacts on the environment. In spite of its availability, until now there are only three wave energy working projects in the US, and they are all experimental sites with just a single device deployed: Makah Bay, Washington; Kaneohe Bay, Hawaii; and off the coast of New Jersey [194]. However, there are several different projects that are developing along the Pacific Northwest coast, of which seven are located along the Oregon coast. The state of Oregon has established itself as the leader in wave energy and has become the national center for wave energy research and commercial demonstration [195]. The combination of potential wave resource and coastline transmission capacity of the Oregon coast along with Oregon State University's research facilities has identified Oregon as an ideal location for wave energy conversion as well as a leader in the U.S. in wave energy development [196]. 
- Waste (Landfill Gas):

Landfill gas is actually a mix of gases including methane, $\mathrm{CO} 2$, and water vapor, which is generated by the decomposition of organic materials and waste at landfill disposal sites. The methane in landfill gas can be burned to generate electricity or thermal energy. The Waste Management Company currently collects waste from Seattle and ships it to a massive landfill in north-central Oregon. The methane gas produced as garbage decomposes is collected and burned to generate electricity for the city of Seattle [197]. In Oregon, an energy plant in the city of McMinnville has been using landfill gas to make electricity since June, 2012 [198].

\subsection{Renewable Energy Assessment}

Literature on renewable energy technologies in the Pacific Northwest discussed various subjects and examined different areas concerning this issue. Daim et al. developed a model to create a renewable energy portfolio and assess renewable energy technologies in Oregon that could be used to achieve the mandated levels set by the new Renewable Portfolio Standards [199]. The Pacific Northwest is one of the primary regions in the U.S. with significant wind power potential and wind power projects either installed or planned. Washington currently ranks sixth in the nation in the total capacity of wind power installation while Oregon ranks seventh and is home to the Bigelow project, the eighth largest wind farm in the country [76][76][75][72]. Yin analyzed policies and financial incentives in Oregon and their role in wind development [188]. 
Sailor et al. investigated several scenarios concerning the effect of climate change on wind power generation potential in the Northwest [200, 201]. Solar energy in the United States is still considered expensive and only accounts for a small amount of overall energy usage. Nevertheless, Oregon's solar capacity of grid-connected photovoltaic has grown exponentially from $2.8 \mathrm{MW}$ in 2007 to $14 \mathrm{MW}$ in 2009 , which demonstrates $400 \%$ growth in just two years [202]. It seems that in spite of the common perception that the Northwest climate is cloudy and lacks sunshine, there is still an abundant amount of harvestable sun energy in many regions [203, 204]. Additionally, other literature assessed the potential of ocean and wave energy sources along the coastal area of the Pacific Northwest $[195,205,206]$ although they are not deployed currently in the region and are not likely to be in the near future.

\subsection{Energy Policy Instruments in the Pacific NW}

There are a several federal and state policies that are intended to promote the deployment of RE technologies. Since RE sources vary by location and climate, it is typically more efficient to address the deployment issue at the state level. The Pacific Northwest has adopted a number of federal and state policies and incentives, whether they be financial, market-based, or obligatory, to support RE technologies. The two states of Washington and Oregon have adopted the Renewable Portfolio Standards as a guide for attaining targeted levels of renewable fuels. The RPS policy was a trigger for increased wind energy capacity installation as well as the start-up of pilot projects for 
geothermal and wave energy sources. It's clear that the policy system in the Pacific Northwest has successfully increased the adoption of RE, however, some challenges have emerged such as a large number of non-working wind farms in the region and a reserve balancing problem that is exhausting the power of the hydroelectric dams.

\subsubsection{Voluntary Green Power Option (Green Pricing)}

Green pricing is a state policy that requires all electric utilities to offer customers an optional green power program where by paying a premium on their electricity bills supports the incremental cost of the additional renewable energy. Oregon and Washington are the second and third top states selling this offer to customers[207]. A predetermined portion of the electricity sold by a utility as green power must be generated using qualifying renewables, and each utility should declare the sources of the electricity included in its green power program to its customers. By creating a market for renewable energy, this policy not only provides an additional revenue stream for renewable energy projects, but also increases consumer knowledge of the benefits of renewable energy.

Beginning in 2002, customers served by Oregon's investor-owned utilities were offered a range of service and had access to several renewable energy options: 1) New Wind Energy - Customers each month can choose to buy certain amount of new wind generation through PGE's Clean Wind program or Pacific Power's Blue Sky program- 2) Renewable Energy Blend - Customers can purchase $100 \%$ of their actual electricity usage 
from Green Mountain Energy Company generated from wind and geothermal sources, and-3) Renewable Energy and Habitat Restoration - Customers can purchase 100\% of their electricity from renewable sources and at the same time help restore native fish habitat. Washington State signed a bill in 2001 requiring the state's electric utilities to offer customers green power option beginning January 1, 2002. Utilities are now required to regularly notify customers about the option of purchasing renewable energy at fixed or variable rates. Qualified energy sources are: wind, solar, geothermal, landfill gas, wastewater treatment gas, wave or tidal action, biomass, and low-impact hydro [208].

\subsubsection{Net Metering}

Net Metering is a state policy that allows customers to use their own renewable power generation systems to compensate for their energy consumption. They are given retail credit for feeding the power they generate backward into the grid when it exceeds their demand. Net Metering is a low-cost and effective method to encourage private owner to invest in renewable energy technologies. Forty three states and Washington, D.C. now offer Net Metering options for their customers [209]. Both Oregon and Washington have initiated Net Metering requirement standards for the state's primary investor-owned utilities for projects of $100 \mathrm{~kW}$ or less [186], for their municipal utilities, and for residential systems. Qualifying systems are solar power, wind power, hydropower, fuel cells, and biomass. 


\subsubsection{Interconnection Standards}

Although renewable energy systems can be considered standalone systems without any connection to the electricity grid (off-grid), connecting to the grid offers the system owner great benefits. Any surplus electricity being produced can be directly fed back into the grid and can generate revenue for the owner. On the other hand, if the system is not producing enough power, the electricity from the grid can still be bought from public utilities. The process of interconnection is designed to ensure that power generation systems are safely interconnected according to certain standards and rules. Oregon has three separate Interconnection Standards: one for net-metered systems, one for small generator facilities (non-net metered systems), and one for large generator facilities (non-net metered systems).

\subsubsection{Feed-in Tariff (FIT)}

The traditional Feed-in Tariff policy is to pay a premium for electricity generated by utilities from renewable sources. This type of financial policy has proven to be the world's most effective renewable energy policy [186]. Oregon's model is slightly different in that utility companies actually also pay customers who have solar panels for the power they produce and use. Oregon passed FIT legislation in 2009 which will be used for compliance with the state's renewable portfolio standard (RPS) and which applies only to solar energy. The rate the FIT will be paid at is not yet identified and is still to be determined by utilities and approved by the PUC [210]. Washington State is one of three states with any form of active feed-in tariffs in the United States. Unlike 
Oregon, Washington policy requires a full system of feed-in tariffs for all renewable energy technologies. The bill is shaped in line of Germany's successful FIT policy and includes different tariffs not only for solar energy but also for wind [211]. FIT is different than net metering policy, as the incentive rate is provided for participants for the energy they generate and use themselves, rather than the energy they feed back to the grid. In Oregon, Portland General Electric and Pacific Power began in 2010 their Feed-in Tariff pilot programs only for solar photovoltaic panels [212]. Feed-in Tariffs has been proven to be an effective and important energy policy but it will not be considered in this research since the application scope is wind energy and the FIT is applied mainly for solar energy standalone systems in the Pacific NW.

\subsubsection{Renewable Portfolio Standard (RPS)}

The Oregon RPS states that by 2025, large electric utilities that serve more than $3 \%$ of Oregon's electric load will be required to generate $25 \%$ of Oregon's electric load from eligible renewable energy. For the three largest utilities: Portland General Electric, Pacific Power, and Eugene Water and Electric Board, the targets are 5\% RE in 2011, $15 \%$ in $2015,20 \%$ in 2020 and $25 \%$ in 2025 . Smaller utilities are subject to a different requirement with targets of $5 \%$ or $10 \%$ by 2025 , depending on the size of the utility, but they are required not to use coal in new power generation, or the targets for the large utilities will apply. Eligible renewable sources in the state of Oregon are hydropower, biomass, wind, solar PV, solar thermal, geothermal, wave, tidal and ocean [213]. Utilities can fulfill their commitment in any of the following ways: by building a new eligible 
facility, buying power from another eligible facility, or buying renewable energy credits. The three largest utilities in Oregon have confirmed that they have achieved the 5\% 2011 goal. Washington passed a renewable energy standard (RES) through ballot initiative in 2006. The RES requires utilities that serve more than 25,000 customers to obtain $15 \%$ of their electricity from renewables by 2020 and to invest in energy efficiency.

\subsubsection{Financial Incentives}

Since renewable energies have a relatively high initial cost, financial policies are needed to encourage investment and deployment of such systems. Financial incentives can be broken down into categories: state tax credits and incentives paid through public purpose charges such as several tax credits, rebates, and grant or loan programs. A federal renewable energy cash grant program was created by the American Recovery and Reinvestment Act of 2009 that may be taken instead of the Federal Business Energy Investment Tax Credit (ITC). Only tax-paying entities are eligible by this grant to receive this credit of up to $30 \%$ of expenditures, depending on the energy source, whereas federal, state, and local government bodies are not eligible. The Production Tax Credit (PTC) is a Federal incentive that provides a tax credit adjusted for electricity produced from renewable energy sources, including wind, biomass, and geothermal. The federal energy PTC will expire by the end of this year, which creates uncertainty in the market and is leading to job cuts in Portland, since it is affecting orders for renewable-energy producers such as Iberdrola and Vestas Wind Systems. "Without the certainty of that 
extension, project developers are not doing projects in the U.S., and manufacturers are

not getting orders," Portland Mayor Sam Adams said [214].

Table 12: Detailed Financial Incentives Policy in the PNW

\begin{tabular}{|c|c|c|}
\hline Policy & Summary & Eligible Technologies \\
\hline $\begin{array}{l}\text { Biomass } \\
\text { Producer or } \\
\text { Collector Tax } \\
\text { Credit }\end{array}$ & $\begin{array}{l}\text { Tax credit for agricultural producers or collectors of } \\
\text { biomass }\end{array}$ & Biomass, biodiesel \\
\hline $\begin{array}{c}\text { Business } \\
\text { Energy Tax } \\
\text { Credit (BETC) }\end{array}$ & $\begin{array}{l}\text { Tax Credit for investments in energy conservation, } \\
\text { recycling, and renewable energy sources. }\end{array}$ & $\begin{array}{l}\text { Energy efficiency } \\
\text { technologies }\end{array}$ \\
\hline $\begin{array}{l}\text { Renewable } \\
\text { Energy } \\
\text { Equipment } \\
\text { Manufacturers' } \\
\text { Tax Credit }\end{array}$ & $\begin{array}{c}\text { Reduced business tax rate for manufacturers and } \\
\text { wholesale marketers of renewable energy electric } \\
\text { systems. }\end{array}$ & $\begin{array}{l}\text { Solar, wind, biomass, } \\
\text { geothermal heat pumps, } \\
\text { hydroelectric, tidal energy, } \\
\text { wave energy }\end{array}$ \\
\hline Energy Trust & $\begin{array}{l}\text { This policy requires large utilities to collect a } 3 \% \\
\text { charge from their customers to support renewable } \\
\text { energy and energy efficiency projects through January } \\
1,2026 \text {. These funds are allocated } 56.7 \% \text { to support } \\
\text { energy efficiency programs and } 17.1 \% \text { as financial } \\
\text { incentives to renewables while the remaining funds } \\
\text { support low-income housing energy assistance and K- } \\
12 \text { school energy-conservation efforts. }\end{array}$ & $\begin{array}{l}\text { Solar water heat, solar space } \\
\text { heat, solar thermal electric, } \\
\text { photovoltaic, wind, biomass, } \\
\text { hydroelectric, geothermal } \\
\text { electric, fuel cells using } \\
\text { renewable fuels, geothermal } \\
\text { direct-use, energy efficiency } \\
\text { equipment and technologies. }\end{array}$ \\
\hline $\begin{array}{l}\text { Federal Clean } \\
\text { Renewable } \\
\text { Energy Bonds } \\
\text { (CREBs) and } \\
\text { Qualified } \\
\text { Energy } \\
\text { Conservation } \\
\text { Bonds } \\
\text { (QECBs) } \\
\end{array}$ & $\begin{array}{c}\text { Both bonds may be used by certain entities -- } \\
\text { primarily in the public sector -- to finance renewable } \\
\text { energy projects. }\end{array}$ & $\begin{array}{c}\text { Solar thermal electric, } \\
\text { Photovoltaic, landfill gas, } \\
\text { wind, biomass, hydroelectric, } \\
\text { geothermal electric, } \\
\text { municipal solid waste, } \\
\text { hydrokinetic power, } \\
\text { anaerobic digestion, tidal } \\
\text { energy, wave energy, ocean } \\
\text { thermal }\end{array}$ \\
\hline $\begin{array}{l}\text { Renewable } \\
\text { Energy } \\
\text { Production } \\
\text { Incentive } \\
\text { (REPI) }\end{array}$ & $\begin{array}{c}\text { Provides incentive payments for electricity generated } \\
\text { and sold by new qualifying renewable energy } \\
\text { facilities. }\end{array}$ & $\begin{array}{c}\text { Solar thermal electric, } \\
\text { photovoltaics, landfill gas, } \\
\text { wind, biomass, geothermal } \\
\text { electric, , wave energy, ocean } \\
\text { thermal }\end{array}$ \\
\hline $\begin{array}{l}\text { Residential } \\
\text { Renewable } \\
\text { Energy Tax } \\
\text { Credit and } \\
\text { rebates }\end{array}$ & $\begin{array}{l}\text { A taxpayer may claim a credit of } 30 \% \text { of qualified } \\
\text { expenditures for a system that serves a residence } \\
\text { located in the United States and is used as a residence } \\
\text { by the taxpayer. }\end{array}$ & $\begin{array}{c}\text { Solar water heat, } \\
\text { photovoltaics, wind, fuel } \\
\text { cells, geothermal heat pumps, } \\
\text { other solar electric } \\
\text { technologies, fuel cells using } \\
\text { renewable fuels }\end{array}$ \\
\hline
\end{tabular}


Oregon's energy policy requires large utilities to collect a 3\% public-purpose charge from their customers to support renewable energy and energy efficiency projects. The Energy Trust of Oregon has been authorized to manage these programs since 2002 . Of the funds collected by the electric utilities, $17.1 \%$ must be allocated to renewables. With the RPS 2025 targets, the legislation modified the public purpose charge for renewables to require that funding be used to support only smaller projects of $20 \mathrm{MW}$ or less and the sunset date on the original 10-year public purpose charge was extended through 2025. The Energy Trust's renewable energy programs include financial incentives for small-scale and utility-scale projects that generate energy from solar, wind, hydro, biomass and geothermal sources. Efficiency programs include incentives for improvements to residential, commercial and new buildings, retrofit, appliances and manufacturing processes. 


\section{CHAPTER 5: CASE STUDY MODEL DEVELOPMENT}

\subsection{Model development}

A comprehensive literature review in the area of renewable energy adoption, renewable energy policy assessment models and decision making in the energy field was conducted and presented in Chapter 2. Based on the literature review an initial assessment model was developed. The model was presented to experts who have a significant level of experience in the area of renewable energy policy in the Pacific Northwest, please refer to Appendix (A) for details. The objective of the research as well as the preliminary assessment model were introduced and explained to the experts in the course of the face-to-face meetings. Experts revised the model construction and assessment variables and their comments and suggestions were recorded and taken into consideration.

The next step was the validation of the model for content validity to obtain experts' judgments about the suitability of the model's variables and their ability to measure what they are intended to measure. A number of web-based content validity instruments were designed and then tested by a group of PhD students in the Department of Engineering and Technology Management (ETM) for clarity and appropriateness. Experts were sent invitations to participate and it was explained that their participation was voluntary and confidential. Please refer to 0 for the research instruments used and experts' correspondence. The objective of the research, the purpose of the web based 
instrument, and definitions of the assessment model variables were provided to the experts. A total of 36 experts, four international scholars and 32 experts from the energy sector in the nation and the Pacific Northwest, had participated in this validation step, please refer to Appendix (A) for details.

\subsection{Finalized Assessment Model}

Based on the content validity results discussed above, the research model was modified and a final generalized research model was developed (see Table 13 and Figure 12). The model was designed to harness the experts' judgment regarding how different policy instruments affect renewable energy adoption and how well each policy works to satisfy its intended goals. However, experts' quantification judgment were given according to the wind energy in the Pacific Northwest region case.

Table 13: Criteria and Policy targets in the HDM Model

\begin{tabular}{|c|c|c|c|}
\hline \multicolumn{2}{|c|}{ Perspective } & Policy targets & Literature \\
\hline \multirow{4}{*}{ Economic } & \multirow{4}{*}{$\begin{array}{l}\text { Economic feasibility } \\
\text { improvement }\end{array}$} & Reducing Investment Cost. & \multirow{4}{*}{$\begin{array}{c}{[25,31} \\
154]\end{array}$} \\
\hline & & Offering future cost reductions. & \\
\hline & & Encouraging private sector investments. & \\
\hline & & Reducing risk of price volatility. & \\
\hline \multirow[b]{2}{*}{ Social } & \multirow{2}{*}{$\begin{array}{l}\text { Community support } \\
\text { encouragement }\end{array}$} & Increase public acceptance. & \multirow{2}{*}{$\begin{array}{l}{[87,140,} \\
215-217]\end{array}$} \\
\hline & & $\begin{array}{c}\text { Increase public knowledge and } \\
\text { awareness. }\end{array}$ & \\
\hline \multirow{3}{*}{ Political } & \multirow{3}{*}{$\begin{array}{c}\text { Regulatory implementation } \\
\text { considerations }\end{array}$} & Compatibility with other policies. & \multirow{3}{*}{$\begin{array}{l}{[26,40,41} \\
\quad 44,218]\end{array}$} \\
\hline & & Policy ease of application. & \\
\hline & & Ratepayer Equity & \\
\hline Environmental & & Mandating emissions reduction. & \\
\hline
\end{tabular}




\begin{tabular}{|c|c|c|c|}
\hline & \multirow{3}{*}{$\begin{array}{l}\text { Environmental protection } \\
\text { promotion }\end{array}$} & Regulating land use. & \multirow{3}{*}{$\begin{array}{c}{[118,219,} \\
220]\end{array}$} \\
\hline & & Preserving natural habitats. & \\
\hline & & $\begin{array}{l}\text { Species and migration corridors } \\
\text { protection. }\end{array}$ & \\
\hline \multirow{4}{*}{ Technical } & \multirow{4}{*}{$\begin{array}{c}\text { Technical system } \\
\text { development }\end{array}$} & Facilitating grid access. & \multirow{4}{*}{$\begin{array}{c}{[59,73,} \\
221-223]\end{array}$} \\
\hline & & Enhancing transmission capabilities. & \\
\hline & & Improving integration capabilities. & \\
\hline & & $\begin{array}{l}\text { Leading to Technological } \\
\text { Development. }\end{array}$ & \\
\hline
\end{tabular}

Different perspectives were considered for the evaluation and selection of policy instruments and each perspective consisted of several policy targets. Each policy instrument can be measured in terms of how much it contributes to increasing these variables and thus becomes more effective in facilitating the adoption of renewable energies. The proposed model includes four levels as described below.

\subsubsection{Level 1: Mission}

This level of the hierarchy describes the mission for the research as being to, "Identify the energy policy instrument that was the most effective in increasing wind energy adoption in the power generation sector in the Pacific Northwest "

\subsubsection{Level 2: Assessment Perspectives}

Assessment perspectives describes the main variables that are important for renewable energy adoption in any region and a policy should achieve and maximize its contribution to these perspectives in order to be effective in increasing renewable energy adoption. The five perspectives detailed below, were identified from the literature as 
major factors in renewable energy adoption, and they are aligned with the Pacific Northwest policy planning priorities.

- Economic feasibility improvement (economic criteria): Although there are great efforts to adopt wind energy in the energy portfolio, wind energy technologies and power generated from these sources are still not economically comparative to conventional fossil fuels. Increasing the economic feasibility of wind energy is a challenge that policy design considers. This variable measures the importance of economic factors that a policy can influence and improve to be effective in increasing the adoption of wind energy.

- Community support encouragement (social criteria): Although there are ambitious government efforts to increase the share of renewable energy in the energy portfolio, it is acknowledged that social factors may be a limiting factor in achieving this target, especially in the case of wind energy. This variable measures the importance of community support encouragement factors that a policy can influence and improve to be effective in increasing the adoption of wind energy.

- Regulatory implementation consideration (political criteria): In any policy planning, a policy instrument should be applicable and could be implemented. The objective is to form a policy that doesn't conflict with other policies, is easy to employ, and insures a fair allocation of cost between stakeholders. This 
variable measures the importance of general regulatory considerations for a policy to be deemed effective in increasing the adoption of wind energy.

- Environmental protection promotion (environmental criteria): The wide use of wind energy technologies for generating electricity can be seen as one way of meeting environmental and climate change goals, but with certain challenges such as land use and natural habitat disturbance. This variable measures the importance of environmental regulations that a policy can influence and improve to be effective in increasing the adoption of wind energy

- Technical system development: Understanding the energy system changes and the need for technical development is important for improving current policy and future policy planning. Different goals are stated under this major objective that clarify the technical issues needed to be enhanced for wind energy adoption to occur efficiently. This variable measures the importance of a policy to aid development in the technical system to be considered effective in increasing the adoption of wind energy.

\subsubsection{Level 3: Policy Targets}

The policy targets level lists in more detail the different variables for each assessment perspective. These variables signify the policy targets that would lead to enhancing the adoption of renewable energy sources. Consequently, energy policy instruments will be assessed with respect to their likely contribution to satisfy each of these targets. 


\section{Variables under improving economic feasibility}

- Reducing investment cost: Although the cost of RE power generation is lower than that of conventional sources in the long run, the upfront cost of wind farm installation poses a burden on investors. There is a need for huge investment and investors for the development of wind facilities to be cost competitive. This variable measures the importance of reducing the investment cost for wind energy adoption.

- Offering future cost reductions: To be cost effective, wind energy requires large scale facilities for power generation and support to maintain low operating cost. This variable measures the importance of maintaining low future operating cost for wind energy adoption.

- Encouraging private sector investments: Diffusion of new wind projects can be accelerated by a policy of stimulating investments by means of public-private partnerships (PPPs) implemented at all governmental levels, or by encouraging private investors' facilities. This variable measures the importance of the role of private sector investors and local ownership for wind energy adoption.

- Reducing risk of price volatility: It is expected that most customers are interested in low power rates as well as utility companies are interested in low rate generation. Therefore, policy instruments with mechanisms that protect from price fluctuation are favorable. This variable measures the importance of reducing market price fluctuation for wind energy adoption. 


\section{Variables under community support encouragement}

- Increasing social acceptance: One factor that can potentially be a powerful barrier to the success of wind energy adoption is social acceptance. Social acceptance refers to the specific acceptance of siting decisions and renewable energy projects by local stakeholders, mainly residents and local authorities. This variable measures the importance of different social stakeholders' acceptance for wind energy adoption and wind facilities.

- Increasing public knowledge and awareness: Enhancing the perceptions that wind energy is a promising and a strategically important energy source significantly increases the possibility of support for its deployment and project development. This variable measures the importance of increasing public knowledge and awareness for increasing wind energy adoption.

\section{Variables under regulatory implementation considerations}

- Compatibility with other policies: compatibility is how well a policy is expected to work in the presence of other policies with no conflict in outputs. This variable measures the importance of a policy to work in the presence of other policies with no conflict in outputs.

- Policy ease of application: A policy should be easy to apply and work in the current policy system, this policy target explains if a certain policy is easy to 
implement. This variable measures the importance of each policy to be easy to apply and work in the current policy system.

- Ratepayer Equity: This means insuring an equally level playing field among generating sources and owners which includes an economic outcome but from a public regulatory consideration. This policy target regulates how the additional cost of wind projects is paid for. This variable measures the importance of a policy to regulating ratepayer equity.

\section{Variables under environmental protection promotion}

- Mandating emissions reduction: Reducing emissions and GHG is one of the main drivers for RE adoption. Setting this issue to work as legislation can push this adoption as utilities and power producers would be obligated to emit only a certain amount of emissions. This variable measures the importance of mandating environmental regulations for the adoption of wind energy.

- Regulating land use: The use of food resources such as the land, for energy production, is a rising issue for research and debate. This variable measures the importance of regulating land use and land allocation for wind energy adoption and wind facilities distribution.

- Preserving natural habitats: One of the major challenges for wind energy deployment is their effect of wind facilities on natural bird and animal habitats. 
This variable measures the importance of mandating the preservation of natural habitats for wind energy adoption.

- Protecting species and migration corridors: The movement and migration of species is not random and there is a need to develop more accurate spatial data of migration corridors in regions of high potential for wind development. This variable measures the importance of initiating migration corridors research projects for wind energy adoption.

\section{Variables under technical system development}

- Facilitating grid access: Since wind power generation plants need a large area of land to produce energy on a utility scale; most of these facilities are located in remote areas, which in turn call for new extension of available transmission lines or call for granting access to current transmission lines without causing congestion. This variable measures the importance of grid access and ease of interconnection for wind energy development.

- Enhancing transmission capabilities: The difference in nature between conventional power sources and wind energy effects the way the transmission grid is used and presents a few challenges since it was originally designed for conventional. The intermittent nature of wind energy requires the development of the grid in a way to balance between supply and demand by enhanced transmission capabilities. Transmission capabilities include resource assessment, 
research and development, private-public sector relationships, and infrastructural support. This variable measures the importance of enhancing transmission capabilities and scheduling for wind energy development.

- Improving Integration Capabilities: The characteristics of wind energy is different than conventional energy resources such as: site specificity, intermittency, resource intensity, and technology maturity. These characteristics require advanced integration capabilities such as optimum energy conversion and minimizing harmonic distortion. This variable measures the importance of improving these integration capabilities for the adoption of wind energy.

- Leading to technological development: In spite of the variety of available renewable energy sources, there are still technical obstacles to their adoption in the current power system. Technology advancements, like advancements in equipment manufacturing and the development of complementary storage technologies (i.e. a wind turbine construction industry development in the state/region), have helped in overcoming some of these issues. This variable measures the importance of technological development to and around wind energy for wind energy adoption.

\subsubsection{Level 4: Energy Policy Instruments}

As the adoption of renewable energy sources in the power generation sector gains more attention globally, the significance of designing a policy system that facilitates this adoption and overcomes many of the obstacles is crucial. Nationwide in the U.S., there 
have been many policy instruments deployed on the state or federal level. A survey of

policies designed to increase the adoption of renewable energies in the power generation

sector in the Pacific Northwest revealed six main policy instruments that are currently

active and being applied for wind energy development in the region. At the bottom level

of the hierarchy are the policy alternatives which will be assessed and ranked with respect

to policy targets, perspectives, and finally the mission. Please refer to Table 14 for a

description of alternatives. It should be noted that the alternatives assessed in this

research are the ones that were most mentioned in the literature and ones identified in the

interviews with experts.

Table 14: List of Alternatives in the HDM Model

\begin{tabular}{|c|c|}
\hline Policy & Description \\
\hline $\begin{array}{c}\text { Renewable } \\
\text { Portfolio } \\
\text { Standards }\end{array}$ & $\begin{array}{l}\text { Oregon RPS states that by } 2025 \text {, large electric utilities that serve more than } 3 \% \\
\text { of Oregon's electric load are required to generate } 25 \% \text { of Oregon's electric } \\
\text { load from eligible renewable energy. Smaller utilities are exempted from this } \\
\text { requirement, and instead must meet targets of } 5 \% \text { or } 10 \% \text { by } 2025 \text {, depending } \\
\text { on the size of the utility, but are still required not to use coal in new power } \\
\text { generation or the targets for the large utilities apply. }\end{array}$ \\
\hline $\begin{array}{l}\text { Voluntary Green } \\
\text { Power option }\end{array}$ & $\begin{array}{l}\text { Green power option is a state policy that requires all electric utilities to offer } \\
\text { customers an optional green-power program by paying a premium on their } \\
\text { electricity bills to support the incremental cost of the additional renewable } \\
\text { energy. }\end{array}$ \\
\hline Tax Credits & Federal or state funding for startup renewable energy, private-investor owned. \\
\hline $\begin{array}{l}\text { Public Purpose } \\
\text { Charge }\end{array}$ & $\begin{array}{l}\text { This policy requires large utilities to collect a } 3 \% \text { charge from their customers } \\
\text { to support renewable energy and energy efficiency projects through January } 1 \text {, } \\
2026 \text {. These funds are allocated } 56.7 \% \text { to support energy efficiency programs } \\
\text { and } 17.1 \% \text { as financial incentives to renewables while the remaining funds } \\
\text { support low-income housing energy assistance and K-12 school energy- } \\
\text { conservation efforts. }\end{array}$ \\
\hline Net Metering & $\begin{array}{l}\text { Net Metering is a state policy that allows customers to use their own renewable } \\
\text { power generation systems to compensate for their energy consumption. They } \\
\text { are given retail credit for feeding the power they generate backward into the } \\
\text { grid when it exceeds their demand. }\end{array}$ \\
\hline $\begin{array}{l}\text { Interconnection } \\
\text { Standards }\end{array}$ & $\begin{array}{l}\text { The process of interconnection is designed to ensure that power generation } \\
\text { systems are safely interconnected according to certain standards and rules. }\end{array}$ \\
\hline
\end{tabular}



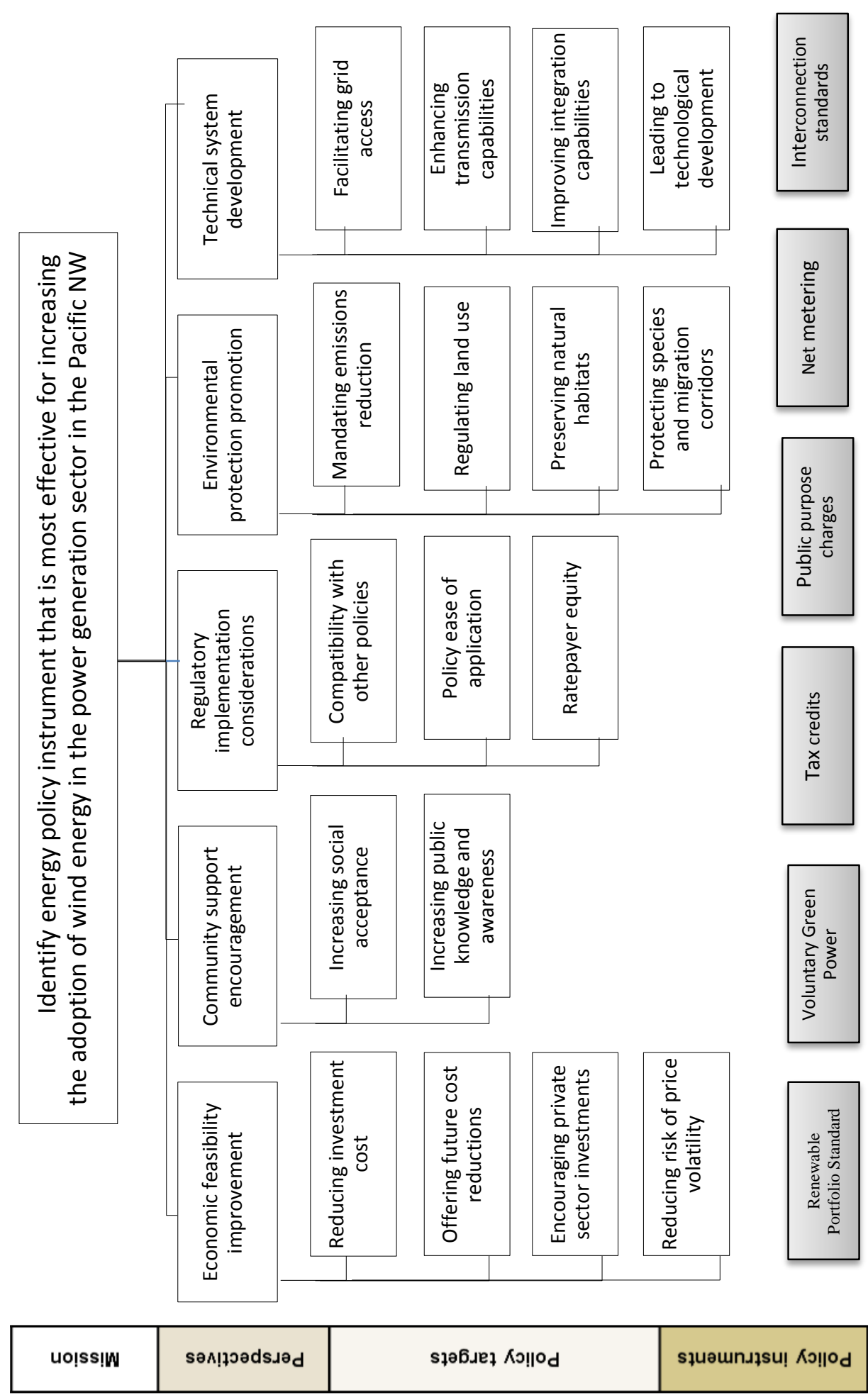

Figure 12: Finalized Hierarchical Decision Model 


\subsection{Data collection and expert panels design}

This research recruited 25 experts who were distributed between six expert panels to give judgment quantification for the model variables and determine the relative priorities of alternatives. Experts were distributed into these panels according to their field of expertise. It should be noted that some experts had been placed in more than one panel. Experts were chosen from various sectors (academia, government, nongovernmental organizations and utilities).

Data collection instruments were developed by using Excel spreadsheets. The method used for judgment quantification for all panels was the pairwise comparison method. These instruments were tested by a group of ETM PhD students to test their clarity and avoid any communication related problems with experts. Data collection instruments then were sent to experts according to panels' distribution via e-mail and responses were received via e-mails too. Please refer to Appendix A and Appendix B for detailed research instruments and judgment quantification results

A total of six expert panels contributed to the Judgment quantification of the assessment model. Please refer to Table 15 below for the role of each expert panel and number of experts in each panel. 
Table 15: Role of Each Expert Panel and Required Expertise.

\begin{tabular}{|c|c|c|c|}
\hline \multirow{2}{*}{ Panels } & \multicolumn{2}{|c|}{ Expert role } & \multirow{2}{*}{$\begin{array}{l}\text { Number of } \\
\text { experts }\end{array}$} \\
\hline & Step 1 & Step 2 & \\
\hline EP1 & \multicolumn{2}{|c|}{$\begin{array}{l}\text { Evaluate the relative importance of assessment perspectives with respect } \\
\text { to the mission }\end{array}$} & 16 \\
\hline EP2 & $\begin{array}{c}\text { Evaluate relative priorities of policy } \\
\text { targets with respect to the economic } \\
\text { perspective. }\end{array}$ & $\begin{array}{l}\text { Evaluate relative contribution of } \\
\text { policy instruments with respect to } \\
\text { the economic targets. }\end{array}$ & 9 \\
\hline EP3 & $\begin{array}{l}\text { Evaluate relative priorities of policy } \\
\text { targets with respect to the social } \\
\text { perspective. }\end{array}$ & $\begin{array}{l}\text { Evaluate relative contribution of } \\
\text { policy instruments with respect to } \\
\text { the social targets. }\end{array}$ & 11 \\
\hline EP4 & $\begin{array}{l}\text { Evaluate relative priorities of policy } \\
\text { targets with respect to the } \\
\text { regulatory perspective. }\end{array}$ & $\begin{array}{l}\text { Evaluate relative contribution of } \\
\text { policy instruments with respect to } \\
\text { the regulatory targets. }\end{array}$ & 11 \\
\hline EP5 & $\begin{array}{l}\text { Evaluate relative priorities of policy } \\
\text { targets with respect to the } \\
\text { environmental perspective. }\end{array}$ & $\begin{array}{l}\text { Evaluate relative contribution of } \\
\text { policy instruments with respect to } \\
\text { the environmental targets. }\end{array}$ & 6 \\
\hline EP6 & $\begin{array}{l}\text { Evaluate relative priorities of policy } \\
\text { targets with respect to the technical } \\
\text { perspective. }\end{array}$ & $\begin{array}{l}\text { Evaluate relative contribution of } \\
\text { policy instruments with respect to } \\
\text { the technical targets. }\end{array}$ & 8 \\
\hline
\end{tabular}

Experts participated in the judgment quantification process had various

backgrounds and positions and were affiliated with different sectors. Experts also had various fields of expertise in the areas of policy planning, policy assessment, energy economics, power planning and distribution, and renewable energy adoption. Please see Table 16 below for profiles of all the experts who provided judgment quantification.

Table 16: Quantification Judgment Experts' Profiles

\begin{tabular}{|c|c|c|c|}
\hline Experts & Affiliation & Positions & Sector \\
\hline Expert 1 & Oregon Public Utility Commission & Senior Utility Analyst & Government \\
\hline Expert 2 & Oregon Public Utility Commission & Senior Utility Analyst & Government \\
\hline Expert 3 & Oregon Department of Energy & Policy Analyst & Government \\
\hline Expert 4 & Oregon Department of Energy & Senior Analyst & Government \\
\hline
\end{tabular}




\begin{tabular}{|c|c|c|c|}
\hline Expert 5 & Oregon Department of Energy & Policy Analyst & Government \\
\hline Expert 6 & $\begin{array}{c}\text { Bonneville Environmental } \\
\text { Foundation }\end{array}$ & President & NGO \\
\hline Expert 7 & NW Power \& Conservation Council & Oregon representative & NGO \\
\hline Expert 8 & Energy Trust of Oregon & Senior Manager of Planning & NGO \\
\hline Expert 9 & Energy Trust of Oregon & $\begin{array}{c}\text { Director of Planning \& } \\
\text { Evaluation }\end{array}$ & NGO \\
\hline Expert 10 & Renewable Northwest Projects & Senior Analyst & NGO \\
\hline Expert 11 & Energy Trust of Oregon & Evaluation Manager & NGO \\
\hline Expert 12 & $\begin{array}{l}\text { NW Environmental Business } \\
\text { Council }\end{array}$ & Analyst & NGO \\
\hline Expert 13 & $\begin{array}{l}\text { Pacific Northwest National } \\
\text { Laboratory }\end{array}$ & Project Manager & Research lab \\
\hline Expert 14 & $\begin{array}{l}\text { Pacific Northwest National } \\
\text { Laboratory }\end{array}$ & Senior Analyst & Research lab \\
\hline Expert 15 & $\begin{array}{c}\text { Pacific Northwest National } \\
\text { Laboratory }\end{array}$ & $\begin{array}{c}\text { Energy and Environment } \\
\text { Directorate }\end{array}$ & Research lab \\
\hline Expert 16 & Bonneville Power Administration & Revenue Analyst & Utilities \\
\hline Expert 17 & Portland General Electric & Analyst & Utilities \\
\hline Expert 18 & Eugene Water \& Electric & Power Planning Manager & Utilities \\
\hline Expert 19 & Bonneville Power Administration & Senior Analyst & Utilities \\
\hline Expert 20 & Portland General Electric & Policy Analyst & Utilities \\
\hline Expert 21 & Portland General Electric & Senior Analyst & Utilities \\
\hline Expert 22 & Bonneville Power Administration & $\begin{array}{c}\text { NEPA and Policy Planning } \\
\text { Supervisor }\end{array}$ & Utilities \\
\hline Expert 23 & Bonneville Power Administration & Customer Service Engineering & Utilities \\
\hline Expert 24 & Bonneville Power Administration & Smart Grid Program Manager & Utilities \\
\hline Expert 25 & Bonneville Power Administration & $\begin{array}{c}\text { BPA Transmission Services, } \\
\text { STAR Program }\end{array}$ & Utilities \\
\hline
\end{tabular}

Experts were distributed through the panels according to their knowledge and expertise in the area being assessed. Some experts were assigned to more than one panel. Please refer to Table 17 for the distribution of experts throughout the panels. 
Table 17: Distribution of Experts over Judgment Quantification Panels

\begin{tabular}{|c|c|c|c|c|c|c|}
\hline Experts & Panel 1 & Panel 2 & Panel 3 & Panel 4 & Panel 5 & Panel 6 \\
\hline Expert 1 & $\mathrm{X}$ & $\mathrm{X}$ & & $\mathrm{X}$ & & \\
\hline Expert 2 & $\mathrm{X}$ & $\mathrm{X}$ & & $\mathrm{X}$ & & \\
\hline Expert 3 & $\mathrm{X}$ & $\mathrm{X}$ & & $\mathrm{X}$ & & \\
\hline Expert 4 & & $\mathrm{X}$ & & $\mathrm{X}$ & & \\
\hline Expert 5 & & $\mathrm{X}$ & & & & $\mathrm{X}$ \\
\hline Expert 6 & $\mathrm{X}$ & & $\mathrm{X}$ & & $\mathrm{X}$ & \\
\hline Expert 7 & $\mathrm{X}$ & & $\mathrm{X}$ & $\mathrm{X}$ & & \\
\hline Expert 8 & & & $\mathrm{X}$ & & & \\
\hline Expert 9 & $\mathrm{X}$ & & & $\mathrm{X}$ & & $\mathrm{X}$ \\
\hline Expert 10 & $\mathrm{X}$ & & $\mathrm{X}$ & & $\mathrm{X}$ & \\
\hline Expert 11 & $\mathrm{X}$ & & & $\mathrm{X}$ & & \\
\hline Expert 12 & & $\mathrm{X}$ & $\mathrm{X}$ & & & \\
\hline Expert 13 & & & $\mathrm{X}$ & $\mathrm{X}$ & $\mathrm{X}$ & \\
\hline Expert 14 & & $\mathrm{X}$ & & $\mathrm{X}$ & & \\
\hline Expert 15 & $\mathrm{X}$ & & $\mathrm{X}$ & & $\mathrm{X}$ & \\
\hline Expert 16 & $\mathrm{X}$ & & & $\mathrm{X}$ & & $\mathrm{X}$ \\
\hline Expert 17 & $\mathrm{X}$ & $\mathrm{X}$ & $\mathrm{X}$ & & & \\
\hline Expert 18 & $\mathrm{X}$ & & & & $\mathrm{X}$ & $\mathrm{X}$ \\
\hline Expert 19 & $\mathrm{X}$ & & & & & $\mathrm{X}$ \\
\hline Expert 20 & & & $\mathrm{X}$ & $\mathrm{X}$ & & \\
\hline Expert 21 & $\mathrm{X}$ & & $\mathrm{X}$ & & & \\
\hline Expert 22 & & & & & & \\
\hline Expert 23 & $\mathrm{X}$ & & & & & \\
\hline Expert 24 & $\mathrm{X}$ & $\mathrm{X}$ & & & \\
\hline Expert 25 & & & & & & \\
\hline Total & 16 & 9 & & & \\
\hline
\end{tabular}




\section{CHAPTER 6: RESULTS AND DATA ANALYSIS}

This chapter discusses the judgment quantification results, experts'

inconsistencies, and group disagreements for each of the expert panels. Synthesis of the priorities, sensitivity analyses and scenario analysis will also be discussed in detail. PCM software was used to analyze expert pairwise comparisons. As discussed in Chapter 3, any expert's inconsistency or group disagreement below the value of 0.1 was accepted. Groups with any disagreements were divided into subgroups.

\subsection{Expert Panel 1}

Sixteen experts in total have provided pairwise comparison judgments in Expert

Panel 1. The distribution of sectors is as follows: 3 from government, 2 from research labs, 6 from utilities and 5 from non-governmental organizations. Please refer to Table 18 for experts' profiles.

Table 18: Expert Panel 1 Experts' Profiles

\begin{tabular}{|c|c|c|}
\hline Expert & Affiliation & Sector \\
\hline Exp1 & Oregon Public Utility Commission & Government \\
\hline Exp2 & NW Power \& Conservation Council & NGO \\
\hline Exp3 & Oregon Department of Energy & Government \\
\hline Exp4 & Pacific Northwest National Laboratory & Research lab \\
\hline Exp5 & Energy Trust of Oregon & NGO \\
\hline Exp6 & Eugene Water \& Electric & Utilities \\
\hline Exp7 & Bonneville Power Administration \\
\hline Exp8 & Renewable Northwest Projects & NGO \\
\hline Exp9 & Bonneville Power Administration & Utilities \\
\hline Exp10 & Bonneville Environmental Foundation & NGO \\
\hline
\end{tabular}




\begin{tabular}{|c|c|c|}
\hline Exp11 & Portland General Electric & Utilities \\
\hline Exp12 & Portland General Electric & Utilities \\
\hline Exp13 & Oregon Public Utility Commission & Government \\
\hline Exp14 & Energy Trust of Oregon & NGO \\
\hline Exp15 & Pacific Northwest National Laboratory & Research lab \\
\hline Exp16 & Bonneville Power Administration & Utilities \\
\hline
\end{tabular}

\subsubsection{Expert Panel 1 Results}

Expert Panel 1 was asked to evaluate the relative importance of five perspectives for energy policy to be effective with respect to the mission statement. There were 16 experts in Expert Panel 1. The arithmetic means of the experts' judgments for the relative importance of considered perspective are shown in the Figure 13 below.

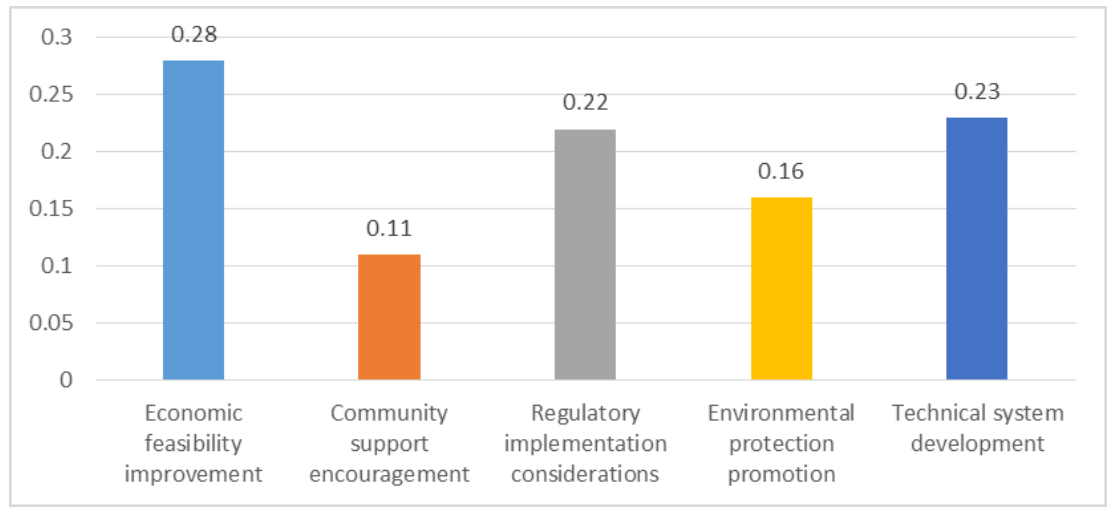

Figure 13: relative importance of energy policy design criteria

According to the results, Economic Feasibility Improvement (28\%) is the most important perspective with respect to the mission. Technical System Development (23\%) and Regulatory Implementation Consideration (22\%) have almost equal relative importance and rank second and third respectively. Environmental Protection Promotion 
(16\%) follows, while Community Support Encouragement is the least important policy

effectiveness perspective and ranks fifth.

\subsubsection{Analysis of Expert Panel 1 Results}

Individual results of the relative importance and the mean of 16 experts from

Expert Panel 1 are presented in Table 19. Looking at Expert Panel 1 results, all of the experts reflect an acceptable level of consistency in their judgments $(<0.1)$. There is also no significant level of disagreement among the experts (0.08).

Table 19: analysis of expert panel 1 results, assessment perspectives with respect to the mission

\begin{tabular}{|c|c|c|c|c|c|c|}
\hline Expert & $\begin{array}{c}\text { Economic } \\
\text { Feasibility } \\
\text { Improvement }\end{array}$ & $\begin{array}{c}\text { Community } \\
\text { Support } \\
\text { Encouragement }\end{array}$ & $\begin{array}{c}\text { Regulatory } \\
\text { Implementati } \\
\text { on } \\
\text { Consideratio } \\
\text { ns }\end{array}$ & $\begin{array}{c}\text { Environment } \\
\text { al Protection } \\
\text { Promotion }\end{array}$ & $\begin{array}{c}\text { Technical } \\
\text { System } \\
\text { Development }\end{array}$ & $\begin{array}{c}\text { Inconsi } \\
\text { stency }\end{array}$ \\
\hline Exp1 & 0.36 & 0.14 & 0.16 & 0.19 & 0.15 & 0.058 \\
\hline Exp2 & 0.3 & 0.24 & 0.14 & 0.23 & 0.09 & 0.015 \\
\hline Exp3 & 0.37 & 0.06 & 0.22 & 0.08 & 0.27 & 0.042 \\
\hline Exp4 & 0.33 & 0.14 & 0.16 & 0.11 & 0.26 & 0.006 \\
\hline Exp5 & 0.31 & 0.10 & 0.17 & 0.16 & 0.26 & 0.011 \\
\hline Exp6 & 0.32 & 0.13 & 0.07 & 0.14 & 0.35 & 0.040 \\
\hline Exp7 & 0.21 & 0.12 & 0.25 & 0.23 & 0.20 & 0.026 \\
\hline Exp8 & 0.16 & 0.06 & 0.15 & 0.33 & 0.30 & 0.021 \\
\hline Exp9 & 0.07 & 0.19 & 0.16 & 0.17 & 0.4 & 0.054 \\
\hline Exp10 & 0.22 & 0.10 & 0.17 & 0.20 & 0.31 & 0.025 \\
\hline Exp11 & 0.25 & 0.11 & 0.41 & 0.11 & 0.12 & 0.066 \\
\hline Exp12 & 0.33 & 0.08 & 0.33 & 0.08 & 0.17 & 0.000 \\
\hline Exp13 & 0.37 & 0.04 & 0.38 & 0.02 & 0.18 & 0.076 \\
\hline Exp14 & 0.31 & 0.10 & 0.24 & 0.10 & 0.24 & 0.011 \\
\hline Exp15 & 0.23 & 0.15 & 0.18 & 0.17 & 0.27 & 0.026 \\
\hline Exp16 & 0.27 & 0.07 & 0.30 & 0.24 & 0.12 & 0.028 \\
\hline Mean & 0.28 & 0.11 & 0.22 & 0.16 & 0.23 & \\
\hline $\begin{array}{l}\text { Disagr } \\
\text { eement }\end{array}$ & & & & & & 0.08 \\
\hline
\end{tabular}


All expert in expert panel 1 agreed that economic feasibility improvement is the most important perspective for policy effectiveness evaluation. So the best policy should have policy target that make renewable energy economics competitive with other sources of energy.

\subsection{Expert Panel 2}

Nine experts in total have provided pairwise comparison judgments in Expert Panel 2. The distribution of sectors is as follows: 5 from government, 1 from a research lab, 2 from utilities and 1 from non-governmental organizations. Please refer to Table 20 for experts' profiles. Experts in Expert Panel 2 gave judgments on two steps: $2 \mathrm{a}$ and $2 \mathrm{~b}$. The first task for expert panel 2 (2a) is to evaluate relative priorities for policy targets with respect to the economic feasibility improvement Perspective. The second task (5b) is to evaluate relative priorities for the decision alternatives with respect to the economic policy targets.

Table 20: expert panel 2 experts' profiles

\begin{tabular}{|c|c|c|}
\hline Expert & Affiliation & Sector \\
\hline Exp1 & Energy Trust of Oregon & NGO \\
\hline Exp2 & Oregon Public Utility Commission & Government \\
\hline Exp3 & Oregon Department of Energy & Government \\
\hline Exp4 & Oregon Department of Energy & Government \\
\hline Exp5 & Bonneville Power Administration & Utilities \\
\hline Exp6 & Oregon Department of Energy & Government \\
\hline Exp7 & Portland General Electric & Utilities \\
\hline Exp8 & Pacific Northwest National Laboratory & Research lab \\
\hline Exp9 & Oregon Public Utility Commission & Government \\
\hline
\end{tabular}




\subsubsection{Expert Panel 2a Results}

Expert Panel 2a was asked to evaluate the relative importance of four policy targets with respect to economic perspective (Economic Feasibility Improvement). There were nine experts in Expert Panel 1. The arithmetic means of experts' judgments for the relative importance of considered policy targets are shown in Figure 14 below.

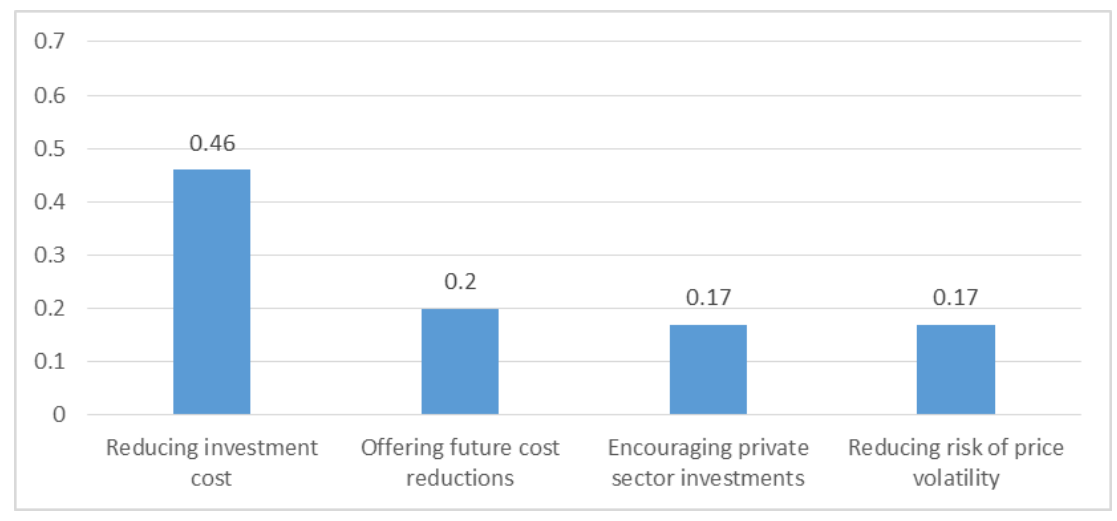

Figure 14: relative importance of economic policy targets to economic feasibility improvement

According to the results, Reducing Investment Cost (46\%) is the most important policy targets with respect to Economic Feasibility Improvement. Offering Future Cost Reductions was ranked second important (with a value of 20\%). Encouraging Private Sector Investment (17\%) and Reducing Risk of Price Volatility (17\%) have equal relative importance and rank third and fourth respectively.

\subsubsection{Analysis of Expert Panel 2a Results}

Individual results of the relative importance and the mean of the 9 experts from expert panel $2 \mathrm{a}$ are presented in Table 21. Looking at expert panel 2a results, all of the 
experts reflect an acceptable level of consistency in their judgments $(<=0.1)$. There was a level of disagreement among the experts (0.126).

Table 21: analysis of expert panel $2 \mathrm{a}$ results, economic policy targets with respect to perspective

\begin{tabular}{|c|c|c|c|c|c|}
\hline Expert & $\begin{array}{c}\text { Reducing } \\
\text { Investment } \\
\text { Cost }\end{array}$ & $\begin{array}{c}\text { Offering } \\
\text { Future Cost } \\
\text { Reductions }\end{array}$ & $\begin{array}{c}\text { Encouraging } \\
\text { Private Sector } \\
\text { Investments }\end{array}$ & $\begin{array}{c}\text { Reducing } \\
\text { Risk of Price } \\
\text { Volatility }\end{array}$ & Inconsistency \\
\hline Exp1 & 0.63 & 0.16 & 0.07 & 0.13 & 0.087 \\
\hline Exp2 & 0.74 & 0.06 & 0.12 & 0.08 & 0.016 \\
\hline Exp3 & 0.34 & 0.34 & 0.24 & 0.08 & 0.031 \\
\hline Exp4 & 0.20 & 0.25 & 0.22 & 0.33 & 0.004 \\
\hline Exp5 & 0.28 & 0.46 & 0.11 & 0.15 & 0.061 \\
\hline Exp6 & 0.57 & 0.17 & 0.18 & 0.07 & 0.015 \\
\hline Exp7 & 0.51 & 0.13 & 0.15 & 0.21 & 0.011 \\
\hline Exp8 & 0.34 & 0.08 & 0.26 & 0.31 & 0.003 \\
\hline Exp9 & 0.56 & 0.12 & 0.19 & 0.13 & 0.057 \\
\hline Mean & 0.46 & 0.20 & 0.17 & 0.17 & \\
\hline Disagreement & & & & & 0.126 \\
\hline
\end{tabular}

Agglomerative Hierarchical Clustering Analysis (AHC) was conducted to identify subgroups within expert panel 2a. Three subgroups within expert panel 2a were identified: subgroups A, B, and C. Please see Figure 15 below for details.

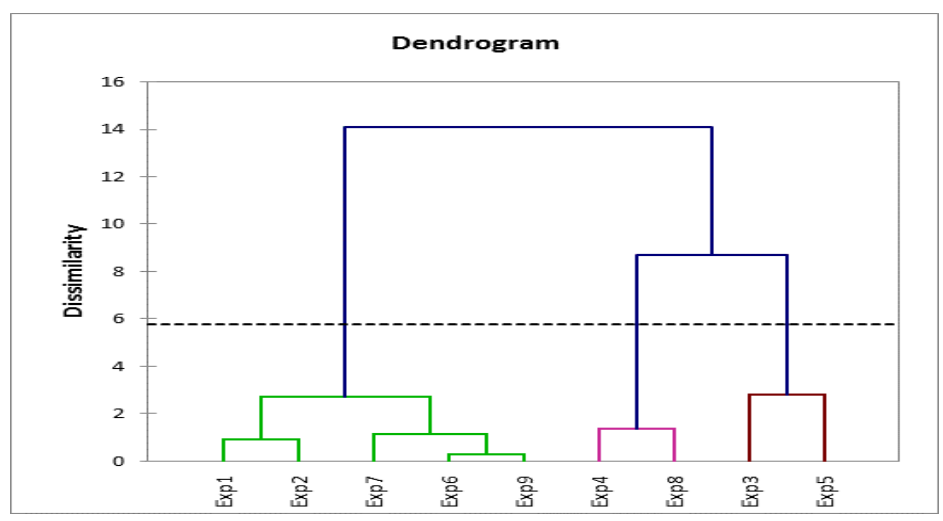

Figure 15: subgroups in expert panel 2a using dendrogram 
Group disagreement indices were calculated for the new subgroups in Expert Panel 2a and are shown in Table 22, Table 23, and Table 24 below. Group disagreement indices for each subgroup - A (0.062), B (0.0678), and C (0.070), are lower than the original total group disagreement and are lower than the threshold value of 0.10 .

Table 22: analysis of subgroup A results in expert panel 2a

\begin{tabular}{|c|c|c|c|c|c|}
\hline Expert & $\begin{array}{c}\text { Reducing } \\
\text { Investment } \\
\text { Cost }\end{array}$ & $\begin{array}{c}\text { Offering } \\
\text { Future Cost } \\
\text { Reductions }\end{array}$ & $\begin{array}{c}\text { Encouraging } \\
\text { Private } \\
\text { Sector } \\
\text { Investments }\end{array}$ & $\begin{array}{c}\text { Reducing } \\
\text { Risk of Price } \\
\text { Volatility }\end{array}$ & Inconsistency \\
\hline Exp1 & 0.63 & 0.16 & 0.07 & 0.13 & 0.087 \\
\hline Exp2 & 0.74 & 0.06 & 0.12 & 0.08 & 0.016 \\
\hline Exp6 & 0.57 & 0.17 & 0.18 & 0.07 & 0.015 \\
\hline Exp7 & 0.51 & 0.13 & 0.15 & 0.21 & 0.011 \\
\hline Exp9 & 0.56 & 0.12 & 0.19 & 0.13 & 0.057 \\
\hline Mean & 0.60 & 0.13 & 0.14 & 0.13 & \\
\hline Disagreement & & & & & 0.062 \\
\hline
\end{tabular}

Subgroup A consists of five experts. The relative priority of the variables in this subgroup is almost the same as the original panel where they agreed that Reducing Investment Cost (0.6) was the most important policy targets and that Reducing Risk of Price Volatility was one of the least important (0.13). This group was further investigated to check for any common characteristics among if they represent a certain viewpoint. These experts are from government, NGO and utilities. It was noticed that 3 experts came from government background which can be representative of the government's interest in improving the economics of wind projects in order to increase the adoption. After the grouping, the disagreement level was reduced to 0.062 . 
Table 23: analysis of subgroup B results in expert panel 2a

\begin{tabular}{|c|c|c|c|c|c|}
\hline Expert & $\begin{array}{c}\text { Reducing } \\
\text { Investment } \\
\text { Cost }\end{array}$ & $\begin{array}{c}\text { Offering } \\
\text { Future Cost } \\
\text { Reductions }\end{array}$ & $\begin{array}{c}\text { Encouraging } \\
\text { Private } \\
\text { Sector } \\
\text { Investments }\end{array}$ & $\begin{array}{c}\text { Reducing } \\
\text { Risk of Price } \\
\text { Volatility }\end{array}$ & Inconsistency \\
\hline Exp4 & 0.20 & 0.25 & 0.22 & 0.33 & 0.004 \\
\hline Exp8 & 0.34 & 0.08 & 0.26 & 0.31 & 0.003 \\
\hline Mean & 0.27 & 0.16 & 0.24 & 0.32 & \\
\hline Disagreement & & & & & 0.078 \\
\hline
\end{tabular}

Subgroup B is a smaller subgroup than A, and it has different relative importance judgments. Reducing Risk of Price Volatility (0.32) is the most important policy targets in this judgment, while Reducing Investment Cost is the second most important (0.27). There is no specific categorization of subgroup B; based on their backgrounds, these experts are from government and research labs. After the grouping, the disagreement level was reduced to 0.078 .

Table 24: analysis of subgroup $\mathrm{C}$ results in expert panel 2a

\begin{tabular}{|c|c|c|c|c|c|}
\hline Expert & $\begin{array}{c}\text { Reducing } \\
\text { Investment } \\
\text { Cost }\end{array}$ & $\begin{array}{c}\text { Offering } \\
\text { Future Cost } \\
\text { Reductions }\end{array}$ & $\begin{array}{c}\text { Encouraging } \\
\text { Private Sector } \\
\text { Investments }\end{array}$ & $\begin{array}{c}\text { Reducing } \\
\text { Risk of Price } \\
\text { Volatility }\end{array}$ & Inconsistency \\
\hline Exp3 & 0.34 & 0.34 & 0.24 & 0.08 & 0.031 \\
\hline Exp5 & 0.28 & 0.46 & 0.11 & 0.15 & 0.061 \\
\hline Mean & 0.31 & 0.40 & 0.18 & 0.11 & \\
\hline Disagreement & & & & & 0.070 \\
\hline
\end{tabular}

Subgroup C consists of 2 experts. In this subgroup, Offering Future Cost

Reductions (0.40) seems to be the most important policy targets with respect to the Economic Feasibility Improvement Perspective. However, Reducing Investment Cost (0.31) is still relatively important, while in this group, Reducing Risk of Price Volatility is again the least important (0.11). There is no specific categorization of subgroup C; 
based on their backgrounds, these experts are from government and utilities. After the grouping, the disagreement level was reduced to 0.07. After regrouping the experts in Expert Panel 2a into three different subgroups, it was noticed that the agreement of the experts in each subgroup improved, compared to the agreement of the original panel.

\subsubsection{Expert Panel 2b Results}

Expert Panel $2 \mathrm{~b}$ was asked to evaluate the relative importance of policy alternatives with respect to the four economic policy targets. The arithmetic means of experts' judgments for the relative importance of considered alternatives are shown in Figure 16, Figure 17, Figure 18, and Figure 19 below.

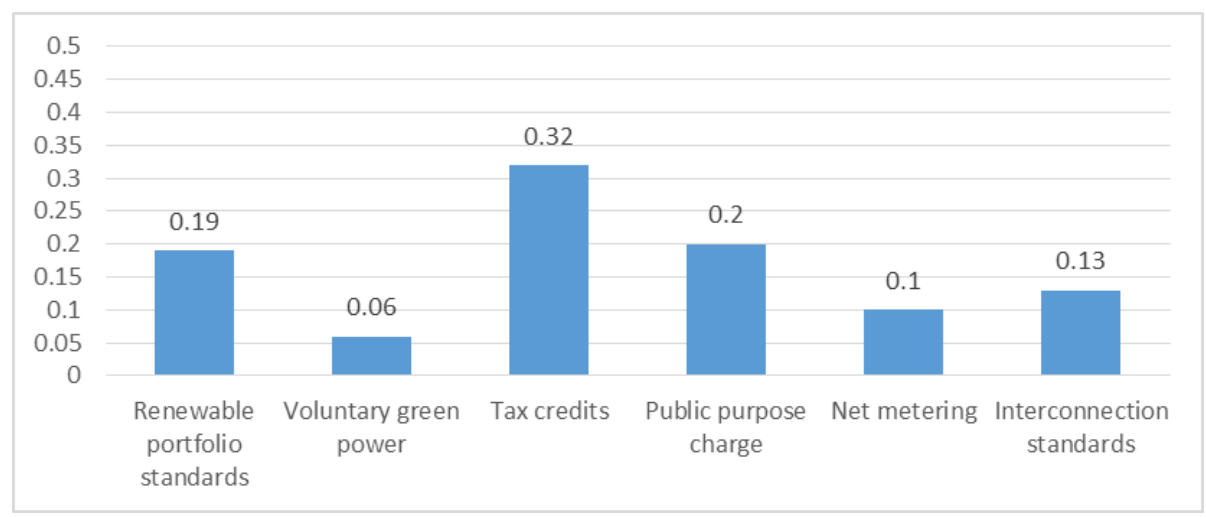

Figure 16: relative importance of decision alternatives with respect to reducing investment cost

According to the results, Tax Credits (32\%) is the most important alternative with respect to Reducing Investment Cost. Public Purpose Charge (20\%) and Renewable Portfolio Standards (19\%) have almost equal relative importance and rank second and third respectively. Interconnection Standard was fourth important with a relative 
importance of $13 \%$. Net Metering scored $10 \%$ while Voluntary Green Power policy was ranked least important with a value of $6 \%$.

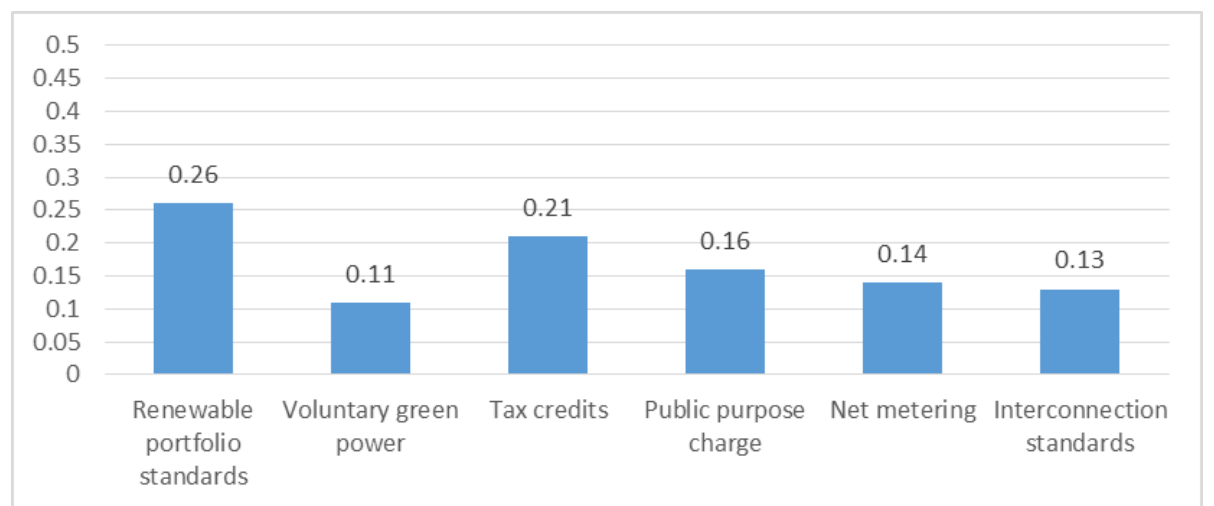

Figure 17: relative importance of decision alternatives with respect to offering future cost reductions

According to the results, Renewable Portfolio Standards (26\%) is the most important alternative with respect to offering future cost reductions. Tax Credits (21\%) ranked second important. Public Purpose Charge was third important (16\%). Net Metering, Interconnection Standard, and Voluntary Green Power Option were all almost equally important with values of $14 \%, 13 \%$, and $11 \%$, respectively.

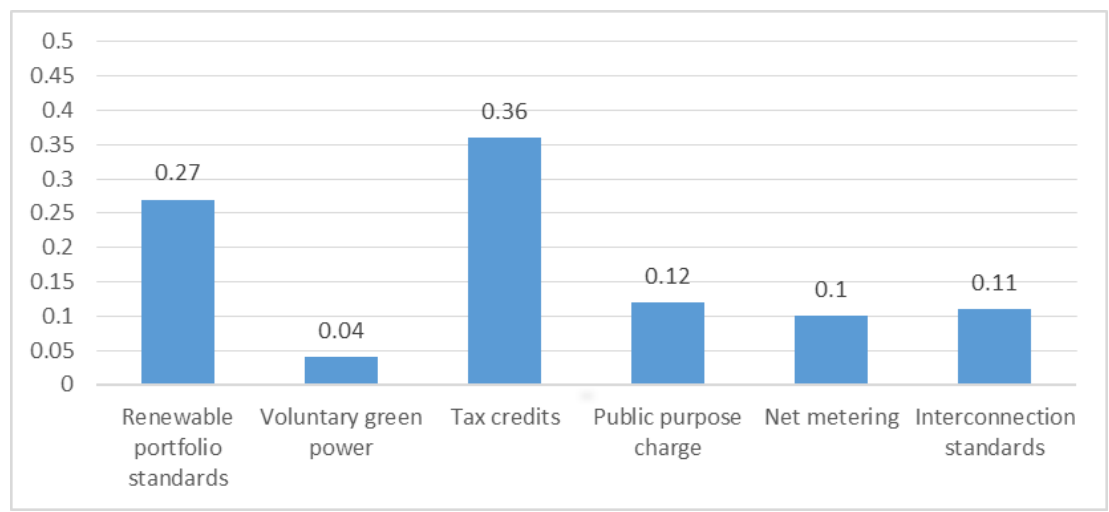

Figure 18: relative importance of decision alternatives with respect to encouraging private sector investment 
According to the results, Tax Credits $(36 \%)$ is the most important alternative with respect to encouraging private sector investment. Renewable Portfolio Standard (27\%) ranked second important. Public Purpose Charge, Interconnection Standard, and Net Metering, were all almost equally important with values of $12 \%, 11 \%$, and $10 \%$, respectively. Voluntary Green Power Option was least important (4\%).

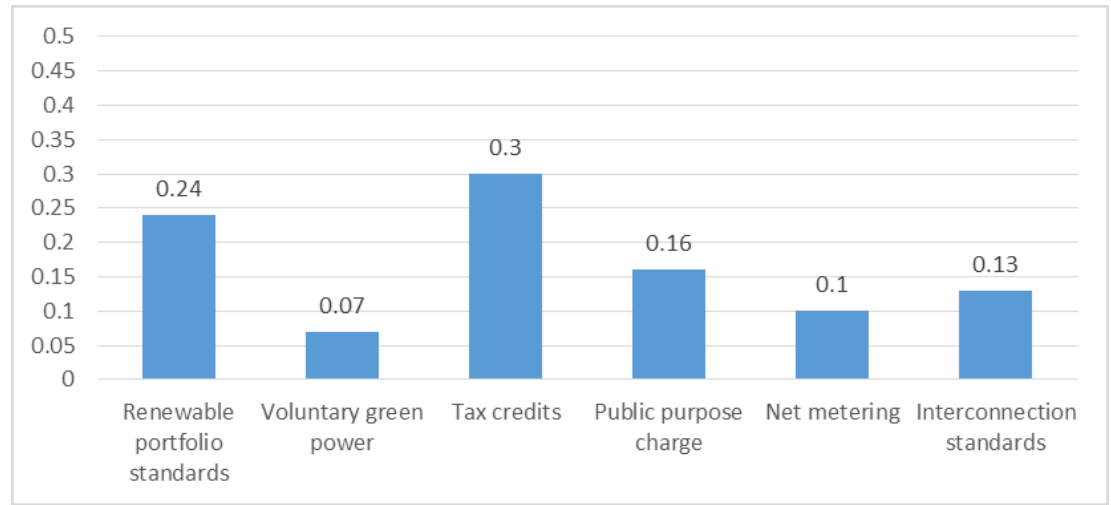

Figure 19: relative importance of decision alternatives with respect to reducing risk of price volatility

According to the results, the relative importance of the alternatives with respect to reducing risk of price volatility was similar to the results with respect to encouraging private sector investment. Tax Credits (30\%) is the most important alternative with respect to reducing risk of price volatility followed by Renewable Portfolio Standard (27\%). Public Purpose Charge, Interconnection Standard, and Net Metering, were all almost equally important with values of $16 \%, 13 \%$, and $11 \%$, respectively. Voluntary Green Power Option was least important (7\%). 


\subsubsection{Analysis of Expert Panel 2b Results}

Individual results of the relative importance and the mean of nine experts from expert Panel $2 \mathrm{~b}$ are presented in Table 25, Table 26, Table 27, and Table 28. Looking at Expert Panel $2 \mathrm{~b}$ results, all of the experts reflect an acceptable level of consistency in their judgments $(<0.1)$. There is also no significant level of disagreement among the experts $(0.088,0.78,0.53$, and 0.088$)$.

Table 25: analysis of expert panel $2 \mathrm{~b}$ results, decision alternatives with respect to reducing investment cost

\begin{tabular}{|c|c|c|c|c|c|c|c|}
\hline Expert & $\begin{array}{c}\text { Renewable } \\
\text { Portfolio } \\
\text { Standards }\end{array}$ & $\begin{array}{c}\text { Voluntary } \\
\text { Green } \\
\text { Power }\end{array}$ & $\begin{array}{c}\text { Tax } \\
\text { Credits }\end{array}$ & $\begin{array}{c}\text { Public } \\
\text { Purpose } \\
\text { Charge }\end{array}$ & $\begin{array}{c}\text { Net } \\
\text { Metering }\end{array}$ & $\begin{array}{c}\text { Interconne } \\
\text { ction } \\
\text { Standards }\end{array}$ & $\begin{array}{c}\text { Inconsi } \\
\text { stency }\end{array}$ \\
\hline Exp1 & 0.09 & 0.04 & 0.43 & 0.29 & 0.03 & 0.11 & 0.101 \\
\hline Exp2 & 0.22 & 0.06 & 0.29 & 0.17 & 0.03 & 0.23 & 0.115 \\
\hline Exp3 & 0.05 & 0.06 & 0.42 & 0.29 & 0.09 & 0.09 & 0.047 \\
\hline Exp4 & 0.15 & 0.17 & 0.19 & 0.17 & 0.17 & 0.17 & 0.007 \\
\hline Exp5 & 0.27 & 0.08 & 0.11 & 0.26 & 0.12 & 0.15 & 0.064 \\
\hline Exp6 & 0.07 & 0.04 & 0.57 & 0.11 & 0.04 & 0.17 & 0.080 \\
\hline Exp7 & 0.39 & 0.07 & 0.24 & 0.09 & 0.11 & 0.11 & 0.013 \\
\hline Exp8 & 0.28 & 0.02 & 0.35 & 0.17 & 0.19 & 0.09 & 0.039 \\
\hline Exp9 & 0.18 & 0.02 & 0.35 & 0.17 & 0.19 & 0.09 & 0.039 \\
\hline Mean & 0.19 & 0.06 & 0.32 & 0.20 & 0.10 & 0.13 & \\
\hline $\begin{array}{c}\text { Disagre } \\
\text { ement }\end{array}$ & & & & & & & 0.088 \\
\hline
\end{tabular}

Table 26: analysis of expert panel $2 \mathrm{~b}$ results decision alternatives with respect to offering future cost reductions

\begin{tabular}{|c|c|c|c|c|c|c|c|}
\hline Expert & $\begin{array}{c}\text { Renewable } \\
\text { Portfolio } \\
\text { Standards }\end{array}$ & $\begin{array}{c}\text { Voluntary } \\
\text { Green } \\
\text { Power }\end{array}$ & $\begin{array}{c}\text { Tax } \\
\text { Credits }\end{array}$ & $\begin{array}{c}\text { Public } \\
\text { Purpose } \\
\text { Charge }\end{array}$ & $\begin{array}{c}\text { Net } \\
\text { Metering }\end{array}$ & $\begin{array}{c}\text { Interconne } \\
\text { ction } \\
\text { Standards }\end{array}$ & $\begin{array}{c}\text { Inconsis } \\
\text { tency }\end{array}$ \\
\hline Exp1 & 0.28 & 0.34 & 0.08 & 0.12 & 0.12 & 0.08 & 0.078 \\
\hline Exp2 & 0.21 & 0.07 & 0.30 & 0.17 & 0.07 & 0.20 & 0.077 \\
\hline Exp3 & 0.20 & 0.05 & 0.26 & 0.17 & 0.22 & 0.11 & 0.037 \\
\hline Exp4 & 0.17 & 0.19 & 0.15 & 0.17 & 0.17 & 0.17 & 0.017 \\
\hline Exp5 & 0.33 & 0.09 & 0.09 & 0.18 & 0.12 & 0.20 & 0.051 \\
\hline
\end{tabular}




\begin{tabular}{|c|c|c|c|c|c|c|c|}
\hline Exp6 & 0.17 & 0.17 & 0.17 & 0.17 & 0.17 & 0.17 & 0.000 \\
\hline Exp7 & 0.43 & 0.07 & 0.19 & 0.10 & 0.11 & 0.11 & 0.020 \\
\hline Exp8 & 0.34 & 0.02 & 0.35 & 0.19 & 0.08 & 0.02 & 0.033 \\
\hline Exp9 & 0.20 & 0.02 & 0.31 & 0.17 & 0.20 & 0.10 & 0.043 \\
\hline Mean & 0.26 & 0.11 & 0.21 & 0.16 & 0.14 & 0.13 & \\
\hline $\begin{array}{c}\text { Disagree } \\
\text { ment }\end{array}$ & & & & & & 0.078 \\
\hline
\end{tabular}

Table 27: analysis of expert panel $2 \mathrm{~b}$ results decision alternatives with respect to encouraging private sector investment

\begin{tabular}{|c|c|c|c|c|c|c|c|}
\hline Expert & $\begin{array}{c}\text { Renewable } \\
\text { Portfolio } \\
\text { Standards }\end{array}$ & $\begin{array}{c}\text { Voluntary } \\
\text { Green } \\
\text { Power }\end{array}$ & $\begin{array}{c}\text { Tax } \\
\text { Credits }\end{array}$ & $\begin{array}{c}\text { Public } \\
\text { Purpose } \\
\text { Charge }\end{array}$ & $\begin{array}{c}\text { Net } \\
\text { Metering }\end{array}$ & $\begin{array}{c}\text { Interconne } \\
\text { ction } \\
\text { Standards }\end{array}$ & $\begin{array}{c}\text { Inconsi } \\
\text { stency }\end{array}$ \\
\hline Exp1 & 0.39 & 0.04 & 0.32 & 0.12 & 0.03 & 0.06 & 0.097 \\
\hline Exp2 & 0.31 & 0.05 & 0.35 & 0.11 & 0.04 & 0.14 & 0.040 \\
\hline Exp3 & 0.18 & 0.02 & 0.27 & 0.18 & 0.23 & 0.12 & 0.047 \\
\hline Exp4 & 0.33 & 0.08 & 0.26 & 0.10 & 0.10 & 0.12 & 0.024 \\
\hline Exp5 & 0.30 & 0.05 & 0.32 & 0.08 & 0.12 & 0.13 & 0.104 \\
\hline Exp6 & 0.21 & 0.03 & 0.47 & 0.10 & 0.07 & 0.11 & 0.108 \\
\hline Exp7 & 0.33 & 0.07 & 0.33 & 0.08 & 0.09 & 0.09 & 0.011 \\
\hline Exp8 & 0.22 & 0.01 & 0.45 & 0.17 & 0.08 & 0.07 & 0.087 \\
\hline Exp9 & 0.20 & 0.02 & 0.43 & 0.14 & 0.14 & 0.07 & 0.110 \\
\hline Mean & 0.27 & 0.04 & 0.36 & 0.12 & 0.10 & 0.11 & \\
\hline $\begin{array}{c}\text { Disagreem } \\
\text { ent }\end{array}$ & & & & & & & 0.053 \\
\hline
\end{tabular}

Table 28: analysis of expert panel $2 \mathrm{~b}$ results decision alternatives with respect to reducing risk of price volatility

\begin{tabular}{|c|c|c|c|c|c|c|c|}
\hline Expert & $\begin{array}{c}\text { Renewable } \\
\text { Portfolio } \\
\text { Standards }\end{array}$ & $\begin{array}{c}\text { Voluntary } \\
\text { Green } \\
\text { Power }\end{array}$ & $\begin{array}{c}\text { Tax } \\
\text { Credits }\end{array}$ & $\begin{array}{c}\text { Public } \\
\text { Purpose } \\
\text { Charge }\end{array}$ & $\begin{array}{c}\text { Net } \\
\text { Metering }\end{array}$ & $\begin{array}{c}\text { Interconne } \\
\text { ction } \\
\text { Standards }\end{array}$ & $\begin{array}{c}\text { Inconsist } \\
\text { ency }\end{array}$ \\
\hline Exp1 & 0.15 & 0.03 & 0.52 & 0.23 & 0.03 & 0.03 & 0.107 \\
\hline Exp2 & 0.17 & 0.07 & 0.40 & 0.15 & 0.05 & 0.16 & 0.062 \\
\hline Exp3 & 0.42 & 0.02 & 0.27 & 0.17 & 0.09 & 0.04 & 0.083 \\
\hline Exp4 & 0.18 & 0.12 & 0.32 & 0.13 & 0.13 & 0.13 & 0.018 \\
\hline Exp5 & 0.28 & 0.13 & 0.06 & 0.08 & 0.11 & 0.34 & 0.101 \\
\hline Exp6 & 0.16 & 0.06 & 0.43 & 0.12 & 0.07 & 0.16 & 0.065 \\
\hline Exp7 & 0.21 & 0.16 & 0.23 & 0.14 & 0.11 & 0.14 & 0.029 \\
\hline Exp8 & 0.42 & 0.02 & 0.16 & 0.22 & 0.11 & 0.05 & 0.037 \\
\hline Exp9 & 0.20 & 0.02 & 0.31 & 0.17 & 0.20 & 0.10 & 0.043 \\
\hline
\end{tabular}




\begin{tabular}{|c|c|c|c|c|c|c|c|}
\hline Mean & 0.24 & 0.07 & 0.30 & 0.16 & 0.10 & 0.13 & \\
\hline $\begin{array}{c}\text { Disagreem } \\
\text { ent }\end{array}$ & & & & & & & 0.088 \\
\hline
\end{tabular}

\subsection{Expert Panel 3}

Eleven experts in total provided pairwise comparison judgments in expert panel 3.

The distribution of sectors is as follows: 1 from a research lab, 5 from utilities, and 5

from non-governmental organizations. Please refer to Table 29 for experts' profiles.

Experts in Expert Panel 3 gave judgments on two steps: 3a and 3b. The first task for

Expert Panel 3 (3a) was to evaluate relative priorities for policy targets with respect to the

Community Support Encouragement perspective and the second task (3b) was to evaluate

relative priorities for the alternatives with respect to the Social policy targets.

Table 29: Expert Panel 3 Experts' Profiles

\begin{tabular}{|c|c|c|}
\hline Expert & Affiliation & Sector \\
\hline Exp1 & Energy Trust of Oregon & NGO \\
\hline Exp2 & NW Power \& Conservation Council & NGO \\
\hline Exp3 & Pacific Northwest National Laboratory & NGO \\
\hline Exp4 & NW Environmental Business Council & NGO \\
\hline Exp5 & Energy Trust of Oregon & Utilities \\
\hline Exp6 & Bonneville Power Administration & Utilities \\
\hline Exp7 & Bonneville Power Administration & NGO \\
\hline Exp8 & Bonneville Environmental Foundation & Utilities \\
\hline Exp9 & Bonneville Power Administration & Utilities \\
\hline Exp10 & Portland General Electric & Utilities \\
\hline Exp11 & Portland General Electric & Res \\
\hline
\end{tabular}




\subsubsection{Expert Panel 3a Results}

Expert Panel 3a was asked to evaluate the relative importance of four policy targets with respect to Social Perspective (Community Support Encouragement). There were 11 experts in Expert Panel 3. The arithmetic means of experts' judgments for the relative importance of considered policy targets are shown in Figure 20 below.

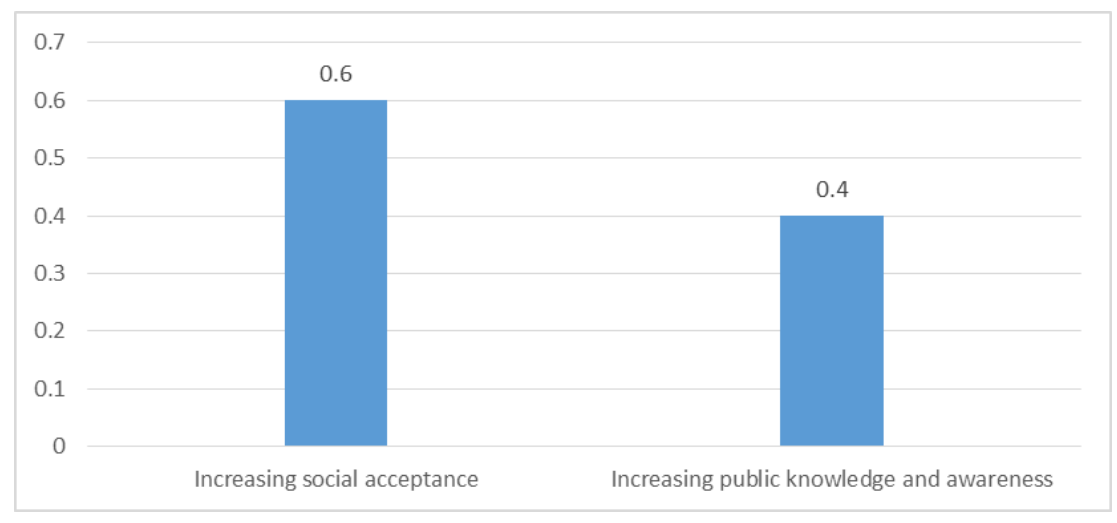

Figure 20: relative importance of social policy targets to community support encouragement According to the results, Increasing Social Acceptance (60\%) is the most important policy targets with respect to Community Support Encouragement. Increasing Public Knowledge and Awareness was ranked second important with a value of (40\%).

\subsubsection{Analysis of Expert Panel 3a Results}

Almost all the experts in Expert Panel 3a agreed that Increasing Social Acceptance is slightly more important than Increasing Public Knowledge and Awareness with respect to Community Support Encouragement. The inconsistency is zero since there are only two items to compare and the disagreement level is 0.101 . 
Table 30: Analysis of Expert Panel 3a Results, Social Policy targets with Respect to Perspective

\begin{tabular}{|c|c|c|c|}
\hline Expert & $\begin{array}{c}\text { Increasing Social } \\
\text { Acceptance }\end{array}$ & $\begin{array}{c}\text { Increasing Public } \\
\text { Knowledge and } \\
\text { Awareness }\end{array}$ & Inconsistency \\
\hline Exp1 & 0.80 & 0.20 & 0 \\
\hline Exp2 & 0.50 & 0.50 & 0 \\
\hline Exp3 & 0.70 & 0.30 & 0 \\
\hline Exp4 & 0.75 & 0.25 & 0 \\
\hline Exp5 & 0.60 & 0.40 & 0 \\
\hline Exp6 & 0.50 & 0.50 & 0 \\
\hline Exp7 & 0.50 & 0.50 & 0 \\
\hline Exp8 & 0.60 & 0.40 & 0 \\
\hline Exp9 & 0.70 & 0.30 & 0 \\
\hline Exp10 & 0.50 & 0.50 & 0 \\
\hline Exp11 & 0.50 & 0.50 & 0.101 \\
\hline Mean & 0.60 & 0.40 & 0 \\
\hline Disagreement & & & \\
\hline
\end{tabular}

\subsubsection{Expert Panel 3b Results}

Expert Panel 3b was asked to evaluate the relative importance of policy

alternatives with respect to the two social policy targets. The arithmetic means of experts' judgments for the relative importance of considered alternatives are shown in Figure 21 and Figure 22 below. 


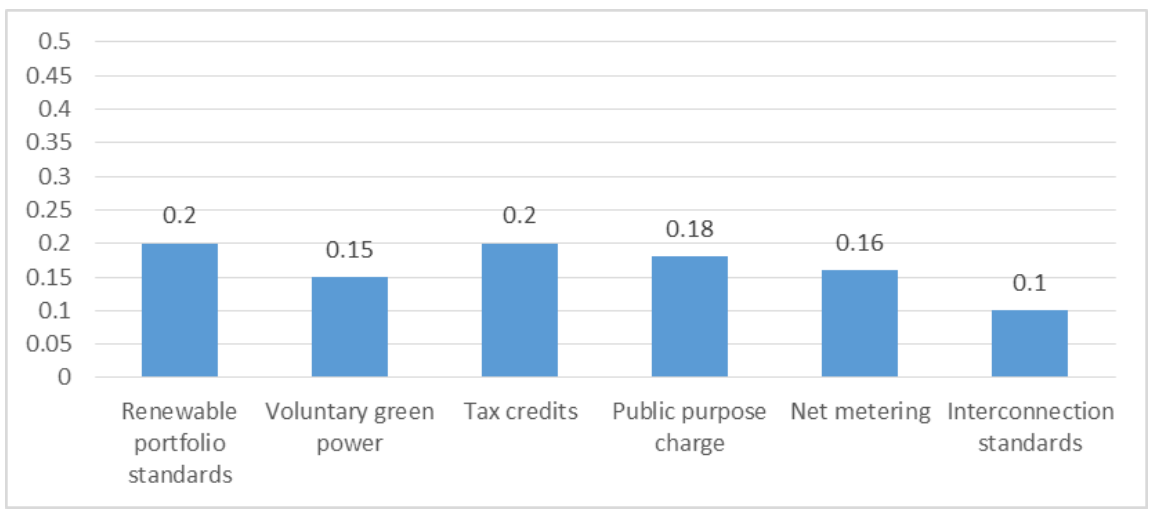

Figure 21: relative importance of decision alternatives with respect to increasing social acceptance According to the results, Tax Credits and Renewable Portfolio Standard were equally important alternatives (20\%) with respect to Increasing Social Acceptance.

Public Utility Charge followed in importance (18\%). Net Metering and Voluntary Green Power were almost equally important with values of $16 \%$ and $15 \%$, respectively.

Interconnection Standards was least important (4\%).

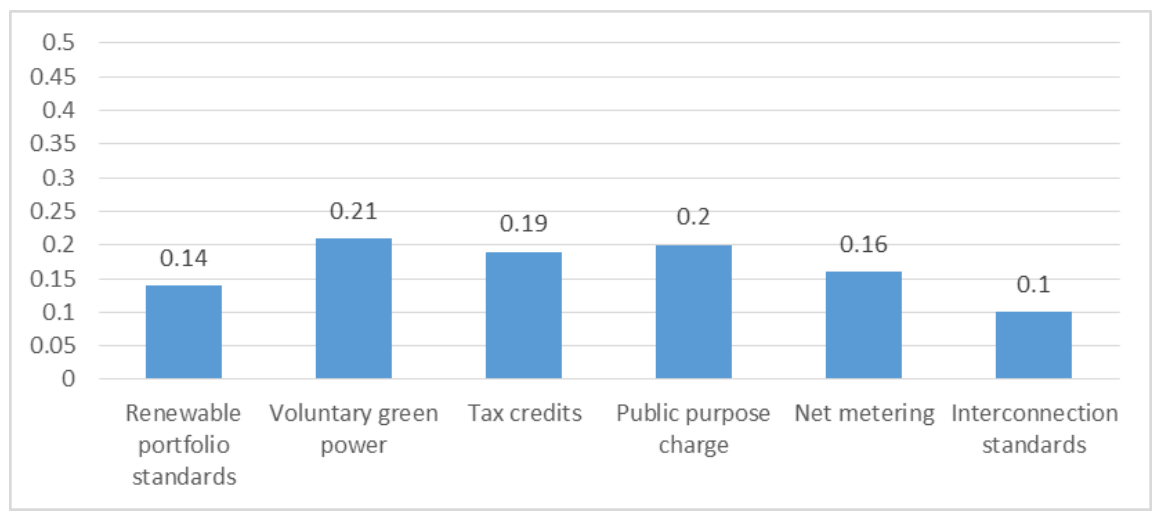

Figure 22: relative importance of decision alternatives with respect to increasing public knowledge and awareness

Unlike Increasing Social Acceptance, according to the results, three policies were almost equally important with respect to Increasing Public Knowledge and Awareness: 
Voluntary Green Power, Public Purpose Charge, and Tax Credits (21\%, 20\%, and 19\% respectively). Net Metering was ranked fourth (16\%), followed by Renewable Portfolio Standards (14\%). Interconnection Standards was least important (10\%).

\subsubsection{Analysis of Expert Panel 3b Results}

Individual results of the relative importance and the mean of the 11 experts from Expert Panel 3b are presented in Table 31 and Table 32. Looking at Expert Panel 3b results, all of the experts reflect an acceptable level of consistency in their judgments $(<0.1)$. There is also no significant level of disagreement among the experts $(0.071$, $0.068)$.

Table 31: analysis of expert panel $3 \mathrm{~b}$ results, decision alternatives with respect to increasing social acceptance

\begin{tabular}{|c|c|c|c|c|c|c|c|}
\hline Expert & $\begin{array}{c}\text { Renewable } \\
\text { Portfolio } \\
\text { Standards }\end{array}$ & $\begin{array}{c}\text { Voluntary } \\
\text { Green } \\
\text { Power }\end{array}$ & $\begin{array}{c}\text { Tax } \\
\text { Credits }\end{array}$ & $\begin{array}{c}\text { Public } \\
\text { Purpose } \\
\text { Charge }\end{array}$ & $\begin{array}{c}\text { Net } \\
\text { Metering }\end{array}$ & $\begin{array}{c}\text { Interconne } \\
\text { ction } \\
\text { Standards }\end{array}$ & $\begin{array}{c}\text { Inconsis } \\
\text { tency }\end{array}$ \\
\hline Exp1 & 0.17 & 0.19 & 0.29 & 0.29 & 0.03 & 0.03 & 0.095 \\
\hline Exp2 & 0.28 & 0.08 & 0.2 & 0.19 & 0.14 & 0.10 & 0.027 \\
\hline Exp3 & 0.29 & 0.10 & 0.18 & 0.19 & 0.15 & 0.09 & 0.010 \\
\hline Exp4 & 0.21 & 0.24 & 0.19 & 0.19 & 0.14 & 0.02 & 0.017 \\
\hline Exp5 & 0.15 & 0.21 & 0.07 & 0.27 & 0.20 & 0.09 & 0.018 \\
\hline Exp6 & 0.27 & 0.08 & 0.32 & 0.11 & 0.28 & 0.14 & 0.033 \\
\hline Exp7 & 0.07 & 0.08 & 0.32 & 0.11 & 0.05 & 0.14 & 0.033 \\
\hline Exp8 & 0.17 & 0.17 & 0.17 & 0.17 & 0.17 & 0.17 & 0.000 \\
\hline Exp9 & 0.17 & 0.16 & 0.15 & 0.21 & 0.24 & 0.08 & 0.022 \\
\hline Exp10 & 0.37 & 0.07 & 0.25 & 0.10 & 0.10 & 0.10 & 0.003 \\
\hline Exp11 & 0.05 & 0.21 & 0.15 & 0.19 & 0.17 & 0.23 & 0.083 \\
\hline Mean & 0.20 & 0.15 & 0.20 & 0.15 & 0.16 & 0.10 & \\
\hline $\begin{array}{c}\text { Disagreem } \\
\text { ent }\end{array}$ & & & & & & & 0.071 \\
\hline
\end{tabular}


Table 32: analysis of expert panel $3 \mathrm{~b}$ results, decision alternatives with respect to increasing public knowledge and awareness

\begin{tabular}{|c|c|c|c|c|c|c|c|}
\hline Expert & $\begin{array}{c}\text { Renewable } \\
\text { Portfolio } \\
\text { Standards }\end{array}$ & $\begin{array}{c}\text { Voluntary } \\
\text { Green } \\
\text { Power }\end{array}$ & $\begin{array}{c}\text { Tax } \\
\text { Credits }\end{array}$ & $\begin{array}{c}\text { Public } \\
\text { Purpose } \\
\text { Charge }\end{array}$ & $\begin{array}{c}\text { Net } \\
\text { Metering }\end{array}$ & $\begin{array}{c}\text { Interconne } \\
\text { ction } \\
\text { Standards }\end{array}$ & $\begin{array}{c}\text { Inconsi } \\
\text { stency }\end{array}$ \\
\hline Exp1 & 0.17 & 0.19 & 0.29 & 0.29 & 0.03 & 0.03 & 0.095 \\
\hline Exp2 & 0.16 & 0.12 & 0.14 & 0.23 & 0.20 & 0.12 & 0.014 \\
\hline Exp3 & 0.12 & 0.13 & 0.37 & 0.11 & 0.17 & 0.09 & 0.021 \\
\hline Exp4 & 0.21 & 0.24 & 0.19 & 0.19 & 0.14 & 0.02 & 0.017 \\
\hline Exp5 & 0.08 & 0.21 & 0.14 & 0.44 & 0.08 & 0.05 & 0.022 \\
\hline Exp6 & 0.12 & 0.32 & 0.12 & 0.17 & 0.15 & 0.14 & 0.011 \\
\hline Exp7 & 0.10 & 0.29 & 0.23 & 0.06 & 0.19 & 0.13 & 0.056 \\
\hline Exp8 & 0.10 & 0.19 & 0.16 & 0.19 & 0.20 & 0.16 & 0.007 \\
\hline Exp9 & 0.17 & 0.18 & 0.15 & 0.18 & 0.26 & 0.07 & 0.007 \\
\hline Exp10 & 0.20 & 0.15 & 0.16 & 0.22 & 0.17 & 0.10 & 0.021 \\
\hline Exp11 & 0.09 & 0.28 & 0.14 & 0.18 & 0.18 & 0.14 & 0.019 \\
\hline Mean & 0.14 & 0.21 & 0.19 & 0.20 & 0.16 & 0.10 & \\
\hline $\begin{array}{c}\text { Disagreem } \\
\text { ent }\end{array}$ & & & & & & & 0.068 \\
\hline
\end{tabular}

\subsection{Expert Panel 4}

Eleven experts in total provided pairwise comparison judgments in Expert Panel

4. The distribution of sectors is as follows: 4 from government, 2 from research labs, 1 from utilities, and 4 from non-governmental organizations. Please refer to Table 33 for experts' profiles. Experts in Expert Panel 4 gave judgments on two steps: $4 \mathrm{a}$ and $4 \mathrm{~b}$. The first task for Expert Panel 4 (4a) was to evaluate relative priorities for policy targets with respect to the Regulatory Implementation Consideration perspective and the second task 
(4b) was to evaluate relative priorities for the alternatives with respect to the Regulatory policy targets.

Table 33: expert panel 4 experts' profiles

\begin{tabular}{|c|c|c|}
\hline Expert & Affiliation & Sector \\
\hline Exp1 & Oregon Public Utility Commission & Government \\
\hline Exp2 & NW Power \& Conservation Council & NGO \\
\hline Exp3 & Oregon Department of Energy & Government \\
\hline Exp4 & NW Environmental Business Council & NGO \\
\hline Exp5 & Renewable Northwest Projects & NGO \\
\hline Exp6 & Oregon Department of Energy & Government \\
\hline Exp7 & Bonneville Power Administration & Utilities \\
\hline Exp8 & Pacific Northwest National Laboratory & Research lab \\
\hline Exp9 & Oregon Public Utility Commission & Government \\
\hline Exp10 & Energy Trust of Oregon & NGO \\
\hline Exp11 & Pacific Northwest National Laboratory & Research lab \\
\hline
\end{tabular}

\subsubsection{Expert Panel 4a Results}

Expert Panel 4a was asked to evaluate the relative importance of three policy targets with respect to Regulatory Perspective (Regulatory Implementation Consideration). There were 11 experts in Expert Panel 4. The arithmetic means of experts' judgments for the relative importance of considered policy targets are shown in Figure 23 below. 


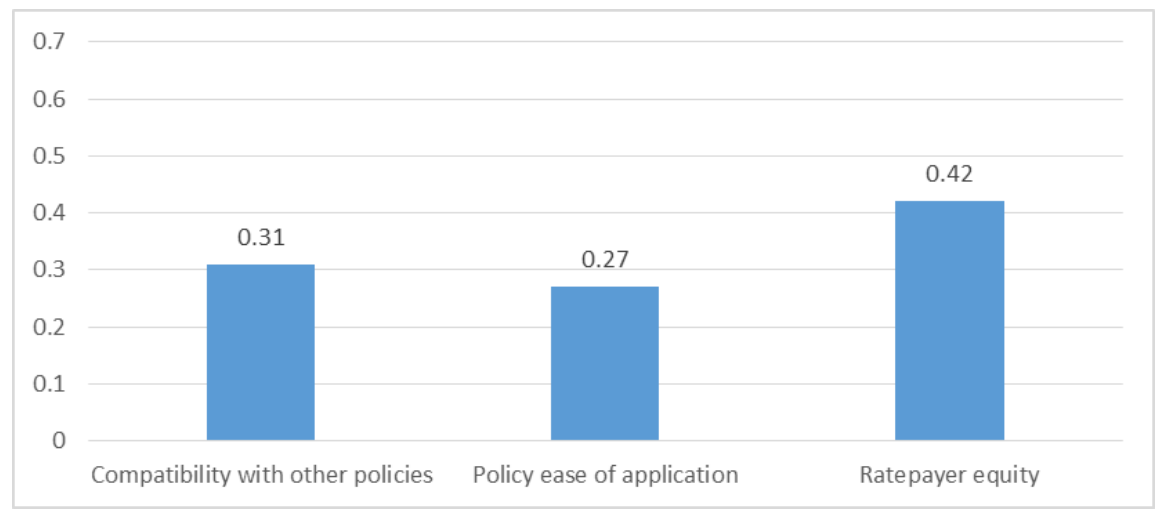

Figure 23: relative importance of regulatory policy targets to regulatory implementation considerations

According to the results, Ratepayer Equity (42\%) is the most important policy targets with respect to the Regulatory Implementation consideration. Compatibility with other policies and Policy Ease of Application came second and third with values of (31\%) and $(27 \%)$, respectively.

\subsubsection{Analysis of Expert Panel 4a Results}

Individual results of the relative importance and the mean of 11 experts from Expert Panel 4a are presented in Table 34 below. Looking at Expert Panel 4a results, all of the experts reflect an acceptable level of consistency in their judgments $(<0.1)$. There was, however, a significant level of disagreement among the experts (0.200).

Table 34: analysis of expert panel 4a results, regulatory policy targets with respect to perspective

\begin{tabular}{|c|c|c|c|c|}
\hline Expert & $\begin{array}{c}\text { Compatibility } \\
\text { with Other } \\
\text { Policies }\end{array}$ & $\begin{array}{c}\text { Policy Ease } \\
\text { of } \\
\text { Application }\end{array}$ & $\begin{array}{c}\text { Ratepayer } \\
\text { Equity }\end{array}$ & Inconsistency \\
\hline Exp1 & 0.11 & 0.07 & 0.81 & 0.009 \\
\hline Exp2 & 0.38 & 0.38 & 0.25 & 0.000 \\
\hline
\end{tabular}




\begin{tabular}{|c|l|l|l|l|}
\hline Exp3 & 0.24 & 0.43 & 0.32 & 0.023 \\
\hline Exp4 & 0.57 & 0.32 & 0.11 & 0.022 \\
\hline Exp5 & 0.20 & 0.49 & 0.31 & 0.059 \\
\hline Exp6 & 0.20 & 0.20 & 0.60 & 0.000 \\
\hline Exp7 & 0.54 & 0.05 & 0.41 & 0.005 \\
\hline Exp8 & 0.09 & 0.09 & 0.82 & 0.000 \\
\hline Exp9 & 0.20 & 0.31 & 0.49 & 0.059 \\
\hline Exp10 & 0.67 & 0.17 & 0.17 & 0.000 \\
\hline Exp11 & 0.21 & 0.42 & 0.37 & 0.006 \\
\hline Mean & 0.31 & 0.27 & 0.42 & \\
\hline Disagreement & & & & 0.200 \\
\hline
\end{tabular}

Agglomerative Hierarchical Clustering analysis (AHC) was conducted to identify subgroups within Expert Panel 4a. Three subgroups within Expert Panel 4a were identified: subgroups A, B, and C. Please see Figure 24 below for details.

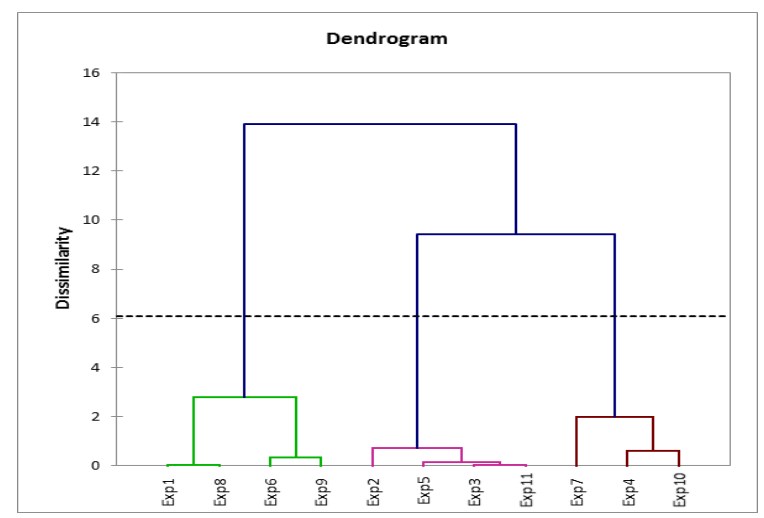

Figure 24: subgroups in expert panel 4a using dendrogram

Group disagreement indices were calculated for the new subgroups in Expert

Panel 4a and are shown in Table 35, Table 36 and Table 37 below. 
Table 35: analysis of subgroup A results in expert panel 4a

\begin{tabular}{|c|c|c|c|c|}
\hline Expert & $\begin{array}{c}\text { Compatibility } \\
\text { with Other } \\
\text { Policies }\end{array}$ & $\begin{array}{c}\text { Policy Ease } \\
\text { of } \\
\text { Application }\end{array}$ & $\begin{array}{c}\text { Ratepayer } \\
\text { Equity }\end{array}$ & Inconsistency \\
\hline Exp1 & 0.11 & 0.07 & 0.81 & 0.009 \\
\hline Exp6 & 0.20 & 0.20 & 0.60 & 0.000 \\
\hline Exp8 & 0.09 & 0.09 & 0.82 & 0.000 \\
\hline Exp9 & 0.20 & 0.31 & 0.49 & 0.059 \\
\hline Mean & 0.15 & 0.17 & 0.68 & \\
\hline Disagreement & & & & 0.118 \\
\hline
\end{tabular}

Subgroup A consists of four experts. These experts agreed with the original panel that Ratepayer Equity is the most important policy targets. Based on their backgrounds, most of these experts are from the government sector. After the grouping, the disagreement level was reduced to 0.118 . Although it is still higher than the acceptable threshold, the subgrouping is accepted since the disagreement was reduced significantly.

Table 36: Analysis of subgroup B results in expert panel 4a

\begin{tabular}{|c|c|c|c|c|}
\hline Expert & $\begin{array}{c}\text { Compatibility } \\
\text { with Other } \\
\text { Policies }\end{array}$ & $\begin{array}{c}\text { Policy Ease } \\
\text { of } \\
\text { Application }\end{array}$ & $\begin{array}{c}\text { Ratepayer } \\
\text { Equity }\end{array}$ & Inconsistency \\
\hline Exp2 & 0.38 & 0.38 & 0.25 & 0.000 \\
\hline Exp3 & 0.24 & 0.43 & 0.32 & 0.023 \\
\hline Exp5 & 0.20 & 0.49 & 0.31 & 0.059 \\
\hline Exp11 & 0.21 & 0.42 & 0.37 & 0.006 \\
\hline Mean & 0.26 & 0.43 & 0.31 & \\
\hline Disagreement & & & & 0.061 \\
\hline
\end{tabular}

Subgroup B consists of four experts. These experts, unlike the original panel, agreed that Policy Ease of Application is the most important policy targets. Based on their backgrounds, these experts are from government, NGO and research lab sectors. Two out of four experts are from non-governmental organizations which implies the 
interest of these organizations in having a policy that was easy to apply without extensive regulations and opposing from different parties. After the grouping, the disagreement level was reduced to 0.118 . Although it is still higher than the acceptable threshold, the subgrouping is accepted, since the disagreement was reduced significantly.

Table 37: analysis of subgroup $\mathrm{C}$ results in expert panel 4a

\begin{tabular}{|c|c|c|c|c|}
\hline Expert & $\begin{array}{c}\text { Compatibility } \\
\text { with Other } \\
\text { Policies }\end{array}$ & $\begin{array}{c}\text { Policy Ease } \\
\text { of } \\
\text { Application }\end{array}$ & $\begin{array}{c}\text { Ratepayer } \\
\text { Equity }\end{array}$ & Inconsistency \\
\hline Exp4 & 0.57 & 0.32 & 0.11 & 0.022 \\
\hline Exp7 & 0.54 & 0.05 & 0.41 & 0.005 \\
\hline Exp10 & 0.67 & 0.17 & 0.17 & 0.000 \\
\hline Mean & 0.59 & 0.18 & 0.23 & \\
\hline Disagreement & & & & 0.128 \\
\hline
\end{tabular}

Subgroup C consists of three experts. The relative priority of the variables in this subgroup is slightly different than the original panel where they agreed that Policy Ease of Application (0.18) was the least important policy targets. The relative importance of Compatibility with Other Policies (0.59) was higher than the original panel. Two of the experts in this subgroup were from the NGO sector, while one was from utilities. This also implies the interest of NGOs in the design of policies and whether it is applicable or not. After the grouping, the disagreement level was reduced to 0.128 which is still high, but significantly lower than the original panel.

\subsubsection{Expert Panel 4b Results}

Expert panel $4 \mathrm{~b}$ was asked to evaluate the relative importance of policy alternatives with respect to the three Regulatory policy targets. The arithmetic means of 
experts' judgments for the relative importance of considered alternatives are shown in Figure 25, Figure 26, and Figure 27 below.

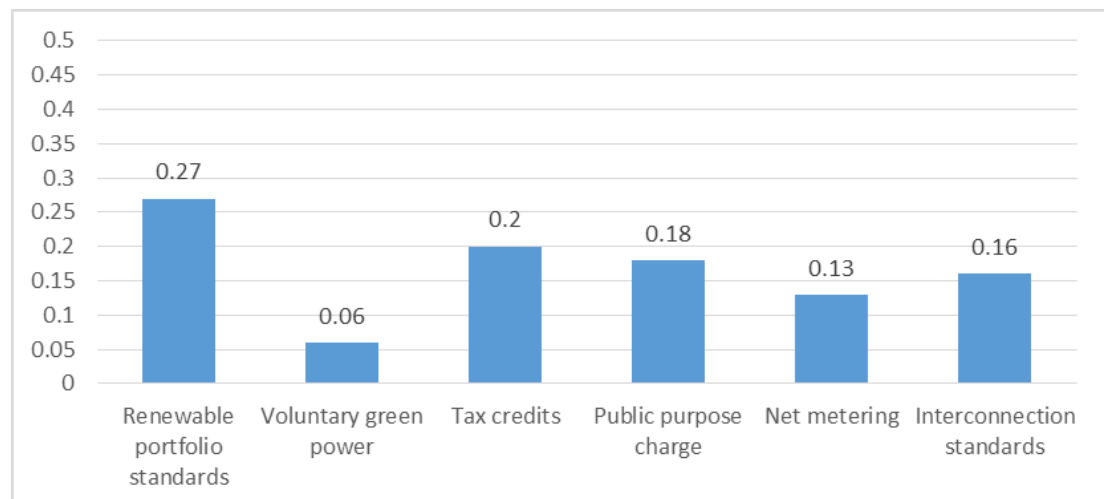

Figure 25: relative importance of decision alternatives with respect to compatibility with other policies

According to the results, Renewable Portfolio Standard scored the most important (27\%) with respect to Compatibility with Other Policies. Tax Credits, Public Purpose Charge, and Interconnection Standard followed in importance $(20 \%, 18 \%$, and $16 \%$, respectively). Net Metering and Voluntary Green Power were the least important (13\% and $6 \%$, respectively).

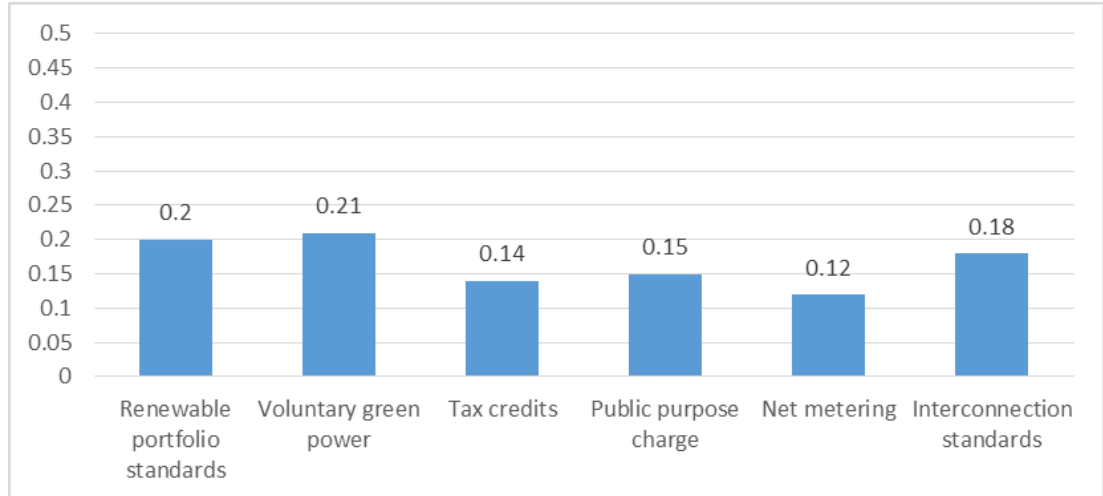

Figure 26: relative importance of decision alternatives with respect to policy ease of application 
Voluntary Green Power and Renewable Portfolio Standards were almost equally important with respect to Policy Ease of Application (21\%, 20\%). Interconnection Standard was third (18\%), followed by Public Purpose Charge (15\%) and Tax Credits (14\%). The policy that scored lowest in this policy targets was Net Metering (12\%).

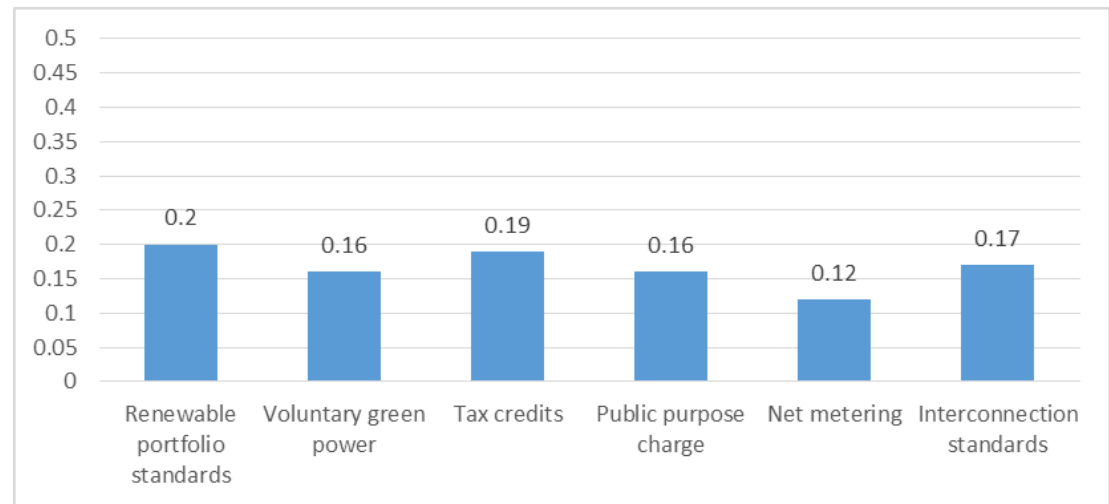

Figure 27: relative importance of decision alternatives with respect to ratepayer equity

According to the results, Renewable Portfolio Standards and Tax Credits were almost equally important alternatives $(20 \%, 19 \%)$ with respect to Ratepayer Equity. Interconnection Standards was third important (17\%), Public Purpose Charge and Voluntary Green Power were equally important (16\%). Net Metering was least important $(12 \%)$.

\subsubsection{Analysis of Expert Panel 4b Results}

Individual results of the relative importance and the mean of 11 experts from Expert panel $4 \mathrm{~b}$ are presented in 
Table 38, Table 39, and Table 40 below. Looking at Expert panel $4 \mathrm{~b}$ results, all of the experts reflect an acceptable level of consistency in their judgments $(<0.1)$. There is also no significant level of disagreement among the experts $(0.61,0.84$, and 0.82$)$.

Table 38: analysis of expert panel $4 \mathrm{~b}$ results, decision alternatives with respect to compatibility with other policies

\begin{tabular}{|c|c|c|c|c|c|c|c|}
\hline Expert & $\begin{array}{c}\text { Renewabl } \\
\text { e Portfolio } \\
\text { Standards }\end{array}$ & $\begin{array}{c}\text { Voluntary } \\
\text { Green } \\
\text { Power }\end{array}$ & $\begin{array}{c}\text { Tax } \\
\text { Credits }\end{array}$ & $\begin{array}{c}\text { Public } \\
\text { Purpose } \\
\text { Charge }\end{array}$ & $\begin{array}{c}\text { Net } \\
\text { Metering }\end{array}$ & $\begin{array}{c}\text { Interconn } \\
\text { ection } \\
\text { Standards }\end{array}$ & $\begin{array}{c}\text { Inconsiste } \\
\text { ncy }\end{array}$ \\
\hline Exp1 & 0.10 & 0.08 & 0.29 & 0.14 & 0.08 & 0.31 & 0.089 \\
\hline Exp2 & 0.34 & 0.07 & 0.15 & 0.21 & 0.14 & 0.10 & 0.021 \\
\hline Exp3 & 0.22 & 0.04 & 0.24 & 0.20 & 0.16 & 0.14 & 0.030 \\
\hline Exp4 & 0.25 & 0.06 & 0.17 & 0.22 & 0.16 & 0.13 & 0.057 \\
\hline Exp5 & 0.21 & 0.11 & 0.15 & 0.21 & 0.15 & 0.18 & 0.074 \\
\hline Exp6 & 0.36 & 0.10 & 0.11 & 0.12 & 0.15 & 0.15 & 0.056 \\
\hline Exp7 & 0.23 & 0.06 & 0.14 & 0.30 & 0.06 & 0.20 & 0.080 \\
\hline Exp8 & 0.29 & 0.01 & 0.33 & 0.13 & 0.15 & 0.10 & 0.077 \\
\hline Exp9 & 0.24 & 0.03 & 0.22 & 0.22 & 0.16 & 0.12 & 0.068 \\
\hline Exp10 & 0.27 & 0.06 & 0.19 & 0.02 & 0.08 & 0.19 & 0.048 \\
\hline Exp11 & 0.41 & 0.05 & 0.22 & 0.05 & 0.09 & 0.18 & 0.108 \\
\hline Mean & 0.27 & 0.06 & 0.20 & 0.18 & 0.13 & 0.16 & \\
\hline Disagreem & & & & & & & 0.061 \\
\hline ent & & & & & & & \\
\hline
\end{tabular}

Table 39: analysis of expert panel $4 \mathrm{~b}$ results, decision alternatives with respect to policy ease of application

\begin{tabular}{|c|c|c|c|c|c|c|c|}
\hline Expert & $\begin{array}{c}\text { Renewabl } \\
\text { e Portfolio } \\
\text { Standards }\end{array}$ & $\begin{array}{c}\text { Voluntary } \\
\text { Green } \\
\text { Power }\end{array}$ & $\begin{array}{c}\text { Tax } \\
\text { Credits }\end{array}$ & $\begin{array}{c}\text { Public } \\
\text { Purpose } \\
\text { Charge }\end{array}$ & $\begin{array}{c}\text { Net } \\
\text { Metering }\end{array}$ & $\begin{array}{c}\text { Interconn } \\
\text { ection } \\
\text { Standards }\end{array}$ & $\begin{array}{c}\text { Inconsiste } \\
\text { ncy }\end{array}$ \\
\hline Exp1 & 0.16 & 0.32 & 0.19 & 0.11 & 0.08 & 0.15 & 0.051 \\
\hline Exp2 & 0.20 & 0.16 & 0.16 & 0.24 & 0.15 & 0.09 & 0.017 \\
\hline Exp3 & 0.15 & 0.26 & 0.10 & 0.05 & 0.18 & 0.26 & 0.017 \\
\hline Exp4 & 0.21 & 0.21 & 0.14 & 0.21 & 0.12 & 0.11 & 0.015 \\
\hline Exp5 & 0.29 & 0.08 & 0.05 & 0.15 & 0.16 & 0.28 & 0.022 \\
\hline Exp6 & 0.24 & 0.06 & 0.08 & 0.12 & 0.20 & 0.09 & 0.055 \\
\hline Exp7 & 0.33 & 0.05 & 0.13 & 0.25 & 0.06 & 0.18 & 0.089 \\
\hline Exp8 & 0.11 & 0.24 & 0.19 & 0.08 & 0.15 & 0.22 & 0.061 \\
\hline Exp9 & 0.15 & 0.24 & 0.19 & 0.15 & 0.11 & 0.15 & 0.039 \\
\hline
\end{tabular}




\begin{tabular}{|c|c|c|c|c|c|c|c|}
\hline Exp10 & 0.29 & 0.12 & 0.10 & 0.22 & 0.09 & 0.18 & 0.081 \\
\hline Exp11 & 0.12 & 0.54 & 0.19 & 0.06 & 0.06 & 0.04 & 0.086 \\
\hline Mean & 0.20 & 0.21 & 0.14 & 0.15 & 0.12 & 0.18 & \\
\hline $\begin{array}{c}\text { Disagreem } \\
\text { ent }\end{array}$ & & & & & & & 0.084 \\
\hline
\end{tabular}

Table 40: analysis of expert panel $4 \mathrm{~b}$ results, decision alternatives with respect to ratepayer equity

\begin{tabular}{|c|c|c|c|c|c|c|c|}
\hline Expert & $\begin{array}{c}\text { Renewabl } \\
\text { e Portfolio } \\
\text { Standards }\end{array}$ & $\begin{array}{c}\text { Voluntary } \\
\text { Green } \\
\text { Power }\end{array}$ & $\begin{array}{c}\text { Tax } \\
\text { Credits }\end{array}$ & $\begin{array}{c}\text { Public } \\
\text { Purpose } \\
\text { Charge }\end{array}$ & $\begin{array}{c}\text { Net } \\
\text { Metering }\end{array}$ & $\begin{array}{c}\text { Interconn } \\
\text { ection } \\
\text { Standards }\end{array}$ & $\begin{array}{c}\text { Inconsiste } \\
\text { ncy }\end{array}$ \\
\hline Exp1 & 0.20 & 0.20 & 0.16 & 0.16 & 0.05 & 0.22 & 0.042 \\
\hline Exp2 & 0.25 & 0.08 & 0.15 & 0.28 & 0.16 & 0.08 & 0.011 \\
\hline Exp3 & 0.11 & 0.16 & 0.42 & 0.06 & 0.07 & 0.18 & 0.079 \\
\hline Exp4 & 0.24 & 0.11 & 0.24 & 0.11 & 0.15 & 0.15 & 0.053 \\
\hline Exp5 & 0.12 & 0.24 & 0.16 & 0.14 & 0.15 & 0.19 & 0.035 \\
\hline Exp6 & 0.09 & 0.22 & 0.09 & 0.15 & 0.22 & 0.22 & 0.025 \\
\hline Exp7 & 0.26 & 0.13 & 0.13 & 0.18 & 0.05 & 0.25 & 0.093 \\
\hline Exp8 & 0.23 & 0.02 & 0.27 & 0.21 & 0.21 & 0.06 & 0.074 \\
\hline Exp9 & 0.22 & 0.25 & 0.25 & 0.22 & 0.09 & 0.19 & 0.042 \\
\hline Exp10 & 0.36 & 0.04 & 0.04 & 0.28 & 0.14 & 0.14 & 0.030 \\
\hline Exp11 & 0.07 & 0.26 & 0.34 & 0.08 & 0.06 & 0.19 & 0.032 \\
\hline Mean & 0.20 & 0.16 & 0.19 & 0.16 & 0.12 & 0.17 & \\
\hline $\begin{array}{c}\text { Disagreem } \\
\text { ent }\end{array}$ & & & & & & & 0.082 \\
\hline
\end{tabular}

\subsection{Expert Panel 5}

Six experts in total provided pairwise comparison judgments in expert panel 5.

The distribution of sectors is as follows: 1 from a research lab, 2 from utilities and 3 from non-governmental organizations. Please refer to Table 41 for experts' profiles. Experts in expert panel 5 gave judgments on two steps: $5 \mathrm{a}$ and $5 \mathrm{~b}$. The first task for expert panel 5 (5a) was to evaluate relative priorities for policy targets with respect to the 
Environmental Protection Promotion Perspective and the second task (5b) was to evaluate relative priorities for the alternatives with respect to the Environmental policy targets.

Table 41: expert panel 5 experts' profiles

\begin{tabular}{|c|c|c|}
\hline Expert & Affiliation & Sector \\
\hline Exp1 & Pacific Northwest National Laboratory & Research lab \\
\hline Exp2 & NW Environmental Business Council & NGO \\
\hline Exp3 & Energy Trust of Oregon & NGO \\
\hline Exp4 & Bonneville Power Administration & Utilities \\
\hline Exp5 & Bonneville Environmental Foundation & NGO \\
\hline Exp6 & Portland General Electric & Utilities \\
\hline
\end{tabular}

\subsubsection{Expert Panel 5a Results}

Expert Panel 5a was asked to evaluate the relative importance of four policy targets with respect to Environmental Perspective (Environmental Protection Promotion). There were six experts in expert panel 5. The arithmetic means of experts' judgments for the relative importance of considered policy targets are shown in Figure 28 below.

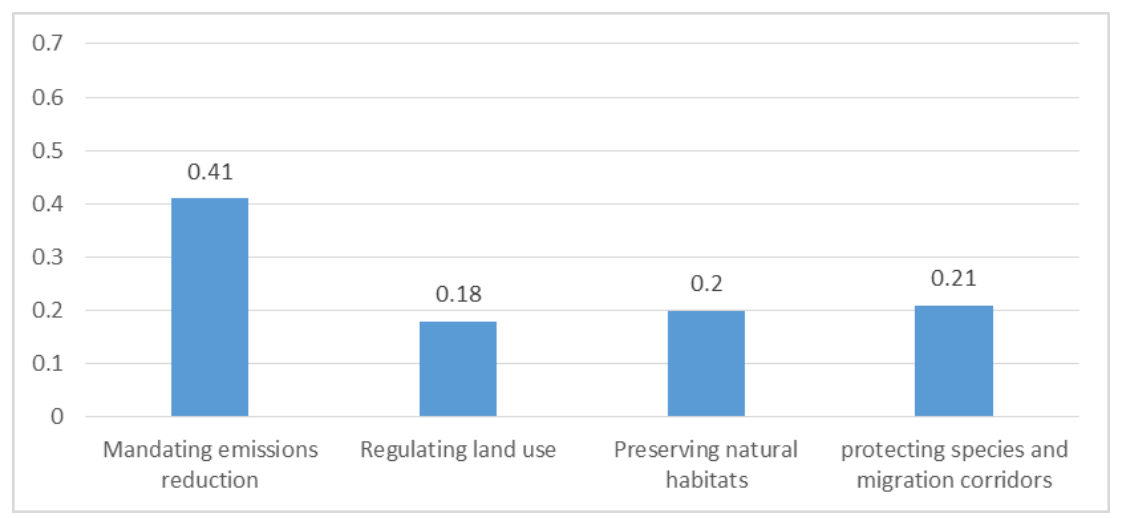

Figure 28: relative importance of policy targets with respect to environmental protection promotion. 
According to the results, Mandating Emission Reductions (41\%) is the most important policy targets with respect to Environmental Protection Promotion. Protecting Species and Migration Corridors and Preserving Natural Habitats had almost equal importance of (21\%) and (20\%) respectively. Regulating Land Use ranked close in importance but was the lowest $(18 \%)$ in the group.

\subsubsection{Analysis of Expert Panel 5a Results}

Individual results of the relative importance and the mean of six experts from expert panel 5a are presented in Table 42 below. Looking at expert panel 5a results, all of the experts reflect an acceptable level of consistency in their judgments $(<0.1)$. There is also no significant level of disagreement among the experts (0.080).

Table 42: analysis of expert panel 5a results, environmental policy targets with respect to perspective

\begin{tabular}{|c|c|c|c|c|c|}
\hline Expert & $\begin{array}{c}\text { Mandating } \\
\text { Emissions } \\
\text { Reduction }\end{array}$ & $\begin{array}{c}\text { Regulating } \\
\text { Land Use }\end{array}$ & $\begin{array}{c}\text { Preserving } \\
\text { Natural } \\
\text { Habitats }\end{array}$ & $\begin{array}{c}\text { Protecting } \\
\text { Species and } \\
\text { Migration } \\
\text { Corridors }\end{array}$ & Inconsistency \\
\hline Exp1 & 0.43 & 0.22 & 0.22 & 0.13 & 0.020 \\
\hline Exp2 & 0.57 & 0.12 & 0.16 & 0.16 & 0.004 \\
\hline Exp3 & 0.44 & 0.17 & 0.17 & 0.23 & 0.004 \\
\hline Exp4 & 0.18 & 0.27 & 0.27 & 0.27 & 0.000 \\
\hline Exp5 & 0.36 & 0.16 & 0.24 & 0.24 & 0.000 \\
\hline Exp6 & 0.48 & 0.14 & 0.16 & 0.22 & 0.017 \\
\hline Mean & 0.41 & 0.18 & 0.20 & 0.21 & \\
\hline Disagreement & & & & & 0.080 \\
\hline
\end{tabular}




\subsubsection{Expert Panel 5b Results}

Expert panel $5 \mathrm{~b}$ was asked to evaluate the relative importance of policy

alternatives with respect to the four Environmental policy targets. The arithmetic means of the experts' judgments for the relative importance of considered alternatives are shown in Figure 29, Figure 30, Figure 31, and Figure 32 below.

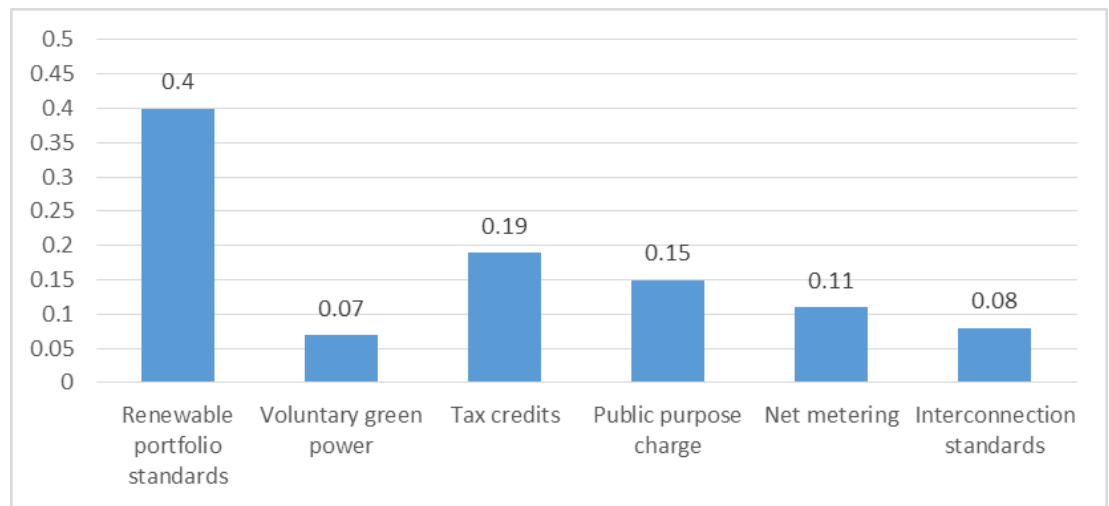

Figure 29: relative importance of decision alternatives with respect to mandating emission reduction

According to Expert panel 5b results, Renewable Portfolio Standards was the leading policy with respect to Mandating Emission Reduction (40\%). Tax Credits was ranked second (19\%), followed by Public Purpose Charge and Net Metering (15\%, 11\% respectively). Interconnection Standards and Voluntary Green Power ranked lowest and were almost equally important ( $8 \%$ and $7 \%$ respectively). 


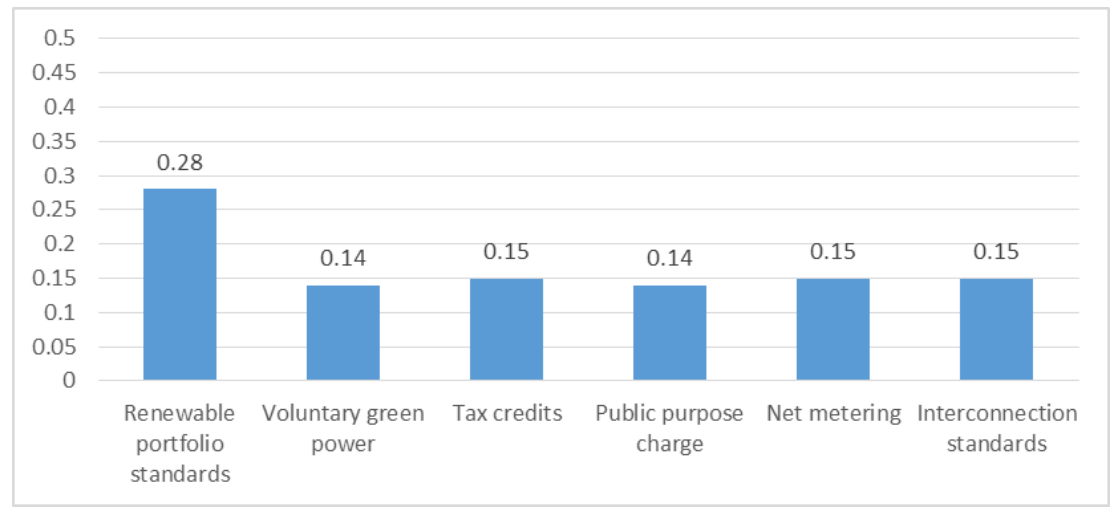

Figure 30: relative importance of decision alternatives with respect to regulating land use

According to the results, Renewable Portfolio Standard ranked the first important with respect to Regulating Land Use. All other alternatives: Interconnection Standards, Net Metering, Tax Credits, Public Purpose Charge, and Voluntary Green Power, were almost equally important $(15 \%, 15 \%, 15 \%, 14 \%$, and $14 \%$ respectively).

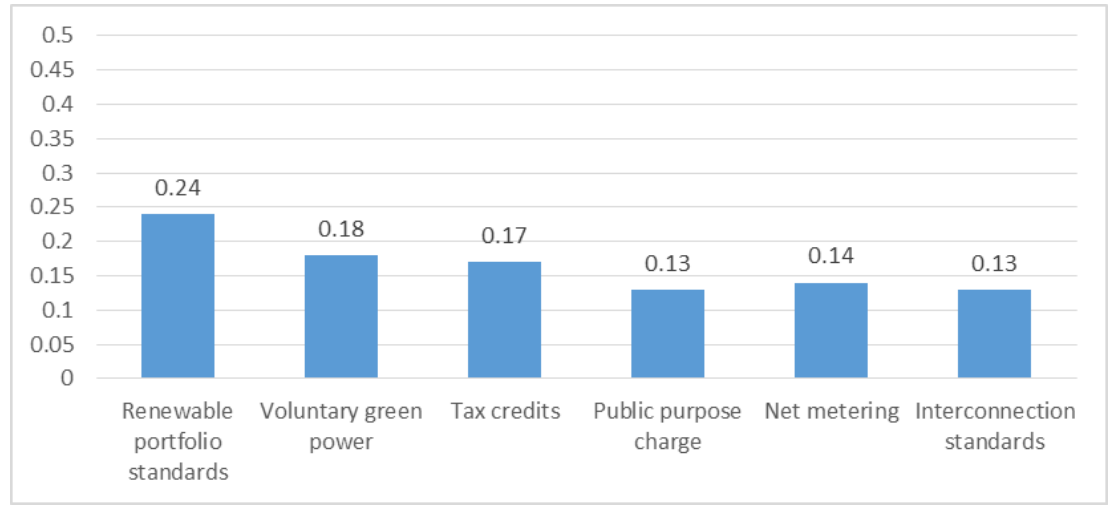

Figure 31: relative importance of decision alternatives with respect to preserving natural habitats

According to the results, Renewable Portfolio Standards was ranked the most important with respect to Preserving Natural Habitats. This was followed by Voluntary Green Power and Tax Credits (18\% and 17\% respectively). Net Metering was ranked 
fourth important (14\%), and both Public Purpose Charge and Interconnection Standards ranked equally and least important (13\%).

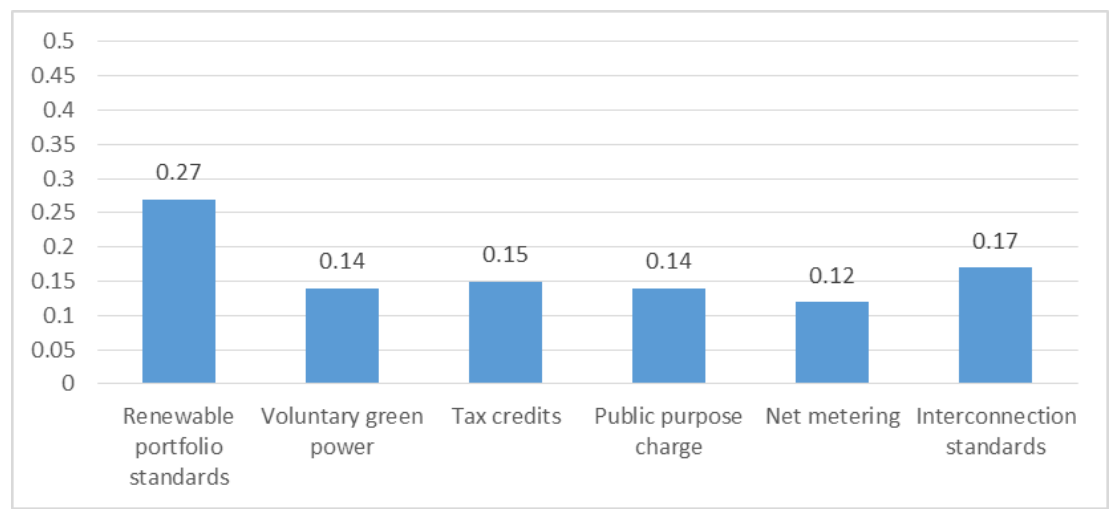

Figure 32: relative importance of decision alternatives with respect to protecting species and migration corridors

According to the results, Renewable Portfolio Standards was ranked first important with respect to Protecting Species and Migration Corridors. Interconnection Standards (17\%) was second while Tax Credits ranked third (15\%). Voluntary Green Power and Public Purpose Charge were equally important (14\%), while Net Metering ranked last (12\%).

\subsubsection{Analysis of Expert Panel 5b Results}

Individual results of the relative importance and the mean of six experts from expert panel $5 \mathrm{~b}$ are presented in Table 43, Table 44, Table 45 and Table 46 below. Looking at expert panel $5 \mathrm{~b}$ results, all of the experts reflect an acceptable level of consistency in their judgments $(<0.1)$. There is also no significant level of disagreement among the experts $(0.054,0.100,0.089$, and 0.102$)$. 
Table 43: analysis of expert panel $5 \mathrm{~b}$ results, decision alternatives with respect to mandating emission reduction

\begin{tabular}{|c|c|c|c|c|c|c|c|}
\hline Expert & $\begin{array}{c}\text { Renewabl } \\
\text { e Portfolio } \\
\text { Standards }\end{array}$ & $\begin{array}{c}\text { Voluntary } \\
\text { Green } \\
\text { Power }\end{array}$ & $\begin{array}{c}\text { Tax } \\
\text { Credits }\end{array}$ & $\begin{array}{c}\text { Public } \\
\text { Purpose } \\
\text { Charge }\end{array}$ & $\begin{array}{c}\text { Net } \\
\text { Metering }\end{array}$ & $\begin{array}{c}\text { Interconn } \\
\text { ection } \\
\text { Standards }\end{array}$ & $\begin{array}{c}\text { Inconsiste } \\
\text { ncy }\end{array}$ \\
\hline Exp1 & 0.44 & 0.06 & 0.19 & 0.13 & 0.22 & 0.08 & 0.012 \\
\hline Exp2 & 0.41 & 0.14 & 0.21 & 0.10 & 0.11 & 0.03 & 0.028 \\
\hline Exp3 & 0.32 & 0.04 & 0.17 & 0.28 & 0.11 & 0.09 & 0.023 \\
\hline Exp4 & 0.30 & 0.06 & 0.20 & 0.13 & 0.15 & 0.13 & 0.034 \\
\hline Exp5 & 0.41 & 0.08 & 0.10 & 0.19 & 0.11 & 0.11 & 0.004 \\
\hline Exp6 & 0.49 & 0.06 & 0.26 & 0.08 & 0.05 & 0.05 & 0.011 \\
\hline Mean & 0.40 & 0.07 & 0.19 & 0.15 & 0.11 & 0.08 & \\
\hline $\begin{array}{c}\text { Disagreem } \\
\text { ent }\end{array}$ & & & & & & 0.054 \\
\hline
\end{tabular}

Table 44: analysis of expert panel $5 \mathrm{~b}$ results, decision alternatives with respect to regulating land use

\begin{tabular}{|c|c|c|c|c|c|c|c|}
\hline Expert & $\begin{array}{c}\text { Renewabl } \\
\text { e Portfolio } \\
\text { Standards }\end{array}$ & $\begin{array}{c}\text { Voluntary } \\
\text { Green } \\
\text { Power }\end{array}$ & $\begin{array}{c}\text { Tax } \\
\text { Credits }\end{array}$ & $\begin{array}{c}\text { Public } \\
\text { Purpose } \\
\text { Charge }\end{array}$ & $\begin{array}{c}\text { Net } \\
\text { Metering }\end{array}$ & $\begin{array}{c}\text { Interconn } \\
\text { ection } \\
\text { Standards }\end{array}$ & $\begin{array}{c}\text { Inconsiste } \\
\text { ncy }\end{array}$ \\
\hline Exp1 & 0.08 & 0.32 & 0.07 & 0.10 & 0.18 & 0.24 & 0.006 \\
\hline Exp2 & 0.17 & 0.17 & 0.17 & 0.17 & 0.17 & 0.17 & 0.000 \\
\hline Exp3 & 0.38 & 0.07 & 0.23 & 0.08 & 0.13 & 0.11 & 0.035 \\
\hline Exp4 & 0.22 & 0.07 & 0.11 & 0.23 & 0.19 & 0.19 & 0.104 \\
\hline Exp5 & 0.20 & 0.15 & 0.13 & 0.20 & 0.15 & 0.15 & 0.010 \\
\hline Exp6 & 0.60 & 0.04 & 0.19 & 0.06 & 0.05 & 0.05 & 0.043 \\
\hline Mean & 0.28 & 0.14 & 0.15 & 0.14 & 0.15 & 0.15 & \\
\hline $\begin{array}{c}\text { Disagreem } \\
\text { ent }\end{array}$ & & & & & & & 0.100 \\
\hline
\end{tabular}

Table 45: analysis of expert panel $5 \mathrm{~b}$ results, decision alternatives with respect to preserving natural habitats

\begin{tabular}{|c|c|c|c|c|c|c|c|}
\hline Expert & $\begin{array}{c}\text { Renewabl } \\
\text { e Portfolio } \\
\text { Standards }\end{array}$ & $\begin{array}{c}\text { Voluntary } \\
\text { Green } \\
\text { Power }\end{array}$ & $\begin{array}{c}\text { Tax } \\
\text { Credits }\end{array}$ & $\begin{array}{c}\text { Public } \\
\text { Purpose } \\
\text { Charge }\end{array}$ & $\begin{array}{c}\text { Net } \\
\text { Metering }\end{array}$ & $\begin{array}{c}\text { Interconn } \\
\text { ection } \\
\text { Standards }\end{array}$ & $\begin{array}{c}\text { Inconsiste } \\
\text { ncy }\end{array}$ \\
\hline Exp1 & 0.15 & 0.23 & 0.11 & 0.15 & 0.17 & 0.19 & 0.016 \\
\hline Exp2 & 0.17 & 0.17 & 0.17 & 0.17 & 0.17 & 0.17 & 0.000 \\
\hline Exp3 & 0.36 & 0.07 & 0.24 & 0.11 & 0.12 & 0.11 & 0.049 \\
\hline Exp4 & 0.15 & 0.39 & 0.11 & 0.10 & 0.13 & 0.12 & 0.022 \\
\hline Exp5 & 0.16 & 0.15 & 0.16 & 0.17 & 0.19 & 0.18 & 0.009 \\
\hline Exp6 & 0.49 & 0.06 & 0.26 & 0.08 & 0.05 & 0.05 & 0.011 \\
\hline
\end{tabular}




\begin{tabular}{|c|c|c|c|c|c|c|c|}
\hline Mean & 0.24 & 0.18 & 0.17 & 0.13 & 0.14 & 0.13 & \\
\hline $\begin{array}{c}\text { Disagreem } \\
\text { ent }\end{array}$ & & & & & & & 0.089 \\
\hline
\end{tabular}

Table 46: analysis of expert panel $5 \mathrm{~b}$ results, decision alternatives with respect to protecting species and migration corridors

\begin{tabular}{|c|c|c|c|c|c|c|c|}
\hline Expert & $\begin{array}{c}\text { Renewabl } \\
\text { e Portfolio } \\
\text { Standards }\end{array}$ & $\begin{array}{c}\text { Voluntary } \\
\text { Green } \\
\text { Power }\end{array}$ & $\begin{array}{c}\text { Tax } \\
\text { Credits }\end{array}$ & $\begin{array}{c}\text { Public } \\
\text { Purpose } \\
\text { Charge }\end{array}$ & $\begin{array}{c}\text { Net } \\
\text { Metering }\end{array}$ & $\begin{array}{c}\text { Interconn } \\
\text { ection } \\
\text { Standards }\end{array}$ & $\begin{array}{c}\text { Inconsiste } \\
\text { ncy }\end{array}$ \\
\hline Exp1 & 0.10 & 0.26 & 0.09 & 0.13 & 0.18 & 0.23 & 0.025 \\
\hline Exp2 & 0.17 & 0.17 & 0.17 & 0.17 & 0.17 & 0.17 & 0.000 \\
\hline Exp3 & 0.38 & 0.07 & 0.23 & 0.08 & 0.13 & 0.11 & 0.035 \\
\hline Exp4 & 0.15 & 0.11 & 0.11 & 0.20 & 0.08 & 0.35 & 0.067 \\
\hline Exp5 & 0.21 & 0.19 & 0.13 & 0.20 & 0.13 & 0.13 & 0.002 \\
\hline Exp6 & 0.60 & 0.04 & 0.19 & 0.06 & 0.05 & 0.05 & 0.043 \\
\hline Mean & 0.27 & 0.14 & 0.15 & 0.14 & 0.12 & 0.18 & \\
\hline $\begin{array}{c}\text { Disagreem } \\
\text { ent }\end{array}$ & & & & & & & 0.102 \\
\hline
\end{tabular}

\subsection{Expert Panel 6}

Eight experts in total provided pairwise comparison judgments in expert panel 6.

The distribution of sectors is as follows: 1 from government, 1 from a research lab, 5 from utilities and 1 from a non-governmental organization. Please refer to Table 47 for experts' profiles. Experts in Expert Panel 6 gave judgments on two steps: $6 a$ and $6 \mathrm{~b}$. The first task for Expert Panel 6 (6a) was to evaluate relative priorities for policy targets with respect to the Technical System Development perspective and the second task (6b) was to evaluate relative priorities for the alternatives with respect to the Technical policy targets. 
Table 47: expert panel 6 experts' profiles

\begin{tabular}{|c|c|c|}
\hline Expert & Affiliation & Sector \\
\hline Exp1 & Eugene Water \& Electric & Utilities \\
\hline Exp2 & Bonneville Power Administration & Utilities \\
\hline Exp3 & Oregon Department of Energy & Government \\
\hline Exp4 & Bonneville Power Administration & Utilities \\
\hline Exp5 & Energy Trust of Oregon & NGO \\
\hline Exp6 & Portland General Electric & Utilities \\
\hline Exp7 & Pacific Northwest National Laboratory & Research lab \\
\hline Exp8 & Bonneville Power Administration & Utilities \\
\hline
\end{tabular}

\subsubsection{Expert Panel 6a Results}

Expert panel 6a was asked to evaluate the relative importance of four policy targets with respect to Technical perspective (Technical System Development). There were eight experts in Expert Panel 6. The arithmetic mean of experts' judgments for the relative importance of considered policy targets are shown in Figure 33 below.

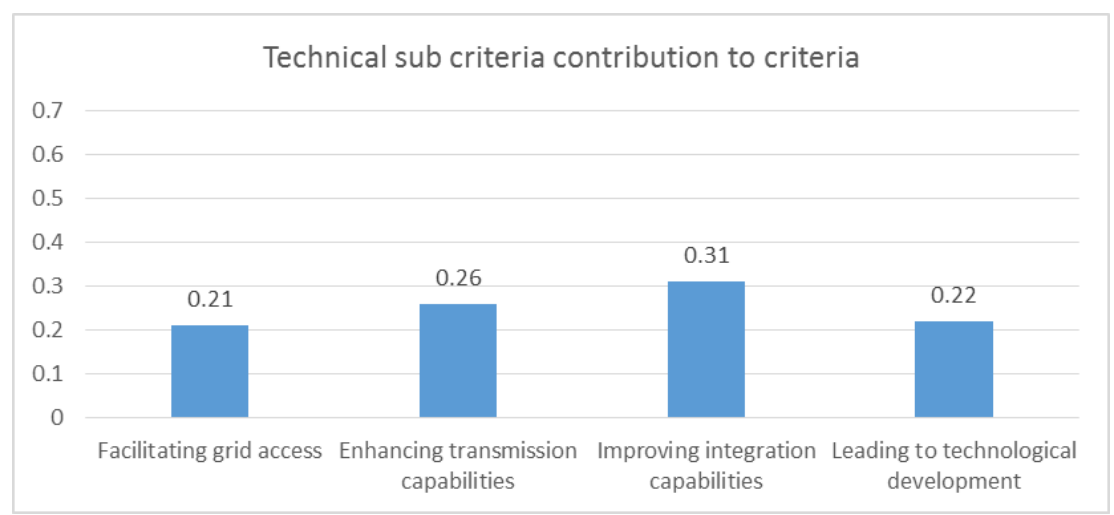

Figure 33: Relative Importance of Regulatory Policy targets to Technical System Development 
According to the results, Improving Integration Capabilities was the most important policy targets with respect to Technical System Development (31\%).

Enhancing Transmission Capabilities was second (26\%), while Leading Technological Development (22\%) and Facilitating Grid Access (21\%) were almost equally important and ranked last.

\subsubsection{Analysis of Expert Panel 6a Results}

Individual results of the relative importance and the mean of eight experts from expert panel 6a are presented in Table 48 below. Looking at expert panel 6a results, all of the experts reflect an acceptable level of consistency in their judgments $(<0.1)$. There was a level of disagreement among the experts $(0.155)$.

Table 48: analysis of expert panel 6a results, technical policy targets with respect to perspective

\begin{tabular}{|c|c|c|c|c|c|}
\hline Expert & $\begin{array}{c}\text { Facilitating } \\
\text { Grid Access }\end{array}$ & $\begin{array}{c}\text { Enhancing } \\
\text { Transmission } \\
\text { Capabilities }\end{array}$ & $\begin{array}{c}\text { Improving } \\
\text { Integration } \\
\text { Capabilities }\end{array}$ & $\begin{array}{c}\text { Leading to } \\
\text { Technological } \\
\text { Development }\end{array}$ & Inconsistency \\
\hline Exp1 & 0.06 & 0.07 & 0.13 & 0.74 & 0.017 \\
\hline Exp2 & 0.17 & 0.33 & 0.36 & 0.13 & 0.009 \\
\hline Exp3 & 0.19 & 0.29 & 0.36 & 0.16 & 0.018 \\
\hline Exp4 & 0.08 & 0.55 & 0.19 & 0.18 & 0.041 \\
\hline Exp5 & 0.28 & 0.16 & 0.39 & 0.17 & 0.035 \\
\hline Exp6 & 0.41 & 0.18 & 0.27 & 0.14 & 0.000 \\
\hline Exp7 & 0.14 & 0.35 & 0.38 & 0.13 & 0.026 \\
\hline Exp8 & 0.36 & 0.11 & 0.42 & 0.11 & 0.002 \\
\hline Mean & 0.21 & 0.26 & 0.31 & 0.22 & \\
\hline Disagreement & & & & & 0.155 \\
\hline
\end{tabular}


Agglomerative Hierarchical Clustering analysis (AHC) was conducted to identify subgroups within expert panel 6a. Four subgroups within Expert Panel 6a were identified: subgroups A, B, C and D. Please see Figure 34 below for details.

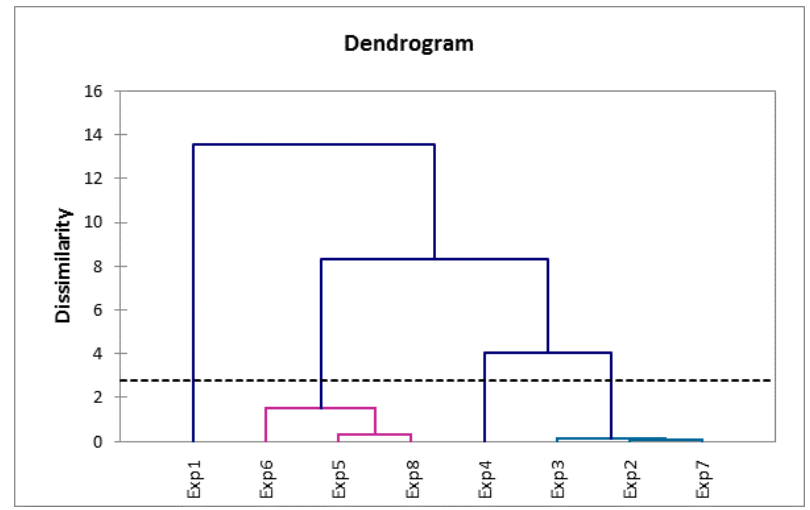

Figure 34: subgroups in expert panel 6a using dendrogram

Group disagreement indices were calculated for the new subgroups in expert panel 6a and are shown in Table 49, Table 50, Table 51, and Table 52 below.

Table 49: analysis of subgroup A results in expert panel 6a

\begin{tabular}{|c|c|c|c|c|c|}
\hline Expert & $\begin{array}{c}\text { Facilitating } \\
\text { Grid Access }\end{array}$ & $\begin{array}{c}\text { Enhancing } \\
\text { Transmission } \\
\text { Capabilities }\end{array}$ & $\begin{array}{c}\text { Improving } \\
\text { Integration } \\
\text { Capabilities }\end{array}$ & $\begin{array}{c}\text { Leading to } \\
\text { Technological } \\
\text { Development }\end{array}$ & Inconsistency \\
\hline Exp1 & 0.06 & 0.07 & 0.13 & 0.74 & 0.017 \\
\hline Mean & 0.06 & 0.07 & 0.13 & 0.74 & \\
\hline Disagreement & & & & & \\
\hline
\end{tabular}

Subgroup A consists of one expert. The relative priority of the variables in this subgroup is not the same as in the original panel. The expert in this group identified Leading to Technological Development (0.74) as the most important policy targets by far, 
and Facilitating Grid Access was the lowest policy targets as the original panel. The expert's background is from Utilities.

Table 50: analysis of subgroup B results in expert panel 6a

\begin{tabular}{|c|c|c|c|c|c|}
\hline Expert & $\begin{array}{c}\text { Facilitating } \\
\text { Grid Access }\end{array}$ & $\begin{array}{c}\text { Enhancing } \\
\text { Transmission } \\
\text { Capabilities }\end{array}$ & $\begin{array}{c}\text { Improving } \\
\text { Integration } \\
\text { Capabilities }\end{array}$ & $\begin{array}{c}\text { Leading to } \\
\text { Technological } \\
\text { Development }\end{array}$ & Inconsistency \\
\hline Exp5 & 0.28 & 0.16 & 0.39 & 0.17 & 0.035 \\
\hline Exp6 & 0.41 & 0.18 & 0.27 & 0.14 & 0.000 \\
\hline Exp8 & 0.36 & 0.11 & 0.42 & 0.11 & 0.002 \\
\hline Mean & 0.35 & 0.15 & 0.36 & 0.14 & \\
\hline Disagreement & & & & & 0.057 \\
\hline
\end{tabular}

Subgroup B consists of three experts. Experts in this subgroup agreed with the original panel that Improving Integration Capabilities was the most important policy targets (0.36). Two of three experts in this subgroup were from utilities and one was from NGO. After the grouping, the disagreement level was reduced to 0.057.

Table 51: analysis of subgroup $\mathrm{C}$ results in expert panel $6 \mathrm{a}$

\begin{tabular}{|c|c|c|c|c|c|}
\hline Expert & $\begin{array}{c}\text { Facilitating } \\
\text { Grid Access }\end{array}$ & $\begin{array}{c}\text { Enhancing } \\
\text { Transmission } \\
\text { Capabilities }\end{array}$ & $\begin{array}{c}\text { Improving } \\
\text { Integration } \\
\text { Capabilities }\end{array}$ & $\begin{array}{c}\text { Leading to } \\
\text { Technological } \\
\text { Development }\end{array}$ & Inconsistency \\
\hline Exp4 & 0.08 & 0.55 & 0.19 & 0.18 & 0.041 \\
\hline Mean & 0.08 & 0.55 & 0.19 & 0.18 & \\
\hline Disagreement & & & & & \\
\hline
\end{tabular}

Subgroup C consists of one expert. The expert in this subgroup scored Enhancing Transmission Capabilities as the most important sub-criterion (0.55) but agreed with the original panel that the two least important policy targets were Facilitating Grid Access and Leading to Technological Development. The expert's background is from utilities. 
Table 52: analysis of subgroup D results in expert panel 6a

\begin{tabular}{|c|c|c|c|c|c|}
\hline Expert & $\begin{array}{c}\text { Facilitating } \\
\text { Grid Access }\end{array}$ & $\begin{array}{c}\text { Enhancing } \\
\text { Transmission } \\
\text { Capabilities }\end{array}$ & $\begin{array}{c}\text { Improving } \\
\text { Integration } \\
\text { Capabilities }\end{array}$ & $\begin{array}{c}\text { Leading to } \\
\text { Technological } \\
\text { Development }\end{array}$ & Inconsistency \\
\hline Exp2 & 0.17 & 0.33 & 0.36 & 0.13 & 0.009 \\
\hline Exp3 & 0.19 & 0.29 & 0.36 & 0.16 & 0.018 \\
\hline Exp7 & 0.14 & 0.35 & 0.38 & 0.13 & 0.026 \\
\hline Mean & 0.17 & 0.33 & 0.37 & 0.14 & \\
\hline Disagreement & & & & & 0.022 \\
\hline
\end{tabular}

Subgroup D consists of three experts. The relative priority of the variables in this subgroup is almost the same as the original panel where they agreed that Improving Integration Capabilities and Enhancing Transmission Capabilities were the two most important policy targets ( 0.37 and 0.33 respectively). There is no specific categorization of subgroup D; based on their backgrounds, these experts are from government, NGO and utilities. After the grouping, the disagreement level was reduced to 0.022 .

\subsubsection{Expert Panel 6b Results}

Expert Panel 6b was asked to evaluate the relative importance of policy alternatives with respect to the four technical policy targets. The arithmetic means of experts' judgments for the relative importance of considered alternatives are shown in Figure 35, Figure 36, Figure 37, and Figure 38 below. 


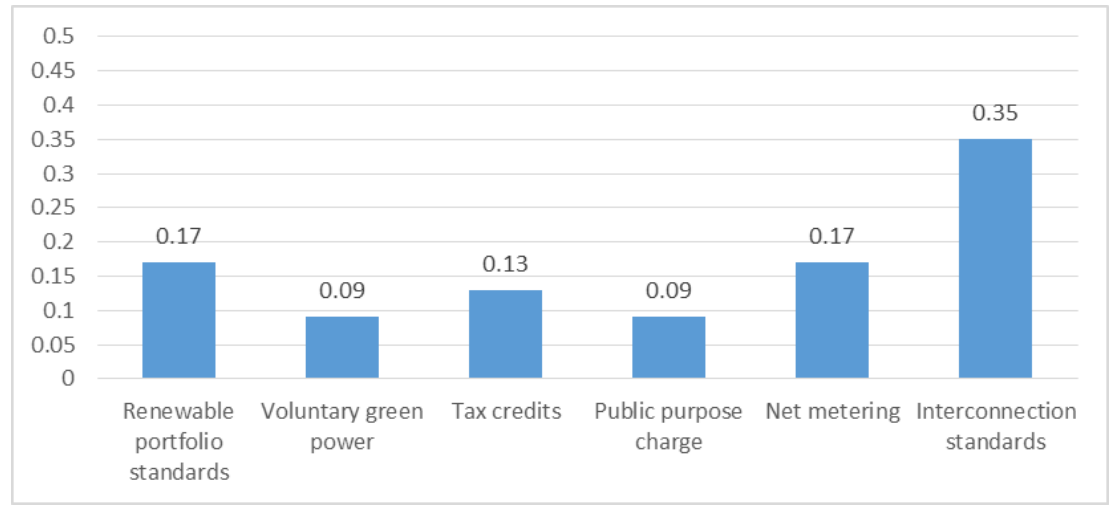

Figure 35: relative importance of decision alternatives with respect to facilitating grid access

According to the results, Interconnection Standards was the most important policy with respect to Facilitating Grid Access (35\%). Net Metering and Renewable Portfolio Standards were equally important (17\%). Tax Credits ranked the fourth important (13\%), followed by Public Purpose Charge and Voluntary Green Power which were also equally important (9\%).

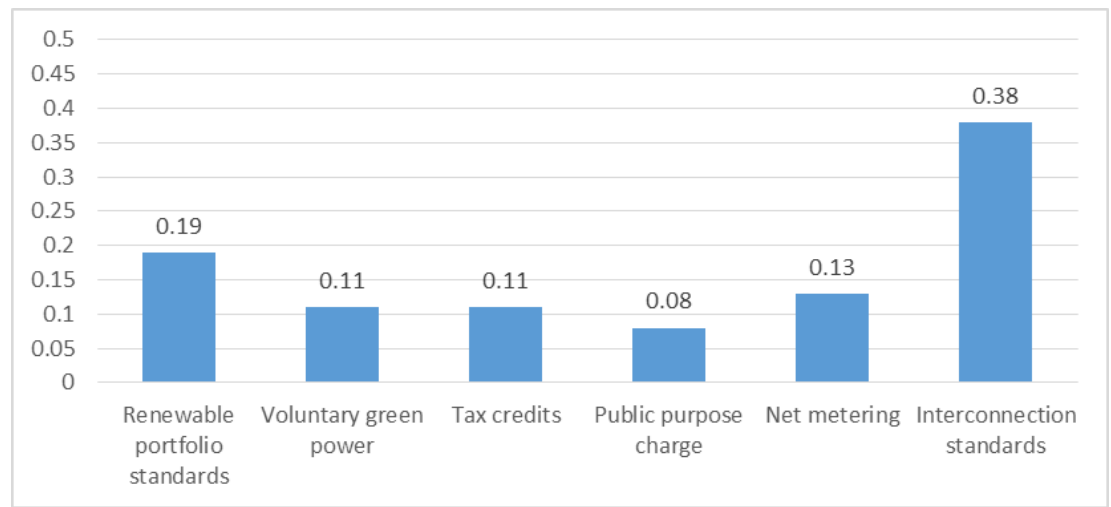

Figure 36: relative importance of decision alternatives with respect to enhancing transmission capabilities 
According to the results, Interconnection Standards scored the highest with respect to Enhancing Transmission Capabilities (38\%), followed by Renewable Portfolio Standards (19\%). Net Metering was the third important (13\%) while both Tax Credits and Voluntary Green Power were equally important (11\%). Public Purpose Charge was the least important, and was the ranked sixth $(8 \%)$.

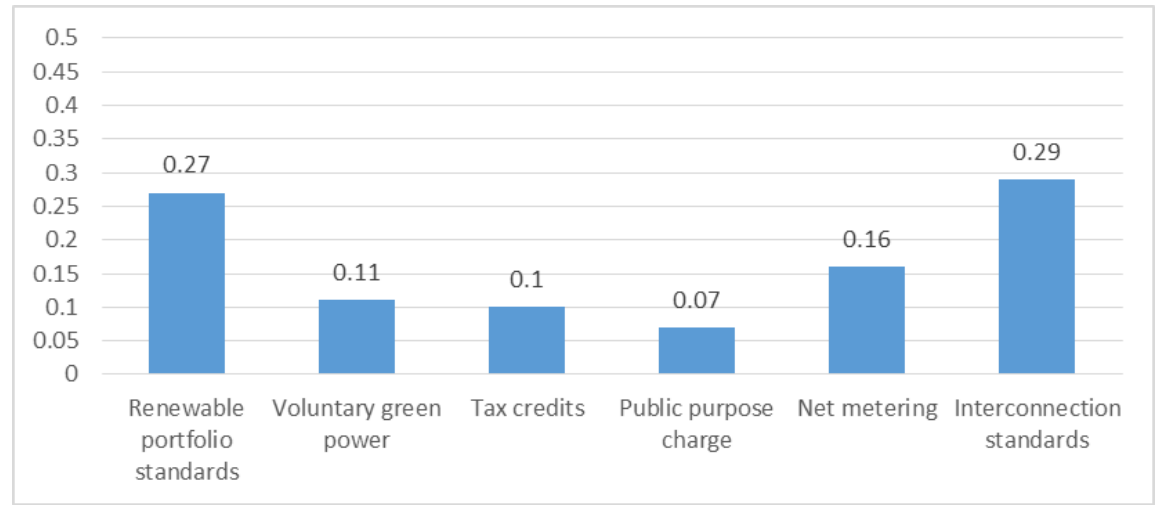

Figure 37: relative importance of decision alternatives with respect to improving integration capabilities

According to the results, and very similar to the enhancing transmission capabilities policy targets, Interconnection Standards was the most important with respect to Improving Integration Capabilities (29\%). It was followed by Renewable Portfolio Standards (27\%). Net Metering was ranked third (16\%) and Tax Credits was fourth in importance (10\%). The least important alternative was Public Purpose Charge (7\%). 


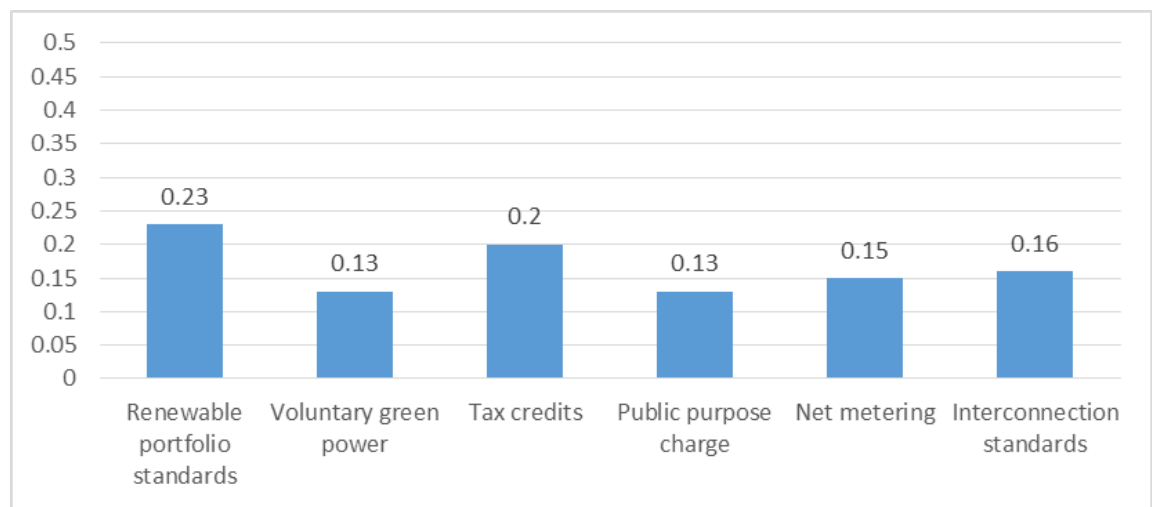

Figure 38: relative importance of decision alternatives with respect to leading to technological development

Renewable Portfolio Standards was the most important alternative (23\%) with respect to the Leading to Technological Development policy targets. Tax Credits policy was close and ranked second (20\%). All other alternatives: Interconnection Standards, Net Metering, Public Purpose Charge, and Voluntary Green Power were almost equally important with relative importance of $16 \%, 15 \%, 13 \%$, and $13 \%$ respectively.

\subsubsection{Analysis of Expert Panel 6b Results}

Individual results of the relative importance and the mean of eight experts from expert panel $6 \mathrm{~b}$ are presented in Table 53, Table 54, Table 55 and Table 60. Looking at expert panel $6 \mathrm{~b}$ results, all of the experts reflect an acceptable level of consistency in their judgments $(<0.1)$. There is also no significant level of disagreement among the experts in most result tables $(0.099,0.101$, and 0.079$)$ but there was a level of disagreement among the experts in Table $55(0.200)$. 
Table 53: analysis of expert panel $6 \mathrm{~b}$ results, decision alternatives with respect to facilitating grid access

\begin{tabular}{|c|c|c|c|c|c|c|c|}
\hline Expert & $\begin{array}{c}\text { Renewabl } \\
\text { e Portfolio } \\
\text { Standards }\end{array}$ & $\begin{array}{c}\text { Voluntary } \\
\text { Green } \\
\text { Power }\end{array}$ & $\begin{array}{c}\text { Tax } \\
\text { Credits }\end{array}$ & $\begin{array}{c}\text { Public } \\
\text { Purpose } \\
\text { Charge }\end{array}$ & $\begin{array}{c}\text { Net } \\
\text { Metering }\end{array}$ & $\begin{array}{c}\text { Interconn } \\
\text { ection } \\
\text { Standards }\end{array}$ & $\begin{array}{c}\text { Inconsiste } \\
\text { ncy }\end{array}$ \\
\hline Exp1 & 0.07 & 0.20 & 0.13 & 0.11 & 0.23 & 0.25 & 0.010 \\
\hline Exp2 & 0.19 & 0.10 & 0.25 & 0.11 & 0.10 & 0.24 & 0.036 \\
\hline Exp3 & 0.21 & 0.14 & 0.24 & 0.13 & 0.09 & 0.19 & 0.042 \\
\hline Exp4 & 0.27 & 0.03 & 0.10 & 0.15 & 0.06 & 0.36 & 0.105 \\
\hline Exp5 & 0.03 & 0.04 & 0.10 & 0.13 & 0.35 & 0.35 & 0.089 \\
\hline Exp6 & 0.13 & 0.09 & 0.08 & 0.01 & 0.02 & 0.66 & 0.105 \\
\hline Exp7 & 0.26 & 0.10 & 0.04 & 0.03 & 0.32 & 0.26 & 0.058 \\
\hline Exp8 & 0.17 & 0.03 & 0.06 & 0.05 & 0.21 & 0.48 & 0.104 \\
\hline Mean & 0.17 & 0.09 & 0.13 & 0.09 & 0.17 & 0.35 & \\
\hline $\begin{array}{c}\text { Disagreem } \\
\text { ent }\end{array}$ & & & & & & & 0.099 \\
\hline
\end{tabular}

Table 54: analysis of expert panel $6 \mathrm{~b}$ results, decision alternatives with respect to enhancing transmission capabilities

\begin{tabular}{|c|c|c|c|c|c|c|c|}
\hline Expert & $\begin{array}{c}\text { Renewabl } \\
\text { e Portfolio } \\
\text { Standards }\end{array}$ & $\begin{array}{c}\text { Voluntary } \\
\text { Green } \\
\text { Power }\end{array}$ & $\begin{array}{c}\text { Tax } \\
\text { Credits }\end{array}$ & $\begin{array}{c}\text { Public } \\
\text { Purpose } \\
\text { Charge }\end{array}$ & $\begin{array}{c}\text { Net } \\
\text { Metering }\end{array}$ & $\begin{array}{c}\text { Interconn } \\
\text { ection } \\
\text { Standards }\end{array}$ & $\begin{array}{c}\text { Inconsiste } \\
\text { ncy }\end{array}$ \\
\hline Exp1 & 0.10 & 0.18 & 0.15 & 0.10 & 0.24 & 0.24 & 0.004 \\
\hline Exp2 & 0.06 & 0.07 & 0.07 & 0.07 & 0.08 & 0.64 & 0.006 \\
\hline Exp3 & 0.12 & 0.14 & 0.12 & 0.12 & 0.13 & 0.38 & 0.027 \\
\hline Exp4 & 0.15 & 0.03 & 0.07 & 0.19 & 0.07 & 0.50 & 0.106 \\
\hline Exp5 & 0.31 & 0.12 & 0.04 & 0.06 & 0.14 & 0.22 & 0.103 \\
\hline Exp6 & 0.25 & 0.19 & 0.29 & 0.03 & 0.04 & 0.19 & 0.070 \\
\hline Exp7 & 0.42 & 0.10 & 0.03 & 0.03 & 0.19 & 0.23 & 0.110 \\
\hline Exp8 & 0.12 & 0.02 & 0.14 & 0.02 & 0.19 & 0.52 & 0.039 \\
\hline Mean & 0.19 & 0.11 & 0.11 & 0.08 & 0.13 & 0.38 & \\
\hline $\begin{array}{c}\text { Disagreem } \\
\text { ent }\end{array}$ & & & & & & & 0.101 \\
\hline
\end{tabular}

Table 55: analysis of expert panel $6 \mathrm{~b}$ results, decision alternatives with respect to improving integration capabilities

\begin{tabular}{|c|c|c|c|c|c|c|c|}
\hline Expert & $\begin{array}{c}\text { Renewabl } \\
\text { e Portfolio } \\
\text { Standards }\end{array}$ & $\begin{array}{c}\text { Voluntary } \\
\text { Green } \\
\text { Power }\end{array}$ & $\begin{array}{c}\text { Tax } \\
\text { credits }\end{array}$ & $\begin{array}{c}\text { Public } \\
\text { Purpose } \\
\text { Charge }\end{array}$ & $\begin{array}{c}\text { Net } \\
\text { Metering }\end{array}$ & $\begin{array}{c}\text { Interconn } \\
\text { ection } \\
\text { Standards }\end{array}$ & $\begin{array}{c}\text { Inconsiste } \\
\text { ncy }\end{array}$ \\
\hline Exp1 & 0.09 & 0.18 & 0.13 & 0.10 & 0.25 & 0.25 & 0.010 \\
\hline
\end{tabular}




\begin{tabular}{|c|c|c|c|c|c|c|c|}
\hline Exp2 & 0.07 & 0.11 & 0.05 & 0.07 & 0.07 & 0.63 & 0.034 \\
\hline Exp3 & 0.11 & 0.16 & 0.11 & 0.08 & 0.16 & 0.39 & 0.025 \\
\hline Exp4 & 0.39 & 0.08 & 0.06 & 0.14 & 0.12 & 0.21 & 0.102 \\
\hline Exp5 & 0.72 & 0.02 & 0.01 & 0.05 & 0.09 & 0.11 & 0.051 \\
\hline Exp6 & 0.25 & 0.25 & 0.30 & 0.03 & 0.05 & 0.13 & 0.082 \\
\hline Exp7 & 0.37 & 0.08 & 0.05 & 0.03 & 0.28 & 0.19 & 0.099 \\
\hline Exp8 & 0.18 & 0.03 & 0.09 & 0.03 & 0.24 & 0.43 & 0.044 \\
\hline Mean & 0.27 & 0.11 & 0.10 & 0.07 & 0.16 & 0.29 & \\
\hline $\begin{array}{c}\text { Disagreem } \\
\text { ent }\end{array}$ & & & & & & 0.131 \\
\hline
\end{tabular}

Agglomerative Hierarchical Clustering analysis (AHC) was conducted to identify subgroups within Expert Panel $6 \mathrm{~b}$-Improving Integration Capabilities. Four subgroups within expert panel 6b - Improving Integration Capabilities were identified, Subgroups A, B, C and D. Please see Figure 39 below for details.

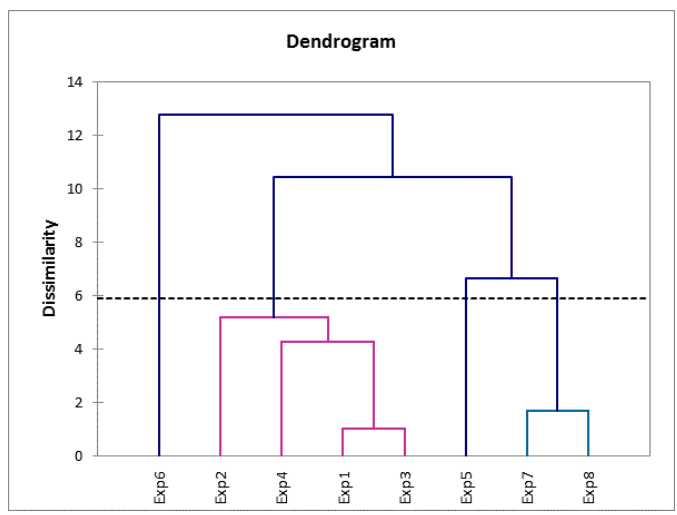

Figure 39: subgroups in expert panel $6 \mathrm{~b}$ - improving integration capabilities using dendrogram Group disagreement indices were calculated for the new subgroups in Expert

Panel 6b - Improving Integration Capabilities, and are shown in Table 49, Table 50, Table 51 and Table 52 below. 
Table 56: analysis of subgroup A results in expert panel $6 \mathrm{~b}$ - improving integration capabilities

\begin{tabular}{|c|c|c|c|c|c|c|c|}
\hline Expert & $\begin{array}{c}\text { Renewabl } \\
\text { e Portfolio } \\
\text { Standards }\end{array}$ & $\begin{array}{c}\text { Voluntary } \\
\text { Green } \\
\text { Power }\end{array}$ & $\begin{array}{c}\text { Tax } \\
\text { Credits }\end{array}$ & $\begin{array}{c}\text { Public } \\
\text { Purpose } \\
\text { Charge }\end{array}$ & $\begin{array}{c}\text { Net } \\
\text { Metering }\end{array}$ & $\begin{array}{c}\text { Interconn } \\
\text { ection } \\
\text { Standards }\end{array}$ & $\begin{array}{c}\text { Inconsiste } \\
\text { ncy }\end{array}$ \\
\hline Exp6 & 0.25 & 0.25 & 0.30 & 0.03 & 0.05 & 0.13 & 0.082 \\
\hline Mean & 0.25 & 0.25 & 0.30 & 0.03 & 0.05 & 0.13 & \\
\hline $\begin{array}{c}\text { Disagreem } \\
\text { ent }\end{array}$ & & & & & & & \\
\hline
\end{tabular}

Subgroup A consists of one expert. The relative priority of the variables in this subgroup is not the same as in the original panel. The expert in this group identified tax credits $(0.3)$ as the most effective policy to improve integration capabilities followed by Renewable Portfolio Standards and Voluntary Green Power (both equally 0.25). The expert's background is from utilities.

Table 57: analysis of subgroup B results in expert panel $6 \mathrm{~b} /$ improving integration capabilities.

\begin{tabular}{|c|c|c|c|c|c|c|c|}
\hline Expert & $\begin{array}{c}\text { Renewabl } \\
\text { e Portfolio } \\
\text { Standards }\end{array}$ & $\begin{array}{c}\text { Voluntary } \\
\text { Green } \\
\text { Power }\end{array}$ & $\begin{array}{c}\text { Tax } \\
\text { Credits }\end{array}$ & $\begin{array}{c}\text { Public } \\
\text { Purpose } \\
\text { Charge }\end{array}$ & $\begin{array}{c}\text { Net } \\
\text { Metering }\end{array}$ & $\begin{array}{c}\text { Interconn } \\
\text { ection } \\
\text { Standards }\end{array}$ & $\begin{array}{c}\text { Inconsiste } \\
\text { ncy }\end{array}$ \\
\hline Exp1 & 0.09 & 0.18 & 0.13 & 0.10 & 0.25 & 0.25 & 0.010 \\
\hline Exp2 & 0.07 & 0.11 & 0.05 & 0.07 & 0.07 & 0.63 & 0.034 \\
\hline Exp3 & 0.11 & 0.16 & 0.11 & 0.08 & 0.16 & 0.39 & 0.025 \\
\hline Exp4 & 0.39 & 0.08 & 0.06 & 0.14 & 0.12 & 0.21 & 0.102 \\
\hline Mean & 0.17 & 0.13 & 0.09 & 0.10 & 0.15 & 0.37 & \\
\hline $\begin{array}{c}\text { Disagreem } \\
\text { ent }\end{array}$ & & & & & & & 0.107 \\
\hline
\end{tabular}

Subgroup B consists of four experts. These experts agreed with the original panel that Interconnection Standards was the most important policy $(0.37)$ followed by Renewable Portfolio Standards (0.17). Based on their backgrounds, three of these experts are from utilities and is one from the government sector. After the grouping, the 
disagreement level was reduced to 0.107 . Although it is still higher than the acceptable threshold, the subgrouping is accepted since the disagreement was reduced significantly.

Table 58: analysis of subgroup $\mathrm{C}$ results in expert panel $6 \mathrm{~b}$ - improving integration capabilities

\begin{tabular}{|c|c|c|c|c|c|c|c|}
\hline Expert & $\begin{array}{c}\text { Renewabl } \\
\text { e Portfolio } \\
\text { Standards }\end{array}$ & $\begin{array}{c}\text { Voluntary } \\
\text { Green } \\
\text { Power }\end{array}$ & $\begin{array}{c}\text { Tax } \\
\text { Credits }\end{array}$ & $\begin{array}{c}\text { Public } \\
\text { Purpose } \\
\text { Charge }\end{array}$ & $\begin{array}{c}\text { Net } \\
\text { Metering }\end{array}$ & $\begin{array}{c}\text { Interconn } \\
\text { ection } \\
\text { Standards }\end{array}$ & $\begin{array}{c}\text { Inconsiste } \\
\text { ncy }\end{array}$ \\
\hline Exp5 & 0.72 & 0.02 & 0.01 & 0.05 & 0.09 & 0.11 & 0.051 \\
\hline Mean & 0.72 & 0.02 & 0.01 & 0.05 & 0.09 & 0.11 & \\
\hline $\begin{array}{c}\text { Disagreem } \\
\text { ent }\end{array}$ & & & & & & \\
\hline
\end{tabular}

Subgroup C consists of one expert. The relative priority of the variables in this subgroup is not the same as in the original panel. The expert in this group identified Renewable Portfolio Standards as the most important policy (0.72) but agreed with the original panel that the three policies: Voluntary Green Power, Tax Credits, and Public Purpose Charge were the least important. The expert's background is from NGO.

Table 59: analysis of subgroup D results in expert panel 6b - improving integration capabilities

\begin{tabular}{|c|c|c|c|c|c|c|c|}
\hline Expert & $\begin{array}{c}\text { Renewabl } \\
\text { e Portfolio } \\
\text { Standards }\end{array}$ & $\begin{array}{c}\text { Voluntary } \\
\text { Green } \\
\text { Power }\end{array}$ & $\begin{array}{c}\text { Tax } \\
\text { Credits }\end{array}$ & $\begin{array}{c}\text { Public } \\
\text { Purpose } \\
\text { Charge }\end{array}$ & $\begin{array}{c}\text { Net } \\
\text { Metering }\end{array}$ & $\begin{array}{c}\text { Interconn } \\
\text { ection } \\
\text { Standards }\end{array}$ & $\begin{array}{c}\text { Inconsiste } \\
\text { ncy }\end{array}$ \\
\hline Exp7 & 0.37 & 0.08 & 0.05 & 0.03 & 0.28 & 0.19 & 0.099 \\
\hline Exp8 & 0.18 & 0.03 & 0.09 & 0.03 & 0.24 & 0.43 & 0.044 \\
\hline Mean & 0.27 & 0.06 & 0.07 & 0.03 & 0.26 & 0.31 & \\
\hline $\begin{array}{c}\text { Disagreem } \\
\text { ent }\end{array}$ & & & & & & 0.094 \\
\hline
\end{tabular}

Subgroup D consists of three experts. These experts agreed with the original panel's results and identified that Interconnection Standards was the most important policy (0.31), followed by Renewable Portfolio Standards (0.27), and Net Metering 
(0.26). Based on their backgrounds, one expert was from utilities and one from research labs. After the grouping, the disagreement level was reduced to 0.094 .

Table 60: analysis of expert panel $6 \mathrm{~b}$ results, decision alternatives with respect to leading to technological development

\begin{tabular}{|c|c|c|c|c|c|c|c|}
\hline Expert & $\begin{array}{c}\text { Renewabl } \\
\text { e Portfolio } \\
\text { Standards }\end{array}$ & $\begin{array}{c}\text { Voluntary } \\
\text { Green } \\
\text { Power }\end{array}$ & $\begin{array}{c}\text { Tax } \\
\text { Credits }\end{array}$ & $\begin{array}{c}\text { Public } \\
\text { Purpose } \\
\text { Charge }\end{array}$ & $\begin{array}{c}\text { Net } \\
\text { Metering }\end{array}$ & $\begin{array}{c}\text { Interconn } \\
\text { ection } \\
\text { Standards }\end{array}$ & $\begin{array}{c}\text { Inconsiste } \\
\text { ncy }\end{array}$ \\
\hline Exp1 & 0.10 & 0.17 & 0.18 & 0.10 & 0.22 & 0.22 & 0.010 \\
\hline Exp2 & 0.15 & 0.22 & 0.23 & 0.14 & 0.14 & 0.12 & 0.046 \\
\hline Exp3 & 0.13 & 0.22 & 0.21 & 0.12 & 0.12 & 0.20 & 0.039 \\
\hline Exp4 & 0.21 & 0.05 & 0.22 & 0.25 & 0.02 & 0.25 & 0.087 \\
\hline Exp5 & 0.47 & 0.06 & 0.06 & 0.11 & 0.14 & 0.14 & 0.043 \\
\hline Exp6 & 0.21 & 0.19 & 0.21 & 0.14 & 0.19 & 0.06 & 0.015 \\
\hline Exp7 & 0.31 & 0.07 & 0.17 & 0.08 & 0.13 & 0.25 & 0.115 \\
\hline Exp8 & 0.24 & 0.07 & 0.29 & 0.09 & 0.24 & 0.06 & 0.070 \\
\hline Mean & 0.23 & 0.13 & 0.20 & 0.13 & 0.15 & 0.16 & \\
\hline $\begin{array}{c}\text { Disagreem } \\
\text { ent }\end{array}$ & & & & & & & 0.079 \\
\hline
\end{tabular}

\subsection{Synthesis of Priorities}

Based on panel results, synthesis of priorities is calculated for different levels of the decision hierarchy: the relative priority of assessment perspectives with respect to the mission was analyzed with expert panel 1 results. Other relative priorities that can be decided are the relative contribution of policy targets with respect to the mission, relative importance of policy alternatives with respect to perspectives, and overall importance of policy alternatives with respect to the mission. A detailed calculation matrix and the 
results of the syntheses are presented in Appendix (D)Appendix (D). As demonstrated in the previous sections, some disagreements between experts have been identified in expert panels $2 \mathrm{a}, 4 \mathrm{a}, 6 \mathrm{a}$, and $6 \mathrm{~b}$. These panels were segregated into subgroups to resolve this matter. Analysis of each subgroup in the next section will identify whether or not expert disagreements and regrouping have an effect on the final rankings of policy alternatives. The final rankings of policy alternatives are recalculated based on each subgroup's judgments and compared with the original rankings, which are based on the original panels' responses.

\subsubsection{Relative Importance of Policy targets with Respect to the Mission}

The relative importance of all policy targets, with respect to the mission, is analyzed in this section. This analysis gives more in-depth insight about the details of each criterion and can be useful for policy makers and analysts for future policy planning and objective setting. Priorities for policy targets with respect to the mission are shown in Figure 40 below. 


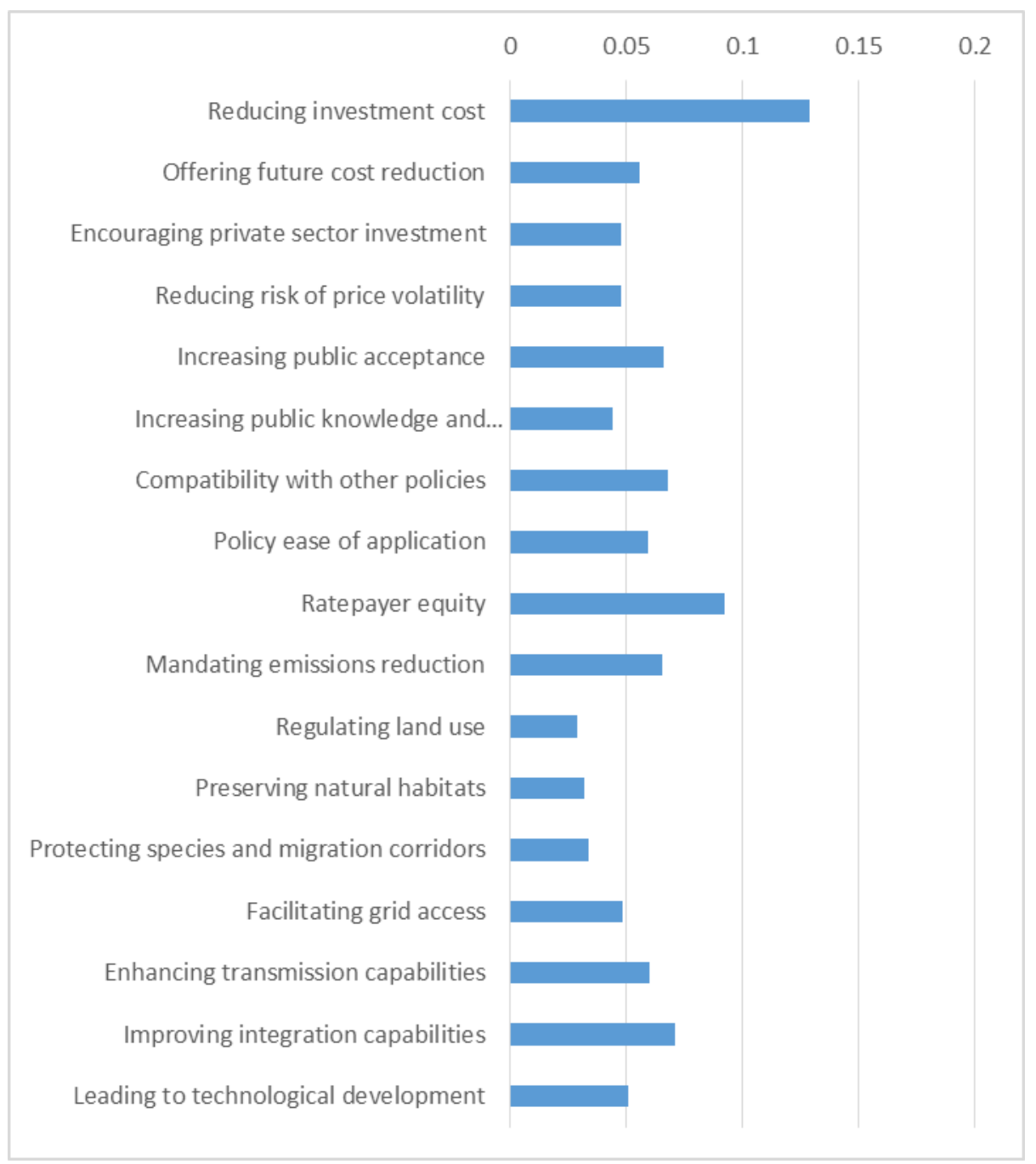

Figure 40: relative importance of policy targets with respect to the mission

Reducing Investment Cost (0.129), Ratepayer Equity (0.092), and Improving Integration Capabilities (0.071) are the highest three weighted sub-factors with respect to the mission. Compatibility with Other Policies, Increasing Public Acceptance, and Mandating Emission Reduction had almost equally weights (0.068, 0.066 and 0.066 respectively). Environmental sub-factors such as: Protecting Species and Migration 
Corridors, Preserving Natural Habitats, and Regulating Land Use are the lowest ranked sub-factors $(0.034,0.032$, and 0.029 respectively). The remaining sub-factors: Enhancing Transmission Capabilities (0.060), Policy Ease of Application (0.059), Offering Future Cost Reductions (0.056), Leading to Technological Development (0.051), Facilitating Grid Access (0.048), Encouraging Private Sector Investment (0.048), Reducing Risk of Price Volatility (0.048), and Increasing Public Knowledge and Awareness (0.044), are of medium importance and have relatively closer weights.

It was noted that Reducing Investment Cost was ranked significantly higher than other policy targets, which confirms the fact that initial capital is still the dominant barrier for wind energy facilities. Ratepayer Equity was the second most important policy targets; this policy targets could include some financial aspects, but from a public, rather than private, perspective. It is obvious that insuring a truly level playing field among utility companies, generating sources owners and customers is important for wind energy sources.

Technical policy targets in general scored relatively high, which emphasized the fact that wind energy has an adoption system that is different from conventional sources and that the region should increase its efforts to overcome this issue. Whereas financial factors were proven to be important, three of the four environmental policy targets were scored as the least important policy targets. This can be justified since the Pacific Northwest region is already environmentally aware and has environmental regulations in 
place, so policy is not as urgently needed to be effective in that area. However,

Mandating Emissions Reductions scored almost as high as Technical policy targets which emphasized the need to adopt new carbon cap policies, such as cap and trade or carbon tax policy.

\subsubsection{Relative Importance of Policy Alternatives with Respect to Perspectives}

The relative importance of policy alternatives with respect to each assessment Perspectives is analyzed in this section. This analysis can be valuable for future policy portfolio planning because it explains the strong points of each policy, which can then be incorporated as feedback for policy makers. Priorities for decision alternatives with respect to the Perspectives are shown in Figure 41, Figure 42, Figure 43, Figure 44, and Figure 45 below.

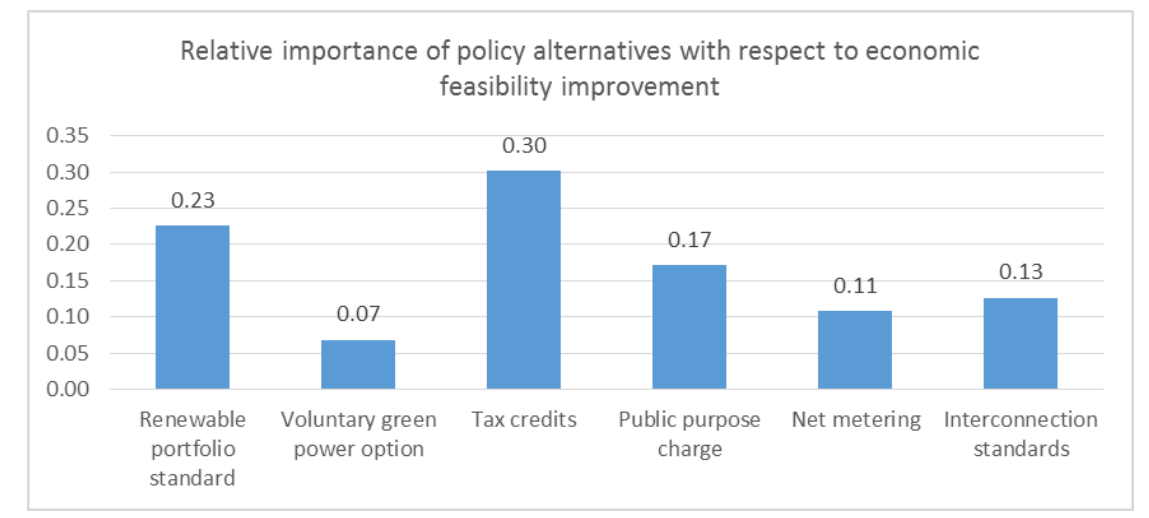

Figure 41: relative importance of policy alternatives with respect to economic feasibility improvement 
According to the results, two policy alternatives have relatively higher weights in terms of their effectiveness on Economic Feasibility Improvement than other policy alternatives. These two policies are Tax Credits (30\%) and Renewable Portfolio Standard (23\%). Voluntary Green Power was ranked the last (7\%) while all other policy alternatives had almost the same relative priority. Since Tax Credits policy is targeted to aid the establishment and operation of wind facilities, it is expected to score the highest in Perspective. On the other hand, Renewable Portfolio Standard is targeted to create the market and need for renewables not to impact Economic Feasibility Improvement. Scoring high in this criterion can be explained by the economy of scale concept. Since power generators are mandated to increase their renewable energy sources share in their portfolio, and because wind is one of the most mature and available technologies in the area, the amount of wind capacity installed is increased, which in turn increases the production, and hence increases the economic feasibility of the project.

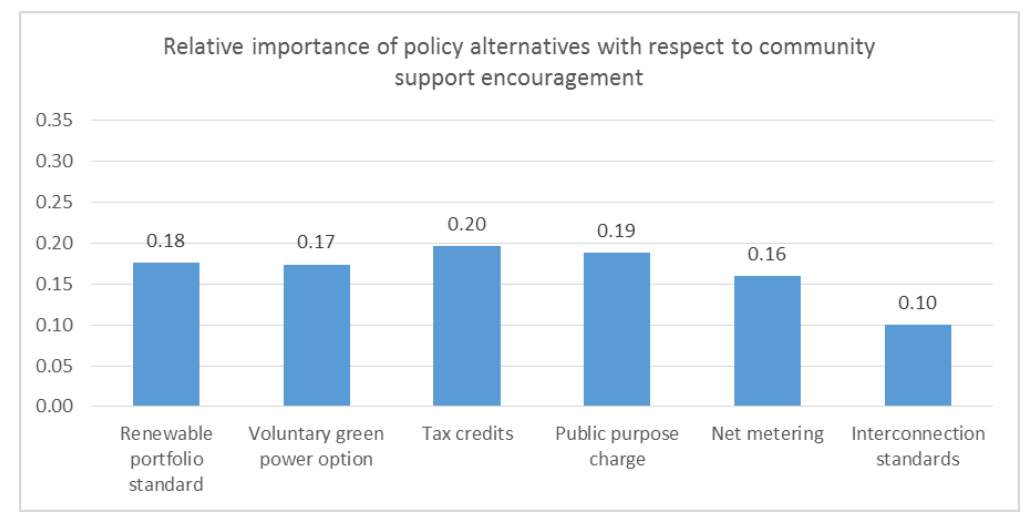

Figure 42: relative importance of policy alternatives with respect to community support encouragement 
According to the results, most of the policy alternatives have relatively close weights in terms of their effectiveness on Community Support Encouragement. Interconnection Standards was ranked the last (10\%). Tax credit was the most important policy in this criterion since it encourages investors and standalone system owners to install and build wind facilities. It is noted that Public Purpose Charge had scored a relatively high importance in this Perspective. This can be explained by the fact that part of the fund is allocated as financial incentives for small-scale and utility-scale projects that generate energy from wind and hydro, and as energy efficiency incentives for improvements to residential buildings and appliances.

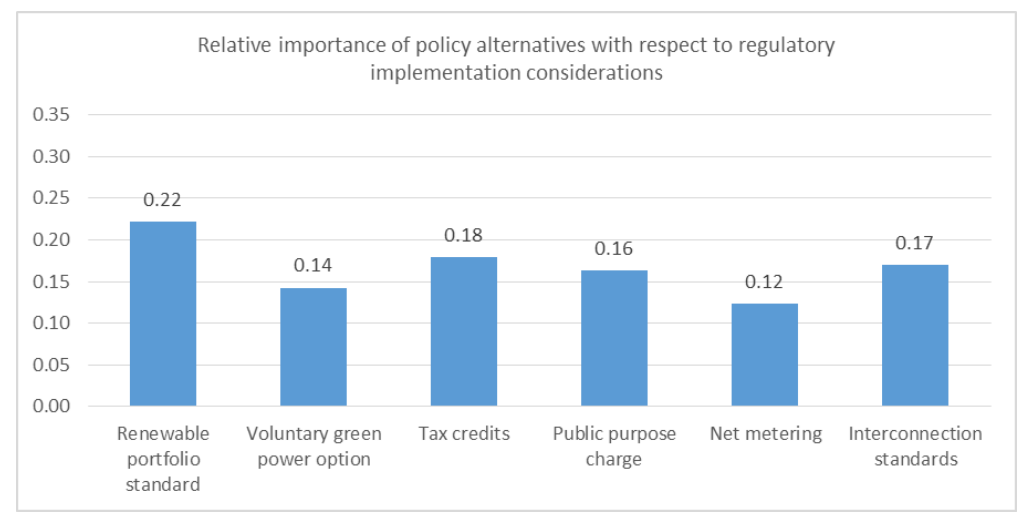

Figure 43: relative importance of policy alternatives with respect to regulatory implementation considerations

According to the results, Renewable Portfolio Standard was ranked the first in terms of Regulatory Considerations (22\%). Tax Credits, Interconnection Standards, and Public Purpose Charge had almost equal priorities (18\%, 17\%, and 16\%, respectively). It can be noticed that the difference in weight between the highest and lowest ranked policy 
is 0.08 which shows that there is no dominant policy with respect to this criterion in general.

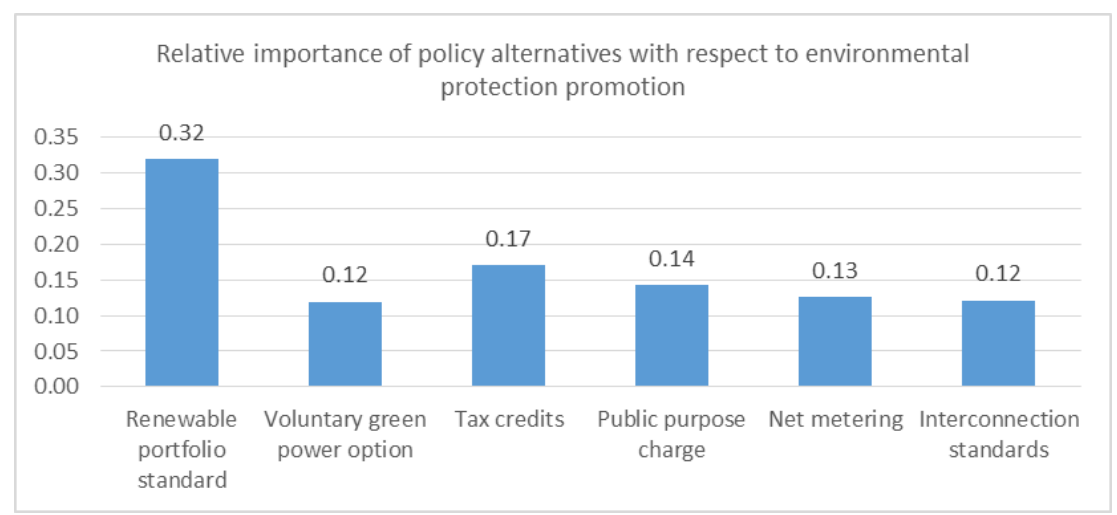

Figure 44: Relative Importance of Policy Alternatives with Respect to Environmental Protection Promotion

According to the results, Renewable Portfolio Standards had the highest priority in terms of its effect on Environmental Protection Promotion (32\%), followed by Tax Credits (17\%). All other decision alternatives were almost equally important. Although Renewable Portfolio Standards is a policy targeted to increase the market share of renewables in the energy portfolio, it is a dominant policy in this criterion as well and scores the highest importance. This can be explained by the fact that since wind energy is a clean source of energy and environmentally friendly, mandating the use of this source will eventually be translated to environmental protection promotion. 


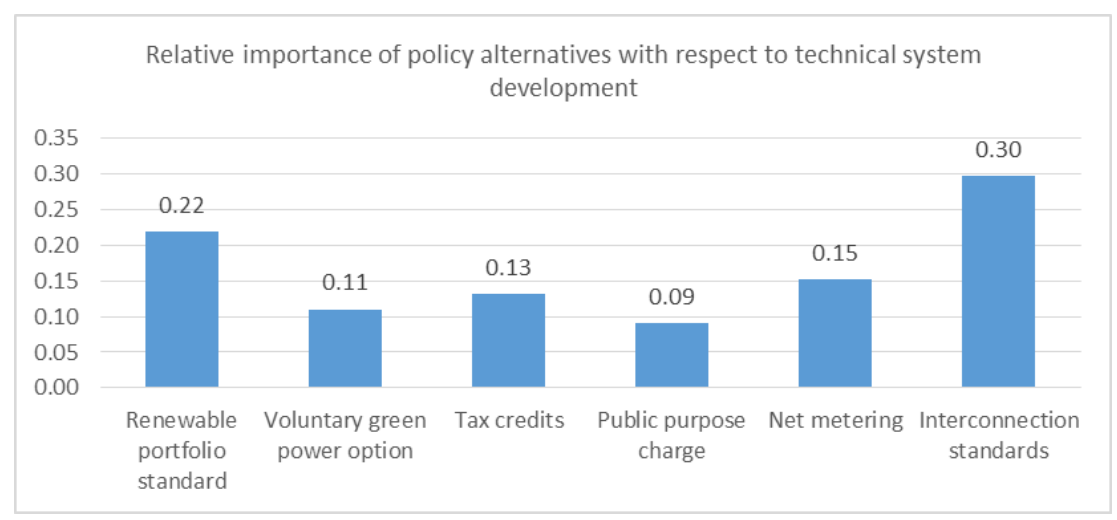

Figure 45: relative importance of policy alternatives with respect to technical system development According to the results, Interconnection Standards was the highest important policy alternative in terms of its effect on Technical System Development (30\%), followed by Renewable Portfolio Standards (22\%). All other decision alternatives were almost equally important. Interconnection Standards is a policy targeted to establish guidelines for connecting wind facilities to the grid, so it was the dominant policy in this criterion. Public Purpose Charge scored the lowest since only around $17 \%$ of the funds are allocated to renewables and those only to fund small projects.

\subsubsection{Overall Importance of Policy Alternatives with Respect to the Mission}

Global priorities of policy alternatives with respect to the mission are presented in this section. This analysis determines the ranking of the decision alternatives and identifies the policy that is most effective in increasing the adoption of renewable energy according to the assessment Perspectives. The overall importance of all policy alternatives with respect to the mission are shown in Figure 46 below. 


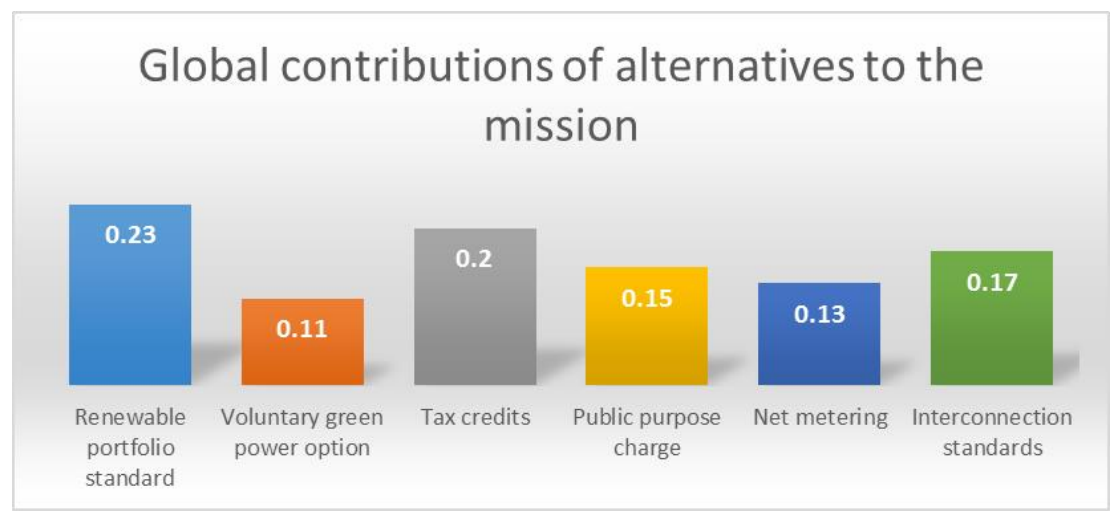

Figure 46: overall importance of policy alternatives with respect to the mission

According to the results, Renewable Portfolio Standards is the leading policy in increasing the adoption of renewable energy in the Pacific Northwest (23\%) and Tax Credits was the second ranked (20\%). Net Metering and Voluntary Green Power were the least important policies (13\% and $11 \%$ respectively).

Renewable Portfolio Standards (RPS) was shown to be the most effective policy in increasing the adoption of wind energy, specifically, in the Pacific Northwest. RPS is an obligatory and enforcing policy which is targeted specifically to increase the share of renewables in the power generation sector and these results show that it is an effective policy. The main purpose of Tax Credits is to financially support investors, however; this policy choice reflected on increasing wind capacity installed which ranked Tax Credits as the second most effective policy in increasing wind adoption. The Voluntary Green Power option is shown to be the least effective policy. This can be explained by the fact that it is a policy that depends on the level of consumer awareness and willingness in purchasing green power, and the interest of utilities in offering green options. 


\subsection{Analysis of Expert Panel Disagreements and Priorities}

The analysis of expert panel results revealed some disagreements in the Panels 2a, 4a, 6a, and 6b - Integration Capabilities. In some cases, disagreement measures was exactly on the border of 0.10 threshold but it was still included as agreement. This was because of the small number of experts in that panel and because the variable evaluated was more of qualitative and relative to opinion rather than quantitative. This section investigates the effect of these disagreements on the overall rankings of policy alternatives. The final rankings of policy alternatives are recalculated based on each subgroup response and compared with the original rankings calculated based on all experts' responses.

\subsubsection{Priorities Analysis with Respect to Expert Panel 2a Disagreement}

As discussed earlier, experts were regrouped according to the proximity of their judgments to reach agreement among them. Table 61 shows the relative contribution of Economic sub-factors with respect to economic Perspective and their rankings for the original panel and the sub-groups for that panel (number in parenthesis is the rank).

Table 61: comparisons of judgments quantification of expert panel 2a before and after grouping

\begin{tabular}{|c|c|c|c|c|}
\hline Experts & $\begin{array}{c}\text { Reduce } \\
\text { Initial } \\
\text { Investment } \\
\text { Cost }\end{array}$ & $\begin{array}{c}\text { Offer Future } \\
\text { Cost } \\
\text { Reductions }\end{array}$ & $\begin{array}{c}\text { Encourage } \\
\text { Private } \\
\text { Sector } \\
\text { Investment }\end{array}$ & $\begin{array}{c}\text { Reduce Risk } \\
\text { of Price } \\
\text { Volatility }\end{array}$ \\
\hline Original panel & $0.46(1)$ & $0.20(2)$ & $0.17(3)$ & $0.17(4)$ \\
\hline Subgroup A & $0.60(1)$ & $0.13(3)$ & $0.14(2)$ & $0.13(4)$ \\
\hline
\end{tabular}




\begin{tabular}{|c|c|c|c|c|}
\hline Subgroup B & $0.27(2)$ & $0.16(4)$ & $0.24(3)$ & $0.32(1)$ \\
\hline Subgroup C & $0.31(2)$ & $0.40(1)$ & $0.18(3)$ & $0.11(4)$ \\
\hline
\end{tabular}

An analysis was conducted to see if the ranking of alternatives with respect to the mission would change if the experts were grouped according to the previous groups.

Table 62 shows the synthesis of priorities and ranking of alternatives with respect to the mission in the case of using of all 16 experts and subgroups.

Table 62: alternatives global ranking with expert panel 2a disagreements

\begin{tabular}{|c|c|c|c|c|c|c|}
\hline Experts & $\begin{array}{c}\text { Renewable } \\
\text { Portfolio } \\
\text { Standard }\end{array}$ & $\begin{array}{c}\text { Green } \\
\text { Power } \\
\text { Option }\end{array}$ & Tax Credits & $\begin{array}{c}\text { Public } \\
\text { Purpose } \\
\text { Charge }\end{array}$ & $\begin{array}{c}\text { Net } \\
\text { Metering }\end{array}$ & $\begin{array}{c}\text { Interconnect } \\
\text { ion } \\
\text { Standards }\end{array}$ \\
\hline $\begin{array}{c}\text { Original } \\
\text { panel }\end{array}$ & 1 & 6 & 2 & 4 & 5 & 3 \\
\hline Subgroup A & 1 & 6 & 2 & 4 & 5 & 3 \\
\hline Subgroup B & 1 & 6 & 2 & 4 & 5 & 3 \\
\hline Subgroup C & 1 & 6 & 2 & 4 & 5 & 3 \\
\hline
\end{tabular}

There are not any changes in the rankings and relative contributions of policy alternatives to the mission when the relative priorities from the three different sub-groups are compared to the original panel. Renewable Portfolio Standards was the first ranked policy alternative when the results from all experts were used and when the results from each individual subgroup of that panel were used.

\subsubsection{Priorities Analysis with Respect to Expert Panel 4a Disagreement}

Expert Panel 4a, which evaluated the relative contribution of Regulatory policy targets to the Regulatory Perspective, also showed some disagreement and the panel was 
regrouped into three subgroups. Table 63 shows the relative contribution of Regulatory sub-factors with respect to Regulatory Perspective and their ranking for the original panel as well as for the subgroups for that panel (number in parenthesis is the rank).

Table 63: expert panel 4a disagreement results

\begin{tabular}{|c|c|c|c|}
\hline Experts & $\begin{array}{c}\text { Compatibility } \\
\text { with Other } \\
\text { Policies }\end{array}$ & $\begin{array}{c}\text { Policy Ease } \\
\text { of } \\
\text { Application }\end{array}$ & $\begin{array}{c}\text { Ratepayer } \\
\text { Equity }\end{array}$ \\
\hline Original panel & $0.31(2)$ & $0.27(3)$ & $0.42(1)$ \\
\hline Subgroup A & $0.15(3)$ & $0.17(2)$ & $0.68(1)$ \\
\hline Subgroup B & $0.26(3)$ & $0.43(1)$ & $0.31(2)$ \\
\hline Subgroup C & $0.59(1)$ & $0.18(3)$ & $0.23(2)$ \\
\hline
\end{tabular}

As before, an analysis was conducted to see if the ranking of alternatives with respect to the mission would change if the experts were grouped according to the previous groups. Table 64 shows the synthesis of priorities and ranking of alternatives with respect to the mission in the case of using all 11 experts and subgroups.

Table 64: alternatives global ranking with expert panel 4a disagreements

\begin{tabular}{|c|c|c|c|c|c|c|}
\hline Experts & $\begin{array}{c}\text { Renewable } \\
\text { portfolio } \\
\text { standard }\end{array}$ & $\begin{array}{c}\text { Green } \\
\text { Power } \\
\text { Option }\end{array}$ & Tax Credits & $\begin{array}{c}\text { Public } \\
\text { Purpose } \\
\text { Charge }\end{array}$ & $\begin{array}{c}\text { Net } \\
\text { Metering }\end{array}$ & $\begin{array}{c}\text { Interconnect } \\
\text { ion } \\
\text { Standards }\end{array}$ \\
\hline $\begin{array}{c}\text { Original } \\
\text { panel }\end{array}$ & 1 & 6 & 2 & 4 & 5 & 3 \\
\hline Subgroup A & 1 & 6 & 2 & 4 & 5 & 3 \\
\hline Subgroup B & 1 & 6 & 2 & 4 & 5 & 3 \\
\hline Subgroup C & 1 & 6 & 2 & 4 & 5 & 3 \\
\hline
\end{tabular}


Analysis of Expert Panel 4a disagreement revealed that there are not any changes in the rankings and relative contributions of policy alternatives to the mission when the relative priorities from the three different sub-groups are compared to the original panel.

\subsubsection{Priorities Analysis with Respect to Expert Panel 6a Disagreement}

Disagreement was also found among experts in Expert Panel 6a who gave their judgments for the relative contribution of Technical policy targets with respect to the Technical Perspective. The original panel was divided into four subgroups. Table 65 shows the mean values of policy targets contributions as well as the rankings of these policy targets with respect to the Perspective (number in parenthesis is the rank).

Table 65: expert panel 6a disagreement results

\begin{tabular}{|c|c|c|c|c|}
\hline Experts & $\begin{array}{c}\text { Facilitating } \\
\text { Grid Access }\end{array}$ & $\begin{array}{c}\text { Enhancing } \\
\text { Transmission } \\
\text { Capabilities }\end{array}$ & $\begin{array}{c}\text { Improving } \\
\text { Integration } \\
\text { Capabilities }\end{array}$ & $\begin{array}{c}\text { Leading to } \\
\text { Technological } \\
\text { Development }\end{array}$ \\
\hline Original panel & $0.21(4)$ & $0.26(2)$ & $0.31(1)$ & $0.22(3)$ \\
\hline Subgroup A & $0.06(4)$ & $0.07(3)$ & $0.13(2)$ & $0.74(1)$ \\
\hline Subgroup B & $0.35(2)$ & $0.15(3)$ & $0.36(1)$ & $0.14(4)$ \\
\hline Subgroup C & $0.08(4)$ & $0.55(1)$ & $0.19(2)$ & $0.18(3)$ \\
\hline Subgroup D & $0.17(3)$ & $0.33(2)$ & $0.37(1)$ & $0.14(4)$ \\
\hline
\end{tabular}

An analysis was conducted to see if the ranking of alternatives with respect to the mission would change if the experts were grouped according to the previous groups. Table 66 shows the synthesis of priorities and ranking of alternatives with respect to the mission when using all eight experts and subgroups. 
Table 66: alternatives global ranking with expert panel 6a disagreements

\begin{tabular}{|c|c|c|c|c|c|c|}
\hline Experts & $\begin{array}{c}\text { Renewable } \\
\text { Portfolio } \\
\text { Standard }\end{array}$ & $\begin{array}{c}\text { Green } \\
\text { Power } \\
\text { Option }\end{array}$ & Tax Credits & $\begin{array}{c}\text { Public } \\
\text { Purpose } \\
\text { Charge }\end{array}$ & $\begin{array}{c}\text { Net } \\
\text { Metering }\end{array}$ & $\begin{array}{c}\text { Interconnect } \\
\text { ion } \\
\text { Standards }\end{array}$ \\
\hline $\begin{array}{c}\text { Original } \\
\text { panel }\end{array}$ & 1 & 6 & 2 & 4 & 5 & 3 \\
\hline Subgroup A & 1 & 6 & 2 & 3 & 5 & 4 \\
\hline Subgroup B & 1 & 6 & 2 & 4 & 5 & 3 \\
\hline Subgroup C & 1 & 6 & 2 & 4 & 5 & 3 \\
\hline Subgroup D & 1 & 6 & 2 & 4 & 5 & 3 \\
\hline
\end{tabular}

Analysis of Expert Panel 6a disagreement revealed that there are no significant changes in the rankings and relative contributions of policy alternatives to the mission when the relative priorities from the four different sub-groups are compared to the original panel.

\subsubsection{Priorities Analysis with Respect to Expert Panel 6b - Integration Capabilities Disagreement}

Expert Panel 6 also showed disagreement in the case of judging the relative importance of the model alternatives with respect to one technical sub-criterion (Improving Integration Capabilities). As discussed earlier, experts were regrouped according to the proximity of their judgments to reach agreement among them. Table 67 shows the relative contribution of each alternative with respect to this policy targets as well as their ranking for the original panel and the subgroups for that panel (number in parenthesis is the rank). 
Table 67: expert panel 6b disagreement results

\begin{tabular}{|c|c|c|c|c|c|c|}
\hline Experts & $\begin{array}{c}\text { Renewable } \\
\text { Portfolio } \\
\text { Standard }\end{array}$ & $\begin{array}{c}\text { Green } \\
\text { Power } \\
\text { Option }\end{array}$ & Tax Credits & $\begin{array}{c}\text { Public } \\
\text { Purpose } \\
\text { Charge }\end{array}$ & $\begin{array}{c}\text { Net } \\
\text { Metering }\end{array}$ & $\begin{array}{c}\text { Interconnect } \\
\text { ion } \\
\text { Standards }\end{array}$ \\
\hline $\begin{array}{c}\text { Original } \\
\text { panel }\end{array}$ & $0.27(2)$ & $0.11(4)$ & $0.10(5)$ & $0.07(6)$ & $0.16(3)$ & $0.29(1)$ \\
\hline Subgroup A & $0.25(2)$ & $0.25(3)$ & $0.30(1)$ & $0.03(6)$ & $0.05(5)$ & $0.13(4)$ \\
\hline Subgroup B & $0.17(2)$ & $0.13(3)$ & $0.09(1)$ & $0.10(6)$ & $0.15(5)$ & $0.37(4)$ \\
\hline Subgroup C & $0.72(1)$ & $0.02(5)$ & $0.01(6)$ & $0.05(4)$ & $0.09(3)$ & $0.11(2)$ \\
\hline Subgroup D & $0.27(2)$ & $0.06(5)$ & $0.07(6)$ & 0.03 & $0.26(3)$ & $0.31(1)$ \\
\hline
\end{tabular}

An analysis was conducted to see if the ranking of alternatives with respect to the mission would change if the experts were grouped according to the previous groups.

Table 68 shows the synthesis of priorities and ranking of alternatives with respect to the mission in the case of using all 16 experts and subgroups.

Table 68: alternatives global ranking with expert panel $6 \mathrm{~b}$ disagreements

\begin{tabular}{|c|c|c|c|c|c|c|}
\hline Experts & $\begin{array}{c}\text { Renewable } \\
\text { Portfolio } \\
\text { Standard }\end{array}$ & $\begin{array}{c}\text { Green } \\
\text { Power } \\
\text { Option }\end{array}$ & Tax Credits & $\begin{array}{c}\text { Public } \\
\text { Purpose } \\
\text { Charge }\end{array}$ & $\begin{array}{c}\text { Net } \\
\text { Metering }\end{array}$ & $\begin{array}{c}\text { Interconnect } \\
\text { ion } \\
\text { Standards }\end{array}$ \\
\hline $\begin{array}{c}\text { Original } \\
\text { panel }\end{array}$ & 1 & 6 & 2 & 4 & 5 & 3 \\
\hline Subgroup A & 1 & 5 & 2 & 4 & 6 & 3 \\
\hline Subgroup B & 1 & 6 & 2 & 4 & 5 & 3 \\
\hline Subgroup C & 1 & 6 & 2 & 4 & 5 & 3 \\
\hline Subgroup D & 1 & 6 & 2 & 4 & 5 & 3 \\
\hline
\end{tabular}

There are not any changes in the rankings and relative contributions of policy alternatives to the mission when the relative priorities from the three different sub-groups are compared to the original panel. Renewable Portfolio Standards was the first ranked 
policy alternative when the results from all experts were used and when the results from each individual subgroup of that panel were used.

The results reveal that policy alternatives under consideration will maintain the current ranking for the majority of the panels and their subgroups, regardless of the significant group disagreements among the experts. That implies that if any sub-group was the decision maker, ranking of alternatives and final decision will not change from the model's original results.

\subsection{Sensitivity Analysis}

Sensitivity analysis is conducted to help with answering the "what if" questions and to anticipate different rankings of decision alternatives with respect to changes in the priorities in decision Perspectives. In this study, Sensitivity Analysis serves as a test tool for measuring the effect of any future changes on the decision alternatives ranking and choices. Two types of sensitivity analysis were conducted which helped to investigate the impact of changes at the policy assessment Perspectives level on the ranking of alternatives. First, sensitivity analysis was utilized at the policy assessment Perspectives level to determine the allowable range of perturbations of Perspectives that will preserve the current ranking of the best alternative. Second, sensitivity analysis was utilized to show the allowable range of perturbations of each assessment Perspectives in order to maintain the current ranking of all alternatives. Sensitivity analyses were conducted using 
the method presented in Section 3.4. Please refer to Table 69 below for the current ranking of decision alternatives.

Table 69: global weights and rankings of policy alternatives with respect to the mission

\begin{tabular}{|c|c|c|}
\hline Policy Alternatives & Global Weights & Rank \\
\hline Renewable Portfolio Standard & 0.23 & 1 \\
\hline Tax Credits & 0.2 & 2 \\
\hline Interconnection Standards & 0.17 & 3 \\
\hline Public Purpose Charge & 0.15 & 4 \\
\hline Net Metering & 0.13 & 5 \\
\hline Voluntary Green Power Option & 0.11 & 6 \\
\hline
\end{tabular}

\subsubsection{HDM SA at the Policy Design Considerations Level to Preserve the Ranking of the Best Alternative}

When concerned with only the current top-ranked policy alternative, sensitivity analysis is explained in chapter three was conducted, and results for allowable range of perturbations, tolerances, and sensitivity coefficients are shown in Table 70 below.

Table 70: HDM SA at the policy assessment perspectives level to preserve the rank of the best alternative

\begin{tabular}{|c|c|c|c|c|c|}
\hline & $\begin{array}{c}\text { Economic } \\
\text { Feasibility } \\
\text { Improvemen } \\
\mathrm{t}\end{array}$ & $\begin{array}{c}\text { Community } \\
\text { Support } \\
\text { Encourageme } \\
\mathrm{nt}\end{array}$ & $\begin{array}{c}\text { Regulatory } \\
\text { Implementatio } \\
\mathrm{n} \\
\text { Considerations }\end{array}$ & $\begin{array}{c}\text { Environment } \\
\text { al Protection } \\
\text { Promotion }\end{array}$ & $\begin{array}{c}\text { Technical } \\
\text { System } \\
\text { Developmen } \\
\mathrm{t}\end{array}$ \\
\hline Base values & 0.28 & 0.11 & 0.22 & 0.16 & 0.23 \\
\hline $\begin{array}{c}\text { Allowable ranges of } \\
\text { perturbations }\end{array}$ & {$[-0.28,0.2]$} & {$[-0.11,0.53]$} & {$[-0.22,0.78]$} & {$[-0.16,0.84]$} & {$[-0.23,0.33]$} \\
\hline Tolerance & {$[0,0.48]$} & {$[0,0.64]$} & {$[0,1]$} & {$[0,1]$} & {$[0,0.56]$} \\
\hline $\begin{array}{c}\text { Sensitivity } \\
\text { coefficient }\end{array}$ & 2.083 & 1.563 & 1.000 & 1.000 & 1.786 \\
\hline
\end{tabular}


From Table 70, we can see that almost all Perspectives have close sensitivity coefficients, but that they are not very sensitive. However, the most critical criterion is the one with the largest value (Economic Feasibility Improvement). Tolerance values show that although the lower limit of this Perspective is not very sensitive and can drop down to zero, the upper limit is very sensitive and it can only reach a value of 0.48 . Any increase beyond this will affect the rank of current best alternative and Renewable Portfolio Standards would no longer be the best alternative. Regulatory Implementation Considerations and Environmental Protection Promotion are considered not critical and their values vary between $0-1$ without affecting the rank of the first alternative. The tolerance ranges for policy assessment Perspectives are: Economic Feasibility Improvement [0, 0.48], Community Support Encouragement [0, 0.64], Regulatory Implementation Consideration [0, 1], Environmental Protection Promotion [0, 1], and Technical System Development $[0,0.56]$. Sensitivity coefficients for all Perspectives revealed that the model is robust and that the first ranked alternative, Renewable portfolio standards, is not sensitive to priority changes.

\subsubsection{HDM SA at the Policy Design Considerations Level to Preserve the Ranking of all Alternatives}

This analysis is used to discover the allowable ranges of perturbations at the assessment Perspectives level that would provide insight into the conditions under which policy alternatives would keep their original rankings. Allowable ranges of perturbations 
introduced to Perspectives level in the HDM model and tolerances are presented in Table 71 below.

Table 71: HDM SA at the assessment perspectives level to preserve the ranking of all alternatives

\begin{tabular}{|c|c|c|c|c|c|}
\hline & $\begin{array}{c}\text { Economic } \\
\text { Feasibility } \\
\text { Improvement }\end{array}$ & $\begin{array}{c}\text { Community } \\
\text { Support } \\
\text { Encouragement }\end{array}$ & $\begin{array}{c}\text { Regulatory } \\
\text { Implementation } \\
\text { Considerations }\end{array}$ & $\begin{array}{c}\text { Environmental } \\
\text { Protection } \\
\text { Promotion }\end{array}$ & $\begin{array}{c}\text { Technical } \\
\text { System } \\
\text { Development }\end{array}$ \\
\hline Base values & 0.28 & 0.11 & 0.22 & 0.16 & 0.23 \\
\hline $\begin{array}{c}\text { Allowable ranges } \\
\text { of perturbations }\end{array}$ & {$[-0.15,0.2]$} & {$[-0.11,0.16]$} & {$[-0.22,0.78]$} & {$[-0.16,0.38]$} & {$[-0.08,0.12]$} \\
\hline Tolerance & {$[0.13,0.48]$} & {$[0,0.27]$} & {$[0,1]$} & {$[0,0.54]$} & {$[0.15,0.35]$} \\
\hline $\begin{array}{c}\text { Sensitivity } \\
\text { coefficient }\end{array}$ & 2.857 & 3.704 & 1.000 & 1.852 & 5.000 \\
\hline
\end{tabular}

From Table 71, we can see that the largest sensitivity coefficient occurs with the Technical System Development criterion, which makes it the most critical assessment criterion to preserve the current ranking of all policy alternatives. Regulatory Implementation Considerations, however, is the least sensitive criterion with sensitivity coefficient of 1.0. If the Technical System Development perspective priority dropped down below 0.15 or went over 0.35 , the rank of all alternatives would change and Renewable Portfolio Standards would not remain the first alternative. The tolerance ranges for policy assessment perspectives are: Economic Feasibility Improvement [0.13, 0.48], Community Support Encouragement [0. 0.38], Regulatory Implementation Consideration [0, 1], Environmental Protection Promotion [0, 0.54], and Technical System Development $[0.15,0.35]$. Out of all the assessment perspectives, Environmental Protection Promotion and Regulatory Implementation Considerations are the least sensitive, whereas the other two perspectives (Economic Feasibility Improvement and 
Community Support Encouragement) have almost the same sensitivity levels. The results indicate that the current ranking order of all decision alternatives is not very sensitive to changes in perspectives level weights but still subject to priority changes. This situation is expected, since the number of decision alternatives is relatively small and all policies have the same final objective: to increase adoption of renewable energy.

\subsubsection{Scenario analysis}

Future scenario analysis was conducted to understand the "what-if scenarios" and determine the effects of changing the relative importance of the assessment perspectives on alternatives' rankings. Extreme weight variations were considered on the perspectives level to determine the change in alternatives ranking. Five cases for sensitivity analysis were considered by assigning one criterion a value of 0.96 and the other perspectives a value of 0.01 each (see Table 72). Each scenario replicates a situation where there is different regional emphasis on perspectives driving the adoption of a new renewable energy source, see Table 73.

Table 72: Perspectives weights in case of extreme variations scenarios

\begin{tabular}{|c|c|c|c|c|c|}
\hline Perspectives & $\begin{array}{c}\text { Economic } \\
\text { Feasibility } \\
\text { Improvement }\end{array}$ & $\begin{array}{c}\text { Community } \\
\text { Support } \\
\text { Encouragement }\end{array}$ & $\begin{array}{c}\text { Regulatory } \\
\text { Implementatio } \\
\mathrm{n} \\
\text { Considerations }\end{array}$ & $\begin{array}{c}\text { Environmental } \\
\text { Protection } \\
\text { Promotion }\end{array}$ & $\begin{array}{c}\text { Technical } \\
\text { System } \\
\text { Development }\end{array}$ \\
\hline Contribution & 0.28 & 0.11 & 0.22 & 0.16 & 0.23 \\
\hline Scenario 1 & 0.96 & 0.01 & 0.01 & 0.01 & 0.01 \\
\hline Scenario 2 & 0.01 & 0.96 & 0.01 & 0.01 & 0.01 \\
\hline Scenario 3 & 0.01 & 0.01 & 0.96 & 0.01 & 0.01 \\
\hline Scenario 4 & 0.01 & 0.01 & 0.01 & 0.96 & 0.01 \\
\hline Scenario 5 & 0.01 & 0.01 & 0.01 & 0.01 & 0.96 \\
\hline
\end{tabular}


Table 73: Scenarios and regional emphasis

\begin{tabular}{|c|c|}
\hline Scenario & Regional emphasis \\
\hline Economic Feasibility & Improve economic feasibility of RE and make it cost competitive. \\
\hline Community Sensitive & $\begin{array}{c}\text { Encourage community support for RE in the case of community opposing new } \\
\text { projects }\end{array}$ \\
\hline Regulation Dominant & $\begin{array}{c}\text { General regulatory considerations for a policy to be deemed valid and } \\
\text { applicable }\end{array}$ \\
\hline Environment Sensitive & Meeting specific environmental variables and targets. \\
\hline Technical Focus & Develop the technical system accompanying integrating RE sources to the \\
& \begin{tabular}{c} 
grid. \\
\hline
\end{tabular}
\end{tabular}

Variations of global alternatives weights with respect to each scenario are shown in Figure 47, Figure 48, Figure 49, Figure 50 and Figure 51.

\section{- Economic feasibility scenario}

In this scenario it is assumed that any region's priority in energy adoption planning is to increase the economic feasibility of renewable energy sources and make them more competitive to other fuels.

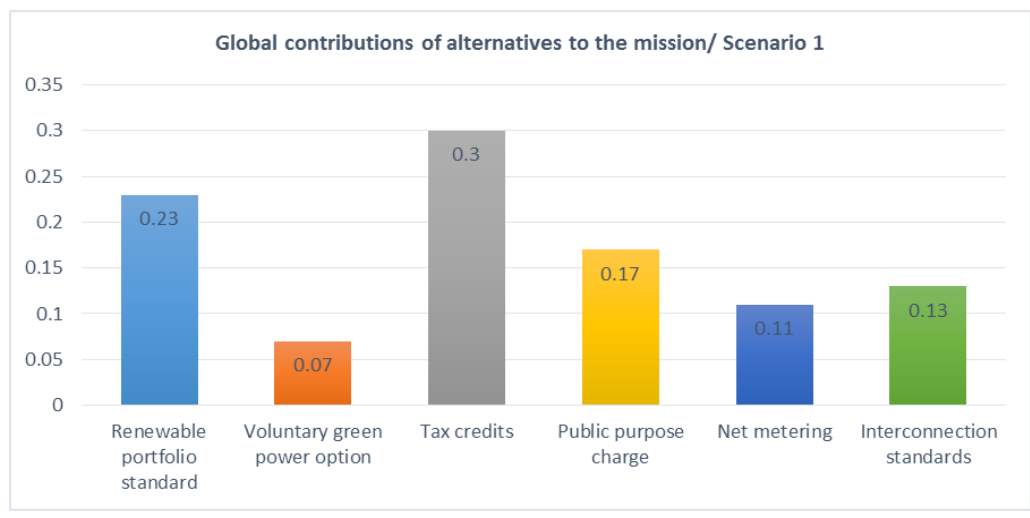

Figure 47: Global contributions of alternatives to the mission/ Scenario 1 
Results indicate that in the scenario preferring economic perspective, tax credits policy is the most effective policy followed by renewable portfolio standards. It can be noticed that public purpose charge had gained more importance in this scenario. Although it is expected that the financial policies will be the most effective, it is surprisingly that renewable portfolio standard shows strength in the economic scenario too and was ranked the second most effective policy instrument.

\section{- Community sensitive scenario}

In this scenario it is assumed that any region's priority in energy portfolio planning is encourage community support for RE in the case of community opposing new projects.

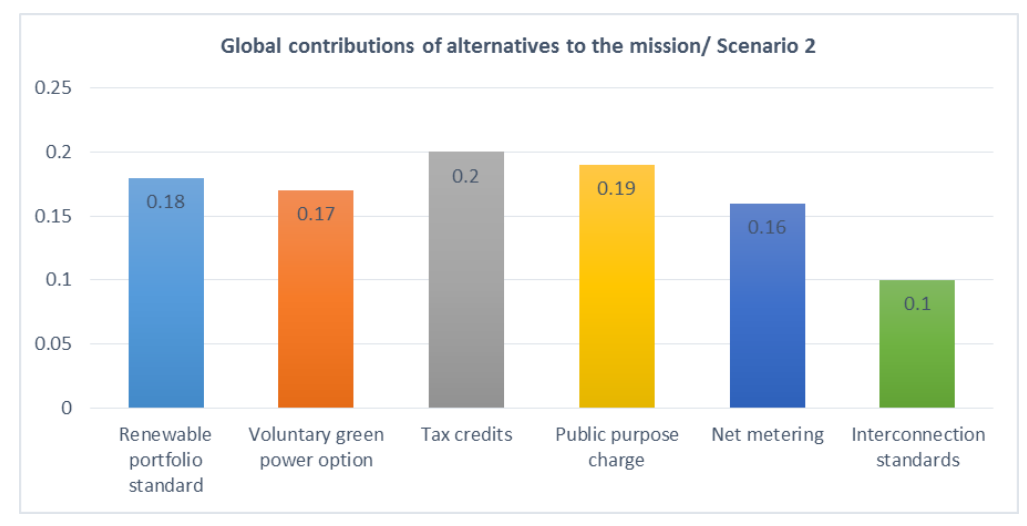

Figure 48: Global contributions of alternatives to the mission/ Scenario 2

Similar effects were observed for the four other scenarios assigning a value of 0.96 for social, regulatory, environmental and technical perspectives as shown in Table 74. Scenario 2, community support encouragement (social Perspective) was the most 
important criterion. This scenario assumed that any region's priority in energy portfolio planning is encourage community support for RE in the case of community opposing new projects. The rank order of the alternatives changed noticeably where RPS is not at the top alternatives and interconnection standards moved to be the least important. However, Tax Credits is still the most effective policy in this scenario.

\section{- Regulation dominant scenario}

In scenario 3, it is assumed that any region's priority in energy portfolio planning are general regulatory considerations for a policy to be deemed valid and applicable.

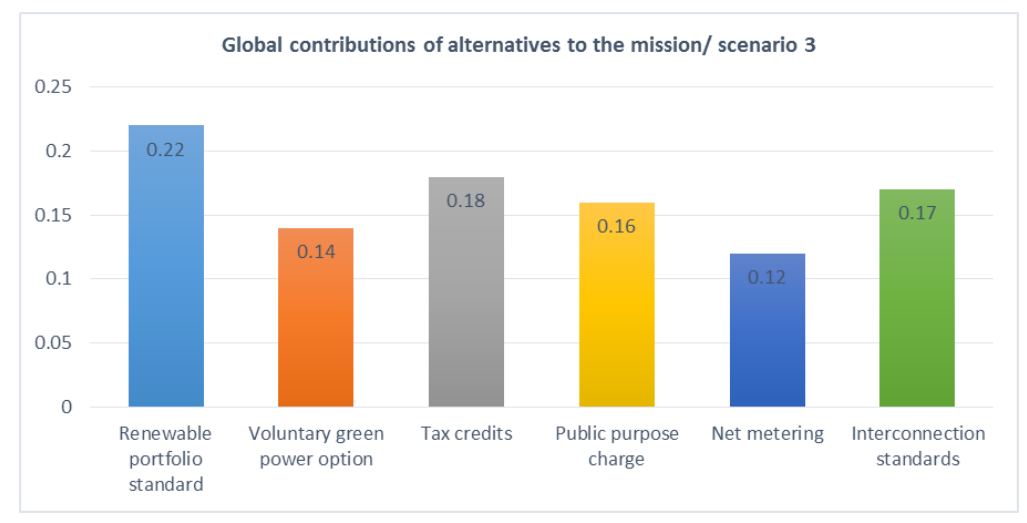

Figure 49: Global contributions of alternatives to the mission/ Scenario 3

Results revealed in this case that policy planners should emphasize on renewable portfolio standards in the policy portfolio along with tax credits. 
- Environment sensitive scenario

In the environment sensitive scenario 4 , it is assumed that any region's priority in energy portfolio planning is meeting specific environmental variables and targets.

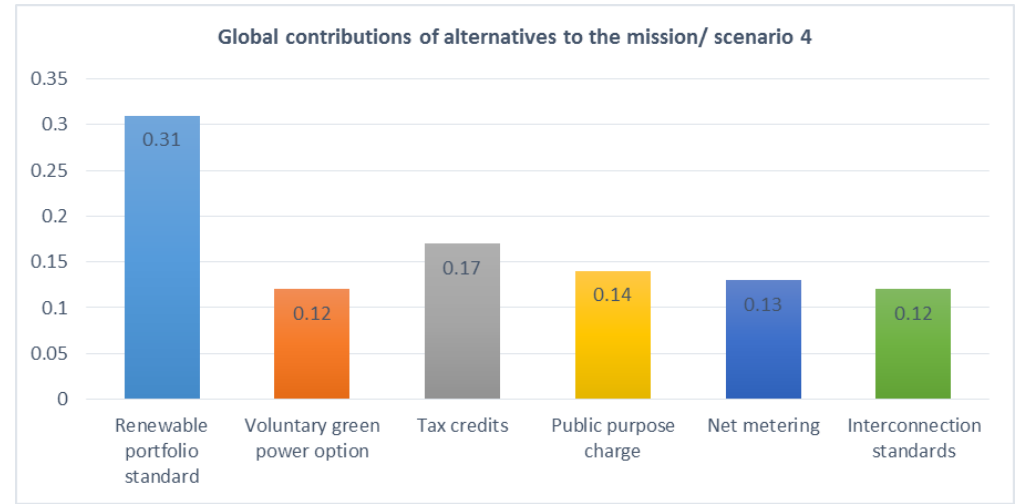

Figure 50: Global contributions of alternatives to the mission/ Scenario 4

Analysis showed that policy planners should also emphasize on renewable portfolio standards in the policy portfolio.

\section{- Technical focus scenario}

For the final scenario, scenario 5 the focus is on technical development. In this scenario it is assumed that any region's priority in energy portfolio planning is develop the technical system and improve integrating RE sources to the grid. 


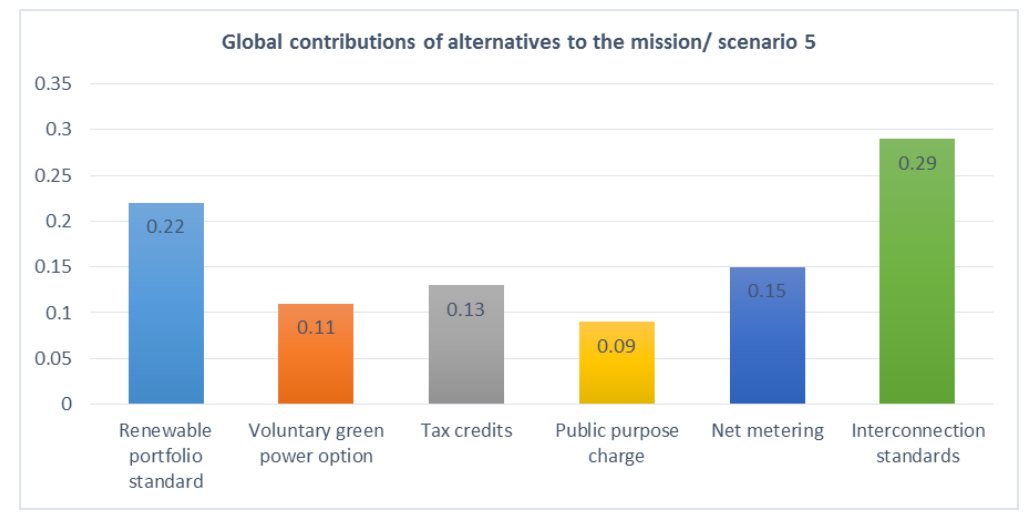

Figure 51: Global contributions of alternatives to the mission/ Scenario 5

It is shown that in the case of a regions need for technical development to integrate new renewable sources to the grid, policy planners should emphasize on interconnection standards in the policy portfolio

Summary of most and least favorite policy instrument alternative for each scenario and priority of all evaluated alternatives are summarized in Table 74.

Table 74: Alternatives rankings in case of extreme variations scenarios

\begin{tabular}{|c|c|c|c|c|c|c|}
\hline Alternatives & $\begin{array}{c}\text { Renewable } \\
\text { Portfolio } \\
\text { Standards } \\
\end{array}$ & $\begin{array}{c}\text { Voluntary } \\
\text { Green } \\
\text { Power } \\
\end{array}$ & Tax Credits & $\begin{array}{c}\text { Public } \\
\text { Purpose } \\
\text { Charge } \\
\end{array}$ & $\begin{array}{c}\text { Net } \\
\text { Metering }\end{array}$ & $\begin{array}{c}\text { Interconnect } \\
\text { ion } \\
\text { Standards } \\
\end{array}$ \\
\hline Rankings & $\star \quad 1$ & 6 & 2 & 4 & 5 & 3 \\
\hline Scenario 1 & 2 & 6 & $\star$ & 3 & 5 & 4 \\
\hline Scenario 2 & 3 & 4 & $\star$ & 2 & 5 & 6 \\
\hline Scenario 3 & $\star$ & 5 & 2 & 4 & 6 & 3 \\
\hline Scenario 4 & $\star$ & 6 & 2 & 3 & 4 & 5 \\
\hline Scenario 5 & 2 & 5 & 4 & 6 & 3 & $\star$ \\
\hline
\end{tabular}

$\star$ Policy ranked first. 
Scenario analysis reveals that Renewable portfolio standards and Tax credits are the most two effective policy instruments which implies that in any future regional development for renewable energy, these two policies or any form of them should be included in the policy portfolio for energy planning.

\subsection{Criterion-Related Validity}

Criterion-related validity reflects the degree to which the assessment model is effective in performing in real-life evaluation; meaning that the results and recommendations achieved from the model are applicable, accurate, and valid. Face to face meetings as well as email communications were conducted with a group of policy analysts and academics scholars in the Pacific Northwest in the assessment of the energy policy field in order to accomplish the criterion-related validity step of this study. Experts were presented with the results of the research and asked to evaluate the appropriateness and generalizability of the model as well as the appropriateness of the results obtained. Experts confirmed that the results from the model were appropriate and valid.

\subsection{Summary of the Study}

A general assessment framework was introduced in this research to evaluate the effectiveness of policy instruments on increasing the adoption of renewable energies in the power generation sector. The model was applied to the Pacific Northwest as a case 
study. Research process and results from the experts' judgments analysis can be summarized as follows:

1. Objective of the research is to evaluate current energy policy instruments in terms of their effect on increasing the adoption of renewable energy sources. This was done by developing an HDM assessment model consisted of four levels: mission, perspectives, policy targets, and alternatives.

2. The model was applied and quantified according to the case of wind energy in the Pacific Northwest region.

3. Expert panels were formed in two different stages of the study: building and finalizing the assessment model, and providing judgment quantification for the model's variables.

4. Six expert panels were formed to assign quantifying judgments to the perspectives, policy targets, and alternatives.

5. Disagreements among experts were analyzed and it was concluded that these disagreements did not affect the final ranking of alternatives: Renewable Portfolio Standards (0.23), Tax Credits (0.2), Interconnection Standards (0.17), Public Purpose Charge (0.15), Net Metering (0.13) and Voluntary Green Power (0.11).

6. Sensitivity analysis was conducted to determine the most critical perspective for energy planning and allowable range of perturbations. Technical system development was found to be the most critical perspective to maintain the current ranking of all alternatives, as its allowable range of perturbations is between -0.08 
and 0.12 . To maintain the rank of the top alternative, Economic Feasibility Improvement was found to be have a small effect on changing the rank of RPS with an allowable range of perturbations between -0.28 and 0.2 , however, the model is robust and the first ranked alternative is not subject to any changes.

7. Scenario analysis revealed that for different regional planning priorities there is a different best alternative. However, RPS and Tax Credits were the two most favorite in most cases.

8. Results of the research were presented and discussed with experts to get feedback and criterion-related validity. Experts confirmed the results are concurrent with their professional judgment and that the model is generalizable to other regions. 


\section{CHAPTER 7: DISCUSSION}

After collecting all the data and analyzing this data to get final results, insightful information can be obtained from these analyses. This chapter discusses these conclusions and explains research limitations and future work expected.

\subsection{Results analysis and conclusion}

This section represents a discussion of expert panels' results and the implications of global and relative weights of model's variables.

\subsubsection{Assessment perspectives}

Results from expert panel showed that economic feasibility improvement was the most influential perspective for wind projects in the region of the Pacific Northwest. The fact that technical system development came second emphasizes on the region's need to improve the technical system and transmission system in order to increase the adoption. Policy instruments are needed to be formed in a way that maximize the benefits within these two perspectives.

The analysis of experts' opinions showed interesting results and provided insights into the actual important perspectives for increasing wind energy adoption. Results showed that for increasing the deployment of wind energy in the power generation sector, increasing economic feasibility of these projects and the need for more development of the technical system for this power are the two most influential variables. Experts form 
government sector showed more interest in increasing the economic feasibility of wind energy which indicate that the government direction for facilitating and increasing wind projects is by supporting these projects financially. The fact that economic feasibility improvement perspectives is the most important perspectives confirms that cost of power generated from wind sources is still not competitive with conventional sources.

Analyzing the economic policy targets further reveals that the upfront cost and installation cost are still the main obstacle for wind project, other economic variables can be considered as intermediate inputs and do not have a great influence on the initial investment decision. This implies that wind energy is a mature energy and the market is ready for this energy with stabilized prices of energy and an interest to invest from private investor, however, startup cost for these investments is still the major financial obstacle.

Community support encouragement Perspectives was found to be the least important one for increasing wind energy in the power generation sector and hence not a very influential factor. This was discussed with experts and they noted that although community support is important to increase renewable energy projects, for utility scale projects economic feasibility of the project and technical abilities to integrate this new sources to the grid are more important. For the case study, wind energy is already an established power source in the Pacific Northwest power source portfolio and considered as a mature and accepted technology, however, economic factors were the most important issues. 
Regulatory implementation considerations was the third most important perspective for wind adoption in the region. This result signifies the fact that a policy cannot be effective in any perspective unless it can be implemented from a regulatory point of view. Further analysis uncovered that government is leaning to support ratepayer equity policy target which coincides with its interest in the economic perspective. On the other hand, the two policy targets that explains the applicability of policy where more pursued from non-governmental organization to insure the applicability of a policy instrument in order to achieve all policy targets.

Environmental protection promotion was not considered as a very influential perspective to increase the adoption in the region. This was discussed with the experts and it was noted that the Pacific Northwest region has a very strong environmental regulations to protect natural habitats and land preservations, adding a new policy is not considered a priority nor will have any further effect on the adoption. None of the environmental policy targets had high contribution to the environmental Perspectives except for mandating emission reduction. This indicates that environmental variables other than mandating emissions reductions are perceived as externalities (cost-benefit) of wind energy adoption and do not have a great influence on the adoption decision. On the other hand, Mandating Emission Reductions was found to be a very important target that policy should be effective in achieving. This signifies the importance of having a separate emission reduction policy which mandates certain levels of emissions. Such policy can be 
effective if it satisfies the economic feasibility Perspectives and force a level of penalties on GHG that makes renewable energy a less expensive solution.

Technical system development was the second most effective perspective on increasing the adoption of wind in the region. This confirms the need for a new and developed technical system in the region for a successful increase in wind energy capacity and that the region's technical system cannot accommodate more projects in its current situation. The four examined policy targets were almost of same important which implies the need for a better policy that serves to fulfill these targets. Improving Integration Capabilities was the most dominant policy targets with respect to Technical System Development which includes the need for more advanced integration capabilities such as optimum energy conversion. Experts from utilities were the experts that elevated this policy target which demonstrates that utilities feel the need for a policy that targets this issue specifically. Further analysis of policy alternative can reveal the best policy to achieve this target.

\subsubsection{Policy effectiveness}

As presented in the previous chapter, effectiveness of each policy instrument alternative on increasing the adoption of wind energy in the Pacific Northwest was determined by how much a policy influenced the important Perspectives for the adoption and policies were ranked accordingly. Among the policy instruments that were evaluated in this research, renewable portfolio standards in combination with tax credits were 
noticed to be the most effective policies in increasing the adoption of wind energy in the case of the Pacific Northwest. In fact, Renewable portfolio standard was noticed to be the most effective in influencing almost all the variables under consideration the model that were perceived the most important for wind energy adoption. On the other hand, Voluntary green power and net metering policy instruments were found to be the least effective in the case of the case study under consideration. This suggests that these two policies should be reformed and improved.

Policy instruments alternatives in this assessment framework can be classified into three main dimensions according to their dynamic application: regulations (RPS and mandatory green power option), financial incentives (tax credits, public purpose charge) and standards (interconnection standards and net metering). It was noticed that the relative contributions of the three dimensions to the mission were almost equal: regulatory policies (0.34), financial incentives policies (0.35) and standards (0.40). This equal contribution emphasizes the role of each policy and its effectiveness on the adoption process of renewable energy and indicates that policies in all three dimensions are required when a region focuses on the adoption of an energy alternative. However, for regulatory policies it was noticed that RPS had always had higher contribution than mandatory green power option and was the most effective. This finding emphasizes the role that the government have in establishing mandatory levels of renewable sources in the power generation sources portfolio and pushing renewable energies to the market more than trying to create an option for customers to purchase energy from these sources. 
For financial incentives, tax credits were more effective than public purpose charge in almost all the variables considered. This variance in effectiveness between the two policies was discussed with experts and it was noted that it was because public purpose charge policy allocates only a small amount of its funds to support renewable energy projects while tax credits policy is targeted specifically for those projects.

\subsubsection{Policy implications}

Although results explained which Perspectives were more important to increase the adoption of wind energy and which policy instruments were more effective than others in the case of the Pacific Northwest, more in depth analysis was conducted to test out other scenarios and gain insight into which policy would be more effective if planning priorities had changed and if the model was applied to another region. Five policy planning scenarios were developed where in each scenario, the emphasis of regional planning priorities was different. This change of weights reflects the change in decision makers' priorities according to specific regional planning requirements. This analysis can be considered as a decision support tool that assists policymakers in determining the optimal combination of policy instruments addressing these explicit targets. Among the policy instruments assessed, renewable portfolio standards in combination with tax credits were noticed to be the most effective policy instruments in increasing the adoption of wind energy for the current situation and future extreme scenarios. From the Pacific Northwest experience, an effective energy policy portfolio should include some kind of mandatory energy resources such as RPS as well as 
incentives in a form of tax credits. Results confirm the effectiveness of RPS and was congruent with previous studies (Kydes, 2007, Bird et al., 2005, Yin and Powers, 2010), but this analysis explained the long term effect of this policy and its appropriateness with any future scenario. This research also emphasized that Regulatory, Incentives and Standards based policies are needed concurrently to facilitate adoption of a new energy alternative.

\subsection{Contribution}

This research has evaluated energy policy tools effectiveness in terms of their increasing adoption of renewable energy resources in the Pacific Northwest, which will be beneficial for energy planning and situation assessment, and can be used as a policy check tool. The assessment model included a set of variables and elements that are of importance for RE adoption. These variables were identified as important variables that have an effect on the input of the adoption process that can drive the adoption rather than maximizing the outcomes of such adoption. In addition to assessing current policy instruments, the research model had the ability to test future planning Perspectives and their effect on policy making. This research had developed scenarios to demonstrate how this tool can be used for different cases and demonstrated that this assessment model can be flexible to provide insight into what the results would be in the case of any future changes. 
The HDM model was found to be a useful methodology to obtain clear judgments and better understanding of what is actually important for decision makers and experts in the energy policy field. Using this methodology, a new energy policy evaluation approach was developed and validated. This methodology has the ability to consider multiple perspectives and take into consideration the input of multiple decision makers and stakeholders. The HDM model also had the ability to assess individual and group rankings of the Perspectives and alternatives for better analysis. The literature review in Chapter 2 identified gaps as follows:

- Current assessment models take into consideration monetary value, various studies and assessment models focused on drivers of adoption from a limited point of view.

- There isn't a comprehensive multi Perspectives decision making model that measures the effect of energy policy on the input of the renewable energy adoption process in a qualitative, quantitative and systematic way. No MCDM model that can be used for policy choice and explains ineffectiveness.

- Most literature consisted of case studies or single criterion methodology emphasis on current situation lacking the sensitivity analysis for macro and micro changes. The effects of changing priorities in future policy planning areas and the analysis of different scenarios have not been fully explored. 
It was noticed in the literature that there is no complete assessment framework that takes state energy policy objectives and goals into account for analyzing the effectiveness of proposed policies, although some of the previous research has mentioned these points as potential research areas. This research has addressed this gap by developing a framework which can be used for future policy evaluation according to any change in the macro or micro-environment and hence, energy priorities, of the region.

Energy policy planning is implemented with respect to long-term needs or objectives. Since different changes can occur over time, this research also integrates sensitivity analysis in order to enable a more complete decision analysis and provide insight into different future scenarios that may occur due to changing priorities. Integration of sensitivity analysis throughout the proposed approach has increased the objectivity of the energy policy program planning measures. In general, the contribution can be summarized in these points:

- Evaluated and prioritized energy policy instruments in terms of their contribution to the mission of increasing adoption of renewable energy sources in the Pacific Northwest, which will be beneficial for energy planning and situation assessment, and can be used as a policy check tool.

- Developed a comprehensive assessment tool utilizing a multi Perspectives decision making methodology for policy analysis and decision making that considers a larger number of Perspectives and perspectives. 
- Provided a more rigorous framework of analysis that considered future uncertainties and the effect of future changes in energy planning priorities on ranking energy policy tools.

Generally, these contributions have contributed to the existing level of knowledge by enabling a more accurate policy evaluation and planning approach that can provide better understanding of the potential implications of strategic decisions. While the numerical results and policy ranking provided in this research are targeted towards a specific case study, this analysis contributes also to the development of more comprehensive frameworks for the assessment of effectiveness of policy instruments in the context of its Impact on renewable energy adoption which reflects on the policy design and development process.

\subsection{Assumptions and Limitations}

This research utilizes the hierarchical decision model methodology. The methodology in this research utilizes judgments of a number of experts to provide data. However, the results of the research are dependent on the subjectivity of experts. Experts in the expert panels are assumed to be capable to provide judgments and have the required knowledge in energy policy. Expert panels are also assumed to be free of biases. Following the Perspectives in Chapter 3 and forming expert panels form multiple backgrounds and knowledge bases will help balance the bias in judgments and address these assumptions. 
For developing this model and collecting the data it is assumed that the policy assessment Perspectives and policy targets are independent of one another and are mutually exclusive and have a unidirectional hierarchical relationship among all levels. This was confirmed by the experts in the content and context validity steps and tested before the data collection process started. For the model development and variable selection, it is assumed that energy policy is applicable to all sources of renewable energy. This was verified from literature review and experts feedback during model development process.

Results of the model reflect energy policy ranking in a specific case study, the Pacific Northwest energy policy instruments, and may or may not be the same for other regions or countries. However, the structure of the model should not change significantly and it can be assumed to be valid in other situations with slight modifications. Also the research case study is limited to wind energy technology. Further renewable energy sources are not considered in the judgment quantification process. Nevertheless, the model can be expanded to other types of renewable energy sources and other regions and relative importance can be re-evaluated by collecting new judgment quantifications from new experts.

Relative importance among all model's variables and global contribution are calculated based on a point in time. Priorities and judgments of these variables can change with time according to the decision makers' preference or future energy planning 
targets. Sensitivity analysis can help lessen this limitation and give more accurate perception about future changes.

\subsection{Future Work}

This research focused on assessment of energy policy instruments effectiveness on wind energy adoption using the hierarchical decision model and provided a comprehensive literature review which allows opportunities of several possible future research expansion. Variables in this model, and thus in the results, are time-dependent and may change over time. Priorities can change also, depending on planning and policy needs. Sensitivity analysis can provide insight into time effect and priority changes on decisions variables importance, but it is not enough just by itself to address the impact of changing variables, However, due to generalizable nature of the assessment model this study can be repeated for different regions and several other renewable energy sources. As mentioned in the previous section, the scope of this research is only the effect of energy policy on increasing wind energy adoption in the Pacific Northwest. Nevertheless, future research can be conducted to extend the current assessment variables to other states with different policy objectives and adoption barriers. The proposed research could be expanded by integrating the differences and potentials of several renewable energy sources.

It is also expected that there would be new policies that are planned such as the introduction of new policy such as Cap and Trade or Carbon Tax. This situation 
highlights the need to improve this study by implementing the desirability curves methodology which will allow the researcher to take into account any additional alternatives. Desirability Curve characterizes how desirable a certain assessment variable is for the decision maker based on expert judgments. The development of these curves will allow the researcher to compare new alternatives under the same model frame without the need new pairwise comparison at the alternative level.

Scenario analysis was conducted to determine the effect of future changes in regional emphasis priorities on the adoption of renewable energy sources. These scenarios where hypothetical and the results were according to the model developed. A research opportunity seems to be of great value if these scenarios where discussed with experts in the field and conducted according to real life input.

The research evaluated policies according to specific criteria but didn't account for cost effectiveness of each policy and the economies of each alternative. A future research interest is to incorporate the results of the model with economic variables via goal programming methodology as maximizing profit as the output. 


\section{REFERENCES}

[1] W. Bach and W. H. Matthews, "Exploring alternative energy strategies," Proceedings of a Conference on Non-Fossil Fuel and Non-Nuclear Fuel Energy Strategies, vol. 4, pp. 711722, 101979.

[2] A. M. Weinberg, "Are the alternative energy strategies achievable?," Proceedings of a Conference on Non-Fossil Fuel and Non-Nuclear Fuel Energy Strategies, vol. 4, pp. 941951, 101979.

[3] C. J. Ryan, "The choices in the next energy and social revolution," Technological Forecasting and Social Change, vol. 16, pp. 191-208, 31980.

[4] E. H. Warren, "Solar energy market penetration models: Science or number mysticism?," Technological Forecasting and Social Change, vol. 16, pp. 105-118, 21980.

[5] J. R. Burns, "Solar energy and the national energy dilemma : A model for policy evaluation," Technological Forecasting and Social Change, vol. 21, pp. 213-228, 61982.

[6] S. W. Sawyer, "Leaders in change : Solar energy owners and the implications for future adoption rates," Technological Forecasting and Social Change, vol. 21, pp. 201-211, 6 1982.

[7] D. L. Klass, "A critical assessment of renewable energy usage in the USA," Energy Policy, vol. 31, pp. 353-367, 32003.

[8] G. Shrimali and J. Kniefel, "Are government policies effective in promoting deployment of renewable electricity resources?," Energy Policy, vol. 39, pp. 4726-4741, 2011.

[9] "ANNUAL ENERGY OUTLOOK 2010," ed: U.S Energy Information Administration, 2010.

[10] S. T. Anderson and R. G. Newell, "Information programs for technology adoption: the case of energy-efficiency audits," Resource and Energy Economics, vol. 26, pp. 27-50, 3 2004.

[11] L. Neij and K. Åstrand, "Outcome indicators for the evaluation of energy policy instruments and technical change," Energy Policy, vol. 34, pp. 2662-2676, 11// 2006.

[12] N. Enzensberger, M. Wietschel, and O. Rentz, "Policy instruments fostering wind energy projects--a multi-perspective evaluation approach," Energy Policy, vol. 30, pp. 793-801, 2002. 
[13] E. Vine, "Strategies and policies for improving energy efficiency programs: Closing the loop between evaluation and implementation," Energy Policy, vol. 36, pp. 3872-3881, $10 / / 2008$.

[14] D. Diakoulaki and F. Karangelis, "Multi-criteria decision analysis and cost-benefit analysis of alternative scenarios for the power generation sector in Greece," Renewable and Sustainable Energy Reviews, vol. 11, pp. 716-727, 2007.

[15] N. Sheikh, T. Daim, and D. F. Kocaoglu, "Use of multiple perspectives and decision modeling for PV technology assessment," in 2011 Portland International Conference on Management of Engineering \&amp; Technology (PICMET 2011), 31 July-4 Aug. 2011, Piscataway, NJ, USA, 2011, p. 21 pp.

[16] F. Cavallaro, "A comparative assessment of thin-film photovoltaic production processes using the ELECTRE III method," Energy Policy, vol. 38, pp. 463-474, 2010.

[17] M. B. Charles, R. Ryan, N. Ryan, and R. Oloruntoba, "Public policy and biofuels: The way forward?," Energy Policy, vol. 35, pp. 5737-5746, 112007.

[18] E. Rogers, DIFFUSION OF INNOVATIONS. New York: FREE PRESS, 2003.

[19] S. Jacobsson and A. Johnson, "The diffusion of renewable energy technology: an analytical framework and key issues for research," Energy Policy, vol. 28, pp. 625-640, $7 / 312000$.

[20] K. Usha Rao and V. V. N. Kishore, "Wind power technology diffusion analysis in selected states of India," Renewable Energy, vol. 34, pp. 983-988, 2009.

[21] M. Guidolin and C. Mortarino, "Cross-country diffusion of photovoltaic systems: Modelling choices and forecasts for national adoption patterns," Technological Forecasting and Social Change, vol. 77, pp. 279-296, 2010.

[22] P. K. Kapur, O. Singh, U. Chanda, and M. Basirzadeh, "Determining adoption pattern with pricing using two-dimensional innovation diffusion model," The Journal of High Technology Management Research, vol. 21, pp. 136-146, 2010.

[23] P. Sadorsky, "Modeling renewable energy company risk," Energy Policy, vol. In Press, Corrected Proof.

[24] F. M. Bass, "Comments on "A New Product Growth for Model Consumer Durables The Bass Model"," Management Science, vol. 50, pp. 1833-1840, 2004. 
[25] S. Cantono and G. Silverberg, "A percolation model of eco-innovation diffusion: The relationship between diffusion, learning economies and subsidies," Technological Forecasting and Social Change, vol. In Press, Corrected Proof.

[26] P. H. Kobos, J. D. Erickson, and T. E. Drennen, "Technological learning and renewable energy costs: implications for US renewable energy policy," Energy Policy, vol. 34, pp. 1645-1658, 92006.

[27] I. Diaz-Rainey and D. Tzavara, "A Diffusion Model of an Induced Environmental Market: Reconciling WTP to actual adoption of green energy tariffs," in Energy Market, 2009. EEM 2009. 6th International Conference on the European, 2009, pp. 1-8.

[28] L. Neij, "Use of experience curves to analyse the prospects for diffusion and adoption of renewable energy technology," Energy Policy, vol. 25, pp. 1099-1107, 111997.

[29] S. Theodorou, G. Florides, and S. Tassou, "The use of multiple criteria decision making methodologies for the promotion of RES through funding schemes in Cyprus, A review," Energy Policy, vol. 38, pp. 7783-7792, 2010.

[30] (2013). ExternE - External Costs of Energy. Available: http://www.externe.info/externe $d 7 /$ ?q=node/6

[31] D. Diakoulaki, C. Zopounidis, G. Mavrotas, and M. Doumpos, "The use of a preference disaggregation method in energy analysis and policy making," Energy, vol. 24, pp. 157166, 1999.

[32] M. J. Kotchen and M. R. Moore, "Private provision of environmental public goods: Household participation in green-electricity programs," Journal of Environmental Economics and Management, vol. 53, pp. 1-16, 2007.

[33] T. D. Tsoutsos and Y. A. Stamboulis, "The sustainable diffusion of renewable energy technologies as an example of an innovation-focused policy," Technovation, vol. 25, pp. 753-761, 72005.

[34] A. D. Owen, "Renewable energy: Externality costs as market barriers," Hong Kong Editorial Board meeting presentations, vol. 34, pp. 632-642, 32006.

[35] R. R. Harmon and K. R. Cowan, "A multiple perspectives view of the market case for green energy," Knowledge Driven Planning Tools for Emerging and Converging Technologies, vol. 76, pp. 204-213, 12009. 
[36] R. Beck, D. Beimborn, T. Weitzel, and W. König, "Network effects as drivers of individual technology adoption: Analyzing adoption and diffusion of mobile communication services," Information Systems Frontiers, vol. 10, pp. 415-429, 2008.

[37] P. D. Lund, "Effects of energy policies on industry expansion in renewable energy," Renewable Energy, vol. 34, pp. 53-64, 2009.

[38] Q. Shi Yan, W. Zhang, and Q. Wu, "Study on Interregional Technology Diffusion Channels in China," in Management and Service Science (MASS), 2010 International Conference on, 2010, pp. 1-4.

[39] Z. J. Acts and D. B. Audretsch, "Patents as a Measure of Innovative Activity," Kyklos, vol. 42, p. 171, 1989.

[40] F. M. Scherer, "Patents, citations \& innovations: A window on the knowledge economy," Journal of Economics-Zeitschrift Fur Nationalokonomie, vol. 79, pp. 201-204, Jun 2003.

[41] L. Wei-hong and H. Bao-min, "Research on the relationship between R\&amp;D input and patent output in Hebei Province," in Industrial Engineering and Engineering Management (IE\&EM), 2010 IEEE 17Th International Conference on, 2010, pp. 17181722.

[42] Z. J. Acs, L. Anselin, and A. Varga, "Patents and innovation counts as measures of regional production of new knowledge," Research Policy, vol. 31, pp. 1069-1085, 2002.

[43] A. B. Jaffe and M. Trajtenberg, "Geographic localization of knowledge spillovers as evidenced by patent citations," Quarterly Journal of Economics, vol. 108, p. 577, 1993.

[44] A. Kayal, "Measuring the Pace of Technological Progress: Implications for Technological Forecasting," Technological Forecasting and Social Change, vol. 60, pp. 237-245, 31999.

[45] T. U. Daim, G. Rueda, H. Martin, and P. Gerdsri, "Forecasting emerging technologies: Use of bibliometrics and patent analysis," Tech Mining: Exploiting Science and Technology Information Resources, vol. 73, pp. 981-1012, 102006.

[46] J. Bae, K. Seetharaman, P. Suntharasaj, and Y. Ding, "Technology Forecasting of RFID by Using Bibliometric Analysis and Bass Diffusion Model," in Management of Engineering and Technology, Portland International Center for, 2007, pp. 1637-1642.

[47] S. Morris, C. DeYong, Z. Wu, S. Salman, and D. Yemenu, ": a visualization system for exploring document databases for technology forecasting," Computers \& Industrial Engineering, vol. 43, pp. 841-862, 2002. 
[48] Y. Kajikawa and Y. Takeda, "Structure of research on biomass and bio-fuels: A citationbased approach," Technological Forecasting and Social Change, vol. 75, pp. 1349-1359, 112008.

[49] Y. Kajikawa, J. Yoshikawa, Y. Takeda, and K. Matsushima, "Tracking emerging technologies in energy research: Toward a roadmap for sustainable energy," Technological Forecasting and Social Change, vol. 75, pp. 771-782, 72008.

[50] V. Dinica, "Support systems for the diffusion of renewable energy technologies--an investor perspective," Energy Policy, vol. 34, pp. 461-480, 2006.

[51] A. S. Kydes, "Impacts of a renewable portfolio generation standard on US energy markets," Energy Policy, vol. 35, pp. 809-814, 22007.

[52] M.-Y. Huang, J. R. R. Alavalapati, D. R. Carter, and M. H. Langholtz, "Is the choice of renewable portfolio standards random?," Energy Policy, vol. 35, pp. 5571-5575, 112007.

[53] W. Ross Morrow, K. S. Gallagher, G. Collantes, and H. Lee, "Analysis of policies to reduce oil consumption and greenhouse-gas emissions from the US transportation sector," Energy Policy, vol. 38, pp. 1305-1320, 2010.

[54] W. Dritschilo, M. Monroy, E. Nash, B. Schuyler, B. R. Wallerstein, J. De Vita, et al., "Energy vs food resource ratios for alternative energy technologies," Energy, vol. 8, pp. 255-265, 41983.

[55] C. Sherrington, J. Bartley, and D. Moran, "Farm-level constraints on the domestic supply of perennial energy crops in the UK," Energy Policy, vol. 36, pp. 2504-2512, 72008.

[56] J. Noailly and S. Batrakova, "Stimulating energy-efficient innovations in the Dutch building sector: Empirical evidence from patent counts and policy lessons," Energy Policy, vol. 38, pp. 7803-7817, 2010.

[57] E. Luiten, H. van Lente, and K. Blok, "Slow technologies and government intervention: Energy efficiency in industrial process technologies," Technovation, vol. 26, pp. 10291044, 2006.

[58] S. K. Lee, G. Mogi, S. C. Shin, and J. W. Kim, "An AHP/DEA hybrid model for measuring the relative efficiency of energy efficiency technologies," pp. 55-59.

[59] F. Cavallaro and L. Ciraolo, "A multicriteria approach to evaluate wind energy plants on an Italian island," Energy Policy, vol. 33, pp. 235-244, 2005. 
[60] P. Harborne and C. Hendry, "Pathways to commercial wind power in the US, Europe and Japan: The role of demonstration projects and field trials in the innovation process," Energy Policy, vol. 37, pp. 3580-3595, 2009.

[61] P. E. Meyer and J. J. Winebrake, "Modeling technology diffusion of complementary goods: The case of hydrogen vehicles and refueling infrastructure," Technovation, vol. 29, pp. 77-91, 2009.

[62] E. W. E. Association, "Delivering Offshore Wind: Policy Recommendations for LargeScale Deployment of Offshore Wind Power in Europe by 2020," 2007.

[63] F. C. Menz and S. Vachon, "The effectiveness of different policy regimes for promoting wind power: Experiences from the states," Energy Policy, vol. 34, pp. 1786-1796, 2006.

[64] V. Dinica, "Initiating a sustained diffusion of wind power: The role of public-private partnerships in Spain," Energy Policy, vol. 36, pp. 3562-3571, 92008.

[65] D. Poponi, "Analysis of diffusion paths for photovoltaic technology based on experience curves," Solar Energy, vol. 74, pp. 331-340, 2003.

[66] F. Cavallaro, "Multi-criteria decision aid to assess concentrated solar thermal technologies," Renewable Energy, vol. 34, pp. 1678-1685, 2009.

[67] F. Cavallaro, "Fuzzy TOPSIS approach for assessing thermal-energy storage in concentrated solar power (CSP) systems," Applied Energy, vol. 87, pp. 496-503, 2010.

[68] G. R. Timilsina, L. Kurdgelashvili, and P. A. Narbel, "Solar energy: Markets, economics and policies," Renewable and Sustainable Energy Reviews, vol. 16, pp. 449-465, 2012.

[69] K. J. Holmes and L. Papay, "Prospects for electricity from renewable resources in the United States," Journal of Renewable and Sustainable Energy, vol. 3, pp. 042701-14, 2011.

[70] P. M. Jansson and R. A. Michelfelder, "Integrating Renewables into the U.S. Grid: Is It Sustainable?," The Electricity Journal, vol. 21, pp. 9-21, 2008.

[71] S. Abraham, "National Transmission grid Study, US Dept. of Energy, May 2002," ed.

[72] "Renewing our energy future," U.S. Congress, Office of Technology Assessment1995.

[73] J. M. Carrasco, L. G. Franquelo, J. T. Bialasiewicz, E. Galvan, R. C. P. Guisado, M. A. M. Prats, et al., "Power-Electronic Systems for the Grid Integration of Renewable Energy 
Sources: A Survey," Industrial Electronics, IEEE Transactions on, vol. 53, pp. 1002-1016, 2006.

[74] M. George and R. Banerjee, "A methodology for analysis of impacts of grid integration of renewable energy," Energy Policy, vol. 39, pp. 1265-1276, 2011.

[75] E. DeMeo and B. Parsons, "Some common misconceptions about wind power," All States Wind Summit, Austin, Texas. May, vol. 22, 2003.

[76] Available: www.AWEA.org

[77] G. Strbac, A. Shakoor, M. Black, D. Pudjianto, and T. Bopp, "Impact of wind generation on the operation and development of the UK electricity systems," Electric Power Systems Research, vol. 77, pp. 1214-1227, 2007.

[78] H. Langkowski, T. Trung Do, K. D. Dettmann, and D. Schulz, "Grid impedance determination - relevancy for grid integration of renewable energy systems," in Industrial Electronics, 2009. IECON '09. 35th Annual Conference of IEEE, 2009, pp. 516521.

[79] M. Brown, L. Cibulka, J. Cole, and L. Miller, "New Electric Transmission Technologies for Renewable Integration," ASME Conference Proceedings, vol. 2009, pp. 509-519, 2009.

[80] Z. A, "A review of drivers, benefits, and challenges in integrating renewable energy sources into electricity grid," Renewable and Sustainable Energy Reviews, vol. 15, pp. 4775-4779, 2011.

[81] D. P. Kaundinya, P. Balachandra, and N. H. Ravindranath, "Grid-connected versus standalone energy systems for decentralized power-A review of literature," Renewable and Sustainable Energy Reviews, vol. 13, pp. 2041-2050, 2009.

[82] J. M. Loiter and V. Norberg-Bohm, "Technology policy and renewable energy: public roles in the development of new energy technologies," Energy Policy, vol. 27, pp. 85-97, 21999.

[83] V. Norberg-Bohm, "Creating Incentives for Environmentally Enhancing Technological Change: Lessons From 30 Years of U.S. Energy Technology Policy," Technological Forecasting and Social Change, vol. 65, pp. 125-148, 102000.

[84] G. Birgisson and E. Petersen, "Renewable Energy Development Incentives: Strengths, Weaknesses and the Interplay," The Electricity Journal, vol. 19, pp. 40-51, 42006. 
[85] L. Bird, M. Bolinger, T. Gagliano, R. Wiser, M. Brown, and B. Parsons, "Policies and market factors driving wind power development in the United States," Energy Policy, vol. 33, pp. 1397-1407, 2005.

[86] D. Fouquet and T. B. Johansson, "European renewable energy policy at crossroadsFocus on electricity support mechanisms," Transition towards Sustainable Energy Systems, vol. 36, pp. 4079-4092, 112008.

[87] J. Zoellner, P. Schweizer-Ries, and C. Wemheuer, "Public acceptance of renewable energies: Results from case studies in Germany," Transition towards Sustainable Energy Systems, vol. 36, pp. 4136-4141, 112008.

[88] M. A. Schilling and M. Esmundo, "Technology S-curves in renewable energy alternatives: Analysis and implications for industry and government," Energy Policy, vol. 37, pp. 17671781, 2009.

[89] D. Popp, I. Hascic, and N. Medhi, "Technology and the diffusion of renewable energy," Energy Economics, vol. 33, pp. 648-662, 2011.

[90] M. W. Bolinger, R., "PTC, ITC, or Cash Grant? An Analysis of the Choice Facing Renewable Power Projects in the United States," National Renewable Energy Laboratory2009.

[91] R. Craig, "America's Energy and Climate Change Policy," The Electricity Journal, vol. 24, pp. 16-26, 2011.

[92] L. C. Bird, C. Logan, J. Summer, J. Short, W., "Evaluating Renewable Portfolio Standards and Carbon Cap Scenarios in the U.S. Electric Sector," National Renewable Energy Laboratory2010.

[93] H. Yin and N. Powers, "Do state renewable portfolio standards promote in-state renewable generation?," Energy Policy, vol. 38, pp. 1140-1149, 2010.

[94] S. Carley, "State renewable energy electricity policies: An empirical evaluation of effectiveness," Energy Policy, vol. 37, pp. 3071-3081, 2009.

[95] K. S. Cory and B. G. Swezey, "Renewable Portfolio Standards in the States: Balancing Goals and Rules," The Electricity Journal, vol. 20, pp. 21-32, 2007.

[96] K. Palmer and D. Burtraw, "Cost-effectiveness of renewable electricity policies," Energy Economics, vol. 27, pp. 873-894, 2005. 
[97] P. Mozumder and A. Marathe, "Gains from an integrated market for tradable renewable energy credits," Ecological Economics, vol. 49, pp. 259-272, 2004.

[98] N. I. Meyer, "Learning from wind energy policy in the EU: lessons from Denmark, Sweden and Spain," European Environment, vol. 17, pp. 347-362, 2007.

[99] K. C. Cory, T. Kreycik, C, "Feed-in Tariff Policy: Design, Implementation, and RPS Policy Interactions," National Renewable Energy Laboratory2009.

[100] J. Kneifel, "Effects of State Government Policies on Electricity Capacity from NonHydropower Renewable Sources," Unpublished Manuscript, Jun, 2008.

[101] N. H. Afgan and M. G. Carvalho, "Multi-criteria assessment of new and renewable energy power plants," Energy, vol. 27, pp. 739-755, 2002.

[102] N. H. Afgan, A. Veziroglu, and M. G. Carvalho, "Multi-criteria evaluation of hydrogen system options," International Journal of Hydrogen Energy, vol. 32, pp. 3183-3193, 2007.

[103] B. F. Hobbs and G. T. F. Horn, "Building public confidence in energy planning: a multimethod MCDM approach to demand-side planning at BC gas," Energy Policy, vol. 25, pp. 357-375, 1997.

[104] R. L. Keeney, O. Renn, and D. von Winterfeldt, "Structuring West Germany's energy objectives," Energy Policy, vol. 15, pp. 352-362, 1987.

[105] J. R. San Cristóbal, "Multi-criteria decision-making in the selection of a renewable energy project in spain: The Vikor method," Renewable Energy, vol. 36, pp. 498-502, 2011.

[106] V. Schulz and H. Stehfest, "Regional energy supply optimization with multiple objectives," European Journal of Operational Research, vol. 17, pp. 302-312, 1984.

[107] H. Aras, S. Erdogmus, and E. Koç, "Multi-criteria selection for a wind observation station location using analytic hierarchy process," Renewable Energy, vol. 29, pp. 1383-1392, 2004.

[108] S. K. Lee, G. Mogi, and J. W. Kim, "Decision support for prioritizing energy technologies against high oil prices: A fuzzy analytic hierarchy process approach," Journal of Loss Prevention in the Process Industries, vol. 22, pp. 915-920, 2009.

[109] G. Intepe, E. Bozdag, and T. Koc, "The selection of technology forecasting method using a multi-criteria interval-valued intuitionistic fuzzy group decision making approach," Computers \& Industrial Engineering, vol. 65, pp. 277-285, 6// 2013. 
[110] A. L. Porter, S. W. Cunningham, J. Banks, A. T. Roper, T. W. Mason, and F. A. Rossini, Forecasting and management of technology: Wiley, 2011.

[111] S. Moon and Y. Jeon, "How valid are long-term government plans? Technological forecasting of the Korean biotechnology industry," Journal of Policy Modeling, vol. 31, pp. 891-902, 2009.

[112] Y.-H. Chen, C.-Y. Chen, and S.-C. Lee, "Technology forecasting and patent strategy of hydrogen energy and fuel cell technologies," International Journal of Hydrogen Energy, vol. 36, pp. 6957-6969, 2011.

[113] W. Kim, S. K. Han, K. J. Oh, T. Y. Kim, H. Ahn, and C. Song, "The dual analytic hierarchy process to prioritize emerging technologies," Technological Forecasting and Social Change, vol. 77, pp. 566-577, 2010.

[114] J. Climaco, Multicriteria analysis. New York: Springer-Verlag, 1997.

[115] S. D. Pohekar and M. Ramachandran, "Application of multi-criteria decision making to sustainable energy planning--A review," Renewable and Sustainable Energy Reviews, vol. 8, pp. 365-381, 2004.

[116] H. Polatidis, D. A. Haralambopoulos, G. Munda, and R. Vreeker, "Selecting an Appropriate Multi-Criteria Decision Analysis Technique for Renewable Energy Planning," Energy Sources Part B: Economics, Planning \& Policy, vol. 1, pp. 181-193, 2006.

[117] M.-T. Chu, J. Shyu, G.-H. Tzeng, and R. Khosla, "Comparison among three analytical methods for knowledge communities group-decision analysis," Expert Systems with Applications, vol. 33, pp. 1011-1024, 2007.

[118] J.-J. Wang, Y.-Y. Jing, C.-F. Zhang, and J.-H. Zhao, "Review on multi-criteria decision analysis aid in sustainable energy decision-making," Renewable and Sustainable Energy Reviews, vol. 13, pp. 2263-2278, 2009.

[119] P. Zhou, B. W. Ang, and K. L. Poh, "Decision analysis in energy and environmental modeling: An update," Energy, vol. 31, pp. 2604-2622, 2006.

[120] T. L. Saaty, The analytic hierarchy process. New York: McGraw-Hill, 1980.

[121] R. W. Saaty, "The analytic hierarchy process--what it is and how it is used," Mathematical Modelling, vol. 9, pp. 161-176, 1987.

[122] T. L. Saaty, Decision making with dependence and feedback: The analytic network process. Pittsburgh: RSW Publications, 1996. 
[123] E. W. L. Cheng and H. Li, "Analytic Network Process Applied to Project Selection," Journal of Construction Engineering and Management, vol. 131, pp. 459-466, 2005.

[124] J. Oberschmidt, J. Geldermann, J. Ludwig, and M. Schmehl, "Modified PROMETHEE approach for assessing energy technologies," international Journal of Energy Sector Management, vol. 4, pp. 183-212, 2010.

[125] J.-J. Wang, Y.-Y. Jing, C.-F. Zhang, G.-H. Shi, and X.-T. Zhang, "A fuzzy multi-criteria decision-making model for trigeneration system," Energy Policy, vol. 36, pp. 3823-3832, 2008.

[126] M. Wang, S. J. Lin, and Y. C. Lo, "The comparison between MAUT and PROMETHEE," in Industrial Engineering and Engineering Management (IEEM), 2010 IEEE International Conference on, 2010, pp. 753-757.

[127] J. Burton and K. Hubacek, "Is small beautiful? A multicriteria assessment of small-scale energy technology applications in local governments," Energy Policy, vol. 35, pp. 64026412, 2007.

[128] A. Ç. Köne and T. Büke, "An Analytical Network Process (ANP) evaluation of alternative fuels for electricity generation in Turkey," Energy Policy, vol. 35, pp. 5220-5228, 2007.

[129] Z. Jianjian, Y. Zeliang, and C. Shaoyou, "Multi-criteria evaluation of alternative power supply using analytic hierarchy process," in Sustainable Power Generation and Supply, 2009. SUPERGEN '09. International Conference on, 2009, pp. 1-7.

[130] Y. I. Topcu and F. Ulengin, "Energy for the future: An integrated decision aid for the case of Turkey," Energy, vol. 29, pp. 137-154, 2004.

[131] S. K. Lee, G. Mogi, and J. W. Kim, "The competitiveness of Korea as a developer of hydrogen energy technology: The AHP approach," Energy Policy, vol. 36, pp. 1284-1291, 2008.

[132] S. K. Lee, G. Mogi, S. K. Lee, K. S. Hui, and J. W. Kim, "Econometric analysis of the R\&D performance in the national hydrogen energy technology development for measuring relative efficiency: The fuzzy AHP/DEA integrated model approach," International Journal of Hydrogen Energy, vol. 35, pp. 2236-2246, 2010.

[133] R. P. Hämäläinen and R. Karjalainen, "Decision support for risk analysis in energy policy," European Journal of Operational Research, vol. 56, pp. 172-183, 1992.

[134] M. M. Kablan, "Decision support for energy conservation promotion:: an analytic hierarchy process approach," Energy Policy, vol. 32, pp. 1151-1158, 72004. 
[135] T. Kaya and C. Kahraman, "Multicriteria renewable energy planning using an integrated fuzzy VIKOR \& AHP methodology: The case of Istanbul," Energy, vol. 35, pp. 2517-2527, 2010.

[136] A. I. Chatzimouratidis and P. A. Pilavachi, "Technological, economic and sustainability evaluation of power plants using the Analytic Hierarchy Process," Energy Policy, vol. 37, pp. 778-787, 2009.

[137] A. I. Chatzimouratidis and P. A. Pilavachi, "Sensitivity analysis of technological, economic and sustainability evaluation of power plants using the analytic hierarchy process," Energy Policy, vol. 37, pp. 788-798, 2009.

[138] D. A. Haralambopoulos and H. Polatidis, "Renewable energy projects: structuring a multi-criteria group decision-making framework," Renewable Energy, vol. 28, pp. 961973, 2003.

[139] H. Polatidis and D. A. Haralambopoulos, "Local Renewable Energy Planning: A Participatory Multi-Criteria Approach," Energy Sources, vol. 26, pp. 1253-1264, 2004.

[140] M. Beccali, M. Cellura, and M. Mistretta, "Decision-making in energy planning. Application of the Electre method at regional level for the diffusion of renewable energy technology," Renewable Energy, vol. 28, pp. 2063-2087, 102003.

[141] C. Kahraman, I. Kaya, and S. Cebi, "A comparative analysis for multiattribute selection among renewable energy alternatives using fuzzy axiomatic design and fuzzy analytic hierarchy process," Energy, vol. 34, pp. 1603-1616, 2009.

[142] T. Daim, D. Yates, Y. Peng, and B. Jimenez, "Technology assessment for clean energy technologies: The case of the Pacific Northwest," Technology in Society, vol. 31, pp. 232243, 2009.

[143] P. Aragonés-Beltrán, F. Chaparro-González, J. P. Pastor-Ferrando, and F. Rodríguez-Pozo, "An ANP-based approach for the selection of photovoltaic solar power plant investment projects," Renewable and Sustainable Energy Reviews, vol. 14, pp. 249-264, 2010.

[144] J. A. Cherni, I. Dyner, F. Henao, P. Jaramillo, R. Smith, and R. O. Font, "Energy supply for sustainable rural livelihoods. A multi-criteria decision-support system," Energy Policy, vol. 35, pp. 1493-1504, 2007.

[145] A. H. I. Lee, H. H. Chen, and H.-Y. Kang, "Multi-criteria decision making on strategic selection of wind farms," Renewable Energy, vol. 34, pp. 120-126, 12009. 
[146] J. P. Huang, K. L. Poh, and B. W. Ang, "Decision analysis in energy and environmental modeling," Energy, vol. 20, pp. 843-855, 1995.

[147] P. Zhou, B. W. Ang, and K. L. Poh, "A survey of data envelopment analysis in energy and environmental studies," European Journal of Operational Research, vol. 189, pp. 1-18, 2008.

[148] L. A. Greening and S. Bernow, "Design of coordinated energy and environmental policies: use of multi-criteria decision-making," Energy Policy, vol. 32, pp. 721-735, 2004.

[149] R. Lahdelma, P. Salminen, and J. Hokkanen, "Using multicriteria methods in environmental planning and management," Environmental Management, vol. 26, pp. 595-605, 2000.

[150] K. D. Patlitzianas, K. Ntotas, H. Doukas, and J. Psarras, "Assessing the renewable energy producers' environment in EU accession member states," Energy Conversion and Management, vol. 48, pp. 890-897, 2007.

[151] S. Mirasgedis and D. Diakoulaki, "Multicriteria analysis vs. externalities assessment for the comparative evaluation of electricity generation systems," European Journal of Operational Research, vol. 102, pp. 364-379, 1997.

[152] N. H. Afgan and M. G. Carvalho, "Sustainability assessment of a hybrid energy system," Energy Policy, vol. 36, pp. 2903-2910, 2008.

[153] N. H. Afgan, P. A. Pilavachi, and M. G. Carvalho, "Multi-criteria evaluation of natural gas resources," Energy Policy, vol. 35, pp. 704-713, 2007.

[154] S. Roth, S. Hirschberg, C. Bauer, P. Burgherr, R. Dones, T. Heck, et al., "Sustainability of electricity supply technology portfolio," Annals of Nuclear Energy, vol. 36, pp. 409-416, 2009.

[155] G.-H. Tzeng, C.-W. Lin, and S. Opricovic, "Multi-criteria analysis of alternative-fuel buses for public transportation," Energy Policy, vol. 33, pp. 1373-1383, 2005.

[156] F. Begic and N. H. Afgan, "Sustainability assessment tool for the decision making in selection of energy system--Bosnian case," Energy, vol. 32, pp. 1979-1985, 2007.

[157] P. Espie, G. W. Ault, G. M. Burt, and J. R. McDonald, "Multiple criteria decision making techniques applied to electricity distribution system planning," IEE Proceedings -Generation, Transmission \& Distribution, vol. 150, pp. 527-535, 2003. 
[158] M. G. Goumas, V. A. Lygerou, and L. E. Papayannakis, "Computational methods for planning and evaluating geothermal energy projects," Energy Policy, vol. 27, pp. 147154, 1999.

[159] E. Y. Ivanova, N. I. Voropai, and E. Handschin, "A multi - criteria approach to expansion planning of wind power plants in electric power systems," in Power Tech, 2005 IEEE Russia, 2005, pp. 1-4.

[160] I. Linkov, F. K. Satterstrom, G. Kiker, C. Batchelor, T. Bridges, and E. Ferguson, "From comparative risk assessment to multi-criteria decision analysis and adaptive management: Recent developments and applications," Environment International, vol. 32, pp. 1072-1093, 2006.

[161] A. Zani, G. Migliavacca, and A. Grassi, "A scenario analysis for an optimal RES integration into the European transmission grid up to 2050," in Energy Market (EEM), 2011 8th International Conference on the European, 2011, pp. 401-406.

[162] B. F. Hobbs and P. M. Meier, "Multicriteria methods for resource planning: an experimental comparison," Power Systems, IEEE Transactions on, vol. 9, pp. 1811-1817, 2002.

[163] B. Wang, D. F. Kocaoglu, T. U. Daim, and J. Yang, "A decision model for energy resource selection in China," Energy Policy, vol. 38, pp. 7130-7141, 2010.

[164] P. Gerdsri and D. F. Kocaoglu, "HDM for developing national emerging technology strategy and policy supporting sustainable economy: A case study of nanotechnology for Thailand\&\#x2019;s agriculture," in Management of Engineering \& Technology, 2008. PICMET 2008. Portland International Conference on, 2008, pp. 344-350.

[165] F. Elkarmi and I. Mustafa, "Increasing the utilization of solar energy technologies (SET) in Jordan: Analytic hierarchy process," Energy Policy, vol. 21, pp. 978-984, 1993.

[166] S. K. Lee, Y. J. Yoon, and J. W. Kim, "A study on making a long-term improvement in the national energy efficiency and GHG control plans by the AHP approach," Energy Policy, vol. 35, pp. 2862-2868, 2007.

[167] H. Chen and D. F. Kocaoglu, "A sensitivity analysis algorithm for hierarchical decision models," European Journal of Operational Research, vol. 185, pp. 266-288, 2008.

[168] J. E. Smith and D. Von Winterfeldt, "Decision Analysis in" Management Science"," Management science, pp. 561-574, 2004. 
[169] P. E. Williams, "Roles and competencies for distance education programs in higher education institutions," The American Journal of Distance Education, vol. 17, pp. 45-57, 2003.

[170] M. R. de Villiers, P. J. T. de Villiers, and A. P. Kent, "The Delphi technique in health sciences education research," Medical Teacher, vol. 27, pp. 639-643, 2005.

[171] P. Gerdsri and D. Kocaoglu, "A systematic approach to developing national technology policy and strategy for emerging technologies: A case study of nanotechnology for Thailand's agriculture industry," pp. 447-461.

[172] N. Sheikh, T. Daim, and D. F. Kocaoglu, "Use of multiple perspectives and decision modeling for PV technology assessment," pp. 1-21.

[173] K. K. Lilja, K. Laakso, and J. Palomki, "Using the Delphi method," pp. 1-10.

[174] T. U. Daim, "Technology evaluation and acquisition strategies and their implications in the U. S. electronics manufacturing industry," 1998.

[175] G. F. P. Ramos, S. Kuiper, E. Dompeling, A. D. I. van Asselt, W. J. C. de Grauw, J. A. Knottnerus, et al., "Structuring and validating a cost-effectiveness model of primary asthma prevention amongst children," BMC medical research methodology, vol. 11, p. 150, 2011.

[176] C. Evans, "The use of consensus methods and expert panels in pharmacoeconomic studies. Practical applications and methodological shortcomings," Pharmacoeconomics, vol. 12, p. 121, 1997.

[177] C. Evans and B. Crawford, "Expert judgement in pharmacoeconomic studies: guidance and future use," Pharmacoeconomics, vol. 17, pp. 545-553, 2000.

[178] M. McKee, P. Priest, M. Ginzler, and N. Black, "How representative are members of expert panels?," International Journal for Quality in Health Care, vol. 3, p. 89, 1991.

[179] S. Keeney, F. Hasson, and H. P. McKenna, "A critical review of the Delphi technique as a research methodology for nursing," International Journal of Nursing Studies, vol. 38, pp. 195-200, 2001.

[180] A. J. M. R. H. Fink, American Journal of Public Health, vol. 74, pp. 979-983, 1984.

[181] D. J. Weiss and J. Shanteau, "Empirical assessment of expertise," Human Factors: The Journal of the Human Factors and Ergonomics Society, vol. 45, pp. 104-116, 2003. 
[182] P. E. Shrout and J. L. Fleiss, "Intraclass correlations: uses in assessing rater reliability," Psychological bulletin, vol. 86, p. 420, 1979.

[183] D. F. Kocaoglu, "A participative approach to program evaluation," Engineering Management, IEEE Transactions on, pp. 112-118, 1983.

[184] P. Gerdsri, "A systematic approach to developing national technology policy and strategy for emerging technologies.," Portland State University, Portland State University, United States -- Oregon., Dissertations \& Theses @ Portland State University.(Publication No. AAT 3370138). 2009.

[185] P. Oregon. Office of Energy Research and and C. Oregon. Energy, Transition : a book on future energy : nuclear or solar? [Portland]: Prometheus Unbound, Specialty Books, 1977.

[186] (2012). Available: http://www.eia.gov/electricity/state/pdf/sep2010.pdf

[187] "State of Oregon Energy Plan," Oregon Department of Energy2012.

[188] Y. Yao, "A socio-political analysis of policies and incentives applicable to community wind in Oregon," Energy Policy.

[189] O. D. o. Energy, "Biofuels Impact Study," 2010.

[190] (2012). Energy Report - Overview: Renewable Energy. Available: http://www.window.state.tx.us/specialrpt/energy/renewable/

[191] (2012). EIA - State Energy Data System. Available:

http://www.eia.gov/state/seds/hf.jsp?incfile=sep use/total/use tot ORcb.html\&mstat e=Oregon

[192] (2012). State Fact Sheets. Available:

http://www.awea.org/learnabout/publications/factsheets/factsheets state.cfm

[193] (2012). Behind Iberdrola's Portland layoffs: expiring wind-energy tax credits, declining demand, overloaded grid, cheap natural gas / Oregon Live.com. Available:

http://www.oregonlive.com/business/index.ssf/2012/01/behind iberdrolas portland I ay.html

[194] (2012). Ecological Effects of Wave Energy Development in the Pacific Northwest. Available: http://hmsc.oregonstate.edu/waveenergy/ 
[195] M. Stefanovich, "Wave energy and public opinion in the state of Oregon, U.S.A," in OCEANS 2009, MTS/IEEE Biloxi - Marine Technology for Our Future: Global and Local Challenges, 2009, pp. 1-10.

[196] (2012). Renewable Energy Ocean Wave Energy Development. Available: http://www.oregon.gov/ENERGY/RENEW/Hydro/Ocean Wave.shtml

[197] (2012). Landfill Gas « Northwest Renewable News. Available: http://nwrenewablenews.wordpress.com/category/landfill-gas/

[198] (2012). Pacific Northwest landfills powering 7,500 homes / BrighterEnergy.org. Available: http://www.brighterenergy.org/24138/news/bioenergy/pacific-northwestlandfills-powering-7500-homes/

[199] T. U. Daim, G. Kayakutlu, and K. Cowan, "Developing Oregon's renewable energy portfolio using fuzzy goal programming model," Computers \& Industrial Engineering, vol. 59, pp. 786-793, 2010.

[200] D. J. Sailor, M. Smith, and M. Hart, "Climate change implications for wind power resources in the Northwest United States," Renewable Energy, vol. 33, pp. 2393-2406, 112008.

[201] R. W. Baker, E. W. Hewson, N. G. Butler, and E. J. Warchol, "Wind power potential in the Pacific Northwest," J. Appl. Meteorol.;(United States), vol. 17, 1978.

[202] (2012). Solar-Oregon.org. Available: http://www.solar-oregon.org/

[203] Y. Zia A, "Solar energy in the Northwest U.S," Energy, vol. 10, pp. 1159-1164, 1985.

[204] C. Richard W, "Solar energy collection in the Pacific Northwest," Solar Energy, vol. 1, pp. 3-8, 1957.

[205] T. L. Kelly-Yong, K. T. Lee, A. R. Mohamed, and S. Bhatia, "Potential of hydrogen from oil palm biomass as a source of renewable energy worldwide," Energy Policy, vol. 35, pp. 5692-5701, 112007.

[206] M. A. P. Stefanovich, "Does concern for global warming explain support for wave energy development? A case study from Oregon, U.S.A," in OCEANS, 2011 IEEE - Spain, 2011, pp. 1-9.

[207] J. B. Heeter, L., "Status and Trends in U.S. Compliance and Voluntary Renewable Energy Certificate Markets (2010 Data)," National Renewable Energy Laboratory2011. 
[208] (2012). Green Power Network: Mandatory Utility Green Power Option. Available: http://apps3.eere.energy.gov/greenpower/markets/state policies.shtml\#content

[209] (2012). Green Power Network: Net Metering. Available: http://apps3.eere.energy.gov/greenpower/markets/netmetering.shtml

[210] "2009 Updates and Trends," INTERSTATE RENEWABLE ENERGY COUNCIL2009.

[211] (2012). Washington State Introduces Feed-in Tariff / Renewable Energy News Article. Available:

http://www.renewableenergyworld.com/rea/news/article/2009/02/washington-stateintroduces-feed-in-tariff-54645

[212] (2012). Oregon utilities to start feed-in tariff programs / Daily Journal of Commerce. Available: http://djcoregon.com/news/2010/06/15/oregon-utilities-to-start-feed-intariff-programs/

[213] (2007). Senate Bill 838. Available: http://www.oregon.gov/ENERGY/RENEW/docs/sb0838.a.pdf?ga=t

[214] (2012). Energy Central - Member Sign In. Available: http://pro.energycentral.com/professional/news/power/news article.cfm?id=2317113 $\underline{5}$

[215] A. I. Chatzimouratidis and P. A. Pilavachi, "Multicriteria evaluation of power plants impact on the living standard using the analytic hierarchy process," Energy Policy, vol. 36, pp. 1074-1089, 2008.

[216] A. I. Chatzimouratidis and P. A. Pilavachi, "Sensitivity analysis of the evaluation of power plants impact on the living standard using the analytic hierarchy process," Energy Conversion and Management, vol. 49, pp. 3599-3611, 2008.

[217] N. Zografakis, E. Sifaki, M. Pagalou, G. Nikitaki, V. Psarakis, and K. P. Tsagarakis, "Assessment of public acceptance and willingness to pay for renewable energy sources in Crete," Renewable and Sustainable Energy Reviews, vol. 14, pp. 1088-1095, 2010.

[218] (2013). Available: http://www.gao.gov/new.items/d07106.pdf

[219] M. Jefferson, "Sustainable energy development: performance and prospects," Renewable Energy, vol. 31, pp. 571-582, 2006.

[220] R. U. Ayres, H. Turton, and T. Casten, "Energy efficiency, sustainability and economic growth," Energy, vol. 32, pp. 634-648, 2007. 
[221] M. Black and G. Strbac, "Value of storage in providing balancing services for electricity generation systems with high wind penetration," Journal of power sources, vol. 162, pp. 949-953, 2006.

[222] T. J. Hammons, "Integrating renewable energy sources into European grids," International Journal of Electrical Power \& Energy Systems, vol. 30, pp. 462-475, 10 2008.

[223] J. P. Painuly, "Barriers to renewable energy penetration; a framework for analysis," Renewable Energy, vol. 24, pp. 73-89, 2001. 
APPENDICES

Appendix (A) Model development process 


\section{Proposed assessment model}

A comprehensive literature review in the area of renewable energy adoption, renewable energy policy assessment models and decision making in the energy field was conducted and presented in Chapter 2. Based on the findings of this review, a preliminary assessment model was developed containing a large number of assessment variables.

These variables were categorized according to the RISE model perspectives for assessment (economic, social, political, environmental and technical). Please see below for the preliminary assessment model.

Perspectives and Policy targets from literature review

\begin{tabular}{|c|c|c|c|}
\hline RISE perspective & Perspectives & Policy targets & Literature \\
\hline \multirow{3}{*}{ Economic } & \multirow{3}{*}{$\begin{array}{l}\text { Improve economic } \\
\text { feasibility. }\end{array}$} & Reduce initial investment cost. & \multirow[t]{3}{*}[25,31,154]{} \\
\hline & & $\begin{array}{c}\text { Keep production cost } \\
\text { competitive with conventional } \\
\text { resources. }\end{array}$ & \\
\hline & & $\begin{array}{c}\text { Encourage private sector } \\
\text { investments. }\end{array}$ & \\
\hline \multirow{3}{*}{ Social } & \multirow{3}{*}{ Improve quality of life } & Work force impact & \multirow{3}{*}{$\begin{array}{c}{[87,140,215-} \\
217]\end{array}$} \\
\hline & & Use of local energy resources & \\
\hline & & Customers willing to pay & \\
\hline \multirow{2}{*}{ Political } & \multirow{2}{*}{$\begin{array}{l}\text { Increase institutional } \\
\text { support }\end{array}$} & Support Technology R\&D & \multirow{2}{*}{$\begin{array}{c}{[26,40,41,44,} \\
218]\end{array}$} \\
\hline & & Work force training & \\
\hline \multirow[b]{2}{*}{ Environmental } & \multirow{2}{*}{$\begin{array}{l}\text { Minimize environmental } \\
\text { effects }\end{array}$} & Reduce GHG emissions. & \multirow[t]{2}{*}[118,219,220]{} \\
\hline & & $\begin{array}{l}\text { Land conservation and Wild } \\
\text { life protection }\end{array}$ & \\
\hline \multirow{5}{*}{ Technical } & \multirow{5}{*}{$\begin{array}{l}\text { Enhance technical } \\
\text { capabilities }\end{array}$} & Grid access. & \multirow[t]{5}{*}[59,73,221-223]{} \\
\hline & & Transmission capabilities. & \\
\hline & & Smart grid integration & \\
\hline & & Improve source diversity & \\
\hline & & Improve source efficiency & \\
\hline
\end{tabular}




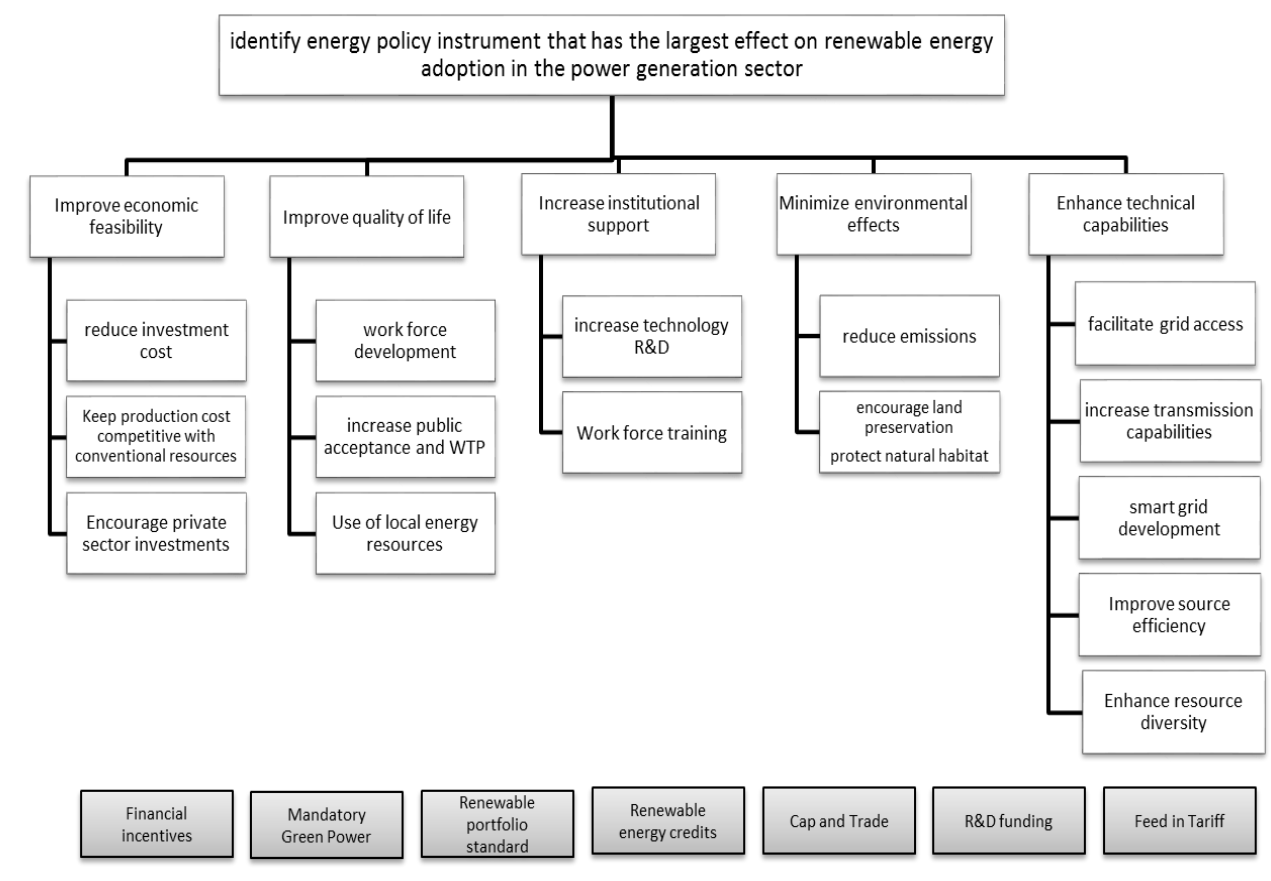

Preliminary Assessment Model

\section{Revised Assessment Model}

The preliminary assessment model was then presented to a group of experts who have experience in different aspects of the renewable energy policy field in the Pacific NW. Please refer to the following table for the profiles of those experts. Variables and perspectives of the proposed model were discussed with the experts. The objective of the research as well as the preliminary assessment model were introduced and explained to the experts in the course of the face-to-face meetings. Their comments and suggestions were recorded and taken into consideration for developing the revised assessment model. 


\begin{tabular}{|c|c|c|c|}
\hline Expert & Affiliation & Position & Sector \\
\hline Expert 1 & Oregon Department of Energy & Senior policy analyst & Government \\
\hline Expert 2 & Oregon Public Utility Commission & Senior utility analyst & Government \\
\hline Expert 3 & Oregon Public Utility Commission & Senior utility analyst & Government \\
\hline Expert 4 & Oregon Department of Energy & Senior Policy Analyst & Government \\
\hline Expert 5 & Bonneville Power Administration & Public Utilities Specialist & Utility \\
\hline Expert 6 & $\begin{array}{c}\text { Northwest Renewable energy } \\
\text { project }\end{array}$ & Policy Advisor & $\begin{array}{c}\text { Non-governmental } \\
\text { organization }\end{array}$ \\
\hline
\end{tabular}

Based on the experts' feedback and comments, it was concluded that the variables in the preliminary model were a mix of policy input to maximize renewable energy benefits which will eventually make RE more desirable, and policy input to overcome factors that can drive the adoption of renewable resources in the power generation sector. It was noted that the suggested model variables were not consistent, and included a mix of drivers, outputs and facilitators of adoption. As a result of the experts' interviews and comments, it was decided that being consistent throughout the model is more effective for comparing between policies and ranking them. It was noted that considering policy effects and effectiveness on the input of the adoption process gives more accurate assessment since outputs of adoption could be a result of different factors and it would hard for judgment quantification expert panels to distinguish between policy effects. Furthermore, comments about alternatives noted that $R \& D$ funding is not a separate policy and renewable energy credits are attached to the RPS and not a separate policy. Based on the interview experts' feedback, the preliminary model was revised. Please see model on following page for the revised assessment model. 


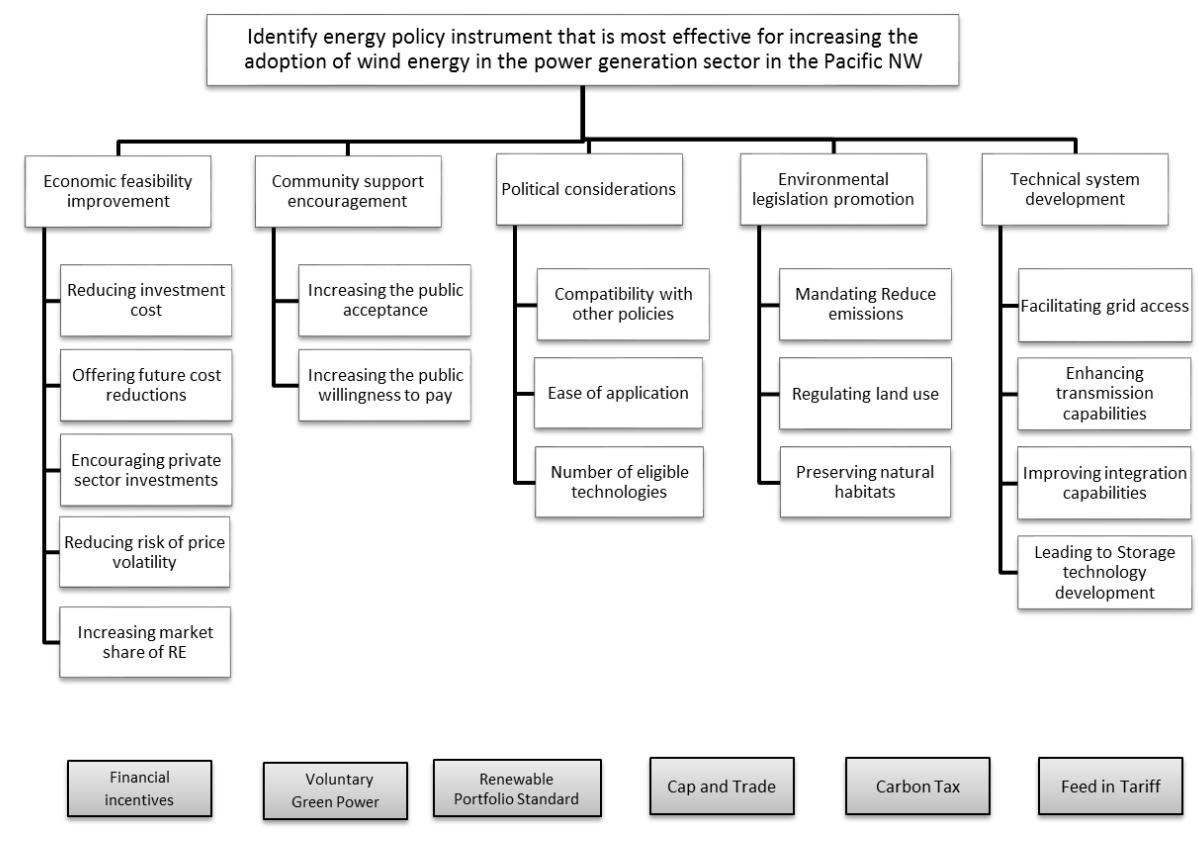

Revised Assessment Model

For final feedback, the revised model was then presented to the experts. A second round of experts' opinions was recorded to insure the rationality of the model and the suitability of the variables in the revised model. It is noted that the revised model covers the important Perspectives and policy targets for the assessment of energy policy effectiveness, that the revised model can distinguish between policy alternatives, and that the experts are able to provide quantified judgments.

\section{Model Validation}

The next step in developing the assessment model was the validation of the revised model to obtain experts' judgments about the suitability of the model's variables and their ability to measure what they are intended to measure. Experts were asked to 
verify that the variables in the model are appropriate for measuring policy effectiveness on RE adoption. Content validations had eliminated variables that were not of importance and added new variables to the revised model. In this stage of model development, a number of web-based content validity instruments were designed and tested by a group of $\mathrm{PhD}$ students in the Department of Engineering and Technology Management (ETM) for clarity and appropriateness. Experts were sent invitations to participate and it was explained that their participation was voluntary and confidential. Please refer to Appendix (A)for the research instruments used and experts' correspondence. The objective of the research, the purpose of the web based instrument, and definitions of the assessment model variables were provided to the experts. In this validation stage, experts were asked to provide their opinions about whether or not the proposed variables were appropriate within the scope of the research by answering yes or no questions.

A total of 36 experts, four international scholars and 32 experts from the energy sector in the Pacific Northwest, had participated in this validation step. Experts were distributed into six panels and model validation was performed through seven content validity instruments, distributed according the experts' expertise. It should be noted that some of the participants were included in more than one panel. Please see table below for content validity instrument distribution and size of expert panels.

Validation Expert Panels Design

\begin{tabular}{|c|c|c|c|}
\hline Panel & Content validity instrument & Role of experts & $\begin{array}{c}\text { Number of } \\
\text { experts }\end{array}$ \\
\hline EP1 & Content validity instrument 1 & Validate Perspectives level & 19 \\
\hline
\end{tabular}




\begin{tabular}{|c|c|c|c|}
\hline EP2 & Content validity instrument 2 & Validate economic policy targets & 13 \\
\hline EP3 & Content validity instrument 3 & Validate social policy targets & 14 \\
\hline EP4 & Content validity instrument 4 & Validate regulatory policy targets & 16 \\
\hline EP5 & Content validity instrument 5 & $\begin{array}{c}\text { Validate environmental policy } \\
\text { targets }\end{array}$ & 14 \\
\hline EP6 & Content validity instrument 6 & Validate technical policy targets & 16 \\
\hline EP7 & Content validity instrument 7 & Validate Alternatives policy targets & 28 \\
\hline
\end{tabular}

At least two-thirds of the experts on any panel had to agree on the variable's appropriateness in order for it to be included in the finalized assessment model. As a result of the content validation, most of the proposed variables were judged to be appropriate for the purpose of this research. A few variables had changed and experts' comments were taken into account for finalizing the assessment model.

Expert Panel 1 focused on validating the appropriateness of policy assessment Perspectives and experts were sent content validity instrument 1. A total of 19 experts provided input. As a result, all assessment Perspectives were accepted and included in the final model. Please see table below for a summary of experts' responses.

Expert Panel 1, Perspectives Level Validation

\begin{tabular}{|c|c|c|c|c|}
\hline Perspectives & $\begin{array}{c}\text { Experts } \\
\text { yes }\end{array}$ & Experts no & $\begin{array}{c}\text { Agreement } \\
\text { percentage }\end{array}$ & Accepted \\
\hline $\begin{array}{c}\text { Economic feasibility } \\
\text { improvement }\end{array}$ & 19 & 0 & $100 \%$ & Yes \\
\hline $\begin{array}{c}\text { Community support } \\
\text { encouragement }\end{array}$ & 16 & 3 & $84 \%$ & Yes \\
\hline Political considerations & 16 & 3 & $84 \%$ & Yes \\
\hline $\begin{array}{c}\text { Environmental legislation } \\
\text { promotion }\end{array}$ & 19 & 0 & $100 \%$ & Yes \\
\hline Technical system development & 18 & 1 & $95 \%$ & Yes \\
\hline
\end{tabular}

Expert panel 2 focused on validating the appropriateness of economic policy targets in satisfying the economic feasibility improvement and experts were sent content 
validity instrument 2 . A total of 13 experts provided input. As a result, all economic policy targets were accepted and included in the final model except one ("Increasing market share of renewable energy"). Two of the experts had comments on why this is not a viable sub-criterion in this situation. Other experts were contacted and asked about this and confirmed that it should be eliminated from the model. Please see table below for a summary of the experts' responses.

Expert Panel 2, Economic Policy targets Validation

\begin{tabular}{|c|c|c|c|c|}
\hline Economic policy targets & $\begin{array}{c}\text { Experts } \\
\text { yes }\end{array}$ & Experts no & $\begin{array}{c}\text { Agreement } \\
\text { percentage }\end{array}$ & Accepted \\
\hline Reducing Investment Cost & 13 & 0 & $100 \%$ & Yes \\
\hline Offering future cost reductions & 11 & 2 & $85 \%$ & Yes \\
\hline $\begin{array}{c}\text { Encouraging private sector } \\
\text { investment }\end{array}$ & 11 & 2 & $85 \%$ & Yes \\
\hline Reducing risk of price volatility & 13 & 0 & $100 \%$ & Yes \\
\hline $\begin{array}{c}\text { Increasing market share of } \\
\text { renewable energy }\end{array}$ & 10 & 3 & $77 \%$ & No \\
\hline
\end{tabular}

Expert Panel 3 focused on validating the appropriateness of social policy targets in satisfying the community support encouragement Perspectives and experts were sent content validity instrument 3. A total of 14 experts provided input. As a result, "Increasing the public acceptance" sub-criterion was accepted, but "Increasing the public willingness to pay" was rejected. Please see table below for a summary of the experts' responses. Comments provided by experts were reviewed and experts were contacted to discuss their comments. A new sub-criterion ("Increasing public knowledge and awareness") was added as a result. 
Expert Panel 3, Social Policy targets Validation

\begin{tabular}{|c|c|c|c|c|}
\hline Social policy targets & $\begin{array}{c}\text { Experts } \\
\text { yes }\end{array}$ & Experts no & $\begin{array}{c}\text { Agreement } \\
\text { percentage }\end{array}$ & Accepted \\
\hline Increasing the public acceptance & 14 & 0 & $100 \%$ & Yes \\
\hline $\begin{array}{c}\text { Increasing the public willingness } \\
\text { to pay }\end{array}$ & 8 & 6 & $57 \%$ & No \\
\hline
\end{tabular}

Expert panel 4 focused on validating the appropriateness of regulatory policy targets in satisfying the political consideration Perspectives and experts were sent content validity instrument 4 . A total of 16 experts provided input. As a result, two regulatory policy targets were accepted and included in the final model, and one was rejected. Please refer to table below for a summary of experts' responses. Comments provided by experts were reviewed and experts were contacted to discuss their comments. A new subcriterion ("Ratepayer equity") was added and the name of the criterion was changed to (“Regulatory implementation consideration") as a result.

Expert Panel 4, Regulatory Policy targets Validation

\begin{tabular}{|c|c|c|c|c|}
\hline Political policy targets & $\begin{array}{c}\text { Experts } \\
\text { yes }\end{array}$ & Experts no & $\begin{array}{c}\text { Agreement } \\
\text { percentage }\end{array}$ & Accepted \\
\hline Compatibility with other policies & 15 & 1 & $94 \%$ & Yes \\
\hline Ease of application & 13 & 3 & $81 \%$ & Yes \\
\hline Number of eligible technologies & 8 & 8 & $50 \%$ & No \\
\hline
\end{tabular}

Expert panel 5 focused on validating the appropriateness of environmental policy targets in satisfying the environmental Perspectives and experts were sent content validity instrument 5. A total of 14 experts provided input. As a result, all environmental policy targets were accepted and included in the final model. Please see table below for a summary of experts' responses. Comments provided by experts were reviewed and 
experts were contacted to discuss their comments. A new sub-criterion ("Protecting species and migration corridors") was added as a result.

Expert Panel 5, Environmental Policy targets Validation

\begin{tabular}{|c|c|c|c|c|}
\hline Environmental policy targets & $\begin{array}{c}\text { Experts } \\
\text { yes }\end{array}$ & Experts no & $\begin{array}{c}\text { Agreement } \\
\text { percentage }\end{array}$ & Accepted \\
\hline Mandating emissions reduction & 13 & 1 & $93 \%$ & Yes \\
\hline Regulating land use & 11 & 3 & $79 \%$ & Yes \\
\hline Preserving natural habitats & 12 & 2 & $86 \%$ & Yes \\
\hline
\end{tabular}

Expert panel 6 focused on validating the appropriateness of technical policy targets in satisfying the technical system development Perspectives and experts were sent content validity instrument 6 . A total of 16 experts provided input. As a result, all technical policy targets were accepted and included in the final model. Please see table below for a summary of experts' responses. Comments provided by experts were reviewed and experts were contacted to discuss their comments. The name of the fourth sub-criterion was changed (from "Leading to storage technology development" to "Leading to technological development") as a result.

Expert Panel 6, Technical Policy targets Validation

\begin{tabular}{|c|c|c|c|c|}
\hline Technical policy targets & $\begin{array}{c}\text { Experts } \\
\text { yes }\end{array}$ & Experts no & $\begin{array}{c}\text { Agreement } \\
\text { percentage }\end{array}$ & Accepted \\
\hline Facilitating grid access & 15 & 1 & $94 \%$ & Yes \\
\hline $\begin{array}{c}\text { Enhancing transmission } \\
\text { capabilities }\end{array}$ & 14 & 2 & $88 \%$ & Yes \\
\hline $\begin{array}{c}\text { Improving Integration } \\
\text { Capabilities }\end{array}$ & 14 & 2 & $88 \%$ & Yes \\
\hline $\begin{array}{c}\text { Leading to storage technology } \\
\text { development }\end{array}$ & 12 & 4 & $75 \%$ & Yes \\
\hline
\end{tabular}


Expert panel 7 focused on validating the appropriateness of policy alternatives being considered in the assessment and in satisfying the mission and experts were sent content validity instrument 7. A total of 28 experts provided input. As a result, all policy alternatives were accepted and included in the final model. Please see table below for a summary of experts' responses. Further investigation was conducted as a result of some experts' comments in this panel. Experts who had questions and comments were contacted either via email or phone calls. The decision was unanimous and the following changes have been made: "Cap and trade" and "Carbon tax policy" have not been applied in the pacific NW yet and are still debatable, so these Perspectives would be better left for future research. "Feed-in tariffs" are currently only applied for solar or small wind generation and not for utility-scale wind resources, so that criterion was also eliminated. "Financial incentives" are better to be separated according to type of incentives. Finally, policies for connection such as "Net metering" and "Interconnection standards" are important and should be evaluated.

Expert Panel 7, Policy Alternatives Validation

\begin{tabular}{|c|c|c|c|c|}
\hline Alternatives & $\begin{array}{c}\text { Experts } \\
\text { yes }\end{array}$ & Experts no & $\begin{array}{c}\text { Agreement } \\
\text { percentage }\end{array}$ & Accepted \\
\hline Financial incentives & 27 & 0 & $100 \%$ & Yes \\
\hline Voluntary Green Power Option & 24 & 3 & $89 \%$ & Yes \\
\hline RPS & 27 & 0 & $100 \%$ & Yes \\
\hline Cap and Trade & 26 & 1 & $96 \%$ & Yes \\
\hline Carbon tax & 27 & 0 & $100 \%$ & Yes \\
\hline Feed in Tariffs & 25 & 2 & $93 \%$ & Yes \\
\hline
\end{tabular}




\section{Appendix (B) Research instruments}


Appendix B-1: Invitation to be an expert in my $\mathrm{PhD}$ research

Dear Mr. X,

My name is Remal Abotah and I am a PhD student in the Department of Engineering and Technology Management (ETM), at Portland State University. I'm doing research in Technology Management field to develop an assessment model for energy policy instruments and their effectiveness on increasing the adoption of the renewable energy technologies.

As a part of my research, I am forming expert panels to help me validate and quantify my research model. I have identified you as an expert in the field. Your background and expertise will be very helpful in my research. If you agree to participate as an expert an Informed Consent Form will be sent to you for signature. I will be sending you the web-based data collection instruments after I receive the signed form. The research instruments will take about 10-15 minutes each to complete.

I will be honored if you accept my invitation and join my expert panel, and will appreciate it greatly if you also suggest other experts on energy policy planning and renewable resource integration.

You can reply to this email or click below on the provided link to reply at your earliest convenience. I look forward to receiving your reply.

https://portlandstate.qualtrics.com//SE/?SID=SV_bDjSizAMcPdgcND 
Appendix B-2: Consent form

Evaluation of policy instruments for the adoption of renewable energy in the U.S.: A Case of the Pacific Northwest

Dear Mr. X:

You are invited to participate in a research study conducted by Remal Abotah from Portland State University, Engineering and Technology Management Department. The researcher aims to evaluate energy policy instruments in the Pacific Northwest and examine their effect on renewable energy adoption. This project is being conducted in partial fulfillment for the requirements of a $\mathrm{PhD}$ degree under supervision of Dr. Tugrul U. Daim. You were selected as a prospective participant because of your expertise in energy policy planning and renewable resource integration in the Pacific Northwest.

If you decide to participate, you will be asked to utilize your expertise in the field and provide judgments through the research instrument. The task takes about 15 to 30 minutes to complete and will not presents any hazard to the participants. You may not receive any direct benefit from taking part in this study, but the study may help to increase knowledge that may help others in the future.

Participation in this study is voluntary and your name and responses will be confidential and will not be shared with a third party. You do not have to take part in this 
study and you may also withdraw from this study at any time without affecting your career or relationship with any one.

If you have concerns or problems about your participation in this study or your rights as a research subject, please contact the Human Subjects Research Review committee, Office of Research Strategic Partnerships, 1600 SW Fourth Avenue, Suite 620, Portland, OR, 97201, (503) 725 3423. If you have any questions about the study itself, contact Remal Abotah at (503) 8968998.

Your signature indicates that you have read and understand the above information and agree to take part in this study. Please understand that you may withdraw your consent at any time without penalty, and that by signing, you are not waiving any legal claims, rights or remedies.

Signature:

Date: 
Appendix B-3: Content validity link- web survey

Dear Mr. X:

Thank you so much for accepting to participate as an expert in my research.

As the first step of the study, I am asking you to help me finalize the assessment model. Please use the link below for taking the content validity survey, which aims to capture your judgment on a number of proposed assessment variables. Once you accept the consent form you will have access to the questions. The survey instrument will provide the necessary instructions and information you will need.

I would appreciate if you please fill out the survey instrument at your earliest convenience.

I am grateful for your time and contributions.

Follow this link to the Survey:

Or copy and paste the URL below into your internet browser: 


\section{Appendix B-4: Content validity instrument- web survey}

\section{Portland State}

\section{Identification and validation of policy effectiveness measures}

The objective of this research is to assess and prioritize available policy instruments in the power generation sector in terms of their effect on increasing adoption of renewable energy technologies. The scope of the research will be wind powe generation in the Pacific NW. This research will utilize the hierarchical decision model (HDM) to demonstrate criteria in layers which can make the current energy paradigm clearer and aid decision makers in discovering what policies can be further established to increase the adoption of sustainable energy technologies. The results of the HDM model can give insight about which policy instruments are optimal within the alternatives that can be uged in national energy planning. A preliminary model of criteria and sub criteria used in evaluating policy effectiveness has been prepared according to comprehensive literature review. In order to effectively use your time, you are asked to take a limited part of the survey. If you neeed more information about the whole model please click here.

The following survey contains the elements of the proposed model. The purpose of this instrument is to identify and validate assesgment criteria as well as policy instruments in this area. The questions are designed to capture your judgment on the validity of the proposed assessment elements as well as your suggestion of any undetected ones during the literature review. Please note that you can navigate the survey and complete it in multiple sessions. However, you will not have access to the survey after you click submit.

\section{Question 1:}

Five major criteria were identified from the literature review as important elements to be considered in energy policy planning in order for the policy to be effective in facilitating the adoption of renewable energy. Please click here for more detail about each criteria.

Mission

Cnteria

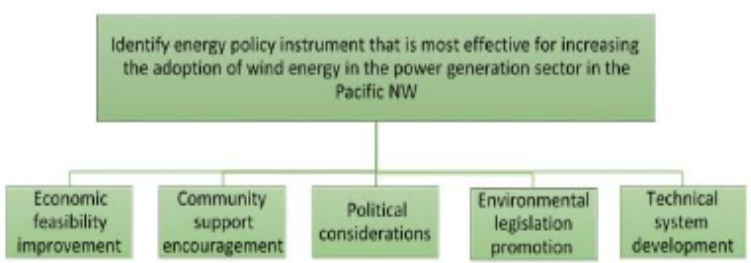

Please specify if the following proposed criteria are important considerations for a policy instrument to accomplish in order to be effective in facilitating wind energy adoption?

\begin{tabular}{|l||c|c|}
\hline & Yos & No \\
\hline Economic feasibility improvement & 0 & 0 \\
Community support encouragement & 0 & 0 \\
political considerations & 0 & 0 \\
Environmental legislation promotion & 0 & 0 \\
Technical system development & 0 & 0 \\
\hline
\end{tabular}

If you think there are other criteria not included in the model, please add them in the space provided. 


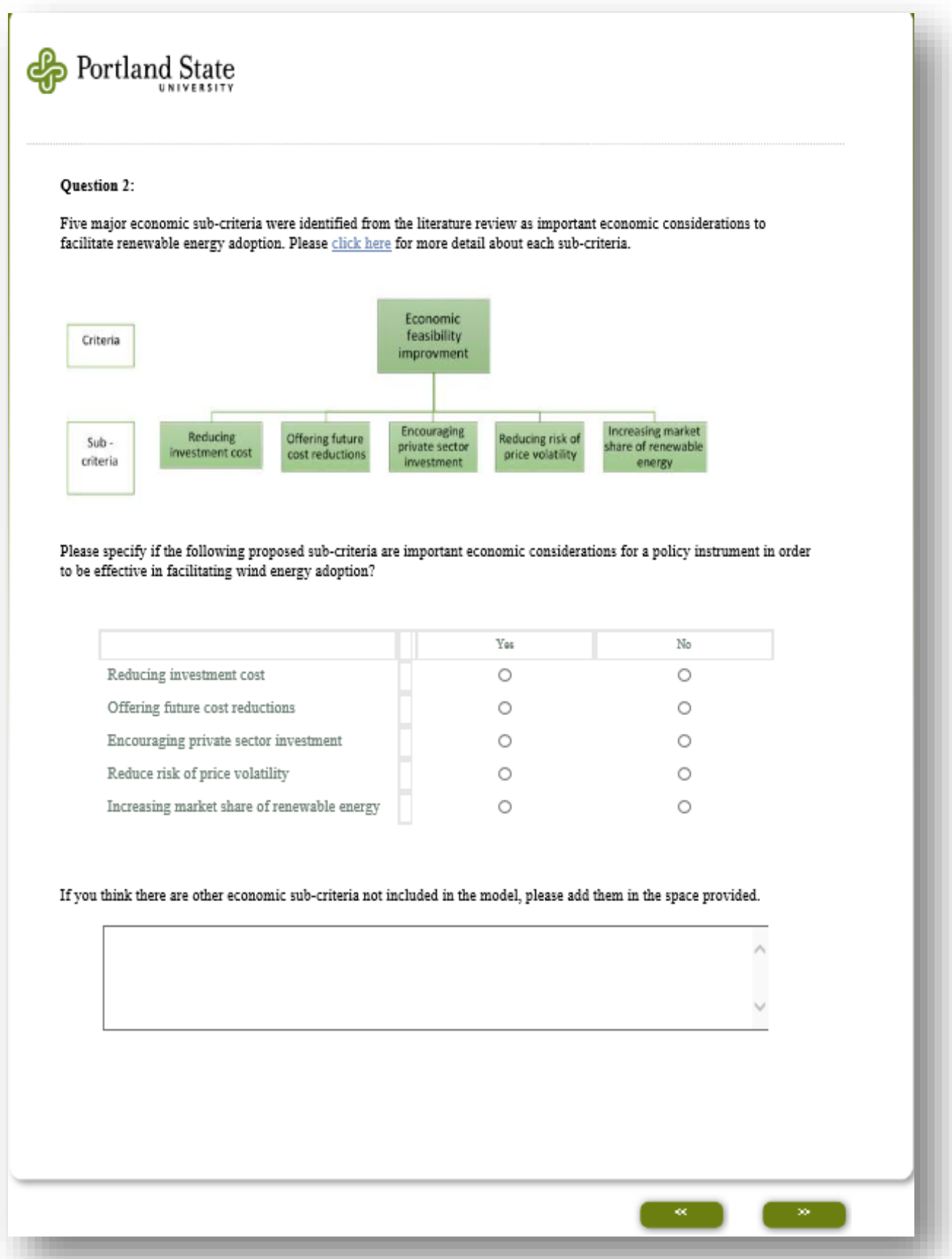




\section{\& Portland State}

Question 3:

Two major sub-criteria were identified from the literature review as important social considerations to facilitate reneewable energy adoption. Please click here for more detail about each sub-criteria.

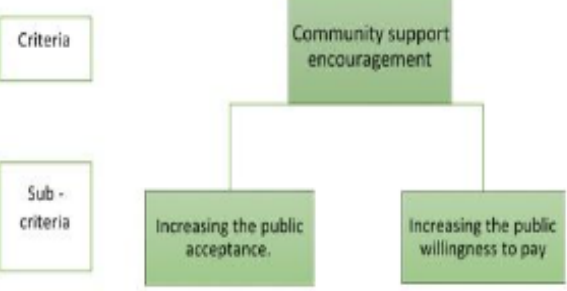

Please specify if the following proposed sub-criteria are important social considerations for a policy instrument in order to be effective in facilitating wind energy adoption?

\begin{tabular}{|l||c|c|}
\hline & Yos & No \\
\hline Increasing public acceptance & 0 & 0 \\
Increasing public willingness to pay & 0 & 0 \\
\hline
\end{tabular}

If you think there are other social sub-criteria not included in the model, please add them in the space provided.

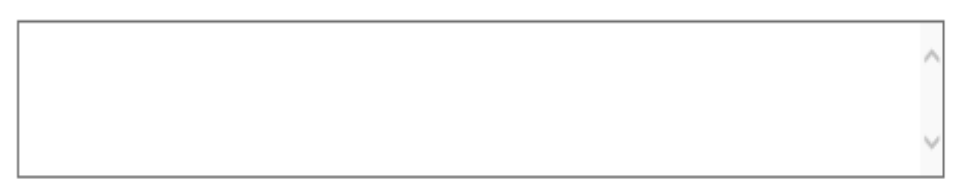




\section{की Portland State}

Question 4:

Three major sub-criteria were identified from the literature review as important political considerations for energy policy instruments to be effective in facilitating renewable energy adoption. Please click here for more detail about each subcriteria.

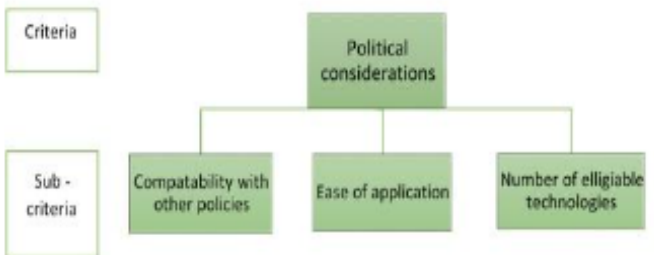

Please specify if the following proposed sub-criteria are important political considerations for a policy instrument in order to be effective in facilitating wind energy adoption?

\begin{tabular}{|l||c|c|}
\hline & $Y_{w 5}$ & No \\
\hline Compatibility with other policies & 0 & 0 \\
Ease of application & 0 & 0 \\
Number of eligible technologies & 0 & 0 \\
\hline
\end{tabular}

If you think there are other political sub-criteria not included in the model, please add them in the space provided.

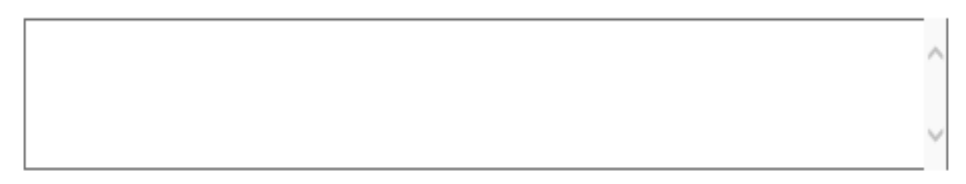




\section{\& Portland State}

Question 5:

Three major sub-criteria were identified from the literature review as important environmental considerations to facilitate renewable energy adoption. Please click here for more detail about each sub-criteria.

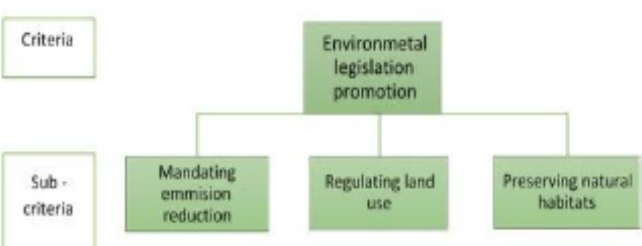

Please specify if the following proposed sub-criteria are important environmental considerations for a policy instrument in order to be effective in facilitating renewable energy adoption?

\begin{tabular}{|l||c|c|}
\hline & Yos & No \\
\hline Mandating emission reduction & 0 & 0 \\
Regulating land use & 0 & 0 \\
preserving natural habitats & 0 & 0 \\
\hline
\end{tabular}

If you think there are other environmental sub-criteria not included in the model, please add them in the space provided.

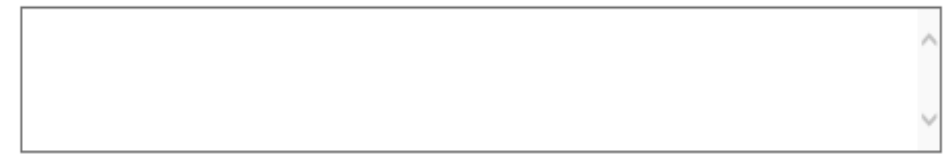




\section{\& Portland State}

Question 6:

Four major sub-criteria were identified from the literature review as important technical considerations for to facilitate renewable energy adoption. Please click here for more detail about each sub-criteria.

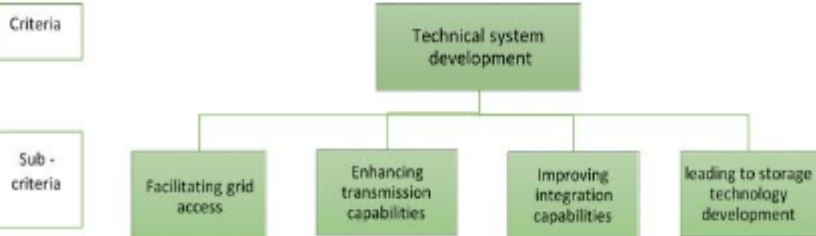

Please specify if the following proposed sub-criteria are important technical considerations for a policy instrument in order to be effective in facilitating wind energy adoption?

\begin{tabular}{l||c|c|}
\hline & Yos & No \\
\hline Facilitating grid access & 0 & 0 \\
Enhancing transmission capabilities & 0 & 0 \\
Improving integration capabilities & 0 & 0 \\
Leading to storage technology development & 0 & 0 \\
\hline
\end{tabular}

If you think there are other sub-criteria not included in the model, please add them in the space provided.

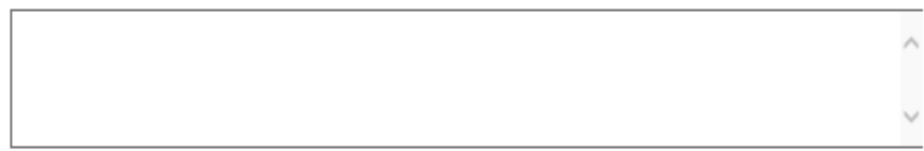

Please indicate your level of confidence in your angtwers

$\begin{array}{lllll}1 & 2 & 3 & 4 & 5 \\ 0 & 0 & 0 & 0 & 0\end{array}$


Part II: Alternatives

Please specify if you are familiar with following energy policy instruments and its effect on facilitating renewable energy adoption.

\begin{tabular}{|l|cc|}
\hline & Yos & No \\
\hline Financial incentives & 0 & 0 \\
Voluntary green power & 0 & 0 \\
Renewable portfolio standards & 0 & 0 \\
Cap and trade & 0 & 0 \\
Carbon tax & 0 & 0 \\
Feed in Tarrifs & 0 & 0 \\
\hline
\end{tabular}

If you think there are other policy instruments not included in the model or you have any suggestions/comments, please add them in the space provided.

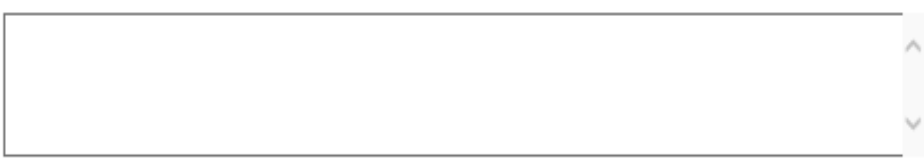

Please indicate your level of confidence in your answers

$\begin{array}{lllll}1 & 2 & 3 & 4 & 5 \\ 0 & 0 & 0 & 0 & 0\end{array}$

Thank you, please click to submit. 
Appendix B-5: Data collection email

Dear Mr. X,

Thank you for your response to my previous requests and helping validating the assessment model for energy policy instruments. After analyzing the input and comments from all experts, the final assessment model has been developed where more than two thirds of the experts approved the model's variables.

I'm now asking your help for the second step of my data collection for this research, the model will be applied to the case of power generation in the Pacific Northwest U.S. Please see the data collection instrument in the attachment of this e-mail in the form of excel file. The instrument is designed to collect your qualitative judgment to determine the relative importance of the model variables by using a judgment quantification method named "Pairwise comparison method." The survey instrument is expected to take only around 15 to 20 minutes of your time. Information and directions are provided in the introduction section in the survey.

I would greatly appreciate if you could please fill out the survey instrument at your earliest convenience.

I am grateful for your time and contributions. 


\section{Appendix B-6: Data collection instruments}

\section{$\underline{\text { Judgment Quantification Instrument }}$}

An Assessment Model for energy policy tools for the adoption of renewable energy: Case of wind energy in the Pacific Northwest U.S

\section{Introduction}

The objective of this study is to provide a comprehensive assessment model for energy policy instruments and evaluate their effectiveness on facilitating renewable energy adoption using five major criteria (Social, Technical, Economic, Environmental, and Political). Criteria, sub criteria, and alternatives were obtained from an extensive literature review and input from expert panels.

This instrument is designed to capture your judgment on relative importance of a number of decision variables using the Hierarchical Decision Model (HDM) and pairwise comparison method. Because your time is valuable, you are asked to judge a limited part of the complete assessment model. If you would like to see the whole model, please go to (HDM model) sheet.

The survey instructions are below, please complete the survey, save, and email your responses to the researcher at remal @ pdx.edu. If you have any questions or concerns, please don't hesitate to contact the researcher at remal@pdx.edu or phone 503-896-8998.

\section{Surrev Instructions}

To determine the relative importance of the different criteria and sub criteria with respect to the mission, please compare the elements in each pair in the following tables. Allocate a total of 100 points to reflect how many times a decision variable is important in comparison to the other. You only need to enter the value of the 1 st variable. [Do not enter "0".] The value of the other variable will be calculated automatically. Given below are a few examples:

\section{Sample question and judgment:}

Please allocate a total of 100 points between the following pairs of variables to reflect your judgment of their relative importance with respect to the level above.

\begin{tabular}{|c|c|c|c|}
\hline Varia ble & weight & weight & Variable \\
\hline A & 80 & 20 & B \\
\hline A & 67 & 33 & C \\
\hline B & 50 & 50 & C \\
\hline C & 25 & 75 & D \\
\hline
\end{tabular}

- If variable $A$ is 4 times as important as variable $B$, enter " 80 " points for the weight of $A$, variable $B$ will get 20 points.

- If variable $\mathrm{A}$ is 2 times as important as variable $\mathrm{C}$, enter " 67 " points for the weight of $\mathrm{A}$, variable $\mathrm{C}$ will get 33 points.

- If variable $B$ is as important as variable $C$, enter " 50 " points for the weight of $B$, variable $C$ will get 50 points.

- If variable $C$ is $1 / 3$ as important as variable $D$, enter " 25 " points for the weight of $C$, variable $D$ will get 75 points.

- The preceding are only ex amples, you can distribute 100 points between the pair of variables according to your judgment. 


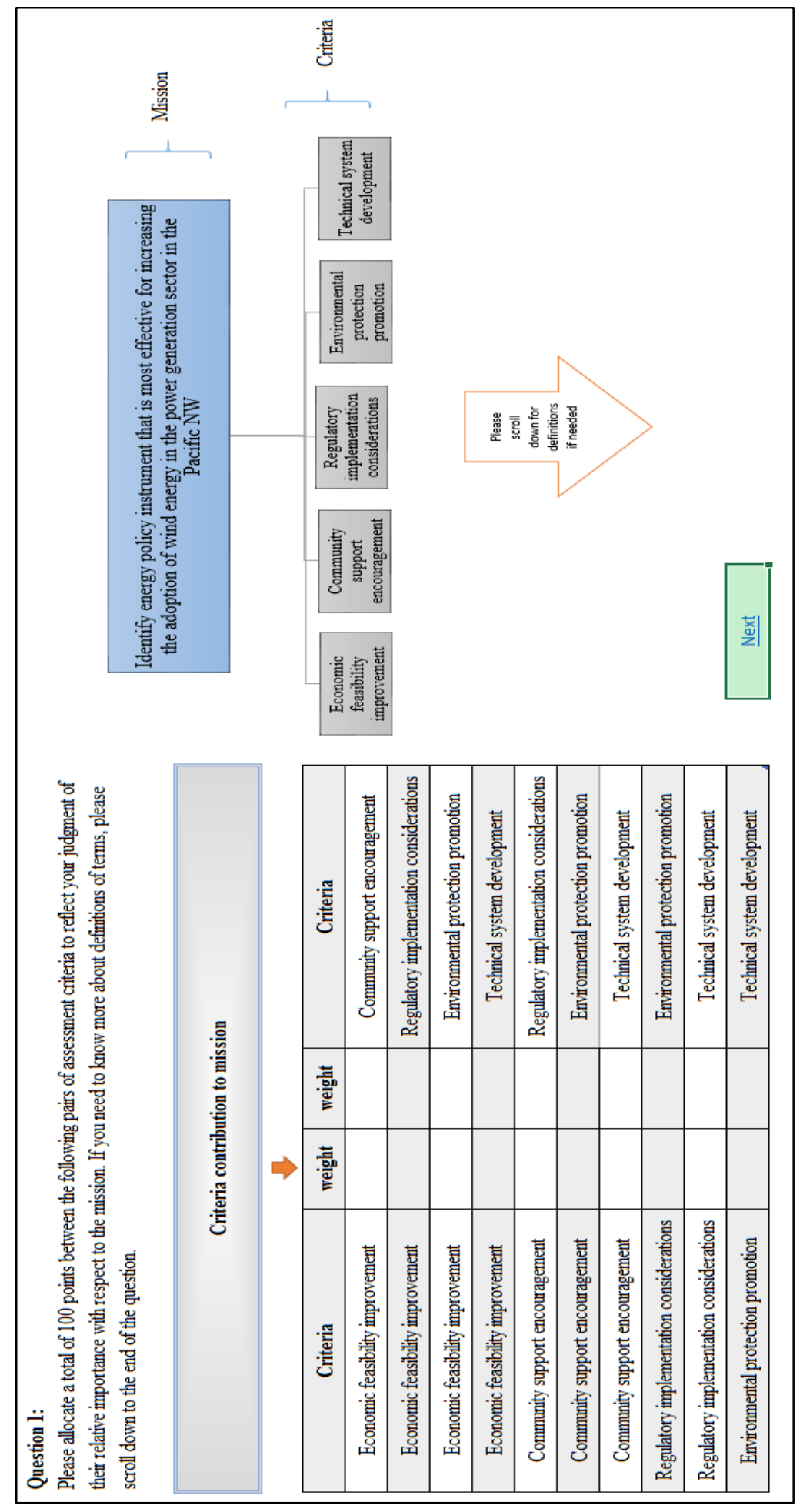


Mission: to laentify energy policy instrument that is most effective for increasing the adoption of wind energy

in the power generation sector in the Pacific $N W$.

Economic feasibility improvement: This variable measures the importance of economic factors that a policy can influence and improve to be effective in increasing the adoption of wind energy. Although there are great efforts to adopt wind energy in the energy portfolio, wind energy technologies are still not economically comparative to conventional fossil fuels. Increasing the economic feasibility of wind energy is a challenge that policy design considers.

Community support encouragement: This variable measures the importance of community support encouragement factors that a policy can influence and improve to be effective in increasing the adoption of wind energy. Although there are ambitious government efforts to increase the share of renewable energy in the energy portfolio, it is acknowledged that social factors may be a limiting factor in achieving this target specially in the case of wind energy

Regulatory implementation consideration: This variable measures the importance of considering general regulatory considerations for a policy to be considered effective in increasing the adoption of wind energy. This variable explains the political aspects and regulatory considerations in policy planning. The objective is to form a policy that doesn't conflict with other policies, easy to employ and insures a fair allocation of cost between stakeholders.

Environmental protection promotion: This variable measures the importance of environmental regulations that a policy can influence and improve to be effective in increasing the adoption of wind energy. The wide use of wind energy technologies for generating electricity can be seen as one way of meeting environmental and climate change but with certain reservations such as land use and natural habitat disturbance.

Technical system development: This variable measures the importance of a policy to aid development in the the technical system to be considered effective in increasing the adoption of wind energy. Understanding the energy system changes and the need for technical development is important for improving current policy and future policy planning. Different goals are stated under this major objective that clarifies the technical issues needed to be enhanced for wind energy adoption to occur efficiently. 


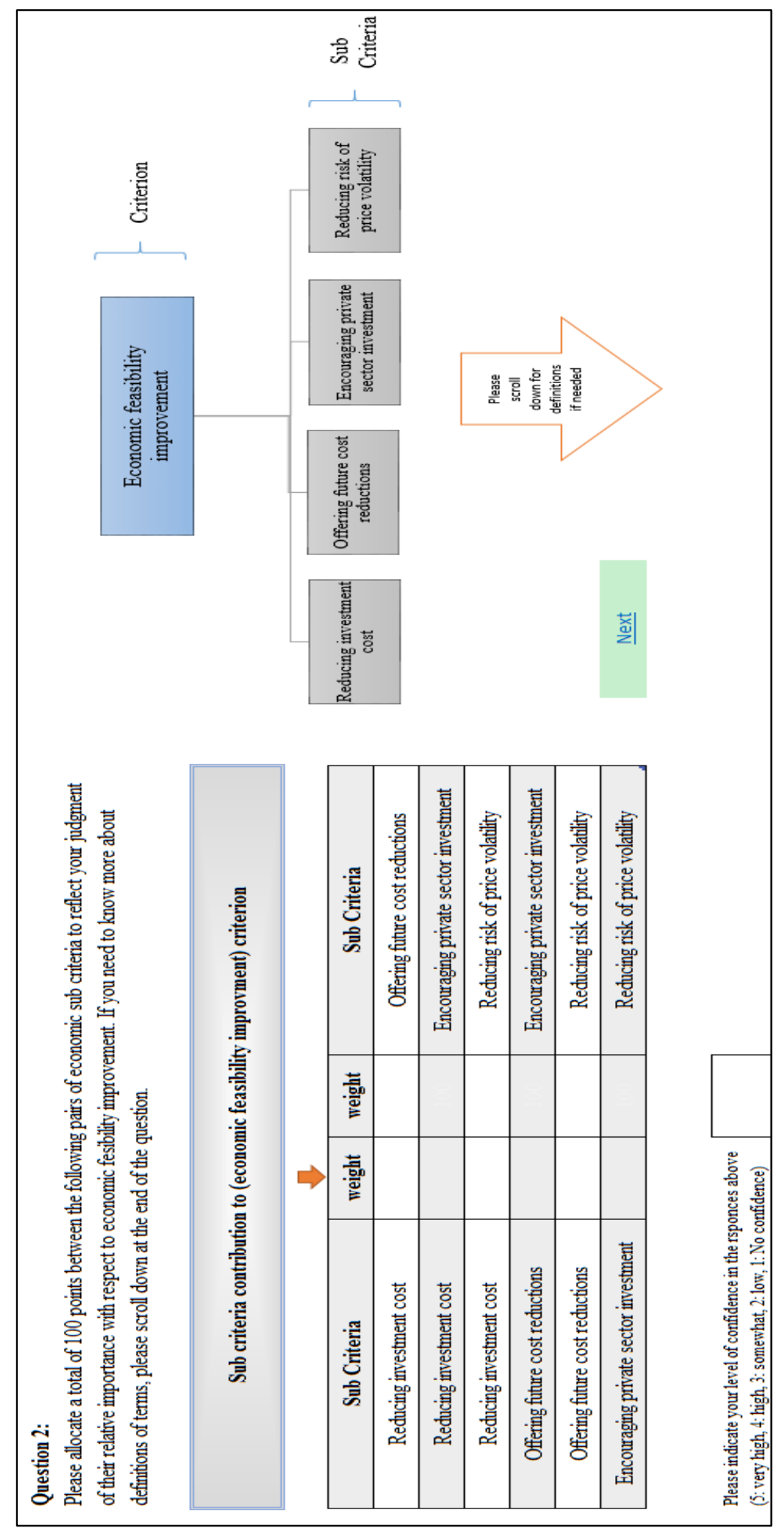


Reducing investment cost: Although the cost of RE power generation is lower than that of conventional sources on the long run, upfront cost of installation for the wind farms poses a burden on investors. There is a need for huge investment and investors for the development of wind facilities to be cost competitive. This variable measures the importance of reducing the investment cost for wind energy adoption

Offering future cost reductions: To be cost effective, wind energy requires large scale facilities for power generation and support to maintain operating cost low. . This variable measures the importance of maintaining low future cost (operating) for wind energy adoption.

Encouraging private sector investments: Diffusion of new wind projects can be accelerated by a policy of stimulating investments by means of public-private partnerships (PPPS) implemented at all governmental levels, or by encouraging private investors' facilities. This variable measures the importance of the role of private sector investors and local ownership for wind energy adoption.

Reducing risk of price volatility: It is expected that most customers are interested in low power rate as well utilities are interested in low rate generation. Therefore, policy instruments have mechanisms that protect from price fluctuation is favorable. This variable measures the importance of reducing market price fluctuation for wind energy adoption. 


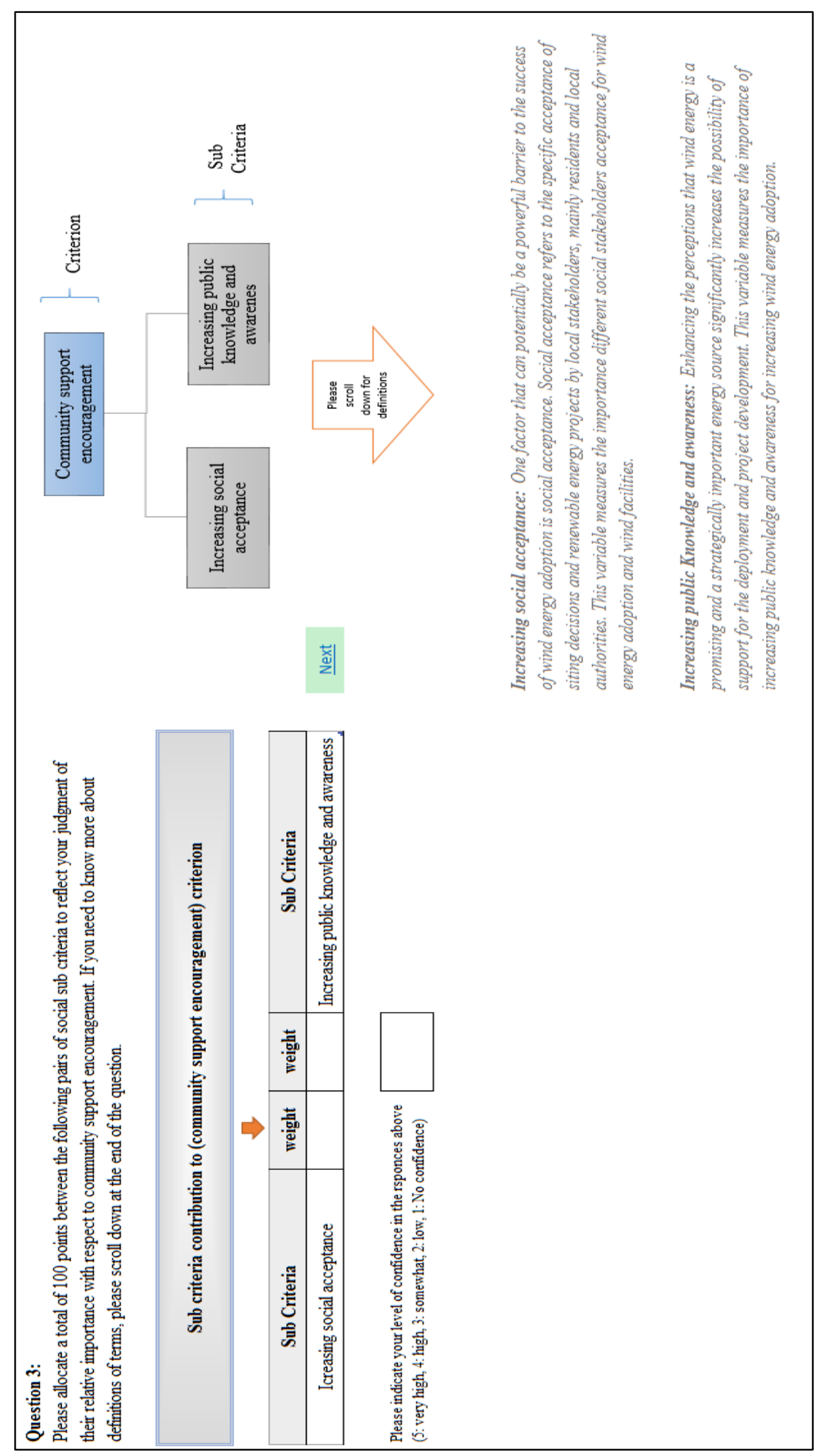

243 


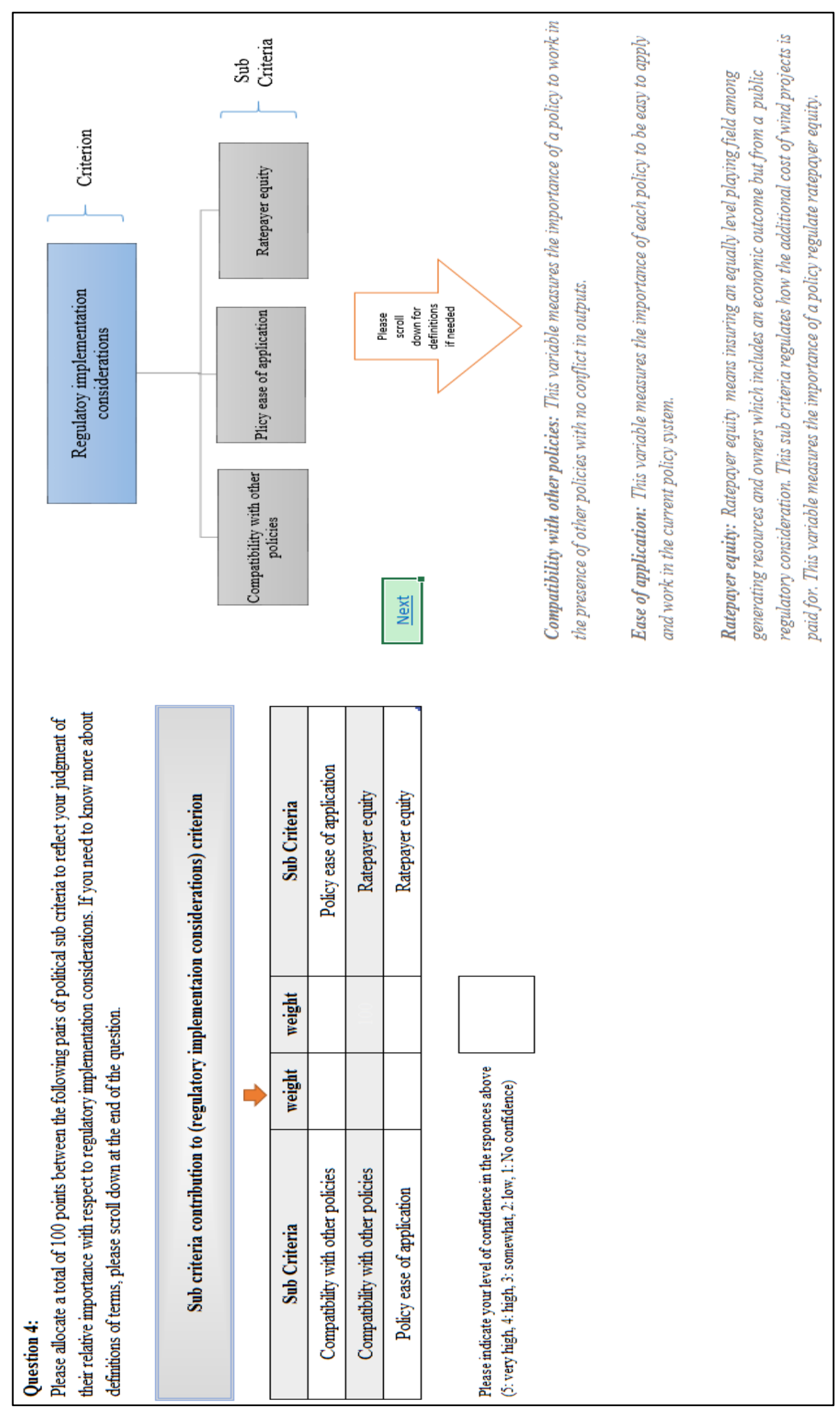




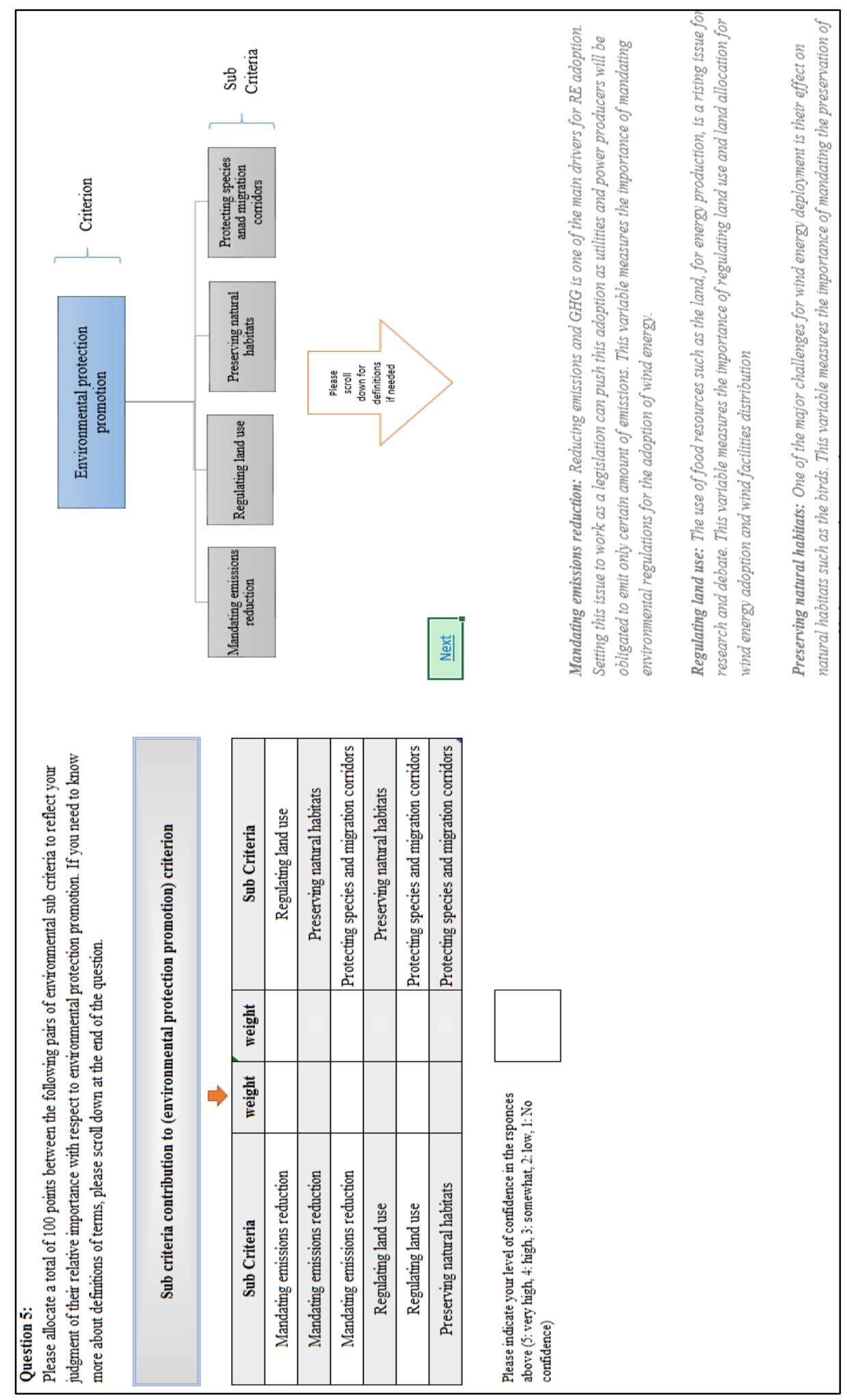




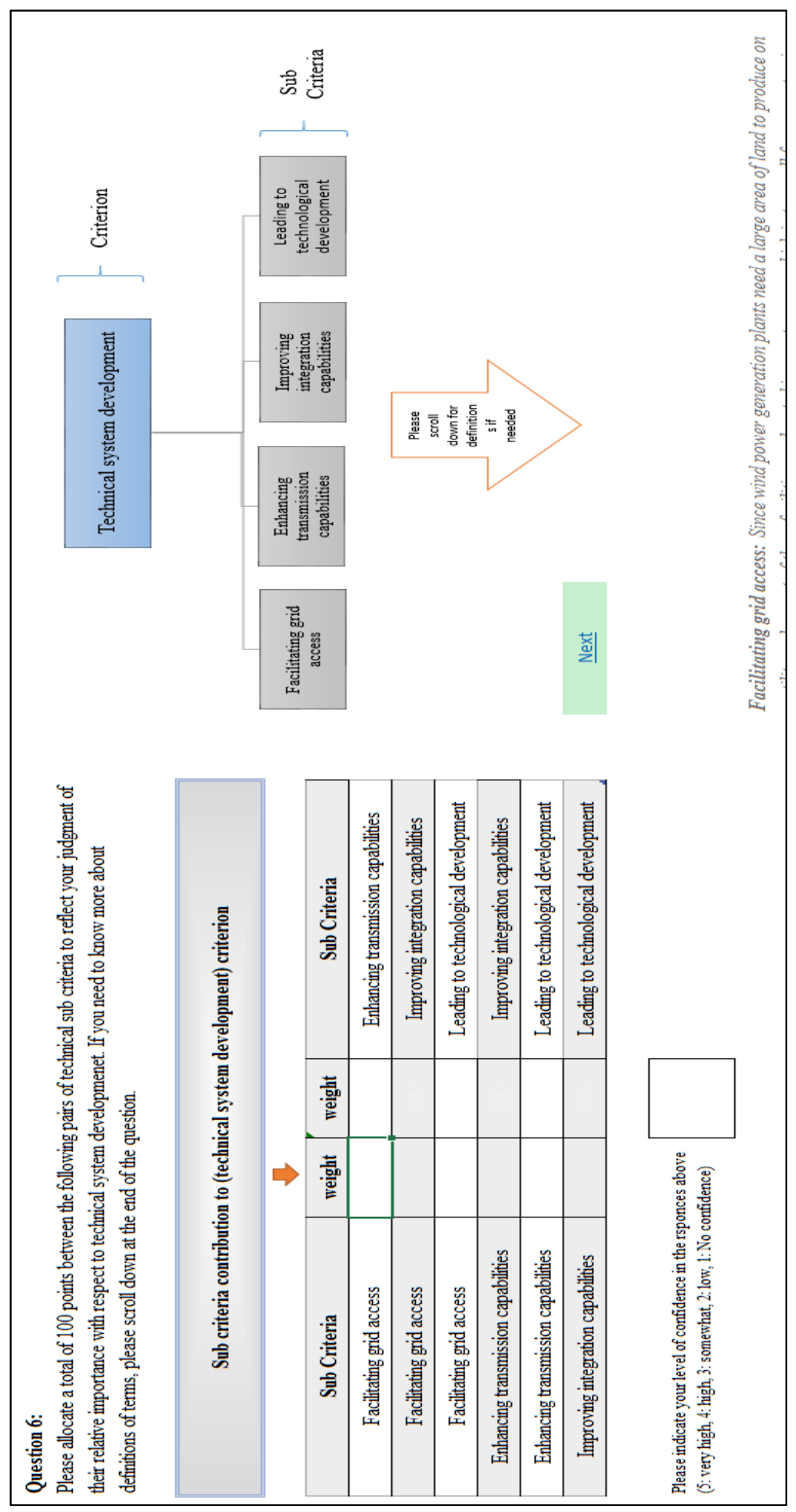


Facilitating grid access: Since wind power generation plants need a large area of land to produce on a utility scale; most of these facilities are located in remote areas, which in turn call for new extension of available transmission lines or granting access to current transmission lines without causing congestion. This variable measures the importance of grid access and ease of interconnection for wind energy development.

Enhancing transmission capabilities: TThe difference in nature between conventional power resources and wind energy affect the way the transmission grid is used and forces challenges since it was originally designed for conventional. The intermittent nature of wind energy forces the development of the grid in a way to balance between supply and demand by enhanced transmission capabilities. This variable measures the importance of enhancing transmission capabilities and schedualing for wind energy development.

Improving integration capabilities: The characteristics of wind energy such as; site specificity, intermittency, resource intensity, and technology maturity require advanced integration capabilities and forecasting methods. This variable measures the importance of improving these integration capabilities for the adoption of wind energy.

Leading to technological development: In spite of the variety of available renewable energy resources, there are still technical obstacles to their adoption in the current energy system. Technology advancements have helped in overcoming some of these issues like advancements in equipment manufacturing and development of complementary storage technologies (i.e. a wind turbine construction industry development in the state/region). This variable measures the importance of technological development to/around wind energy for wind energy adoption. 


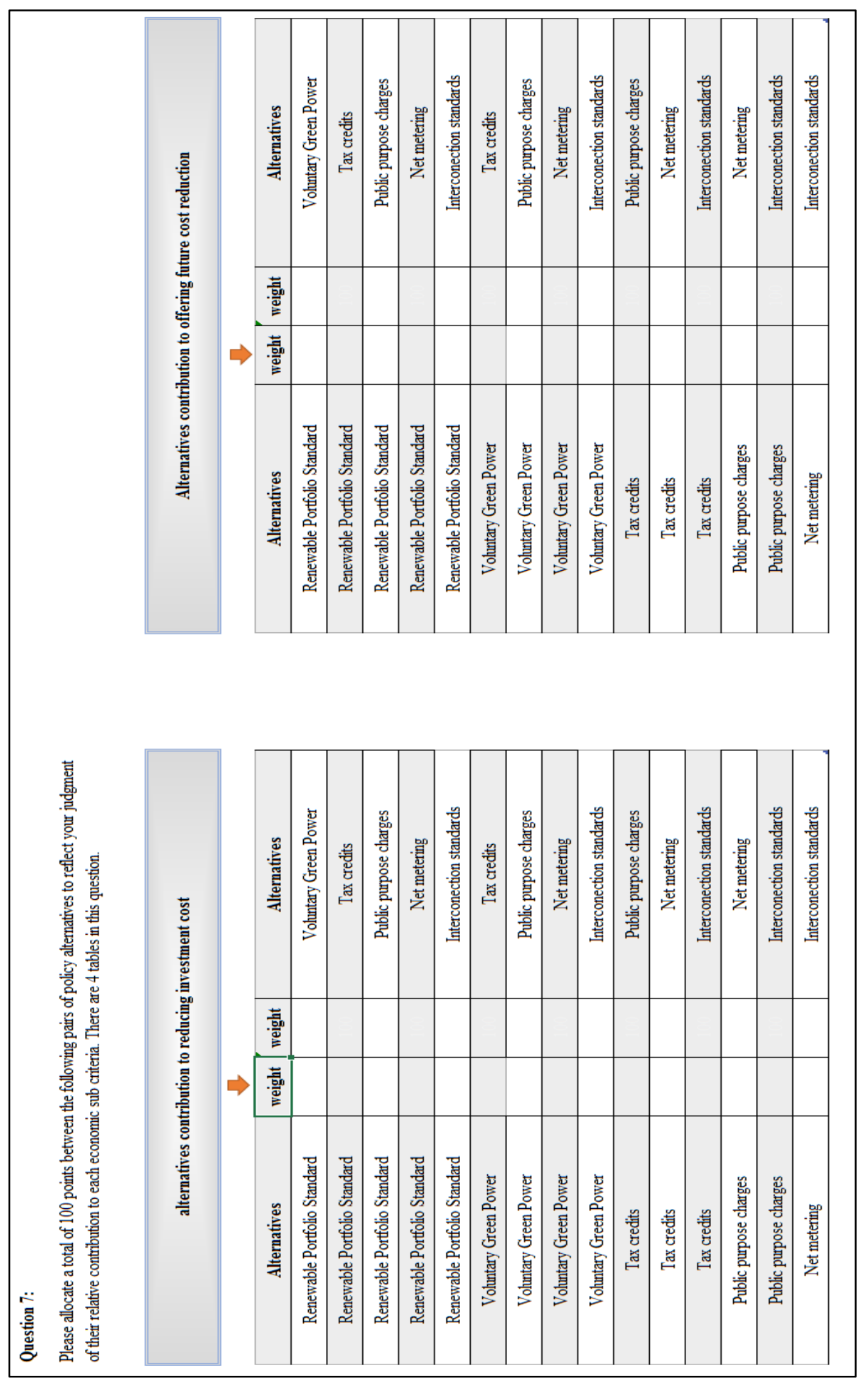




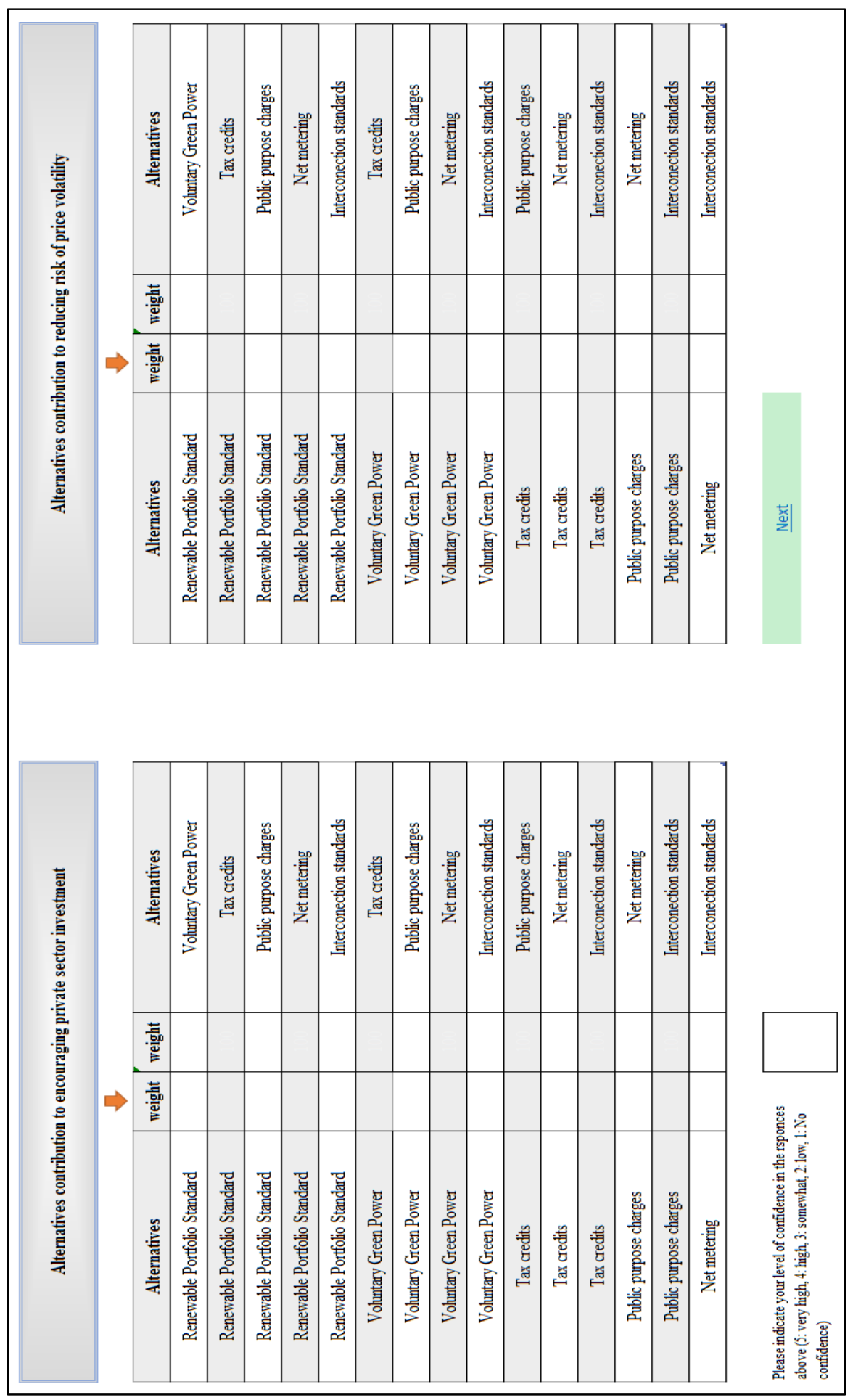


Appendix (C) Judgment Quantifications 
Appendix C-1: Judgment quantification for Perspectives level with respect to the mission.

The tables only show the first part of the ratio. For example: A: B $=80: 20$. Only 80 is shown in the tables.
A: Economic Feasibility Improvement
B: Community Support Encouragement
C: Regulatory Implementation Considerations
D: Environmental Protection Promotion
E: Technical System Development

\begin{tabular}{|c|c|c|c|c|c|c|c|c|c|c|}
\hline & A:B & A:C & A:D & A:E & B:C & B: D & B:E & C: D & C:E & D:E \\
\hline Exp1 & 80 & 80 & 67 & 50 & 50 & 50 & 50 & 50 & 67 & 67 \\
\hline Exp2 & 60 & 70 & 50 & 75 & 70 & 50 & 70 & 50 & 60 & 75 \\
\hline Exp3 & 80 & 75 & 80 & 60 & 20 & 50 & 10 & 80 & 50 & 30 \\
\hline Exp4 & 70 & 70 & 70 & 60 & 50 & 60 & 30 & 60 & 40 & 30 \\
\hline Exp5 & 80 & 70 & 60 & 50 & 40 & 40 & 30 & 60 & 40 & 40 \\
\hline Exp6 & 80 & 80 & 60 & 50 & 80 & 50 & 20 & 40 & 20 & 30 \\
\hline Exp7 & 70 & 50 & 40 & 50 & 30 & 50 & 30 & 50 & 60 & 60 \\
\hline Exp8 & 70 & 55 & 35 & 35 & 30 & 20 & 10 & 30 & 40 & 60 \\
\hline Exp9 & 40 & 40 & 20 & 10 & 50 & 70 & 30 & 40 & 40 & 30 \\
\hline Exp10 & 70 & 60 & 60 & 30 & 30 & 30 & 30 & 50 & 30 & 50 \\
\hline Exp11 & 50 & 30 & 80 & 80 & 20 & 50 & 30 & 70 & 80 & 50 \\
\hline Exp12 & 80 & 50 & 80 & 67 & 20 & 50 & 33 & 80 & 67 & 33 \\
\hline Exp13 & 90 & 50 & 95 & 65 & 5 & 78 & 20 & 95 & 50 & 25 \\
\hline Exp14 & 80 & 50 & 80 & 50 & 33 & 50 & 33 & 67 & 50 & 33 \\
\hline Exp15 & 70 & 60 & 50 & 40 & 50 & 60 & 30 & 50 & 50 & 40 \\
\hline Exp16 & 80 & 50 & 50 & 67 & 20 & 20 & 40 & 70 & 60 & 75 \\
\hline
\end{tabular}


Appendix C-2: Judgment quantification for policy targets level with respect to Perspectives

The tables only show the first part of the ratio. For example: A: $\mathrm{B}=80: 20$. Only 80 is shown in the tables.

Economic policy targets:

A: Reduce Investment Cost

B: Offer Future Cost Reductions

C: Encourage Private Sector Investment

D: Reduce Risk of Price Volatility

\begin{tabular}{|c|c|c|c|c|c|c|}
\hline & A:B & A:C & A:D & B:C & B:D & C:D \\
\hline Exp1 & 90 & 80 & 90 & 80 & 60 & 20 \\
\hline Exp2 & 90 & 90 & 90 & 33 & 33 & 67 \\
\hline Exp3 & 60 & 50 & 80 & 70 & 80 & 80 \\
\hline Exp4 & 40 & 50 & 40 & 50 & 40 & 40 \\
\hline Exp5 & 30 & 60 & 80 & 80 & 70 & 30 \\
\hline Exp6 & 70 & 80 & 90 & 40 & 70 & 70 \\
\hline Exp7 & 80 & 80 & 67 & 50 & 33 & 50 \\
\hline Exp8 & 80 & 60 & 50 & 25 & 20 & 50 \\
\hline Exp9 & 90 & 59 & 85 & 50 & 50 & 50 \\
\hline
\end{tabular}

Social policy targets:

A: Increase Public Acceptance

B: Increase Public Knowledge and Awareness

\begin{tabular}{|c|c|}
\hline & A:B \\
\hline Exp1 & 80 \\
\hline Exp2 & 50 \\
\hline Exp3 & 70 \\
\hline Exp4 & 75 \\
\hline Exp5 & 60 \\
\hline Exp6 & 50 \\
\hline Exp7 & 50 \\
\hline Exp8 & 60 \\
\hline Exp9 & 70 \\
\hline Exp10 & 50 \\
\hline Exp11 & 50 \\
\hline
\end{tabular}


$\underline{\text { Regulatory policy targets: }}$

A: Compatibility with Other Policies

B: Policy Ease of Application

C: Ratepayer Equity

\begin{tabular}{|c|c|c|c|}
\hline & A:B & A:C & B:C \\
\hline Exp1 & 67 & 10 & 10 \\
\hline Exp2 & 50 & 60 & 60 \\
\hline Exp3 & 30 & 50 & 50 \\
\hline Exp4 & 70 & 80 & 80 \\
\hline Exp5 & 20 & 50 & 50 \\
\hline Exp6 & 50 & 25 & 25 \\
\hline Exp7 & 90 & 60 & 10 \\
\hline Exp8 & 50 & 10 & 10 \\
\hline Exp9 & 50 & 20 & 50 \\
\hline Exp10 & 80 & 80 & 50 \\
\hline Exp11 & 30 & 40 & 50 \\
\hline
\end{tabular}

Environmental policy targets:

A: Mandating Emission Reduction

B: Regulating Land Use

C: Preserving Natural Habitats

D: Protecting Species and Migration Corridors

\begin{tabular}{|c|c|c|c|c|c|c|}
\hline & A:B & A:C & A:D & B:C & B:D & C:D \\
\hline Exp1 & 70 & 65 & 75 & 60 & 55 & 70 \\
\hline Exp2 & 80 & 80 & 80 & 40 & 40 & 50 \\
\hline Exp3 & 70 & 70 & 70 & 50 & 40 & 40 \\
\hline Exp4 & 40 & 40 & 40 & 50 & 50 & 50 \\
\hline Exp5 & 70 & 60 & 60 & 40 & 40 & 50 \\
\hline Exp6 & 80 & 80 & 60 & 50 & 40 & 50 \\
\hline
\end{tabular}


Technical policy targets:

A: Facilitating Grid Access

B: Enhancing Transmission Capabilities

C: Improving Integration Capabilities

D: Leading to Technological Development

\begin{tabular}{|c|c|c|c|c|c|c|}
\hline & A:B & A:C & A:D & B:C & B:D & C:D \\
\hline Exp1 & 40 & 25 & 10 & 30 & 10 & 10 \\
\hline Exp2 & 40 & 33 & 50 & 50 & 75 & 75 \\
\hline Exp3 & 50 & 30 & 50 & 50 & 70 & 70 \\
\hline Exp4 & 20 & 30 & 20 & 80 & 80 & 60 \\
\hline Exp5 & 67 & 50 & 50 & 33 & 50 & 80 \\
\hline Exp6 & 70 & 60 & 75 & 40 & 55 & 65 \\
\hline Exp7 & 20 & 30 & 60 & 40 & 70 & 70 \\
\hline Exp8 & 75 & 50 & 75 & 20 & 50 & 80 \\
\hline
\end{tabular}


Appendix C-3: Judgment quantification for alternatives level with respect to

policy targets

The tables only show the first part of the ratio. For example: A: $B=80: 20$. Only 80 is shown in the tables.

A: Renewable Portfolio Standards

B: Voluntary Green Power

C: Tax Credits

D: Public Purpose Charge

E: Net Metering

F: Interconnection Standards

Alternatives - Reduce Investment Cost

\begin{tabular}{|c|c|c|c|c|c|c|c|c|c|c|c|c|c|c|c|}
\hline & A:B & A:C & A:D & A:E & A:F & B:C & B:D & B:E & B:F & C:D & C:E & C:F & D:E & D:F & E:F \\
\hline Exp1 & 50 & 10 & 20 & 90 & 50 & 10 & 10 & 50 & 20 & 50 & 90 & 90 & 80 & 80 & 10 \\
\hline Exp2 & 90 & 33 & 33 & 95 & 40 & 33 & 33 & 50 & 33 & 80 & 90 & 60 & 80 & 50 & 5 \\
\hline Exp3 & 50 & 10 & 10 & 50 & 20 & 20 & 20 & 30 & 40 & 60 & 80 & 90 & 70 & 80 & 50 \\
\hline Exp4 & 50 & 33 & 50 & 50 & 500 & 50 & 50 & 50 & 50 & 50 & 50 & 50 & 50 & 50 & 50 \\
\hline Exp5 & 90 & 60 & 50 & 70 & 50 & 40 & 30 & 50 & 50 & 30 & 30 & 50 & 70 & 70 & 30 \\
\hline Exp6 & 70 & 10 & 20 & 80 & 20 & 10 & 30 & 40 & 20 & 90 & 90 & 90 & 60 & 50 & 10 \\
\hline Exp7 & 80 & 67 & 80 & 80 & 80 & 20 & 50 & 33 & 33 & 80 & 67 & 67 & 50 & 50 & 50 \\
\hline Exp8 & 90 & 60 & 45 & 75 & 85 & 10 & 10 & 15 & 15 & 60 & 70 & 85 & 70 & 90 & 75 \\
\hline Exp9 & 95 & 30 & 50 & 40 & 60 & 10 & 10 & 10 & 10 & 70 & 70 & 85 & 45 & 70 & 70 \\
\hline
\end{tabular}

Alternatives - Offering Future Cost Reductions

\begin{tabular}{|c|c|c|c|c|c|c|c|c|c|c|c|c|c|c|c|}
\hline & A:B & A:C & A D & A:E & A:F & B:C & B:D & B:E & B:F & C:D & C:E & C:F & D:E & D:F & E:F \\
\hline Exp1 & 50 & 90 & 50 & 50 & 90 & 80 & 80 & 80 & 80 & 50 & 50 & 50 & 50 & 50 & 50 \\
\hline Exp2 & 90 & 33 & 33 & 80 & 40 & 33 & 33 & 50 & 33 & 80 & 80 & 60 & 67 & 50 & 20 \\
\hline Exp3 & 80 & 50 & 60 & 40 & 60 & 20 & 20 & 20 & 20 & 70 & 60 & 70 & 60 & 60 & 80 \\
\hline Exp4 & 33 & 67 & 50 & 50 & 50 & 50 & 50 & 50 & 50 & 50 & 50 & 50 & 50 & 50 & 50 \\
\hline Exp5 & 90 & 70 & 60 & 80 & 50 & 50 & 50 & 40 & 40 & 30 & 30 & 30 & 70 & 50 & 40 \\
\hline Exp6 & 50 & 50 & 50 & 50 & 50 & 50 & 50 & 50 & 50 & 50 & 50 & 50 & 50 & 50 & 50 \\
\hline Exp7 & 80 & 80 & 80 & 80 & 80 & 20 & 50 & 33 & 33 & 67 & 67 & 67 & 50 & 50 & 50 \\
\hline Exp8 & 95 & 50 & 60 & 80 & 95 & 5 & 10 & 10 & 5 & 75 & 85 & 90 & 80 & 90 & 80 \\
\hline Exp9 & 95 & 50 & 50 & 40 & 60 & 10 & 10 & 10 & 10 & 70 & 70 & 85 & 45 & 70 & 70 \\
\hline
\end{tabular}


Alternatives - Encouraging Private Sector Investment

\begin{tabular}{|c|c|c|c|c|c|c|c|c|c|c|c|c|c|c|c|}
\hline & A:B & A:C & A D & A:E & A:F & B:C & B:D & B:E & B:F & C:D & C:E & C:F & D:E & D:F & E:F \\
\hline Exp1 & 90 & 70 & 80 & 90 & 80 & 10 & 20 & 60 & 40 & 90 & 90 & 70 & 80 & 80 & 10 \\
\hline Exp2 & 80 & 50 & 80 & 90 & 67 & 10 & 33 & 50 & 33 & 67 & 90 & 80 & 67 & 50 & 10 \\
\hline Exp3 & 80 & 50 & 60 & 40 & 60 & 20 & 20 & 20 & 20 & 70 & 60 & 70 & 60 & 60 & 80 \\
\hline Exp4 & 75 & 67 & 75 & 75 & 75 & 25 & 50 & 50 & 25 & 75 & 75 & 75 & 50 & 50 & 50 \\
\hline Exp5 & 90 & 50 & 50 & 90 & 80 & 10 & 50 & 20 & 30 & 90 & 70 & 60 & 30 & 30 & 50 \\
\hline Exp6 & 70 & 20 & 70 & 90 & 80 & 10 & 20 & 10 & 20 & 90 & 90 & 80 & 60 & 50 & 30 \\
\hline Exp7 & 80 & 50 & 80 & 80 & 80 & 20 & 50 & 33 & 33 & 80 & 80 & 80 & 50 & 50 & 50 \\
\hline Exp8 & 90 & 25 & 60 & 80 & 85 & 5 & 10 & 20 & 5 & 80 & 85 & 90 & 75 & 80 & 70 \\
\hline Exp9 & 95 & 50 & 50 & 40 & 60 & 10 & 10 & 10 & 10 & 85 & 90 & 95 & 45 & 70 & 70 \\
\hline
\end{tabular}

Alternatives - Reduce Risk of Price Volatility

\begin{tabular}{|l|c|c|c|c|c|c|c|c|c|c|c|c|c|c|c|}
\hline & A:B & A:C & $\begin{array}{c}\text { A: } \\
\text { D }\end{array}$ & A:E & A:F & B:C & B:D & B:E & B:F & C:D & C:E & C:F & D:E & D:F & E:F \\
\hline Exp1 & 90 & 10 & 20 & 90 & 90 & 10 & 10 & 50 & 50 & 90 & 90 & 90 & 90 & 90 & 50 \\
\hline Exp2 & 50 & 33 & 60 & 80 & 60 & 10 & 33 & 50 & 33 & 57 & 90 & 80 & 67 & 50 & 10 \\
\hline Exp3 & 90 & 80 & 80 & 70 & 95 & 5 & 10 & 20 & 20 & 70 & 80 & 90 & 70 & 90 & 60 \\
\hline Exp4 & 66 & 50 & 50 & 50 & 50 & 25 & 50 & 50 & 50 & 75 & 75 & 75 & 50 & 50 & 50 \\
\hline Exp5 & 90 & 80 & 60 & 70 & 30 & 80 & 80 & 70 & 30 & 40 & 30 & 20 & 30 & 20 & 20 \\
\hline Exp6 & 50 & 30 & 70 & 70 & 60 & 10 & 20 & 60 & 20 & 80 & 80 & 80 & 50 & 50 & 20 \\
\hline Exp7 & 50 & 50 & 50 & 80 & 50 & 50 & 50 & 50 & 50 & 67 & 67 & 67 & 50 & 50 & 50 \\
\hline Exp8 & 95 & 70 & 65 & 80 & 90 & 10 & 10 & 20 & 25 & 65 & 50 & 75 & 80 & 85 & 75 \\
\hline Exp9 & 95 & 50 & 50 & 40 & 60 & 10 & 10 & 10 & 10 & 70 & 70 & 85 & 45 & 70 & 70 \\
\hline
\end{tabular}

Alternatives - Increase Social Acceptance

\begin{tabular}{|c|c|c|c|c|c|c|c|c|c|c|c|c|c|c|c|}
\hline & A:B & A:C & A:D & A:E & A:F & B:C & B:D & B:E & B:F & C:D & C:E & C:F & D:E & D:F & E:F \\
\hline Exp1 & 20 & 50 & 50 & 90 & 90 & 20 & 20 & 90 & 90 & 50 & 90 & 90 & 90 & 90 & 50 \\
\hline Exp2 & 80 & 50 & 50 & 70 & 80 & 20 & 30 & 50 & 50 & 50 & 50 & 60 & 50 & 60 & 60 \\
\hline Exp3 & 70 & 60 & 60 & 75 & 75 & 30 & 30 & 40 & 60 & 50 & 50 & 65 & 55 & 65 & 65 \\
\hline Exp4 & 40 & 50 & 50 & 70 & 90 & 50 & 50 & 70 & 90 & 50 & 50 & 90 & 50 & 90 & 90 \\
\hline Exp5 & 50 & 60 & 30 & 40 & 70 & 70 & 50 & 60 & 70 & 20 & 20 & 40 & 60 & 70 & 70 \\
\hline Exp6 & 70 & 50 & 70 & 70 & 70 & 50 & 50 & 60 & 80 & 70 & 50 & 70 & 40 & 50 & 70 \\
\hline Exp7 & 30 & 20 & 40 & 20 & 40 & 20 & 30 & 20 & 40 & 80 & 60 & 60 & 20 & 50 & 60 \\
\hline Exp8 & 50 & 50 & 50 & 50 & 50 & 50 & 50 & 50 & 50 & 50 & 50 & 50 & 50 & 50 & 50 \\
\hline Exp9 & 50 & 60 & 40 & 40 & 70 & 60 & 50 & 30 & 60 & 50 & 40 & 70 & 60 & 70 & 80 \\
\hline $\begin{array}{c}\text { Exp1 } \\
0\end{array}$ & 80 & 60 & 80 & 80 & 80 & 20 & 40 & 40 & 40 & 70 & 70 & 70 & 50 & 50 & 50 \\
\hline $\begin{array}{c}\text { Exp1 } \\
1\end{array}$ & 20 & 33 & 33 & 33 & 50 & 50 & 50 & 50 & 67 & 33 & 50 & 50 & 50 & 50 & 50 \\
\hline
\end{tabular}


Alternatives - Increase Public Knowledge and Awareness

\begin{tabular}{|c|c|c|c|c|c|c|c|c|c|c|c|c|c|c|c|}
\hline & A:B & A:C & A:D & A:E & A:F & B:C & B:D & B:E & B:F & C:D & C:E & C:F & D:E & D:F & E:F \\
\hline Exp1 & 20 & 50 & 50 & 90 & 90 & 20 & 20 & 90 & 90 & 50 & 90 & 90 & 90 & 90 & 50 \\
\hline Exp2 & 50 & 50 & 40 & 50 & 60 & 50 & 30 & 40 & 40 & 40 & 50 & 60 & 50 & 60 & 70 \\
\hline Exp3 & 40 & 35 & 50 & 45 & 45 & 20 & 60 & 40 & 60 & 80 & 70 & 80 & 40 & 65 & 70 \\
\hline Exp4 & 40 & 50 & 50 & 70 & 90 & 50 & 50 & 70 & 90 & 50 & 50 & 90 & 50 & 90 & 90 \\
\hline Exp5 & 20 & 30 & 20 & 60 & 70 & 60 & 30 & 70 & 80 & 30 & 60 & 70 & 90 & 90 & 70 \\
\hline Exp6 & 30 & 50 & 30 & 50 & 50 & 70 & 70 & 70 & 70 & 40 & 40 & 50 & 50 & 50 & 50 \\
\hline Exp7 & 30 & 40 & 60 & 30 & 30 & 70 & 70 & 70 & 70 & 90 & 50 & 70 & 30 & 30 & 70 \\
\hline Exp8 & 40 & 40 & 30 & 30 & 40 & 60 & 50 & 50 & 50 & 50 & 50 & 50 & 50 & 50 & 60 \\
\hline Exp9 & 50 & 60 & 40 & 40 & 70 & 60 & 50 & 40 & 70 & 50 & 40 & 70 & 40 & 70 & 80 \\
\hline Exp10 & 50 & 60 & 50 & 50 & 70 & 60 & 30 & 50 & 50 & 50 & 55 & 65 & 50 & 70 & 60 \\
\hline Exp11 & 20 & 33 & 33 & 33 & 50 & 67 & 67 & 50 & 67 & 33 & 50 & 50 & 50 & 50 & 50 \\
\hline
\end{tabular}

Alternatives - Compatibility with Other Policies

\begin{tabular}{|c|c|c|c|c|c|c|c|c|c|c|c|c|c|c|c|}
\hline & A:B & A:C & A:D & A:E & A:F & B:C & B:D & B:E & B:F & C:D & C:E & C:F & D:E & D:F & E:F \\
\hline Exp1 & 40 & 50 & 50 & 60 & 10 & 10 & 33 & 50 & 20 & 80 & 80 & 50 & 60 & 50 & 20 \\
\hline Exp2 & 90 & 60 & 60 & 70 & 75 & 40 & 30 & 30 & 50 & 40 & 50 & 60 & 60 & 70 & 50 \\
\hline Exp3 & 90 & 50 & 60 & 50 & 50 & 20 & 20 & 20 & 20 & 50 & 70 & 70 & 50 & 70 & 50 \\
\hline Exp4 & 90 & 50 & 50 & 60 & 60 & 40 & 25 & 20 & 40 & 30 & 60 & 70 & 45 & 60 & 40 \\
\hline Exp5 & 65 & 45 & 50 & 60 & 70 & 20 & 30 & 60 & 50 & 40 & 30 & 30 & 60 & 50 & 40 \\
\hline Exp6 & 75 & 75 & 75 & 75 & 75 & 25 & 50 & 50 & 50 & 50 & 25 & 25 & 50 & 50 & 50 \\
\hline Exp7 & 80 & 70 & 40 & 80 & 50 & 20 & 30 & 50 & 20 & 50 & 70 & 20 & 90 & 80 & 30 \\
\hline Exp8 & 99 & 50 & 75 & 50 & 65 & 5 & 5 & 5 & 5 & 75 & 85 & 80 & 50 & 60 & 75 \\
\hline Exp9 & 90 & 70 & 50 & 60 & 50 & 10 & 20 & 20 & 15 & 50 & 50 & 80 & 45 & 80 & 45 \\
\hline Exp10 & 80 & 60 & 55 & 70 & 70 & 20 & 30 & 50 & 20 & 60 & 75 & 30 & 65 & 70 & 30 \\
\hline Exp11 & 80 & 70 & 90 & 95 & 60 & 20 & 30 & 30 & 15 & 80 & 75 & 65 & 35 & 10 & 60 \\
\hline
\end{tabular}

\section{Alternatives - Policy Ease of Application}

\begin{tabular}{|c|c|c|c|c|c|c|c|c|c|c|c|c|c|c|c|}
\hline & A:B & A:C & A:D & A:E & A:F & B:C & B:D & B:E & B:F & C:D & C:E & C:F & D:E & D:F & E:F \\
\hline Exp1 & 40 & 30 & 60 & 80 & 40 & 50 & 80 & 80 & 80 & 50 & 60 & 50 & 50 & 40 & 40 \\
\hline Exp2 & 50 & 60 & 50 & 60 & 65 & 60 & 40 & 50 & 50 & 40 & 60 & 70 & 60 & 75 & 65 \\
\hline Exp3 & 30 & 60 & 70 & 50 & 40 & 70 & 80 & 60 & 50 & 60 & 40 & 30 & 20 & 10 & 50 \\
\hline Exp4 & 50 & 55 & 55 & 60 & 70 & 70 & 50 & 60 & 60 & 50 & 50 & 60 & 70 & 70 & 50 \\
\hline Exp5 & 80 & 80 & 70 & 60 & 60 & 50 & 40 & 40 & 20 & 20 & 20 & 10 & 50 & 35 & 40 \\
\hline Exp6 & 75 & 75 & 75 & 50 & 50 & 25 & 25 & 25 & 25 & 25 & 25 & 25 & 25 & 25 & 25 \\
\hline Exp7 & 90 & 70 & 70 & 80 & 60 & 20 & 30 & 50 & 20 & 50 & 70 & 20 & 90 & 80 & 30 \\
\hline Exp8 & 55 & 40 & 45 & 35 & 25 & 65 & 80 & 70 & 60 & 85 & 50 & 40 & 45 & 25 & 50 \\
\hline Exp9 & 50 & 30 & 40 & 60 & 60 & 65 & 75 & 65 & 50 & 50 & 70 & 50 & 60 & 50 & 50 \\
\hline Exp10 & 80 & 60 & 65 & 70 & 70 & 55 & 45 & 60 & 40 & 50 & 30 & 30 & 85 & 70 & 20 \\
\hline Exp11 & 20 & 20 & 80 & 75 & 65 & 90 & 90 & 90 & 90 & 80 & 80 & 80 & 70 & 60 & 80 \\
\hline
\end{tabular}




Alternatives - Ratepayer Equity
\begin{tabular}{|c|c|c|c|c|c|c|c|c|c|c|c|c|c|c|c|}
\hline & A:B & A:C & A:D & A:E & A:F & B:C & B:D & B:E & B:F & C:D & C:E & C:F & D:E & D:F & E:F \\
\hline Exp1 & 50 & 45 & 50 & 90 & 40 & 50 & 60 & 80 & 50 & 40 & 60 & 50 & 67 & 40 & 20 \\
\hline Exp2 & 75 & 60 & 50 & 65 & 70 & 30 & 25 & 35 & 50 & 25 & 55 & 65 & 60 & 75 & 70 \\
\hline Exp3 & 30 & 40 & 50 & 70 & 30 & 10 & 80 & 70 & 60 & 90 & 80 & 70 & 40 & 30 & 20 \\
\hline Exp4 & 70 & 60 & 60 & 50 & 70 & 40 & 40 & 30 & 60 & 80 & 70 & 60 & 50 & 30 & 40 \\
\hline Exp5 & 20 & 40 & 60 & 40 & 50 & 60 & 60 & 50 & 50 & 60 & 50 & 40 & 60 & 50 & 40 \\
\hline Exp6 & 25 & 50 & 50 & 25 & 25 & 75 & 50 & 50 & 50 & 50 & 25 & 25 & 50 & 50 & 50 \\
\hline Exp7 & 80 & 80 & 60 & 70 & 40 & 30 & 60 & 80 & 50 & 50 & 70 & 20 & 90 & 50 & 15 \\
\hline Exp8 & 80 & 50 & 50 & 75 & 85 & 5 & 5 & 5 & 20 & 65 & 50 & 80 & 50 & 75 & 85 \\
\hline Exp9 & 60 & 50 & 60 & 80 & 50 & 75 & 70 & 80 & 50 & 50 & 50 & 60 & 50 & 30 & 30 \\
\hline Exp10 & 90 & 90 & 50 & 67 & 80 & 50 & 20 & 20 & 20 & 20 & 20 & 20 & 80 & 67 & 50 \\
\hline Exp11 & 20 & 20 & 40 & 60 & 30 & 50 & 80 & 80 & 50 & 80 & 80 & 80 & 60 & 20 & 20 \\
\hline
\end{tabular}

\section{Alternatives - Mandating Emissions Reduction}

\begin{tabular}{|c|c|c|c|c|c|c|c|c|c|c|c|c|c|c|c|}
\hline & A:B & A:C & A:D & A:E & A:F & B:C & B:D & B:E & B:F & C:D & C:E & C:F & D:E & D:F & E:F \\
\hline Exp1 & 90 & 65 & 75 & 75 & 90 & 25 & 35 & 35 & 40 & 65 & 60 & 70 & 60 & 60 & 55 \\
\hline Exp2 & 80 & 70 & 80 & 80 & 90 & 40 & 50 & 50 & 90 & 70 & 60 & 90 & 50 & 70 & 70 \\
\hline Exp3 & 90 & 70 & 60 & 70 & 70 & 30 & 10 & 30 & 30 & 40 & 70 & 70 & 70 & 80 & 60 \\
\hline Exp4 & 90 & 60 & 70 & 50 & 70 & 20 & 25 & 30 & 50 & 60 & 50 & 60 & 40 & 40 & 50 \\
\hline Exp5 & 80 & 80 & 70 & 80 & 80 & 40 & 30 & 40 & 40 & 30 & 50 & 50 & 60 & 60 & 50 \\
\hline Exp6 & 90 & 70 & 85 & 90 & 90 & 20 & 50 & 50 & 50 & 80 & 85 & 85 & 70 & 70 & 50 \\
\hline
\end{tabular}

\section{Alternatives - Regulating Land Use}

\begin{tabular}{|c|c|c|c|c|c|c|c|c|c|c|c|c|c|c|c|}
\hline & A:B & A:C & A:D & A:E & A:F & B:C & B:D & B:E & B:F & C:D & C:E & C:F & D:E & D:F & E:F \\
\hline Exp1 & 20 & 50 & 40 & 30 & 30 & 80 & 75 & 70 & 55 & 45 & 25 & 20 & 35 & 30 & 45 \\
\hline Exp2 & 50 & 50 & 50 & 50 & 50 & 50 & 50 & 50 & 50 & 50 & 50 & 50 & 50 & 50 & 50 \\
\hline Exp3 & 90 & 70 & 80 & 70 & 70 & 30 & 60 & 30 & 30 & 80 & 70 & 70 & 50 & 50 & 60 \\
\hline Exp4 & 70 & 50 & 50 & 80 & 50 & 20 & 20 & 20 & 50 & 25 & 20 & 20 & 50 & 50 & 50 \\
\hline Exp5 & 60 & 50 & 50 & 60 & 60 & 50 & 50 & 50 & 50 & 40 & 40 & 40 & 60 & 60 & 50 \\
\hline Exp6 & 90 & 90 & 90 & 90 & 90 & 10 & 30 & 50 & 50 & 80 & 80 & 80 & 50 & 50 & 50 \\
\hline
\end{tabular}

\section{Alternatives - Preserving Natural Habitats}

\begin{tabular}{|c|c|c|c|c|c|c|c|c|c|c|c|c|c|c|c|}
\hline & A:B & A:C & A:D & A:E & A:F & B:C & B:D & B:E & B:F & C:D & C:E & C:F & D:E & D:F & E:F \\
\hline Exp1 & 40 & 65 & 50 & 40 & 40 & 60 & 60 & 60 & 60 & 40 & 30 & 45 & 50 & 40 & 40 \\
\hline Exp2 & 50 & 50 & 50 & 50 & 50 & 50 & 50 & 50 & 50 & 50 & 50 & 50 & 50 & 50 & 50 \\
\hline Exp3 & 90 & 70 & 70 & 70 & 70 & 30 & 55 & 30 & 30 & 80 & 70 & 70 & 60 & 60 & 60 \\
\hline Exp4 & 40 & 60 & 50 & 50 & 50 & 80 & 80 & 80 & 80 & 50 & 50 & 50 & 30 & 50 & 50 \\
\hline Exp5 & 60 & 50 & 50 & 40 & 40 & 50 & 50 & 50 & 50 & 50 & 40 & 50 & 50 & 50 & 50 \\
\hline Exp6 & 90 & 70 & 85 & 90 & 90 & 20 & 50 & 50 & 50 & 80 & 85 & 85 & 70 & 70 & 50 \\
\hline
\end{tabular}


Alternatives - Protecting Species and Migration Corridors

\begin{tabular}{|c|c|c|c|c|c|c|c|c|c|c|c|c|c|c|c|}
\hline & A:B & A:C & A:D & A:E & A:F & B:C & B:D & B:E & B:F & C:D & C:E & C:F & D:E & D:F & E:F \\
\hline Exp1 & 30 & 45 & 45 & 40 & 30 & 70 & 70 & 65 & 50 & 45 & 30 & 20 & 55 & 35 & 40 \\
\hline Exp2 & 50 & 50 & 50 & 50 & 50 & 50 & 50 & 50 & 50 & 50 & 50 & 50 & 50 & 50 & 50 \\
\hline Exp3 & 90 & 70 & 80 & 70 & 70 & 30 & 60 & 30 & 30 & 80 & 70 & 70 & 50 & 50 & 60 \\
\hline Exp4 & 60 & 70 & 40 & 50 & 30 & 40 & 20 & 80 & 20 & 50 & 50 & 20 & 60 & 40 & 20 \\
\hline Exp5 & 60 & 60 & 50 & 60 & 60 & 60 & 50 & 60 & 60 & 40 & 50 & 50 & 60 & 60 & 50 \\
\hline Exp6 & 90 & 90 & 90 & 90 & 90 & 10 & 30 & 50 & 50 & 80 & 80 & 80 & 50 & 50 & 50 \\
\hline
\end{tabular}

\section{Alternatives - Facilitating Grid Access}

\begin{tabular}{|c|c|c|c|c|c|c|c|c|c|c|c|c|c|c|c|}
\hline & A:B & A:C & A:D & A:E & A:F & B:C & B:D & B:E & B:F & C:D & C:E & C:F & D:E & D:F & E:F \\
\hline Exp1 & 30 & 30 & 40 & 30 & 20 & 60 & 60 & 50 & 50 & 60 & 30 & 30 & 30 & 30 & 50 \\
\hline Exp2 & 67 & 50 & 67 & 67 & 33 & 25 & 33 & 50 & 50 & 75 & 67 & 50 & 50 & 25 & 25 \\
\hline Exp3 & 70 & 50 & 60 & 70 & 40 & 40 & 50 & 50 & 60 & 65 & 80 & 50 & 70 & 30 & 45 \\
\hline Exp4 & 90 & 90 & 80 & 80 & 20 & 20 & 20 & 20 & 10 & 50 & 50 & 25 & 90 & 50 & 10 \\
\hline Exp5 & 75 & 10 & 10 & 10 & 10 & 50 & 33 & 10 & 10 & 40 & 20 & 20 & 20 & 20 & 50 \\
\hline Exp6 & 50 & 50 & 95 & 80 & 20 & 40 & 80 & 80 & 20 & 95 & 50 & 5 & 60 & 1 & 1 \\
\hline Exp7 & 80 & 90 & 90 & 40 & 40 & 80 & 70 & 20 & 40 & 50 & 20 & 10 & 10 & 5 & 70 \\
\hline Exp8 & 95 & 80 & 80 & 25 & 10 & 50 & 25 & 25 & 10 & 65 & 25 & 10 & 20 & 10 & 30 \\
\hline
\end{tabular}

\section{Alternatives - Enhancing Transmission Capabilities}

\begin{tabular}{|c|c|c|c|c|c|c|c|c|c|c|c|c|c|c|c|}
\hline & A:B & A:C & A:D & A:E & A:F & B:C & B:D & B:E & B:F & C:D & C:E & C:F & D:E & D:F & E:F \\
\hline Exp1 & 30 & 40 & 50 & 30 & 30 & 60 & 60 & 40 & 40 & 60 & 40 & 40 & 30 & 30 & 50 \\
\hline Exp2 & 50 & 50 & 50 & 33 & 10 & 50 & 50 & 50 & 10 & 50 & 50 & 10 & 50 & 10 & 10 \\
\hline Exp3 & 60 & 50 & 50 & 40 & 20 & 60 & 50 & 60 & 30 & 60 & 50 & 20 & 60 & 20 & 35 \\
\hline Exp4 & 90 & 80 & 50 & 60 & 10 & 35 & 20 & 20 & 5 & 50 & 30 & 10 & 85 & 50 & 5 \\
\hline Exp5 & 90 & 90 & 85 & 80 & 20 & 70 & 70 & 50 & 50 & 50 & 20 & 10 & 20 & 20 & 30 \\
\hline Exp6 & 50 & 50 & 95 & 80 & 50 & 50 & 80 & 80 & 50 & 95 & 80 & 70 & 60 & 20 & 10 \\
\hline Exp7 & 80 & 90 & 90 & 90 & 60 & 70 & 80 & 40 & 20 & 40 & 10 & 10 & 10 & 5 & 75 \\
\hline Exp8 & 90 & 50 & 80 & 50 & 10 & 15 & 50 & 10 & 5 & 85 & 50 & 25 & 5 & 5 & 25 \\
\hline
\end{tabular}

\section{Alternatives - Improving Integration Capabilities}

\begin{tabular}{|l|c|c|c|c|c|c|c|c|c|c|c|c|c|c|c|}
\hline & A:B & A:C & $\begin{array}{c}\text { A: } \\
\text { D }\end{array}$ & A:E & A:F & B:C & B:D & B:E & B:F & C:D & C:E & C:F & D:E & D:F & E:F \\
\hline Exp1 & 30 & 30 & 50 & 30 & 30 & 60 & 60 & 40 & 40 & 60 & 30 & 30 & 30 & 30 & 50 \\
\hline Exp2 & 25 & 75 & 50 & 50 & 10 & 75 & 50 & 50 & 10 & 50 & 50 & 10 & 50 & 10 & 10 \\
\hline Exp3 & 30 & 60 & 60 & 50 & 20 & 60 & 70 & 50 & 20 & 60 & 50 & 20 & 30 & 20 & 40 \\
\hline Exp4 & 80 & 80 & 75 & 90 & 70 & 45 & 30 & 50 & 20 & 50 & 10 & 25 & 60 & 50 & 25 \\
\hline Exp5 & 99 & 99 & 95 & 80 & 80 & 67 & 50 & 20 & 20 & 20 & 20 & 10 & 50 & 33 & 50 \\
\hline Exp6 & 50 & 50 & 95 & 80 & 50 & 50 & 95 & 80 & 50 & 95 & 90 & 60 & 30 & 40 & 30 \\
\hline Exp7 & 90 & 95 & 95 & 55 & 40 & 60 & 55 & 35 & 40 & 50 & 20 & 25 & 10 & 10 & 80 \\
\hline Exp8 & 80 & 60 & 90 & 50 & 25 & 20 & 50 & 20 & 5 & 80 & 25 & 10 & 10 & 10 & 50 \\
\hline
\end{tabular}




Alternatives - Leading to Technological Development
\begin{tabular}{|c|c|c|c|c|c|c|c|c|c|c|c|c|c|c|c|}
\hline & A:B & A:C & A:D & A:E & A:F & B:C & B:D & B:E & B:F & C:D & C:E & C:F & D:E & D:F & E:F \\
\hline Exp1 & 40 & 40 & 50 & 30 & 30 & 60 & 60 & 40 & 40 & 70 & 50 & 50 & 30 & 30 & 50 \\
\hline Exp2 & 25 & 33 & 50 & 50 & 75 & 50 & 50 & 50 & 67 & 67 & 67 & 50 & 50 & 50 & 50 \\
\hline Exp3 & 30 & 30 & 50 & 50 & 60 & 55 & 50 & 60 & 60 & 70 & 60 & 40 & 50 & 30 & 30 \\
\hline Exp4 & 80 & 50 & 50 & 90 & 50 & 10 & 10 & 90 & 10 & 50 & 80 & 50 & 90 & 50 & 10 \\
\hline Exp5 & 80 & 90 & 85 & 80 & 80 & 33 & 33 & 33 & 33 & 20 & 33 & 33 & 33 & 33 & 50 \\
\hline Exp6 & 50 & 50 & 70 & 50 & 75 & 50 & 50 & 50 & 75 & 70 & 50 & 75 & 50 & 75 & 75 \\
\hline Exp7 & 90 & 75 & 85 & 60 & 40 & 30 & 20 & 65 & 30 & 70 & 60 & 50 & 30 & 10 & 50 \\
\hline Exp8 & 85 & 60 & 75 & 50 & 60 & 10 & 50 & 25 & 75 & 80 & 50 & 80 & 30 & 70 & 80 \\
\hline
\end{tabular}




\section{Appendix (D) Calculation Matrix}

\begin{tabular}{|c|c|c|c|c|c|c|c|c|c|c|c|c|c|c|c|c|c|c|c|}
\hline 总 & 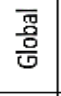 & పे & ప్రి & 营 & $\begin{array}{l}\stackrel{\circ}{0} \\
0 \\
0\end{array}$ & 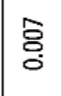 & 冚 & छ̈ & ప్j. & 㫕: & 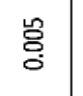 & $\begin{array}{l}\text { ț } \\
\text { d. }\end{array}$ & 壳 & 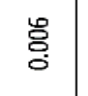 & 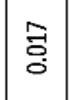 & శ్ & పี & : & ने \\
\hline 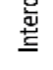 & 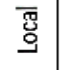 & $\stackrel{9}{0}$ & 愛 & 경 & $\stackrel{\frac{9}{\sigma}}{0}$ & $\overrightarrow{0}$ & 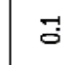 & 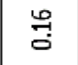 & $\stackrel{\infty}{0}$ & 경 & $\stackrel{\text { o }}{\circ}$ & 몀 & 웜 & 궁 & 骂 & $\stackrel{\infty}{\dddot{g}}$ & Д્రి & 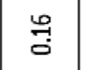 & \\
\hline 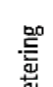 & 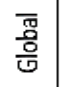 & 恴 & : & 岁 & 总 & ప্টة & ప్రి & ఫ్రి & ò & 亏्ञ & పे & 苛 & 売 & : & $\mid \begin{array}{l}0 \\
\vdots \\
o\end{array}$ & 离 & పే & : & g. \\
\hline$\overline{\underline{z}}$ & 㯊 & $\overrightarrow{0}$ & J્̈ & "̈ & $\overrightarrow{0}$ & 㔛 & $\stackrel{\text { ğ }}{0}$ & m. & శี & fี & नีㅇ & $\stackrel{\leftrightarrow}{\stackrel{a}{0}}$ & 竎 & 궁 & 궁 & $\stackrel{m}{0}$ & $\stackrel{\text { ğ }}{0}$ & 명 & \\
\hline 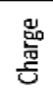 & $\begin{array}{l}\frac{\mathrm{m}}{0} \\
\frac{0}{0}\end{array}$ & 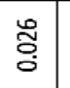 & ठ잉 & ¿ & $\mid \begin{array}{c}\infty \\
0 \\
0\end{array}$ & : & ठㅇㅇㅇ & 亏్ & : & 㟯 & 영 & 离 & 音 & 㟧 & $\begin{array}{l} \\
0 \\
0\end{array}$ & 岁 & 晏 & ఫ్ర & 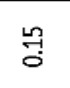 \\
\hline 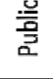 & $\overline{\underline{\mathrm{g}}}$ & $\approx$ & $\stackrel{\circ}{0}$ & 굼 & $\stackrel{\leftrightarrow}{0}$ & $\stackrel{\infty}{0}$ & ż & $\stackrel{\infty}{0}$ & $\stackrel{2}{9}$ & 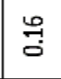 & $\stackrel{\text { 몀 }}{\circ}$ & 吉 & 器 & 志 & 莺 & $\stackrel{\infty}{\circ}$ & 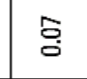 & 器 & \\
\hline$\frac{\underline{\underline{v}}}{2}$ & 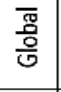 & 志 & స్ & 형 & 咅 & $\stackrel{m}{0}$ & : & 苛 & \begin{tabular}{|l|l}
$\infty$ \\
0 \\
0 \\
0
\end{tabular} & 㐘 & : & 孛 & 㺃 & 总 & 苂 & ప్ర & 훔 & 영 & శ్రి \\
\hline 䎡 & $\overline{\mathrm{g}}$ & $\tilde{\tilde{m}} \mathrm{~g}$ & নี & 弚 & m & $\tilde{\delta}$ & $\stackrel{9}{0}$ & $\tilde{\Xi}$ & $\begin{array}{l}\Delta \\
0\end{array}$ & ğ & $\stackrel{9}{0}$ & 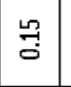 & I & $\stackrel{2}{\stackrel{2}{0}}$ & $\stackrel{m}{0}$ & 켱 & $\overrightarrow{0}$ & $\tilde{\sigma}$ & \\
\hline 㐔 & 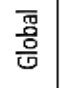 & $\begin{array}{l}0 \\
0 \\
0\end{array}$ & : & 잉 & \% & : & ठั & t: & క్ & 訕 & 峞 & 菅 & 苟 & 营 & $\mid \begin{array}{l}\vec{z} \\
0 \\
0\end{array}$ & ప్ & \%్ర & ప్రి & न̈ㅇㅇ \\
\hline 造 & 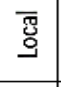 & 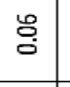 & ت્ & $\stackrel{t}{0}$ & $\Xi$ & $\stackrel{\text { 몀 }}{0}$ & స్ & $\stackrel{\circ}{\circ}$ & $\vec{I}$ & 总 & ఏ্ & 壳 & $\stackrel{\infty}{a}$ & 声 & g: & F & 궁 & 器 & \\
\hline$\stackrel{w}{\alpha}$ & $\begin{array}{l}\frac{\text { 咟 }}{0} \\
\end{array}$ & ठ্ّ & 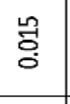 & : & $\vec{j}$ & 音 & : & ؛े. & క్ & 品 & ฮัँ & $\begin{array}{l}\infty \\
\vdots \\
0\end{array}$ & \% & \% & 总 & $\vec{\Xi}$ & : & క్రి: & జే \\
\hline & 傿 & $\stackrel{9}{9}$ & ః̆ & స్ర & $\Xi$ & $\tilde{\delta}$ & 声 & స్త & $\tilde{\delta}$ & $\tilde{\sigma}$ & d & 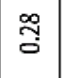 & J & స్ & 경 & I) & స్త & జુ & \\
\hline & 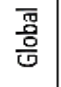 & స్తి & 递 & ㅎํㅇ & 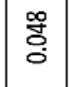 & 总 & 喜 & 。ٍ̆ & 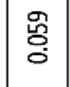 & 亏े & 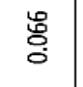 & ఫ్రి & 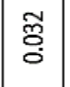 & 蒿 & $\mid \begin{array}{l}0 \\
0 \\
0\end{array}$ & : & $\overrightarrow{5}$ & 명 & \\
\hline 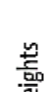 & 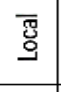 & $\stackrel{8}{0}$ & ఫ్రి & f) & I & 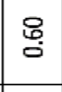 & 果 & $\overrightarrow{\mathrm{m}}$ & స్ & F & F & $\stackrel{\infty}{0}$ & ఫ్రి & $\vec{z}$ & $\vec{\Xi}$ & 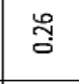 & $\overrightarrow{\mathrm{g}}$ & สี & \\
\hline 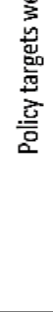 & & 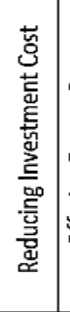 & 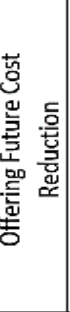 & 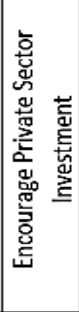 & 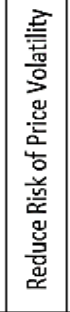 & 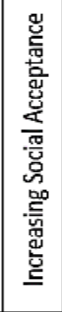 & 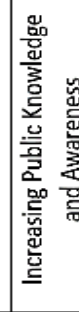 & 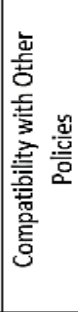 & 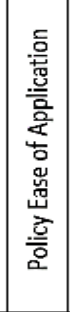 & 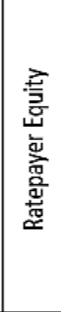 & 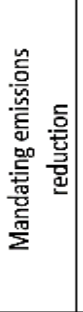 & 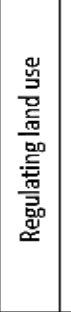 & 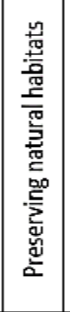 & 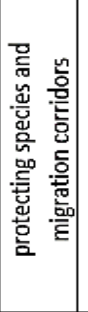 & 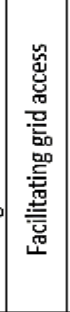 & 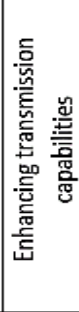 & 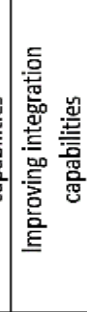 & 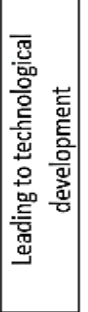 & \\
\hline \multirow{2}{*}{\multicolumn{2}{|c|}{ 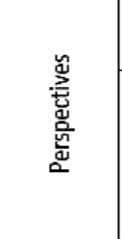 }} & \multicolumn{4}{|c|}{0} & & تี่ & & \multicolumn{4}{|c|}{ :ٌ } & & \\
\hline & & \multicolumn{4}{|c|}{$\begin{array}{l}\text { 咳 } \\
\text { 总 }\end{array}$} & & 愛 & & \multicolumn{4}{|c|}{ 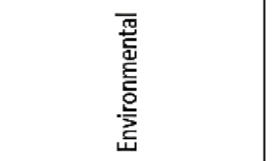 } & \multicolumn{4}{|c|}{ 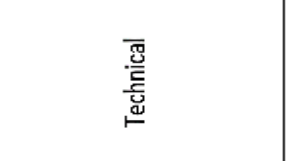 } & \\
\hline
\end{tabular}

